\title{
Borders, independence and post-colonial ties : the role of the state in Caribbean migration
}

Citation for published version (APA):

Vezzoli, S. (2015). Borders, independence and post-colonial ties : the role of the state in Caribbean migration. [Doctoral Thesis, Maastricht University]. Boekenplan. https://doi.org/10.26481/dis.20151120sv

Document status and date:

Published: 01/01/2015

DOI:

10.26481/dis.20151120sv

Document Version:

Publisher's PDF, also known as Version of record

\section{Please check the document version of this publication:}

- A submitted manuscript is the version of the article upon submission and before peer-review. There can be important differences between the submitted version and the official published version of record.

People interested in the research are advised to contact the author for the final version of the publication, or visit the DOI to the publisher's website.

- The final author version and the galley proof are versions of the publication after peer review.

- The final published version features the final layout of the paper including the volume, issue and page numbers.

Link to publication

\footnotetext{
General rights rights.

- You may freely distribute the URL identifying the publication in the public portal. please follow below link for the End User Agreement:

www.umlib.nl/taverne-license

Take down policy

If you believe that this document breaches copyright please contact us at:

repository@maastrichtuniversity.nl

providing details and we will investigate your claim.
}

Copyright and moral rights for the publications made accessible in the public portal are retained by the authors and/or other copyright owners and it is a condition of accessing publications that users recognise and abide by the legal requirements associated with these

- Users may download and print one copy of any publication from the public portal for the purpose of private study or research.

- You may not further distribute the material or use it for any profit-making activity or commercial gain

If the publication is distributed under the terms of Article $25 \mathrm{fa}$ of the Dutch Copyright Act, indicated by the "Taverne" license above, 
Borders, independence and post-colonial ties:

the role of the state in Caribbean migration 
(C) 2015 Simona Vezzoli

Published by Boekenplan, Maastricht

ISBN 9789086663859

Cover picture: Crossing the Maroni river from French Guiana to Suriname on a quick pirogue ride. (C) 2015 Simona Vezzoli

All rights reserved. No part of this publication may be reproduced, stored in a retrieval system, or transmitted in any form, or by any means, electronic, mechanical, photocopying, recording or otherwise, without the prior permission in writing, from the author. 


\title{
Borders, independence and post-colonial ties: the role of the state in Caribbean migration
}

\author{
To obtain the degree of Doctor at Maastricht University, \\ on the authority of the Rector Magnificus Prof. Dr. L.L.G. Soete \\ in accordance with the decision of the Board of Deans \\ to be defended in public on Friday 20 November, 2015, at 10:00 hours.
}

by

Simona Vezzoli 
Supervisor:

Co-supervisor:

Assessment Committee: Prof. Dr. Ronald Skeldon, Chairman

Dr. Stéphanie Condon, Institut National

d'Etudes Démographiques (INED), France

Prof. Dr. Khalid Koser

Dr. Hebe Verrest, University of Amsterdam 
To Giambattista, my dad, who accompanied me in spirit along this journey 


\section{Acknowledgements}

Completing this PhD felt like an extended rollercoaster ride full of excitement and amazing new perspectives on the world, invariably followed by screams and paralysing fears as the ground went missing from under my feet. Fortunately, there was always a companion enjoying the awe-inspiring moments and holding hands as the ride made me lose my orientation, leaving me unable to determine the way forward. My gratitude goes to a large number of people, from those who have felt the joys and pain of this ride with me, to those who provided the occasional smile, a 'Good morning!' or a few words of wisdom which helped get through difficult periods. I will not be able to thank everybody here, including the numerous interviewees who shared their personal stories with me, but know that your support has not been forgotten: you have not only provided essential information, but also the much needed human connection that helped me reach the finish line of this extraordinary ride.

I would like to thank Hein de Haas for providing the opportunity to carry out this research and giving me the conceptual freedom to pursue my interests, while also guiding me to stay 'on track'. I extend my gratitude to Melissa Siegel, who waited patiently for my work to bear fruits. Many thanks to the DEMIG team: Mathias Czaika and Edo Mahendra for always asking sharp questions; María Villares-Varela for being an incredible colleague and friend; Katharina Natter for providing vital support; and Marie-Laurence Flahaux, for being my academic cheerleader. My colleagues at IMI deserve special recognition, particularly Evelyn Ersanilli, who lent a sympathetic ear in innumerable venting sessions; Dominique Jolivet for support and reminding me that there was life beyond the PhD; Sally Kingsborough for her sound 'reality checks'; Agnieszka Kubal and Olivia Sheringham for providing invaluable support; and Oliver Bakewell for the extra boost, particularly at the end of this study. To Yasser Moullan, thanks for the remarkable réunionaise cuisine and Jenny Peebles for panic control and support in the very last stretches. And thanks to Anaïs Rességuier for stimulating chats and a super $\mathrm{PhD}$ retreat.

A number of academics have supported this endeavour in various ways, whom I thank profusely. For the work on Guyana: Dr Elizabeth Thomas-Hope for her ongoing support; Prof Clive Thomas and Dr Thomas Singh for hosting me at the Institute of Development Studies (IDS), University of Guyana; Dr Rishee Thakur for priceless insights and warm hospitality; Ms Audreyanna Thomas for her vision and for allowing me to present initial insights at one of her public events; Major General (Rtd) Joseph Singh and Ellie Price for their valuable feedback on an early version of the chapter; and the administrative team at IDS, particularly Mrs Niebert Paul and Mrs Sharmin Sookdeo for sharing their own migration stories and for their transcription efforts. For the work on Suriname: Rosemarijn Hoefte at the Koninklijk Instituut voor Taal-, Landen Volkenkunde (KITLV), University of Leiden, to whom I am greatly indebted; 
Maurits Hassankhan for his time and key contacts; Prof Martin Schalkwijk, Jack Menke and Ruben Gowricharns for taking the time to discuss my research; and Prof Ad de Bruijne, University of Amsterdam, for his ongoing interest in this research. For the work on French Guiana: Frédéric Piantoni at the Institut de Recherche pour le Développement (IRD) in Cayenne, for taking time to share a wealth of information on Guyane, its society, environment and migration history; Régine Calmont and André Calmont, for their historical perspective; and the staff at the Departmental Archives of Guyane (Archives départementales de la Guyane) in Cayenne. In addition, a special thank you to Peggy Levitt for providing true inspiration. Thank you also to my reading committee - Ronald Skeldon, Khalid Koser, Hebe Verrest, Stéphanie Condon - for your attentive reading and valued comments.

I am also indebted to many people who provided help, extended their friendship and opened their homes and hearts to me in the three Guianas. Meeting such wonderful people opened my eyes to a new way of seeing and valuing life - a lesson that I carry with me as my permanent gift from the Guianas. For that I am infinitely grateful. In Guyana, I thank Sonia for her friendship, her mom for feeding me delicious food and Floyd for providing plenty of coconut water. In Suriname, I owe many thanks to Joan Codrington for giving me a 'home', Carlho Wijdt for sharing amazing personal stories and June Eijken for being a friend, supporter and inspiration. In French Guiana, an immense thank you to Richard Cajozzo for helping me to discover Guyane and Dominique and Joel for their genuine hospitality and tasty meals - extra-special thanks to Dominique for the last rush of contacts, without whom this work would not have been as complete.

Last, but not least, my love and appreciation to my family - mamma, Elena, Stefania, Rossano, Davide, Giorgio and Manola - for always being there, welcoming me home and 'recharging my batteries' whenever I found a moment to visit. To Lee Knight Jr, thank you for providing moral support and gentle encouragement. My wonderful friends all over the world - thank you for allowing me to come into your lives whenever I had a moment and offering me a place to rest my mind and body: Rachel, Moe, Jake and Rory for taking me in when migration policies hit home; Michela, Manuel and Emma for the occasional but heart-warming moments; Teresa, Arne, Tiago and Bruno for friendship and love; Elise for the rare but special encounters; Stefania for being there in the last stretch. A special thank you to Manola and Teresa for their precious support in the last stretches. Finally, to Colin and Terriann Benjamin, thank you for offering a new source of energy, infinite patience and understanding, and for escorting me to the finish line.

Simona Vezzoli, Amsterdam, November 2015 


\section{Table of Contents}

Acknowledgements vi

List of figures $\quad$ xiv

List of tables $\quad$ xvii

Terminology for national and ethnic groups xviii

Chapter 1 - The role of border regimes, independence and post-colonial ties in migration

1. Introduction and research objectives 1

2. Geographical focus: the Caribbean region and the three Guianas 7

3. Methodology and methods: a pragmatist approach 10

3.1 Descriptive statistical analyses of regional trends 13

3.2 Theorization and the development of conceptual scenarios $\quad 14$

3.3. In-depth qualitative analysis of migration processes and migration motives 15

4. Limitations of methodology 21

5. Contribution of study and overview of dissertation 24

Chapter 2 - The role of the state in international migration: Exploring the transition from colony to independence $\quad 27$

$\begin{array}{ll}\text { 1. Introduction } & 27\end{array}$

2. An expanded view of the state's role in migration 29

2.1 The state in migration theories $\quad 29$

2.2 The state and its border regime 31

2.3 The state beyond migration policies 32

3. Changes in political status and migration 36

3.1 Colonialism, independence, non-sovereignty and migration 36

3.2 Post-colonial ties as a migration determinant $\quad 41$ 
3.3 The agency of migrants in a structured post-colonial environment

4. Conceptualising the migration effects of political status changes, border regimes and post-colonial ties

4.1 Synchronous independence and border regime establishment

4.2 Asynchronous independence and border regime establishment

4.3 Non-sovereignty and open border regimes 52

4.4 Comparative migration effects

5. Conclusions

Chapter 3 - Examining the role of border closure and post-colonial ties in Caribbean emigration

1. Introduction 59

2. Characteristics of Caribbean migration trends

2.1 Migrations before the Second World War

2.2 The development of extra-regional migrations

2.3 Evolution of political status and border regimes

3. Scope, data and methodology 75

4. Results 76

4.1 Total migrations from Caribbean countries 76

4.2 Extra-regional migrations and the relevance of the former colonial state

4.3 Intra-regional migrations and the relevance of the colonial sphere within the region

5. Conclusions

Chapter 4 - Closing borders to citizens: the role of states and policies in the evolution of Guyanese emigration

1. Introduction

2. British Guiana's historical migrations and ethnic diversity

3. The long road to independence and the closure of the British border (1953-1966) 
3.1 Political transitions and the rush to beat the 1962 British Immigration Act $\quad 91$

3.2 Independence and the rapid weakening of Britain's influence 93

3.3 The opening of North American migration policies and the diversification of migration destinations 95

3.4 Rapid diversification of migrants and their migration motives 96

4. Co-operative socialism, authoritarianism and 'planeloads of emigrants' (1967-1985)

4.1 Widening authoritarianism and the growth of sudden emigration $\quad 100$

4.2 The unintended migration stimuli of socio-economic reforms $\quad 101$

4.3 Worsening working conditions and the emigration of skilled workers 103

4.4 Migration policies and the diversification to North American destinations

4.5 Greater diversification of emigration composition and regional destinations

5. Persistent instability and the gradual reduction of emigration (1985-2013)

5.1 Economic and ethnic-based uncertainties

5.2 The selectivity of North American migration policies

5.3 Migration as an integral part of everyday life

6. Connecting the state, structural changes and long-term migration: a discussion

6.1 The effects of a border regime and independence

6.2 Weakened post-colonial ties

6.3 Policy influence on migration composition

6.4 Migration motives over 60 years

7. Conclusion

Chapter 5 - The evolution of Surinamese emigration across and beyond independence

1. Introduction 
2. Early migrations and population diversity

2.1 Early labour immigrations and the formation of a diverse population 127

2.2 A gradual shift from immigration to emigration 128

3. From autonomy towards independence: social changes and growing emigration (1954-1972)

3.1 Labour market shifts and labour displacement

3.2 The pursuit of education

3.3 Emerging political motives

3.4 Shifts in the composition of emigration

4. Emigration peaks across independence and the establishment of a border regime (1973-1982)

4.1. Uncertainty and growing anxiety as migration drivers

4.2 Economic conditions and development aid

4.3 Combining uncertainty, migration policies and the role of migrant networks

4.4 Migration diversification across class and ethnic groups

5. Internal political and economic crises driving migration (1983-1994)

5.1 Political emigration drivers: From a military dictatorship to the War of the Interior

5.2 Collapsing economy, shortages of goods, remittances and emigration

5.3 Dutch migration policies and Surinamese migration strategies

5.4 Class, ethnicity and diversification of migration destinations

6. Gradual return to stability and low emigration (1995-2010s)

6.1 Democracy and political stability

6.2 Economic stabilisation but slow development

6.3 The effect of Dutch migration policies

6.4 Current emigration motives and growing immigration

7. Connecting the state, structural changes and long-term migration: a discussion 
7.1 The effects of independence and a border regime and their sequence

7.2 Enduring post-colonial ties

7.3 Migration composition

7.4 Migration motives over 60 years

8. Conclusions

Chapter 6 - Emigration from French Guiana: the effects of non-sovereignty, open borders and state policies

1. Introduction 163

2. Guyane's early immigration history and diverse population 165

3. Exploring Guyane's long-term emigration motives 166

3.1 Incorporation as a French department and institutional shifts 168

3.2 Economic developments and employment opportunities 170

3.3 Social welfare and educational opportunities 174

3.4 Additional emigration motives 178

4. Characteristics of emigration 178

4.1 Destination choices 178

4.2 Age, gender and class composition of emigration 180

5. Beyond emigration: the effects of open borders and non-sovereignty on other forms of mobility

5.1 Return and circulation 182

5.2 Non-migration 183

5.3 A brief word on immigration

6. Connecting the state, structural changes and long-term migration: a discussion 186

6.1 The emigration effects of non-sovereignty and open borders 186

6.2 Guianese emigration and the French state 188

Chapter 7 - A comparative analysis of the effects of independence, border regimes and post-colonial ties on migration in the Caribbean and the three Guianas 
1. Introduction

2. Understanding the migration effects of independence, border regimes and their interactions

3. Wider migration effects of border regimes

4. Colonialism, post-colonial ties and worldviews

200

5. The role of the state: between risk production and risk reduction

204

6. Concluding remarks and future research

References

Appendices

229

Appendix A

Appendix B 236

Appendix C

Appendix D

Appendix E

Summary

Valorisation 


\section{List of figures}

Figure 1.1. Percentage of population abroad and in former colonial state, Guyana, Suriname and French Guiana, 1960-2000 4

Figure 2.1. The state and its migration and non-migration policies 34

Figure 2.2. Possible effects of synchronous independence and the establishment of a border regime on international migration

Figure 2.3. Possible effects of the establishment of a border regime followed by independence on international migration

Figure 2.4. Possible effects of independence followed by the establishment of border regime on international migration

Figure 2.5. Possible effects of status change from colony to non-sovereignty on internal and international migration

Figure 3.1. Evolution of political status and border regimes of Caribbean countries, 1920-2014

Figure 3.2. Evolution of border regimes of former colonies towards their former colonial state: 3 trajectories among the 25 Caribbean states

Figure 3.3. Evolution of travel visa restrictiveness of France, the Netherlands, Britain and the US combined towards nationals from Caribbean countries, by border regime of Caribbean countries, 1973-2013

Figure 3.4. Evolution of visa restrictiveness of France, the Netherlands, Britain and the US towards nationals from Caribbean countries, in relation to border regime of Caribbean countries with their former colonial state, 1973-2013

Figure 3.5. Evolution of visa restrictiveness of Caribbean countries towards nationals from Caribbean countries, by border regime of Caribbean countries of origin, 1973-2013

Figure 3.6. Evolution of visa restrictiveness of Caribbean countries towards nationals from Caribbean countries, by former colonial state and border regime of Caribbean countries of origin with their former colonial state, 1973-2013

Figure 3.7. Evolution of total emigration intensities by border regime (\% of migrants among the population born in the countries), 1960-2000 
Figure 3.8. Emigration intensities in the former colonial states by border regime and former colonial state (\% of migrants in their former colonial states among the population born in the countries), 1960-2000

Figure 3.9. Emigration intensities in North America by border regime and former colonial state (\% of migrants in North America among the population born in the countries), $1960-2000$

Figure 3.10. Evolution of destinations within the Caribbean region, by border regime of Caribbean countries of origin with their former colonial state and by colonial sphere (same or different), 1960-2000

Figure 3.11. Evolution of intra-regional destinations of Caribbean countries, by border regime of Caribbean countries of origin with their former colonial state and by type of sphere and by colonial sphere of destination (same or different), 1960-2000

Figure 4.1. Emigration from Guyana by destination, 1953-1967

Figure 4.2. Guyana-born individuals residing abroad, by country of residence and Guyana's population size, $1960-2000$

Figure 4.3. Emigration from Guyana by destination, 1966-1985

Figure 4.4. Emigration from Guyana by destination, 1986-2010 109

Figure 4.5. Guyana's total emigration flows (1953-2010) and GDP per capita (1960-2010)

Figure 4.6. Overall changes in restrictiveness in migration policy in Canada, Britain and the US, 1953-2013, 5-year average

Figure 4.7. Total inflows from Guyana to Canada and the US, 1946-2010

Figure 4.8. Guyana-born individuals residing in the Caribbean region, by country of residence, $1960-2000$

Figure 5.1. Total immigration to and emigration from Suriname, 1922-1950

Figure 5.2. Emigration from Suriname, 1954-1973

Figure 5.3. Emigration by ethnic group, 1964-1970

Figure 5.4. Migration from and to Suriname, 1970-1985

Figure 5.5. Migration from and to Suriname, 1982-1996 
Figure 5.6. Immigrants to the US who previously resided in Suriname, 1946-2010, and immigrants to Canada who were born in Suriname, 1973-2010

Figure 5.7. Migration from and to Suriname, 1994-2010

Figure 5.8. Long-term migration and GDP per capita growth rate, 1950-2010 152

Figure 5.9. Emigration by country of future residence, 2000-2011

Figure 5.10. Surinamese emigrants by year of departure and main reason for emigration, 2004-2012

Figure 5.11. Period of return of Suriname-born population and period of immigration of foreign-born population, 10-year intervals

Figure 6.1. Intercensal net migration of Guyane-born individuals recorded in metropolitan France and net migration as percentage of Guyane's population, 1954-2006

Figure 6.2. Total emigration and BUMIDOM/ANT migration as percentage of total population in French Guiana, 1962-1984

Figure 6.3. Intercensal net migration, Guyane-born individuals by age group 181

Figure 6.4. Intercensal changes in the population in Guyane by place of birth, 1982-2006

Figure 7.1. Schematic representation of migration trends of Guyana, Suriname and French Guiana with respective moments of transition 


\section{List of tables}

Table 1.1. Change in emigrant population rates by country's political status between 1960 and 2000

Table 1.2. Most similar systems research design with three cases: conditions in 2000

Table 1.3. Data triangulation outline

Table 1.4. Newspapers reviewed

Table 1.5. Interviewees by categories, country of birth and gender

Table 2.1. Examples of migration and non-migration policies

Table 2.2. Comparative table of the effects of four scenarios on the volume, destination, migration category and composition of migration

Table 5.1. Surinamese arrivals to the Netherlands, by religious affiliation

Table 6.1. Migration history of Guyane-born individuals, based on residence in Guyane or in metropolitan France (\%) 


\section{Terminology for national and ethnic groups}

This brief note on terminology clarifies the specific terms used in reference to the three Guianas and their populations, including the ethnic groups that comprise these populations. The people of Guyana are Guyanese, those from Suriname are Surinamese and the people of French Guiana are Guianese. None of these terms change in the plural, unlike 'Italians' or 'Germans'. French Guiana is also referred to in its Francophone version, Guyane.

Each of these populations is composed of multiple ethnic groups, whose names vary, reflecting their different colonial histories and languages. For the sake of comparability, this study initially adopted generic descriptive terms, e.g. AfroGuyanese, Afro-Surinamese and Afro-Guianese. However, early feedback from country experts revealed that this terminology generated confusion. Therefore, this study now adopts the terminology commonly accepted in each of the three Guianas, for which I provide a brief description here. Note that these groups are described and cited appropriately in their respective historical context within each case study (Chapters 4-6). The list provided here is meant only for quick reference; thus, it reports only the groups relevant for this study and does not portray accurately some important groups such as the numerous Amerindian and Maroon groups.

\section{Guyana}

The Afro-Guyanese are descendants of the early enslaved African population brought to British Guiana between the mid-16 $6^{\text {th }}$ century and the end of slavery in 1834.

The Indo-Guyanese, or East Indians, are descendants of indentured contract workers brought to British Guiana in the period between 1838 and 1917.

Portuguese and Chinese are descendants of populations originally brought to British Guiana in the mid-19th century as indentured workers from the Madeira Islands and Hong Kong, respectively. The historical Chinese population should not be confused with the new Chinese population that have been settling in Guyana in the last decade.

The Amerindian population represents the autochthonous population of Guyana. 


\section{$\underline{\text { Suriname }}$}

The Creole population refers to the descendants of the early enslaved African population brought to Suriname up until 1863 who were creolised as a result of ongoing association with Europeans, their customs and values.

Hindustani, or East Indians, are descendants of East Indian contract workers brought to Suriname through the indenture system between 1873 and 1917.

The Javanese population descends from labourers who came from Java, Indonesia, between 1890 and 1940 to work on the plantations.

The Chinese population descends from small numbers of indentured workers brought to Suriname in the mid-19 $9^{\text {th }}$ century. In addition to this historical Chinese population, a new wave of Chinese immigrants has settled in Suriname since the early 1990s.

The Maroon populations are descendants of African slaves who escaped from Dutch plantations to the interior of Suriname during the $17^{\text {th }}$ and $18^{\text {th }}$ centuries.

The Amerindian population represents the autochthonous population of Suriname.

\section{French Guiana}

The Creoles of French Guiana are descendants of African slaves, brought to French Guiana up until 1848, early European settlers and Caribbean immigrants, who comprise the largest segment of the population.

The Maroons are descendants of African slaves who escaped largely from Dutch plantations in Suriname during the $17^{\text {th }}$ and $18^{\text {th }}$ centuries; over time Maroon groups crossed over the Maroni River and settled in areas in the interior of western French Guiana.

The Amerindian population represents the autochthonous population of French Guiana.

Métros are French nationals from metropolitan France, the term usually indicating white complexion. 



\section{Chapter 1 - The role of border regimes, independence and post-colonial ties in migration}

\section{Introduction and research objectives}

Borders have a high symbolic value. They are the physical demarcation of a national territory and represent the location where many migration policies are implemented. These migration policies, or border regimes, are often perceived as a necessity because their absence is expected to cause massive and uncontrolled migrations. This position has been challenged at a conceptual level (Pécoud and de Guchteneire 2007) and with empirical evidence. After the 1980s EU accession of Southern European countries there was no sudden increase of emigration, while after the 1989 opening of the borders by Central-East European countries, emigration initially increased but permanent emigration decreased rapidly (Wallace 2002). Similarly, the accession of the Czech Republic, Hungary, Poland and Slovakia to the EU generated varied emigration outcomes (Kureková 2011). At the same time, the effects of border closure are also unclear. The fact that global migration is becoming increasingly concentrated in those countries that particularly stress the importance of border controls (Czaika and de Haas 2014) seems to suggest that borders and increasingly restrictive immigration policies do not necessarily lead to reduced immigration. Thus, the effects of border regimes appear to be misunderstood: while open borders do not necessarily generate massive migration, border closure seems to produce unanticipated migration effects.

One way to understand this paradox is to question the general assumption that border regimes have become more restrictive. A recent study found that overall migration policies have become less restrictive and that immigration policies of major destination countries have become more selective about the types of immigrants they accept (de Haas, Natter et al. 2014). While selectivity may imply restriction, its effects may result in shifts among migrant categories rather than in the reduction of overall volumes of migration. The second general assumption is that migration policies achieve their intended effects. However, de Haas (2011) hypothesised that migration policies may produce unexpected effects on migration, identifying four migration substitution effects: on migration 
destinations (i.e. spatial substitution), the timing of migration (i.e. inter-temporal substitution), the legal (and irregular) migration channels used by migrants (i.e. categorical substitution), and return decisions (i.e. reverse flow substitution). This suggests that to understand the effects of border regimes, researchers must adopt refined analyses of migration policies that look into their potential effects not only on migration volumes, but also on the timing, destination and composition of migration.

Another way to examine the paradoxical effects of border regimes is to go beyond a strict analysis of migration policies and their effects. Migration is the outcome of complex social processes and border regimes should be considered as an 'intervening' factor (Lee 1966). Moreover, migration policies may in fact be perceived as rules to be negotiated and overcome to achieve one's life aspirations (Castles 2004). Furthermore, other factors, ranging from political and socioeconomic processes to historical and linguistic connections, may be strong migration determinants and lead to the formation of migrant communities and long-term cumulative migration despite restrictive immigration policies (Massey 1990). Social and cultural connections, the presence of migrant communities in destination countries and important events and living conditions in origin countries, including major political shifts, economic transformations and crises, are central to migration decision processes. Disregarding them may distort our understanding of border regimes and their effectiveness. Therefore, research must move beyond a myopic focus on border regimes and put migration policies in context to observe their effects in interaction with other factors and non-migration policies.

The transformation of former colonies into independent countries offers a unique angle to examine the effects of border regimes and major political, institutional, economic and identity shifts on migration patterns. Independence marks the moment when former colonies depart from a dependent status within a larger political entity to acquire full sovereignty over their territory. ${ }^{1} \mathrm{New}$ states gain self-determination to create their own domestic and foreign policies, introduce a number of institutional changes and consolidate the limits of their national territory. Most significantly for migration research, independence generally results in the closure of the border with the former colonial state and, possibly, with several other countries. However, the processes and sequencing of independence and border regimes can vary across former colonial states and are not always synchronous - factors central to this study. Alternatively, a colony may

\footnotetext{
${ }^{1}$ This definition masks exceptions, such as the case of New Zealand, where independence has not occurred at a specific point in time but has been part of a process of progressive detachment from Britain.
} 
not reach independence but become fully part of the colonial state as a nonsovereign overseas territory or department (Christopher 2002). Non-sovereign statuses include various levels of autonomy over territorial matters, with full incorporation the furthest from independence, and different types of border regimes with the former colonial state, with fully incorporated countries benefitting from total freedom of movement. Hence, by examining the transitions from colonial to independent and non-sovereign countries ${ }^{2}$ and the corresponding border regimes, this study provides a unique comparative historical perspective on the open and closed border debate.

How does independence affect migration? And what are the migratory effects of the establishment of border regimes? Do we expect any interactions between these two events? What is the role of historical and cultural connections, often referred to as post-colonial ties, in overcoming newly established border regimes? Empirical evidence suggests that the introduction of border regimes in former colonies may lead to a hike in emigration to 'beat the ban' (Peach 1968; Marshall 1987), but studies on the migration effects of independence are much more limited, with a few exceptions (van Amersfoort 2011). Consequently, migration research offers only patchy explanations of the effects of political status transitions, such as independence, and the establishment of border regimes. To start filling this research gap, this study focuses on migration in the Caribbean region, where several former colonies have obtained independence while others have retained a dependent status as non-sovereign territories or departments.

Within the Caribbean region, three specific countries came to my attention in the early phases of this study because they embodied the paradoxical effects of border regimes and political status transitions: Guyana, Suriname and French Guiana, sometimes referred to as the three Guianas. These three countries, located on the north-eastern coast of South America, share a common history that includes colonialism, the imposition of European governments, and plantation and resource extraction economies, which relied on 'imported' slave and contract labour. Despite these similarities, the three Guianas also display contrasting features. Not only were they colonised by different empires, but they also differ in their political status: Guyana gained independence from Britain in 1966, Suriname obtained independence from the Netherlands in 1975, and French Guiana became fully incorporated into France as a French Overseas Department (Département d'Outre Mer or DOM) 3 in 1946, making it officially part of France.

\footnotetext{
2 I find the term 'country' to be appropriate given the distinct political and national identities which typically characterise these territories in spite of political unity, e.g. the Basque country.

${ }^{3}$ The DOMs include French Guiana, Guadeloupe, Martinique, Réunion and, since 2011, Mayotte.
} 
The three Guianas also display strikingly diverse emigration patterns (Figure 1.1): Guyana has seen an increase in its population abroad, but a drastic decrease in the size of the Guyanese community in Britain, its former colonial state, suggesting that independence has had the effect of increasing emigration overall, while the establishment of the border regime with Britain has reduced emigration to this destination; Suriname has also seen a continuous increase in its population abroad, accompanied, however, by a striking increase in the size of the Surinamese community in the Netherlands, its former colonial state, despite the imposition of a border regime starting in 1975; French Guiana has not undergone either independence or the establishment of a border regime and displays low emigration in general and only a slight increase of emigration to metropolitan France at the turn of the millennium.

Figure 1.1. Percentage of population abroad and in former colonial state, Guyana, Suriname and French Guiana, 1960-2000

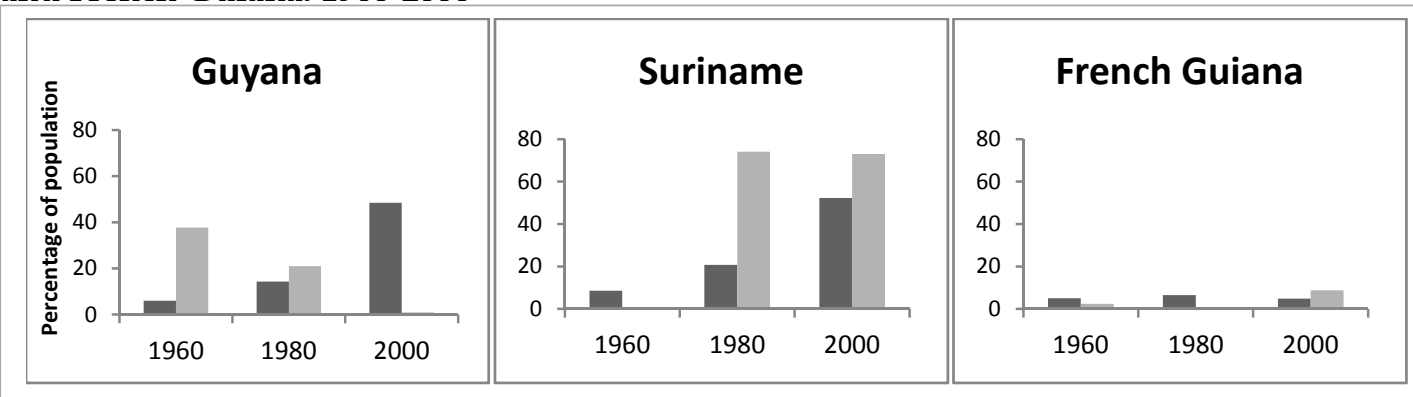

Population abroad as percentage of total country's population

Percentage of total population abroad in former colonial state

Source: World Bank Global Bilateral Migration Database and UN Population Estimates ${ }^{4}$

While these data are known to have limitations, they still raise key questions: Why is emigration highest from countries with closed border regimes? Is independence the driver of increasing emigration from Guyana and Suriname and if so, why? When do border regimes with the former colonial state decrease emigration (i.e. Guyana to Britain) and when do they seem to stimulate emigration

\footnotetext{
${ }^{4}$ World Bank's Global Bilateral Migration database 1960-2000, available at http:

//data.worldbank.org/data-catalog/global-bilateral-migration-database, accessed on March 2013. The 2000 data originally the Global Migrant Origin Database by the University of Sussex; United Nations, Department of Economic and Social Affairs, Population Division (2013). World Population Prospects: The 2012 Revision, DVD Edition, Total population (both sexes combined) by major area, region and country, annually for 1950-2010 (thousands), Estimates 1950-2010. These details apply to all graphs which use these two datasets throughout this study, unless otherwise specified.
} 
(i.e. Suriname to the Netherlands) and why? Why does the absence of border restriction paradoxically not lead to more emigration from French Guiana? And to what extent are the effects of history, or post-colonial ties, affecting emigration destinations? The questions raised by the three Guianas offered the opportunity to challenge widespread assumptions on the effects of open and closed borders, independence and post-colonial ties, and to conduct innovative critical analyses on the role of the state in shaping the volumes, timing, direction and composition of emigration.

This study aims to examine how the state affects migration patterns through the analysis of four interrelated factors: the establishment of border regimes between former colonies and the former colonial state; the processes of political transition to independence and non-sovereignty; post-colonial ties; and non-migration policies such as education, social welfare, or agricultural reforms. This study's main research question is:

\section{How do states in origin and destination countries affect the volume, timing, composition and direction of migration?}

Two sub-questions follow:

(i) What have been the short- and long-term migration effects of independence and the establishment of a border regime?

(ii) What has been the importance of post-colonial ties in shaping migration patterns and how did they affect migration?

This study also examines the effects of the transition from colonial to nonsovereign status and the absence of a border regime on emigration patterns by studying Caribbean non-sovereign countries and specifically the case of French Guiana. Migration patterns are defined in terms of their volume, timing, composition (class, gender, ethnic group, age) and direction, also referred to as destination. By relying on these dimensions of migration and adopting the four hypothesised migration substitution effects that limit the effectiveness of immigration policies (cf. de Haas 2011), here embodied in border regimes, this study elaborates a new conceptual framework, developed in chapter 2 , that allows a systematic and nuanced analysis of the effects of border regimes and political status transitions on emigration. Moreover, through the proposed conceptual framework, the study offers a logical approach to understand when and how post-colonial ties influence migration destination decisions.

This study addresses two weaknesses in migration research. First, a receiving-country bias resulting in the general disregard for origin countries in migration processes. Migration literature abounds concerning both the policy- 
making process in liberal democratic states (Hollifield 1992; Freeman 1995; Bonjour 2011) and the effectiveness of immigration policies (Hatton and Williamson 2002; Mayda and Patel 2004; Ortega and Peri 2009; Czaika and de Haas 2011). This is in stark opposition to the widespread neglect of origin countries, both in regard to the role of the state in migration, and to perceptions of migration and migration policies in origin countries. Some literature explores the role of the state by examining 'brain drain' prevention (Skeldon 2005; Chappell, Sanchez et al. 2009), labour export schemes (Hugo and Stahl 2004) and diaspora engagement strategies and institutions (de Haas 2006; Gamlen 2006; Agunias 2009; Gamlen 2014). However, the role of origin countries in migration processes has been underexplored, whether from the perspective of the state (de Haas and Vezzoli 2011) or that of their populations. Therefore, this study adopts an origin country perspective to identify ways in which states in origin countries perceive and influence emigration and to improve our understanding of how migration policies in origin and destination countries are perceived and influence migration flows.

Second, migration research almost exclusively equates the state with its migration policies, thus ignoring the variety of unexpected ways in which states can influence migration patterns (cf. Massey 1999; de Haas 2005; Zoomers and van Naerssen 2006; de Haas 2011). This study departs from a strict association of the state with its migration policies by exploring the wider role of states, particularly in origin countries. In his seminal article 'Exit, voice and the state', Hirschman (1978) suggested that the origin country state is central in shaping the structural conditions that influence migration decisions. Improved socio-economic conditions, public goods, a country's power and prestige, its respect for social justice, guarantee of human rights and democratic liberties are qualities valued by citizens, as well as areas affected by non-migration policies. The absence of some of these conditions, combined with individual preferences and aspirations, encourage emigration to other countries (Hirschman 1978). Yet the links between development conditions and emigration are complex, particularly in the longer term. Thus, land redistribution reforms may temporarily discourage emigration by segments of the population who access new land, while encouraging the emigration of expropriated landowners. Similarly, free access to education may initially discourage emigration, but in due course cohorts of more educated youth may develop the desire to pursue advanced education abroad. More broadly, we need to consider a set of factors as varied as military occupation, political repression, colonialism, imperial pursuits and independence, which have greatly influenced population movements throughout history (Dowty 1987; Samers 1997; Massey, Arango et al. 1998; Castles and Delgado Wise 2008; Castles and Miller 2009). 
Thus, states in origin countries may in fact have much more power to affect migration than a narrow focus on emigration policies would suggest (Teitelbaum 1984). Researchers are increasingly engaging with this broader perspective by including origin country factors that go beyond demography and economics. For example, Kureková (2011) researched migration patterns from eastern European countries and found that low emigration rates from Hungary, Slovakia and Lithuania could be explained by the generous welfare provisions of these origin countries, demonstrating that the 'welfare magnet' may in fact operate in origin countries. Likewise, Mahendra (2014) analysed the effect of social policies in Indonesia and found they exerted a 'magnet' effect in reducing emigration. While still limited, this type of research has the potential to expand the knowledge of migration processes from an origin country perspective and to generate evidence of the multiple effects of state actions beyond migration policies, which is also the ambition of this study.

\section{Geographical focus: the Caribbean region and the three Guianas}

This study first explores migration patterns in the Caribbean region to examine whether and how independence, border regimes and post-colonial ties shape migration. Next, the focus shifts to the three Guianas to gain insights into the dynamics that shape migration during these moments of transition. The Caribbean has been defined in various ways over the centuries based on geopolitical and cultural interpretations (cf. Gaztambide-Géigel 2004). In this study, the region includes 25 countries that share common economic development rooted in plantation economies and a long history of slavery, indentured labour and voluntary migrations: all independent and non-sovereign countries in the Caribbean Sea, plus Belize, French Guiana, Guyana and Suriname, but excluding Cuba, Haiti and the Dominican Republic. ${ }^{5}$

\footnotetext{
${ }^{5}$ The full list of countries considered in this study are: Anguilla, Antigua \& Barbuda, Aruba, Bahamas, Barbados, Belize, British Virgin Islands, Cayman Islands, Dominica, French Guiana, Grenada, Guadeloupe, Guyana, Jamaica, Martinique, Montserrat, Netherlands Antilles, Puerto Rico, St. Kitts and Nevis, St. Lucia, St. Vincent \& the Grenadines, Trinidad and Tobago, Turks and Caicos, Suriname, US Virgin Islands. For a map of the Caribbean region, see Figure A1 in Annex. Because this study focuses on understanding the association between migration shifts and border regime changes from the 1960s, we exclude Cuba, Haiti and the Dominican Republic, which became independent and separated by a border regime over the $19^{\text {th }}$ and early $20^{\text {th }}$ centuries. While the US territories have also not changed their status in the last 85 years, they were retained because they belong to the group of counterfactual cases that have not been subjected to the structural changes under examination (independence and closure of borders).
} 
The Caribbean is comprised of small states, mainly island states. The countries in this region have had an intense history of both immigration and emigration, a common trait of islands. Islands' intense migratory processes are related to a number of factors, including their endowment with natural resources or lack thereof, a marginal location or alternatively being located at important cross-roads (e.g. Hawaii and Malta) or having constraints such as small rugged territories that cannot easily accommodate growing populations. While in many instances island populations have adapted to both environmental and occasional demographic constraints, emigration has also been a safety-valve either to regulate growing populations on small islands or as a way to obtain remittances and sustain island life (King and Connell 1999).

As small states, island states are often set apart from larger states in the world because their small populations, and usually small land mass, characteristics that have been thought to be a detriment to their economic development. Recent research, however, has shown that small states have on average higher GDP per capita growth as well as higher values for human development indicators such as life expectancy (Easterly and Kraay 2000). In the Caribbean, while some countries have displayed economic growth (e.g. Cayman Islands), others have lagged behind (e.g. Guyana). Nevertheless, availability of public schools since the colonial period has resulted in high levels of education. The lack of employment opportunities for such an educated workforce at home helps to explain why Caribbean countries are among the top countries with high numbers of tertiary educated migrants (Docquier and Schiff 2009). However, because the populations in these countries are small, economic growth may rapidly lead to immigration and return migration (King and Connell 1999). Such dynamics explain why small island states are intensely intertwined with migration processes.

In the Caribbean, mobility is high and it has deep historical roots, having been a survival mechanism in response to violence and exploitation and a form of resistance to the political and socio-economic conditions in individual colonies (Thomas-Hope 1980; Premdas 1999). Zelinsky (1971) argued that there is a link between social and spatial mobility, as moving spatially allows for the breaking of some of the social structures that would not allow upward mobility. In the Caribbean, migration has been a means to overcome such structural constraints. Thomas-Hope (1978) found that formerly enslaved peasants would rather emigrate to work abroad even though employment was available at home, because even after the abolition of slavery, peasants would not be allowed to improve their livelihood within their islands. Therefore, emigration provided a viable alternative to the lack of fundamental socio-economic changes in the islands. 
Table 1.1. Change in emigrant population rates by country's political status between 1960 and 2000

\begin{tabular}{lcc}
\hline & \multicolumn{2}{c}{ Political Status } \\
\hline Growth in emigrant population rate & 13 & 6 \\
\hline Decline in emigrant population rate & 0 & 6
\end{tabular}

Source: Global Bilateral Migration Database, World Bank

A second reason for focusing on the Caribbean region is the rapid changes in political status between the 1960s and the 1980s, when a number of independent states were established and new border regimes were introduced. Moreover, 12 out of the 25 Caribbean countries under consideration retained a non-sovereign status. Data for the 25 countries show that the size of the emigrant populations has increased in 19 countries and decreased only in six between 1960 and 2000 (Table 1.1). No independent country has seen a decrease in their population abroad (emigrant stock) over this period. However, growing emigration is not a unique feature of independent countries as half of the non-sovereign territories also had an increasing emigrant population. Thus, the region offers an ideal context to study how factors such as independence and border regime establishment have affected historical emigration patterns.

The Caribbean region offers a third valuable analytical angle: 400 years of colonial history make it suitable for an investigation of post-colonial ties as drivers of migration between former colonies and their former colonial states before and after independence. Different colonial powers have been involved in the region (Britain, France, the Netherlands and the United States ${ }^{6}$ ); as a result, some groups of countries share a language with a single destination (i.e. Dutch, only spoken in the Netherlands) while others have a language in common with multiple destinations (French or English); in addition, educational proximity to former colonial states and the presence of long-term migrant communities established during colonialism make the Caribbean region the ideal context to explore postcolonial ties.

The peculiar emigration patterns of the three Guianas explain their selection as in-depth case studies. While comparative research on the three Guianas is limited (Giacottino 1995; Lézy 2000), migration researchers have

\footnotetext{
${ }^{6}$ Although the US is not generally considered to have a colonial past, we classify it as a former colonial state because: (i) it briefly occupied Cuba; (ii) Puerto Rico held a colonial status until its establishment as an associated free state in 1950; (iii) the US is the sovereign state of the US Virgin Islands.
} 
indicated that there is much to learn from comparing these three countries, where processes of globalisation have affected mobility (Laëthier unknown). The three Guianas display a number of similarities: they remain relatively marginal as the only non-Iberian countries in South America, while also at the margins of the extended Caribbean region (Redfield 2000), and share similar histories of colonialism, exploration, exploitation and labour immigration. In addition to the emigration patterns presented earlier, the three Guianas show remarkable characteristics: Guyana and Suriname have very high emigration and within the Caribbean they have the highest growth in emigrant population as percentage of their respective populations between 1960 and 2000, while French Guiana has among the lowest emigrant population in the Caribbean region (Table A1 in appendix A). In this respect the three Guianas are extreme cases and as such they can provide richness of information (Flyvbjerg 2006: 229) and allow us to observe whether the strong variation in emigration could be associated with independence, border regimes and/or post-colonial ties.

These three in-depth qualitative case studies have generated a more nuanced perspective on the role of colonialism, the process of independence and non-sovereign dependency, the role of border regimes and post-colonial ties and, more generally, the role of the state in migration processes. Moreover, close attention is paid to the interplay of these factors with various political, social and economic migration drivers at independence and transition to non-sovereignty and thereafter. These case studies also provide an excellent opportunity to understand shifting emigration motives over time as people adapt to important historical changes and make decisions on the timing and destination of migration. The comparative value of these case studies is further explained in the methodological section.

\section{Methodology and methods: a pragmatist approach}

At the onset of this study, existing migration theories provided valuable concepts, particularly: previous empirical evidence on the establishment of borders (Peach 1968; Marshall 1987), notions of migration policies as intervening factors on migration (Lee 1966) and as 'opportunity structures' (Castles 2004) and hypothetical migration substitution effects of migration policies (de Haas 2011). Moreover, insights were gained from literature on the broader role of the state, including in origin countries, beyond migration policies (Massey 1999) and on the expected effects of post-colonial ties on facilitating migration and determining specific destinations (Fassmann and Munz 1992; Thielemann 2006; Hooghe, Trappers et al. 2008). These concepts guided the formulation of initial hypotheses 
for descriptive statistical analyses on the Caribbean region. However, existing theories were insufficient to explain the underlying processes that linked independence, border regime establishment and post-colonial ties to changes in migration patterns. Better evidence was necessary on how people interpreted these events and how such interpretations might have affected emigration.

Given the theoretical gaps, case studies were incorporated in the methodology to generate new empirical knowledge and theoretical insights (Flyvbjerg 2006). The country case studies of Guyana, Suriname and French Guiana were selected to explore the evolution of their emigration patterns from the end of the Second World War to the 2010s. The most suitable approach to carry out such comparative research was historical comparative analysis. Relying on nation states as the comparative units of analysis (Osinsky and Eloranta 2015 forthcoming), historical comparative analysis aims to explain important outcomes, in this case migration patterns, by observing causal links, accounting for the processes that develop over time and using 'systematic and contextualised' comparisons (Mahoney and Rueschemeyer 2003: 6). Through this approach I could: identify and understand factors, and combinations thereof, that could explain the specific evolutions of emigration observed in these three cases; analyse historical sequences both in terms of contextualising the events and placing events in sequential order (i.e. independence taking place before or after the establishment of a border regime); and compare and contrast case study evidence in a systematic and contextualised manner (e.g. the emigration effects of short- or long-term authoritarianism).

To guide me in the primary data collection and generate new concepts to fill existing theoretical gaps, I borrowed techniques associated with grounded theory. Grounded theory is an interpretive methodology that offers systematic ways to collect and code data in order to uncover new concepts that emerge from social actors (Suddaby 2006). With grounded theory, new ideas are allowed to emerge and be tested through the collection and analysis of qualitative data. While the full application of this methodology was not suitable for this study, new concepts were needed to fill theoretical gaps. Hence, the reliance on some of the techniques used in grounded theory, specifically 'theoretical sampling' and 'constant comparison' (Suddaby 2006) to guide a more systematic and rigorous analysis.

This study adopts a state-centred approach as it closely examines the state and its actors as promoters of political agendas and migration and non-migration policies, which affect society's socio-economic circumstances. This approach has two major limitations: first, as is the case in destination countries (Boswell 2007), the state in origin countries is not a single-minded monolith and its policies may in 
fact reflect the diverse interests of various state agencies; second, a state-centred perspective tends to focus on structural factors and the migration constraints they impose, hence disregarding individual responses which may overcome such structural constraints. This study attempts to overcome these limitations by considering various state actors, policies and their objectives. Also, I made a specific effort to account for migration and non-migration policies implemented over the years in different areas, consider the interests of various groups in the population and include individual perspectives on origin country developments and their effects on personal migration histories and migration decisions.

Despite the ambition to identify factors that have been relevant for longterm emigration, this study does not claim to identify and quantify causal relations and effects. Rather, its objective is to learn from people's subjective experiences so as to reach theoretical conclusions on associations between macro-level factors and migration behaviours. The pairing of macro- to micro-level migration determinants provides a better understanding of how the same structural changes can affect various segments of the population differently, e.g. class and ethnic group, and how these factors may encourage migration or, alternatively, motivate people to stay. Factors that are often highly relevant to individuals but are typically excluded from analyses were key in this study: the importance of community and family level determinants including attachment to community, family structures and a wide range of sentimental reasons. Thus, this approach helps us to understand the process of migration decisions in times of critical structural changes, the types of reactions triggered by certain state decisions and also to observe and record the importance of serendipitous encounters or events which may determine migration for an individual, possibly an entire family and even a community. Ultimately, this interpretive approach provided the flexibility to apply the concepts of migration substitution effects previously developed by de Haas (2011) and allowed the emergence of innovative conceptual elaborations (presented in chapter 2).

In the end, the methodology combined three different approaches: (i) First, descriptive statistical analyses of long-term emigration patterns in the Caribbean region identified associations between independence, border regimes and postcolonial ties and emigration patterns, particularly on the volume, timing and destinations. (ii) The insights from regional patterns and existing theories fed into the elaboration of four theoretical scenarios that conceptualize the complex migration effects of independence and the establishment of border controls. (iii) Finally, complementary in-depth qualitative analyses gathered evidence on the role of the state during independence and the establishment of border regimes, and the population's perceptions of these events and migration reactions. 


\subsection{Descriptive statistical analyses of regional trends}

Descriptive statistical analyses of historical Caribbean migration trends provided a crucial overview of the association between independence, the establishment of border regimes, post-colonial ties and long-term emigration patterns. Previous analyses of Caribbean islands had examined the association between political status and migration (McElroy and Sanborn 2005; McElroy and Pearce 2006). However, because the processes and timing of independence and border regimes are not always synchronous but vary across former colonial states, an analysis of the effects of independence on migration would not necessarily capture potential migration effects of the establishment of border regimes. Moreover, these studies did not consider the peculiarity that the borders of some non-sovereign countries were closed despite their continuous political association with the metropolitan state. 7 Thus, the decision was made to focus these first analyses on the evolution of border closures with the former colonial state and their effects on emigration. Specifically, the analyses explored overall, extra-regional and intra-regional emigrations from 1960 to 2000 to observe shifts in emigration intensity and destination and their association with shifts in border regimes with the former colonial state.

These analyses were carried out on the 25 Caribbean countries previously indicated. While migration flows from two databases were considered, ${ }^{8}$ the data for the Caribbean region were too patchy to allow longitudinal analyses. Thus, to accomplish this analysis, migrant stock data were taken from the Global Bilateral Migration Database (GBMD) released by the World Bank, ${ }^{9}$ which contains bilateral migration population ('stock') data for 226 countries, major territories and dependencies for each decade from 1960 to $2000^{10}$ (Özden, Parsons et al. 2011). These data also presented limitations, further discussed in chapter 3. Nevertheless,

\footnotetext{
7 In this study, the term 'former colonial state' indicates that a former colony has obtained independence, while 'metropolitan state' represents the central state that continues to hold important decision-making powers for non-sovereign countries. These distinct terms are used whenever possible in order to demarcate this important difference.

${ }^{8}$ DEMIG TOTAL reports total historical immigration, emigration and net migration, and DEMIG C2C covers bilateral migration flow data for 34 countries over the 1946-2011 period. These databases have been completed as part of the DEMIG project; for more information see Vezzoli, Villares-Varela and de Haas 2014. Both databases are available at http://www.imi.ox.ac.uk/data.

${ }^{9}$ The data for 2000 was originally released by the University of Sussex as the Global Migrant Origin Database.

${ }^{10}$ Data for 2010 and 2013 are available at http: //econ.worldbank.org/WBSITE/EXTERNAL/EXTDEC/EXTDECPROSPECTS/0 „, contentMDK: 22803131 pagePK: 64165401 piPK: 64165026 theSitePK: 476883,00.html. Questions have been raised on the quality of these data and preliminary analysis conducted by the author strengthened this perception. Therefore, it was decided not to use these data so as to increase data reliability.
} 
this database allowed us to account for the presence of Caribbean migrants worldwide by origin and destination countries in a 40-year period, during which important changes in border regimes, political status and immigration policies occurred.

These analyses provided valuable macro-level insights on the emigration characteristics of Caribbean countries according to border regime and colonial sphere. For example, in 200033 percent of all individuals born in Caribbean countries with open borders with their former colonial state resided abroad, compared to 27 percent in countries that saw their borders closed with their former colonial state. However, some trends could not be easily explained. For instance, from the results it was not possible to explain why border closure results in an initial reduction of emigration, but an increase in the long-term, or why former British countries displayed a strong diversion of their emigration flows to the United States, while the Netherlands remained highly attractive for citizens of independent Suriname. And while French non-sovereign countries retained a strong focus towards metropolitan France, Dutch non-sovereign countries were less homogeneously oriented towards the Netherlands. To uncover some of the underlying dynamics, I proceeded to develop a theoretical framework through the use of conceptual scenarios.

\subsection{Theorization and the development of conceptual scenarios}

The migration characteristics displayed by the three Guianas provided the initial material to begin the development of hypothetical scenarios. The scenarios gradually incorporated the complex effects generated by the processes of decolonisation, political status change and the establishment of border regimes as I became aware of the ambiguous ways in which these changes may affect people and ultimately shape migration. The migration substitution effects hypothesised by de Haas (2011) provided a stimulating framework to think of how the migration policies included in border regimes may affect historical migration patterns. Moreover, the migration substitution effects framework offered a systematic manner to examine the complexity of these events with their possible migration consequences.

This process led to the creation of hypothetical scenarios that relied on a theoretical understanding of how policies affect migration patterns, and incorporated notions derived from the exploration of the processes of independence, non-sovereignty and the opening or closure of border regimes. In particular, I relied on literature as well as empirical evidence to recognize similarities and differences in historical developments and identify associations between these changes and migration trends. Thus, the four resulting conceptual scenarios are the product of the interaction between deductive and inductive 
reasoning and are no longer based solely on hypotheses but rest heavily on empirical evidence. Although these scenarios are presented at the beginning of this study in chapter 2, the fully developed scenarios were finalised towards the end of this study. These scenarios proved to be a very useful practical tool that could be used to understand the effects of opening and closing borders in other geographical contexts.

\subsection{In-depth qualitative analysis of migration processes and migration motives}

Based on the striking migration characteristics presented in the introduction, the three Guianas offered unique cases to examine the role of borders, independence and post-colonial ties. The three Guianas also fit within the most similar systems research design (Seawright and Gerring 2008). In its purest form, this analytical model requires comparing two or three cases that are similar in all their background conditions except for the main theoretical explanatory variable and the outcome. As presented above, the historical and socio-economic conditions in these three countries were largely similar in the 1950s and 1960s, when in fact the relative size of their emigrant populations was roughly similar - 7.5 percent of French Guiana's population, 8.2 percent of Guyana's and 11.5 percent of Suriname's in 1960. By 2000, the emigration populations of Guyana and Suriname had grown to about 50 percent of the origin country population, while emigration from French Guiana remained very low (Table 1.2).

Over this time period, independence and the establishment of borders - i.e. the variables of theoretical interest - may have set Guyana and Suriname apart from French Guiana, causing the emigration patterns we see today. To test this hypothesis, a most similar systems design would require the level of political and socio-economic stability to be similar among all cases. Although official socioeconomic figures set French Guiana apart from Suriname and Guyana, we must not forget that French Guiana has also witnessed political contestation, social tension and economic difficulties, including few employment opportunities, making the conditions on the ground possibly less sharply distinct than statistics may suggest. Moreover, other contextual conditions among the three cases are similar, such as population diversity, economic activities (e.g. agriculture, forestry, mining) and challenging developmental conditions, which make these cases suitable for a most similar analytical model. 
Table 1.2. Most similar systems research design with three cases: conditions in 2000

\begin{tabular}{llllll}
\hline Country & $\begin{array}{l}\text { Political } \\
\text { status }\end{array}$ & $\begin{array}{l}\text { Border } \\
\text { regime }\end{array}$ & $\begin{array}{l}\text { Socio- } \\
\text { economic } \\
\text { stability }\end{array}$ & $\begin{array}{l}\text { Political } \\
\text { stability }\end{array}$ & $\begin{array}{l}\text { Emigration, } \\
\mathbf{2 0 0 0}\end{array}$ \\
\hline Guyana & Independence & Yes & Low & Low to medium & $\begin{array}{l}\text { High } \\
\text { (48\% of pop.) }\end{array}$ \\
\hline Suriname & Independence & Yes & Low & Medium & $\begin{array}{l}\text { High } \\
\text { (52\% of pop.) }\end{array}$ \\
\hline $\begin{array}{l}\text { French } \\
\text { Guiana }\end{array}$ & Incorporation & No & Medium ${ }^{12}$ & Medium & $\begin{array}{l}\text { Low } \\
(4.8 \% \text { of }\end{array}$ \\
& & & & & pop. $)^{13}$ \\
\hline
\end{tabular}

I conducted in-depth, qualitative research in the three Guianas between October 2013 and April 2014, during which a total of 84 interviews took place. Based on the conceptual framework guiding this study and the interest in longterm historical political and socio-economic conditions as shapers of emigration, four specific areas were targeted:

- Late colonial strategies, decolonisation and the process to independence and non-sovereignty status, including relations with the former colonial state/metropolitan state and among ethnic groups in diverse populations;

- Conditions surrounding the establishment of border regimes, including the official positions of the former colony and the former colonial state;

- Political events, policy reforms in education, health care, social welfare and income and resource distribution in the post-colonial period;

\footnotetext{
${ }^{11}$ These values are based on an evaluation of the 2000 World Bank's Worldwide Governance Indicators, which include a variable, the 'Political Stability and Absence of Violence/Terrorism' indicator, that 'captures perceptions of the likelihood that the government will be destabilized or overthrown by unconstitutional or violent means, including politically-motivated violence and terrorism.' (World Governance Indicators, Metadata), available at http:

//databank.worldbank.org/data/reports.aspx?source=Worldwide-Governance-Indicators, accessed on April 11, 2013.

${ }^{12}$ Data published in various reports indicate that although living conditions are the highest among all South American countries, socio-economic indicators are not at the level of France. In 2006, the UN reported the unemployment level at 26 percent (http:

/data.un.org/CountryProfile.aspx?crName=French\%20Guiana).

${ }^{13}$ Data for French Guiana must be considered with reservation given preliminary evidence of figures by INSEE that indicate an emigrant stock of 30 percent in 2007.
} 
- Introduction of specific migration policies by former colonial states after the establishment of border regimes and by other potential migration destinations, and official discourses accompanying such policy changes.

Data collection relied primarily on archival research and individual semistructured interviews (Table 1.3). Archival research took place in Guyana, Suriname and French Guiana as well as in Britain, where the National Archives hold ample historical documents on colonial affairs and the British government views on migration from former colonies. The archives in Georgetown, Paramaribo and Cayenne offered a wide range of materials including government documents white papers, declassified government documents such as minutes from meetings, policy documents - and historical literature, journal and newspaper articles on migration issues, development issues and policy changes. Primary sources included Masters and $\mathrm{PhD}$ theses which were central to identify structural changes that may have had migration consequences.

Articles in the press were crucial for two reasons: first, they captured the government's position on migration; second, they identified policy changes, which I could explore further, and their potential impact on these societies. Newspaper articles guided me towards issues of importance over the years, e.g. emigration and immigration, migration policies in destination countries, socio-economic reforms and their effect on the population (Table 1.4). These articles raised my awareness of the information available to the population and how it may have shaped their perceptions of the country's 'well-being' before, during and after independence and the introduction of border regimes. For instance, Surinamese newspapers amply reported the post-independence conditions in neighbouring Guyana, emphasizing the ethnic tensions and deteriorating economy and raising anxiety about Suriname's upcoming independence. Newspaper articles also served to corroborate information collected from the literature. 
Table 1.3. Data triangulation outline

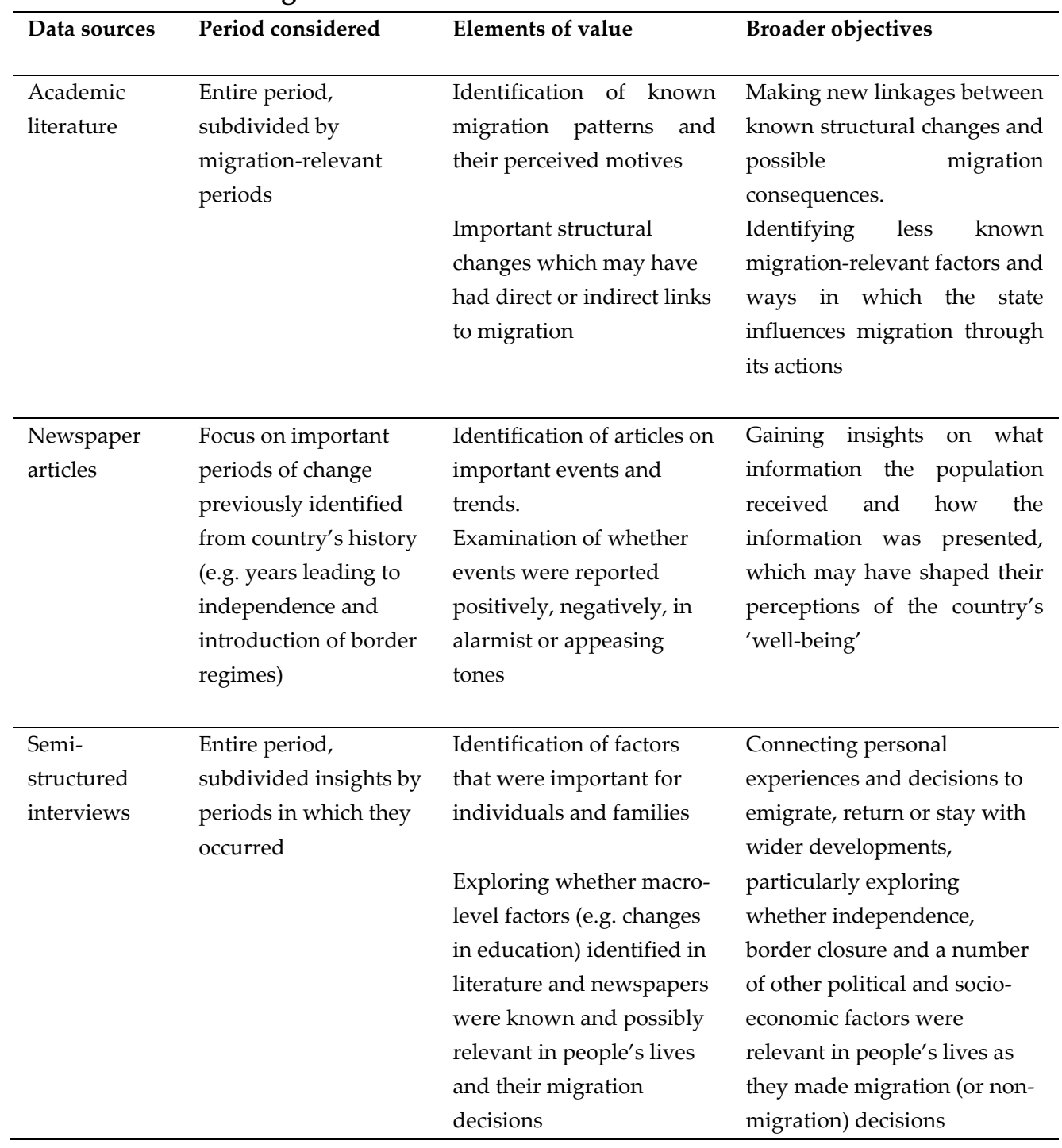


Table 1.4. Newspapers reviewed

\begin{tabular}{|c|c|}
\hline Country & Newspapers \\
\hline Guyana & $\begin{array}{l}\text { - } 13 \text { Guyanese newspapers covering the period 1962-2013, primarily the } \\
\text { Guyana Chronicle and Stabroek News but also including the Guyana } \\
\text { Graphic, Guyana Star, Kaieteur News, the Mirror and the New Nation; } \\
\text { Limited number of historical articles from British newspapers, primarily } \\
\text { The Guardian. }\end{array}$ \\
\hline Suriname & $\begin{array}{l}\text { - Reviewed daily articles in Suriname's newspaper De Ware Tijd, April- } \\
\text { August 1973; October-December } 1979\end{array}$ \\
\hline $\begin{array}{l}\text { French } \\
\text { Guiana }\end{array}$ & $\begin{array}{l}\text { - } 6 \text { French Guianese newspapers covering the period 1961-1982: Debout } \\
\text { Guyane, France-Guyane, Guyane Action, La Presse de Guyane, La Radio } \\
\text { Presse, la Voix de la Guyane } \\
\text { A limited number of issues of popular magazines over the 2007-2012 } \\
\text { period: Magazine Marianne and Pull Up }\end{array}$ \\
\hline
\end{tabular}

The data collected through archival research was compared and integrated with primary data collected through semi-structured interviews. Four categories of interviewees were considered (Table 1.5):

- Migrants - people who emigrated from Guyana, Suriname and French Guiana irrespective of their country of destination. Among the interviewees, some migrants were in their origin country for short-term visits, while others were interviewed in the countries of destination (via Skype);

- Returnees - people who returned from abroad, irrespective of whether their destination was extra-regional or within the Caribbean;

- Non-migrants - people who never emigrated, although they may have had short visits abroad. Specifically, I tried to include people with siblings, relatives and many friends abroad but never emigrated;

- Former or current government representatives - this group included diplomats and people who held government functions and could provide an insider view of the government ideology in relation to the country's migration issues.

The purpose of the interviews was two-fold: first, to gain a greater understanding of how the contextual changes that occurred in these countries, including independence, borders and post-colonial relations, were perceived and lived by people before emigration or over the years for the people who stayed; second, to capture the relevance of structural conditions and migration policies in the decision-making process. Non-migrants could provide insights on the motives and the process of deciding to stay. By interviewing both migrant and non-migrant 
groups, I could shed light on the conditions under which the same factors stimulate emigration among some people and not in others (see sample questions in Table A2 in appendix A). For instance, while the unfavourable economic conditions and severe goods shortages motivated many Surinamese to emigrate in the 1980s-1990s, one interviewee indicated that this was a great time for business in legally trading smuggled goods, which encouraged him to stay.

Table 1.5. Interviewees by categories, country of birth and gender

\begin{tabular}{lrrrrrr}
\hline Interviewee type & \multicolumn{2}{c}{ Guyana } & \multicolumn{2}{c}{ Suriname } & \multicolumn{2}{c}{ French Guiana } \\
\hline & Men & Women & Men & Women & Men & Women \\
\hline Migrant & 3 & 4 & 5 & 4 & 2 & 1 \\
\hline Returnee & 9 & 2 & 7 & 4 & 6 & 5 \\
\hline Non-migrant & 7 & 6 & 4 & 7 & 1 & 4 \\
\hline $\begin{array}{l}\text { Former or current } \\
\text { government rep }\end{array}$ & 1 & - & 1 & - & 1 & - \\
\hline $\begin{array}{l}\text { Total interviews per case } \\
\text { study }\end{array}$ & $\mathbf{2 0}$ & $\mathbf{1 2}$ & $\mathbf{1 7}$ & $\mathbf{1 5}$ & $\mathbf{1 0}$ & $\mathbf{1 0}$ \\
\hline Grand Total Interviews & $\mathbf{M e n}$ & $\mathbf{4 7}$ & Women & $\mathbf{3 7}$ & Total & $\mathbf{8 4}$ \\
\hline
\end{tabular}

To access potential interviewees, I reached out to contacts at the various universities, through people in the neighbourhoods where I lived, at the local church, at various markets and shops, at events and through taxi drivers. Concurrently, I used a snowballing technique to expand the pool of potential interviewees. The interviews in Guyana and Suriname were conducted in English, and in French in French Guiana. I carried out the majority of the interviews without any assistance, with the exception of five interviews in Suriname for which I received the assistance of two interpreters. Moreover, I carried out several informal conversations with academic experts on the historical developments of these countries, including on migration issues and policies. Numerous informal conversations were also carried out with people on various occasions during fieldwork to test my understanding by gaining reactions and alternative perspectives.

In addition to the four broad interview categories, it was essential to take into account the demographic and socio-economic characteristics of the interviewees. It was never an objective to reach a representative sample of all possible variations within the population or to capture all possible migration trajectories. Nevertheless, ethnic group, age, gender as well as pre-departure criteria of residence, class and education level were considered in the decision to 
select interviewees so as to capture some of the possible differences. Various migration destinations and migration in different historical periods were also considered in order to gain insights into migration destination decisions and shifting migration motives (Table A3 in appendix A).

As research progressed and new concepts emerged from archival research and initial interviews, I adopted 'theoretical sampling' (Strauss and Corbin 1998) to identify interviewees that could be familiar with specific events (e.g. specific policy change) or could provide clarity on new concepts that were emerging (e.g. importance of religion in migration decisions). This technique was ideal because a new idea could be retained only if additional evidence supported the preliminary concept, otherwise it would be discarded. So for example, after some exploration of the relevance of religion on emigration, failure to gather any concrete evidence led to the discarding of this idea. A process of 'constant comparison' (Suddaby 2006) was also adopted to compare emerging ideas from various data sources and across cases. This proved crucial to better understand how the state, the processes of independence and the establishment of border regimes or, alternatively, the process of incorporation and continuous open borders, compared across the three cases.

The collected data was ultimately analysed using thematic analysis. The material was subdivided according to important migration periods in each country's history, resulting in different sequential breakdowns across the three Guianas. Thereafter, the thematic coding identified and organised migration motives as they emerged from the material. Categories of main migration drivers were recognised within each period and these time-dependent drivers were substantiated with data that had emerged from the various research activities. While some scholars may find it problematic to make generalisations from a few in-depth case studies, good case studies are essential to identify models and processes which can be used as the basis for generalisations (Flyvbjerg 2006). In fact, the process of triangulation of theories, data and methods followed in this study has generated sufficiently sound findings to allow some general statements about the different ways in which independence, border regimes and post-colonial ties affect migration as well as the wider roles of the state in origin countries in shaping emigration.

\section{Limitations of methodology}

The first limitation was the partial availability and poor quality of migration flow data, which greatly constrained the descriptive statistical analyses which were initially planned. This constraint made it impossible to examine short-term migration variations across the transition to independence and establishment of 
border regimes. As a result, we resorted to using emigrant stocks to examine the long-term evolution of emigration intensities.

Second, while interviews proved to be extremely valuable, a number of drawbacks occurred. Throughout the process of selecting interviewees I attempted to find some balance between the different classes, ethnic groups, age and urban/rural residence. However, this presented difficulties in terms of identifying these individuals and also in determining class and education of individuals at various stages of their lives (before, during or after migration). I decided that given the interest in migration motives the focus would be on the interviewees' socioeconomic status before emigration, which I could roughly assess by the interviewee's profession or the parents' profession and the schools attended while in the Guianas. Moreover, although I was able to identify a diverse group of interviewees in terms of demographic and socio-economic characteristics (see Table A3), some of the categories have small numbers making it impossible to generalise from the information collected. In addition, securing interviews with government representatives proved to be very difficult and time-consuming.

Collecting historical information from interviewees also presented some challenges. While some individuals found it easy to recall important events, relate them to their lives and their past decisions, for the majority of individuals it was necessary to start from a gradual reconstruction of their personal experiences. Thereafter, I would follow up with questions on important events occurring at specific times in their lives which emerged in their personal descriptions, inquiring into whether their personal experiences may have been influenced by macro-level developments. This proved to be successful at times, as it sparked genuine reactions that helped individuals recall and locate past events in their lives. In a few cases, it was also possible to identify how individuals were providing ex-post justifications of their past behaviour, reconstructing their life according to what they felt were acceptable social models. However, in most cases individuals seemed to be genuinely reporting and reflecting on their past experiences.

A note is due also on linguistic and cultural limitations, as well as on the advantages of these limitations. It was advantageous not to be associated with any of the former colonial states or with metropolitan France as interviewees felt free to speak, even negatively, about their feelings on colonialism, their migration and personal experiences of discrimination while in the former colonial state. In Suriname in particular there was a greater opening once people discovered that I was not Dutch. Being a 'foreign' national often aroused curiosity about my interest in their country, which consequently led to interviews where learning was shared. In these interviews, interviewees showed a greater level of comfort, which led to greater insights. 
My cultural and linguistic distance, however, also presented important disadvantages: in Guyana, I was constrained in the interviews with individuals who spoke only 'creolese' and I relied on transcribers to decipher some of their answers; having only a superficial knowledge of Dutch proved challenging in Suriname, most of all in the archives and with people with lower education levels who were not fluent in English. In French Guiana, my unfamiliarity with French accents and French creoles was a barrier first to identifying the appropriate interviewees and then to conducting interviews, leading to a lower number of interviews in this country. Nevertheless, by relying on a varied system of support, consisting of local contacts, interpreters and national experts, I found workable solutions to these challenges.

Eventually, while a research plan was largely adhered to, some improvisation was undertaken to address changing circumstances, obstacles, as well as promising new avenues of research. As a result, research in each of the Guianas has strengths and weaknesses: Guyana has good and balanced coverage of archival material, newspaper articles, interviews and literature; Suriname's review of newspaper and archival articles was limited due to time constraints (e.g. Christmas holidays closure) and language difficulties, but this was compensated by a good number and variety of interviews; French Guiana suffered from a smaller number of interviews and the challenge of addressing emigration in a country where emigration is not seen as the issue of interest, but it benefited from a good sample of archival material to provide evidence of political and socioeconomic issues important in French Guiana. While these discrepancies may be seen as a weakness, this eclectic approach was born out of necessity to adjust to three very different realities, unequal access to institutions and data, and the researcher's own linguistic limitations.

A more fundamental challenge was posed by my intention to allow knowledge to emerge from the interviewees in interaction with my expanding knowledge as a researcher. This led to two potential sources of bias: first, the interviewees included their own justifications, reflections on the past and, as just mentioned, ex-post reconstructions and 'embellishments' according to social norms of what is acceptable (e.g. irregularity was not always readily discussed). These may have been in reaction to me as a researcher, as a woman of a specific nationality, and/or due to conventional challenges in researcher-participant relations. Interview techniques were adopted to ensure coherence of personal stories and consistency with time-specific historical events and living conditions. Second, as a researcher with specific research interests, I brought to this research my own subjectivity, which guided all aspects of research from the identification of interviewees to the selection of policy areas on which to focus. I attempted to reduce such bias by challenging theoretical notions through an inductive approach 
and constantly testing new ideas. Ultimately, however, I am responsible for identifying specific political and socio-economic developments as important drivers of past and current emigration.

Despite these challenges and limitations, the adopted methodology has allowed me to identify important moments of migration change, associate them with contextual developments and explore whether these associations were meaningful in the lives of people who lived through these periods.

\section{Contribution of study and overview of dissertation}

This study expands current migration research in five ways. First, it contributes conceptual insights and empirical evidence on the unanticipated effects of border regimes on migration volumes, timing, composition and destination as well as the dynamics that affect migration in the absence of border regimes. Second, it provides a conceptual framework to understand the impact of independence and non-sovereignty, and a systematic approach to examine the potential migration substitution effects of political status changes, the establishment of border regimes by former colonial states and immigration policies by main destination countries. Third, this study advances an improved and expanded conceptualisation of postcolonial ties which moves beyond the conventional bilateral relations between former colonies and their respective former colonial states; it proposes that colonial and post-colonial experiences shape specific worldviews which influence choices of migration destination. Fourth, it provides explicit evidence of how political, ideological, economic, technological and social factors affect emigration in origin countries. These factors highlight how states in origin countries influence emigration through non-migration policies. Fifth, it contributes to deepening knowledge of Caribbean migrations, particularly by putting the three Guianas on the mental map of migration researchers. Lastly, from a methodological perspective, this study showed that there is great value in using in-depth case studies in a historical comparative perspective to explore themes that have been so far weakly conceptualised in migration research.

The dissertation is structured in the following way: Chapter 2 presents a conceptual framework to examine the role of the state in migration, particularly the state in origin countries, and to analyse the effects of political status change, border regimes establishment and post-colonial ties on emigration patterns. Chapter 3 analyses the role of border regimes and post-colonial ties on overall, extra-regional and intra-regional Caribbean emigration in the period between 1960 and 2010. Chapters 4 and 5 examine the evolution of Guyanese and Surinamese emigration, 
respectively, from the 1950s until the 2010s and analyse how the establishment of border regimes and independence shaped the timing, volume, composition and direction of emigration. Chapter 6 examines the effects of the incorporation of French Guiana into the French State on Guianese emigration patterns from the late 1940s to the 2010s. In chapter 7, I present a comparative analysis of the Caribbean region and the case studies and summarise the main findings on the role of border regimes, political status, post-colonial ties and the wider role of the state in origin countries. I conclude by making suggestions for further research. 



\section{Chapter 2 - The role of the state in international migration: Exploring the transition from colony to independence ${ }^{14}$}

\section{Introduction}

Empirical research suggests that countries that became independent during the $20^{\text {th }}$ century share some similarities in migration patterns, particularly a migration propensity toward the former colonial state (Fassmann and Munz 1992; Massey, Arango et al. 1998; Hooghe, Trappers et al. 2008). The notion of post-colonial ties has been frequently used in quantitative analyses to account for factors that attract migrants to the former colonial state. However, this notion has been weakly conceptualised and we are currently unable to identify the relevance of individual factors, such as language, culture, educational systems or possibly less restrictive migration policies, and to recognise the circumstances under which post-colonial ties may, or may not, influence international migration. In fact, important variations in migration dynamics exist across former colonies: while some countries display high levels of emigration and a concentration in the former colonial state, others show lower volumes of emigration and an important diversification of destinations. These variations prompt us to question how and why changes in political status, shifts in border regimes and post-colonial ties affect migration.

Considerations of the role of the state in migration can be clustered in two main arguments: some scholars argue that the state has largely lost its ability to control migration (Bhagwati 2003; Castles 2004); others suggest that while globalisation and the protection of human rights constrain states' ability to impose highly restrictive policies, migration control remains critically important for states, which will continue to 'attempt to regulate, control, and channel migrants'

\footnotetext{
14 This chapter is based on the author's working paper, 'The Role of the State in International Migration: Exploring the Transition from Colony to Independence.' In IMI Working Paper Series 102/DEMIG Project Papers 26: International Migration Institute, University of Oxford, 2014.
} 
(Strikwerda 1999:394). Both sides of this debate largely confine the role of states to their immigration and emigration policies. A few scholars have argued that the role of the state goes beyond migration policies (Massey 1999; de Haas 2010). For instance, the welfare system has been the focus of research to examine whether it acts as potential 'magnet' attracting migrants to destination countries (Borjas 1999; De Giorgi and Pellizzari 2009); concurrently, the welfare system in origin countries may also act as a 'magnet', retaining potential emigrants at home (Kureková 2011; Mahendra 2014). Such research demonstrates that states in both origin and destination countries affect migration through a broad range of policies - e.g. minimum wage and working hour regulations, education policies, social protection policies or transportation policies. A wider policy approach offers a useful perspective to study the state's far-reaching effects on migration. Such an approach can also help us to examine the decolonisation process, a time when numerous policy reforms are introduced in newly independent countries.

Processes of decolonisation account for the transition from a colonial to a post-colonial political status, which includes independence or the transition to a non-sovereign status with continued dependence on the metropolitan state but a greater degree of autonomy. ${ }^{15}$ The transition to independence entails the establishment of physical borders and a border regime to regulate migration into the former colonial state. Although this suggests greater barriers to migration, long-term emigration patterns from independent countries paradoxically display higher emigration than non-sovereign countries (McElroy and Sanborn 2005), which raises questions about the role of borders and border regulations in preventing or, alternatively, encouraging emigration. Certainly, independence and border regimes may affect migration in interaction with other migration-relevant factors that occur in the transition to independence, such as peaceful or conflictual conditions, intense policy reforms, identity formation and geopolitical positioning in relation to the former colonial state and alternative international partners. These processes are fraught with uncertainty and long-term processes of adjustment, which are highly likely to influence migration decisions.

This chapter proposes a conceptual framework to expand our understanding of the role of the state in shaping migration patterns through migration policies, thus border regimes, as well as other policies. After a brief review of how the state has been theorized in migration studies, I propose a categorisation of state policies to illustrate how both migration and non-migration

15 It could be argued that colonies that have become incorporated or received autonomy have not experienced decolonisation because they retain some characteristics typical of colonies. However, nonsovereign countries have various forms of self-government and often receive economic contributions by the former colonial state (Aldrich and Connell 1998: 3), making them distinct from former colonies. 
policies may lead to potential direct and indirect migration effects. The chapter then conceptualises the transition to independence or non-sovereign status and its potential effects on migration. It then presents hypothetical scenarios that systematically analyse how independence, border regimes and post-colonial ties may affect migration volumes, composition, timing and direction. These scenarios provide innovative insights on the role of the state in origin countries at times of high levels of structural political and policy transformations.

\section{An expanded view of the state's role in migration}

\subsection{The state in migration theories}

Since Ravenstein (1885) laid down his laws of migration in 1885, a number of migration theories have evolved to explain causal mechanisms in migration processes and identify potential migration determinants (cf. Massey, Arango et al. 1993). Most migration theories have, however, provided little explicit elaboration on the role of the state in migration processes, focusing much more on economic drivers both at the individual level and as part of broad macro-economic processes of globalisation. Moreover, when the role of the state is considered, migration scholars tend to reduce it to migration policies (Massey 1999; Strikwerda 1999), and ultimately to immigration policies.

The equating of the state to immigration policies may be related to fluctuating public concerns and political interests to find policy solutions to control immigration volumes. As a result, much migration research focuses on the analysis of immigration policies and their effectiveness in managing migration volumes, rather than analysing how states broadly affect migration, in terms of its timing, destinations and composition of flows. Given such focus on immigration policies, origin countries have lost relevance and these states are generally perceived as unable to prevent emigration without infringing upon basic human rights (Zolberg 2007), particularly after the collapse of the former Soviet Union and its highly restrictive emigration regimes (Dowty 1987; Matthews 1993; de Haas and Vezzoli 2011).

When we take a closer look, however, we notice that some migration theories conceive the state more broadly than its immigration policies alone. Neoclassical economics theory identifies the state's relevance in migration in two specific areas: labour policies and migration policies (Massey, Arango et al. 1993). In this theory, governments in origin and destination countries may alter migration by regulating labour markets, making employment of non-native workers more difficult, increasing wages in countries of origin so as to lower the benefits of 
emigration or by increasing the costs of migration, e.g. introducing greater barriers to entry (Lee 1966; Harris and Todaro 1970; Todaro and Maruszko 1987; Massey, Arango et al. 1993).

In the new economics of labour migration (NELM) theory, the state plays an important role through insurance markets. In this theoretical framework, states may significantly shape migration by promoting reliable insurance markets and capital markets, which give people greater security and allow them to pursue investments in the origin community. Moreover, national governments may introduce policies to alter income distribution, e.g. reducing inequality, and influence feelings of relative deprivation (Stark and Bloom 1985; Massey, Arango et al. 1993). Rather than reducing migration, however, shifts in income distribution and inequality levels may in fact change the composition of migration (Stark and Yitzhaki 1988).

World systems theory frames states as entangled in the global economy via multinational corporations for which they may intervene politically or militarily to protect peripheral markets and raw resources. In this perspective, international migration has little to do with wage rates or employment differentials between countries, but with the global economic structure, trade, investment, flows of goods and capital, and much of the power has been removed from the state and is now held by multinational corporations. However, states may attempt to influence migration by creating immigration policies that aim to contain some of the unintended migration flows created by these macro-level processes, including rural-urban migration and refugees. While these policies may not be effective, they allow states to retain symbolic control in an attempt to retain legitimacy (Massey 1999).

Nevertheless, the importance given to the state in migration remains limited. Yet, the role of the state is central to development. Its ability to create institutions and infrastructure and to provide opportunities for individuals (Skeldon 1997), mainly through a broad range of policies, suggests that the state influences migration in multiple ways. There is thus a need to relate emerging empirical evidence on specific state-driven migration determinants, such as the impact of practices to obtain passports (McKenzie 2005) or of land reform policies (Fitzgerald 2006), to new reflections on the role of the state in migration and to acknowledge that a wide range of commonly used migration determinants (e.g. economic structure, inequality, social welfare) are significantly affected by the state. 


\subsection{The state and its border regime}

The state's role in migration is most commonly associated with its power to control its borders and enforce border regimes. There is a distinction between a physical border and a border regime. A physical border is the spatial division between national territories, which often is also the location where some of the migration policies are implemented. A border regime is a set of policies that regulate the settlement of people by restricting residence, work and rights related to settlement through migration policies, including new citizenship laws, which officially remove the freedom of settlement previously granted to 'colonial subjects'. The establishment of a physical border does not necessarily imply the establishment of a border regime, just as the introduction of a border regime can occur without the official introduction of a border (Langer 1999). Moreover, the establishment of a physical border and a border regime may occur at different times, with the border regime preceding the physical border or vice versa.

Since 1945 almost 100 states have gained independence and established a border regime (Christopher 2002). Border regimes can also be dismantled, as through the Schengen agreement in the European Union. While some research has examined the effects of the dismantling of a border regime (Wallace 2002; Kureková 2011), research on the effects of the establishment of a border regime is limited, with the important exception of literature referring to the establishment of the British border regime in 1962 and its effects on Caribbean migration to Britain (Peach 1968; Marshall 1987). The introduction of border regimes offers a distinctive opportunity to examine whether and how this event produces migration substitution effects on the volume, timing, spatial orientation or composition of migration flows, as hypothesised by de Haas (2011). The introduction of a border regime restricting previously unrestricted migration may trigger one or more of the following unintended and unexpected effects: (1) spatial substitution by diverting migration to alternative destinations; (2) categorical substitution by shifting migration to alternative regular or irregular migration channels; (3) intertemporal substitution by anticipating migration before the tightening of migration policies, also referred to as 'now or never' or 'beat the ban' migration; and (4) reverse flow substitution by restricting decisions to return (de Haas 2011). The introduction of border regimes provides an opportunity to systematically examine whether border regimes generate migration substitution effects that shape the timing, volumes and destination of migration as well as the characteristics of migrants during periods of political status transition. 


\subsection{The state beyond migration policies}

If states and their policies matter, what are the policies that matter and how do they matter? Are the policies identified in migration theories to date the limit of state relevance in migration? To explore these questions, I propose a classification of state policies that applies to states in origin and destination countries and captures state policies, whether they are considered to be migration or nonmigration policies. Such a distinction is not new in migration literature. Skeldon (2007) discussed direct policies, i.e. migration policies, and indirect policies, i.e. all other policies often with development objectives that could have indirect migration effects. He also identified that the latter policies 'may ultimately be more effective instruments for managing migration' (Skeldon 2007: 19). Nevertheless, much debate and research that attempt to understand the links between migration and the role of the state ultimately continue to reduce the state to migration policies, particularly immigration policies. Therefore, this section and the proposed classification have two main purposes: (i) to define and clarify ambiguities that surround migration policies' objectives and specific measures; and (ii) to put nonmigration policies back into the debate as crucial migration drivers.

Immigration policies have been defined as 'rules (i.e., laws, regulations and measures) that national states define and implement with the (often only implicitly stated) objective of affecting the volume, origin, direction, and internal composition of immigration flows' (Czaika and de Haas 2013: 489). Similarly, emigration policies are implemented by states in origin countries to affect emigration flows (de Haas and Vezzoli 2011). In this study, migration policies refer generally to both immigration and emigration policies.

Non-migration policies are regulations that states define and enact to affect a wide range of societal aspects that do not strictly relate to migration, migrants or potential migrants. Yet many of these policies may, intentionally or unintentionally, alter the socio-economic conditions in the country and indirectly stimulate or discourage migration, either of citizens (leaving or returning) or foreign citizens (entering or returning). Among these policies are those that regulate a broad range of areas such as education, welfare protection, labour conditions or military and defence.

In the definition of migration policies provided above, these are set apart from other policies by their migration objectives. In practice, however, the separation is less clear (Czaika and de Haas 2013). States may attempt to influence migration using measures that are not associated with migration - e.g. in social 
welfare or education - while in other instances they may use policy tools ${ }^{16}$ generally associated with migration - e.g. travel visas, work or residence permits to promote non-migration objectives such as attracting investment or stimulating innovation. Figure 2.1 proposes a classification of four groups of policies according to their policy type, policy objective and policy tool.

This classification knowingly reduces the role of states in migration to policies, although in reality, the socio-legal environment in which policies are introduced (i.e. legal culture, institutional culture, bureaucracy, policing practices) may be imperceptible but real ways in which states also influence migration. Perhaps even more intangible, but of no trivial importance, is the role of the state in promoting national identity and policies of inclusion/exclusion, which may be of particular importance at a time of nation-building (Douki 2007) and when countries separate from a larger entity, as in the case of independence (Janssen 2011). Although we must be aware of the subtle effects of state action on migration beyond policies, we can still try to advance new perspectives on how the state may affect migration through migration and non-migration policies.

On the far left of Figure 2.1, policies in group 1 share a stated objective to influence migration patterns and use tools commonly recognised as migration policy measures such as the point system, labour recruitment and family reunification in destination countries and exit visas and rights protection in origin countries. Group 2 consists of policies that are regularly considered migration policies because they use a migration tool, although they challenge the migration policy definition by not having an outright migration objective. For example, business and entrepreneurial visa categories are meant to stimulate investment, employment and innovation much more than promoting migration per se (Sumption 2012; Sumption and Hooper 2014). Although the characteristics of the migrants (e.g. education, skills) may be important, it is their economic contribution and ability to stimulate entrepreneurship and create jobs that is significant. By 2012, the severe conditions following the 2008 economic crisis led Portugal and Ireland to provide residence permits to foreigners who would buy a home costing between 400,000 and 500,000 euros, while Hungary offered residence permits to non-European nationals who would purchase a special issue bond worth at least 250,000 euros. ${ }^{17}$ The issuance of residence permits is a 'reward' for those individuals who, regardless of nationality, are willing to boost the financial and housing market.

\footnotetext{
${ }^{16}$ A policy tool represents the measure identified by the policy to regulate migration; de Haas, Natter and Vezzoli (2014) identify 28 policy tools.

${ }^{17}$ http: //www.telegraph.co.uk/news/worldnews/europe/spain/9689008/Foreigners-offered-chance-tostay-in-Spain-for-130000.html\#
} 
Figure 2.1. The state and its migration and non-migration policies

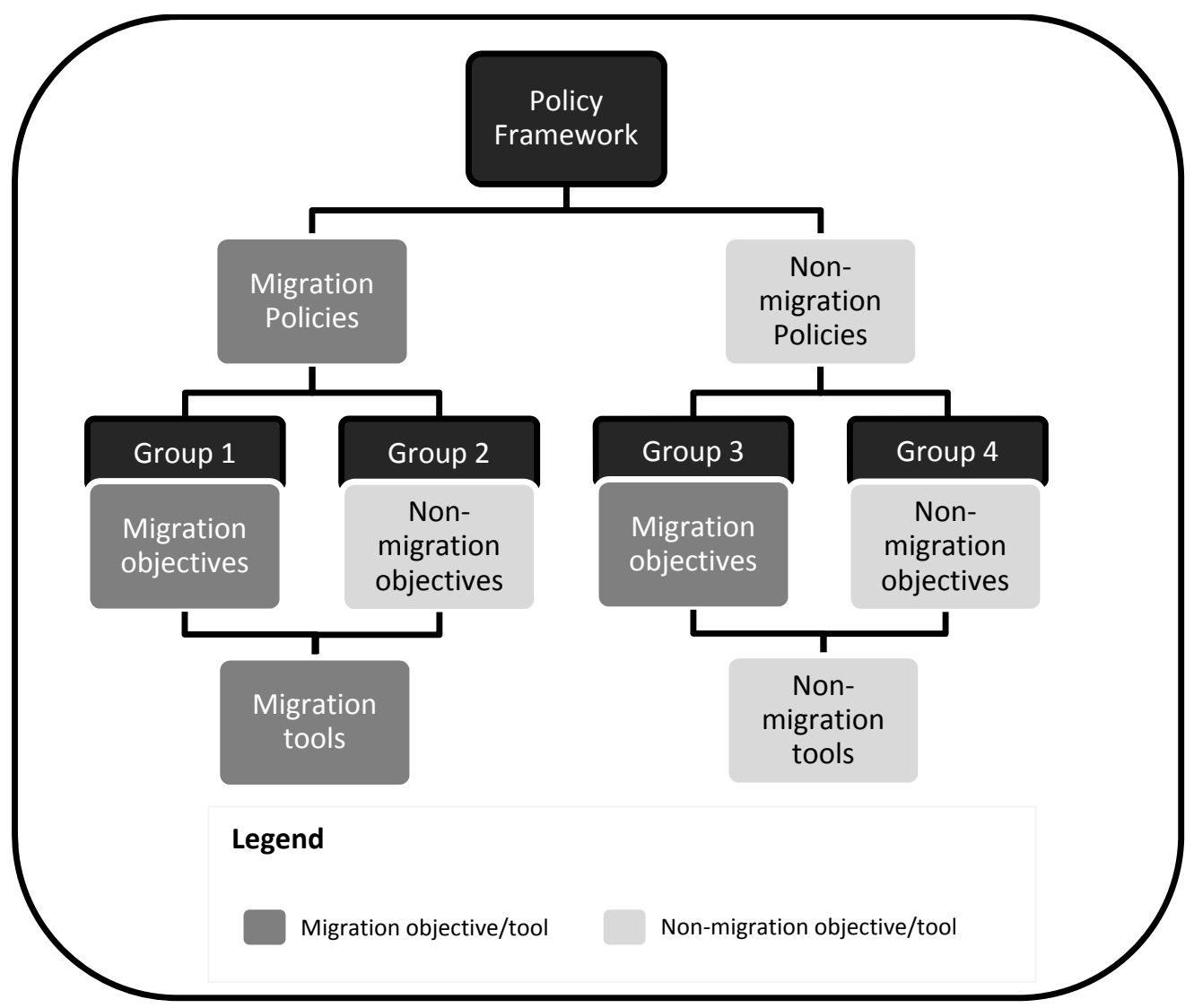

Alternatively, states may also try to affect migration by using policy tools that are not conventionally associated with migration (Group 3, Figure 2.1). Educational reform may be introduced to reduce emigration, prepare citizens for emigration or to attract international students and subsequently high-skilled workers. In the 1970s, the government of Trinidad and Tobago, concerned by the brain drain of qualified workers and students attending university in Europe and North America, introduced reforms and scholarships to increase opportunities in secondary and tertiary education within the Caribbean and promoted national employment opportunities (Central Statistical Office 1970). Notwithstanding their migration objective, such policies are not generally regarded as migration policies because they rely on non-migration tools; thus, they are not included in analyses of migration policies' effects.

Group 4 includes policies that are not considered relevant for migration and contains the vast majority of state-promoted policies that do not have any 
intended association with migration. These policies (e.g. labour market structure, land reforms, social security, transport, promotion of technological development, communications) may trigger changes in living conditions, alter the set of opportunities and challenges faced by specific groups of individuals and affect emigration and immigration without intending to do so. For example, the reduction of government subsidies for elderly care may increase immigration of migrant workers, able to provide equal services at lower costs. Recognising the migration-relevance of this group of policies is particularly important for origin countries, where the state faces legal constraints to affect migration beyond the few emigration policies that we recognise, i.e. those that promote emigration (Douki 2007; Asis 2008) and protect migrant workers in countries where they are subjected to abuse (Hugo and Stahl 2004).

Table 2.1. Examples of migration and non-migration policies

\begin{tabular}{|c|c|c|c|c|}
\hline $\begin{array}{c}\text { Policy group } \\
\qquad \\
\text { Direction of } \\
\text { flow affected } \\
\downarrow\end{array}$ & $\begin{array}{c}\text { Group 1 } \\
\text { Migration } \\
\text { policy, } \\
\text { migration } \\
\text { objective \& } \\
\text { migration tool }\end{array}$ & $\begin{array}{c}\text { Group } 2 \\
\text { Migration } \\
\text { policy, non- } \\
\text { migration } \\
\text { objective, } \\
\text { migration tool }\end{array}$ & $\begin{array}{c}\text { Group } 3 \\
\text { Non-migration } \\
\text { policy (NM), } \\
\text { migration } \\
\text { objective, NM } \\
\text { tool }\end{array}$ & $\begin{array}{c}\text { Group } 4 \\
\text { Non-migration } \\
\text { policy, non- } \\
\text { migration, NM } \\
\text { objective \& NM } \\
\text { tool }\end{array}$ \\
\hline Immigration & $\begin{array}{l}\text { Work permits } \\
\text { for workers; } \\
\text { residence } \\
\text { permits; } \\
\text { regularisation }\end{array}$ & $\begin{array}{l}\text { Permits for } \\
\text { entrepreneurs; } \\
\text { 'Citizenship-by- } \\
\text { investment'18 }\end{array}$ & $\begin{array}{l}\text { Reduction of } \\
\text { welfare benefits } \\
\text { to immigrant } \\
\text { population }\end{array}$ & $\begin{array}{l}\text { Austerity } \\
\text { measures that cut } \\
\text { social care } \\
\text { subsidies; policy } \\
\text { that stimulates } \\
\text { construction of } \\
\text { social housing }\end{array}$ \\
\hline Emigration & $\begin{array}{l}\text { Pre-selection } \\
\text { of workers for } \\
\text { recruitment } \\
\text { abroad; exit } \\
\text { permits }\end{array}$ & $\begin{array}{l}\text { Migration \& } \\
\text { development } \\
\text { policies } \\
\text { (migration } \\
\text { objective may } \\
\text { also be present) }\end{array}$ & $\begin{array}{l}\text { Benefits for } \\
\text { doctors who stay, } \\
\text { increasing } \\
\text { educational } \\
\text { opportunities to } \\
\text { reduce } \\
\text { emigration for } \\
\text { study purposes }\end{array}$ & $\begin{array}{l}\text { Privatisation of } \\
\text { government } \\
\text { services; land } \\
\text { reform; changes } \\
\text { in political status } \\
\text { (e.g. } \\
\text { independence) }\end{array}$ \\
\hline
\end{tabular}

Most current migration research is largely concentrated on policies included in groups 1 and 2, and within these groups the attention is given primarily to immigration policies (Table 2.1). This categorisation also brings to light that although we usually consider policies in Group 2 as migration policies, they do not fully fit our conventional definition of migration policies given the mixed character of their policy objectives. Conversely, policies in Group 3 fit our

\footnotetext{
18 See Sumption and Hooper 2014.
} 
conventional definition of migration policies, but because they are implemented in non-migration policy areas (e.g. education) and utilise non-migration policy tools (e.g. scholarships) they are often difficult to identify and escape most wellintended migration policy analyses. This categorisation does not do enough justice to the wide array of policies in Group 4 which may be relevant for migration but are often ignored, and is meant to encourage us to explore how such nonmigration policies may shape migration. In this study, this framework is used to understand the multifaceted role of the state in migration and to guide the analyses of state-driven migration effects during the process of political status change, the establishment of border regimes and the introduction of numerous policies in the post-independence period.

\section{Changes in political status and migration}

\subsection{Colonialism, independence, non-sovereignty and migration}

Historical-structural migration theories view colonialism as one of the mechanisms that brought peripheral areas and populations into the global economy and promoted migration among certain colonies, as well as between the colonies and European countries (Massey, Arango et al. 1993). In the Caribbean region, societies are the product of large-scale state-endorsed labour movements across continents, which were undertaken to fill labour shortages in the plantation system, first through slavery and later through indentured labour (Segal 1998). Unlike African rural-urban migrations described by Mabogunje (1970), in the Caribbean even rural populations were closely connected to European economies through the plantation system and acculturation was emphasised through education and the creation of a national elite and classes of administrators. Colonial incorporation was so successful that Zelinsky (1971) argued that colonial migrations were nothing other than an extension of domestic migrations, made possible by solid institutional and ideological connections which, in turn, reduced physical barriers (e.g. oceans) between colonies and the colonial state.

Zelinsky (1971) did not provide any elaboration of what may happen to these 'domestic migrations' at the moment of political separation, but world systems theory has argued that in spite of the end of colonialism and the acquisition of rights to sovereignty, newly independent states have continued to exist as dependent entities, generally inserted at the bottom of global political and economic hierarchies (Massey, Arango et al. 1998; Mcllwaine 2008). This would suggest a continuation of various forms of earlier 'domestic migrations'. In fact, many scholars argue that current migration patterns may be seen as continuations 
of historical processes that have expanded within and beyond this region. They suggest that asymmetrical power, accumulation and concentration of capital and labour market demands in developed countries combined with weak economic development and labour market surpluses in developing countries have led to continued dependency and also to significant emigration of high and low-skilled migrants since the 1950s (Thomas-Hope 1980; Levine 1987; Samers 1997; Segal 1998).

This continuation of 'domestic migration' is also expected for those former colonies that have been legally integrated into the former colonial state as nonsovereign countries. However, the migration impact of political integration is far from clear. First, a variety of non-sovereign statuses exist with different levels of autonomy over territorial matters, with full incorporation the furthest from independence. So while the French Overseas Departments (DOMs) are an integral part of France and Hawaii of the USA, the British Virgin Islands are a British Overseas Territory with some autonomy but under the authority of a Governor appointed by the Queen. The type of non-sovereign status is associated with rights of movement to the former colonial state granted to the inhabitants of these countries, which also varies.

Research on independent and non-sovereign countries is limited and touches on a few case studies such as the Federated States of Micronesia, which since 1986 enjoy the right to free migration to the US (Hezel and McGrath 1989; Grieco 2003), and migration effects of Puerto Rico's possible statehood or independence from the US (Santiago unknown). McElroy and Sanborn (2005) investigated migration in small sovereign and non-sovereign Caribbean islands and concluded that in general sovereign states experience higher emigration due to their lower economic growth, while non-sovereign countries are generally more prosperous and have become immigrant-receiving countries. However, this division is not as sharp as suggested, as Guadeloupe and Martinique, both French DOMs, and the Netherland Antilles and the US Virgin Islands, also show net emigration and the independent Bahamas show net immigration.

Grosfoguel (1996) also compared migration from non-sovereign and independent countries and concluded that, in absence of a border regime, nonsovereign countries experience higher emigration, particularly of rural and less educated migrants, as observed for Puerto Rico and Martinique. Audebert (2007) also used the case studies of Puerto Rico and the French Antilles and added Haiti to examine how non-sovereignty helps to maintain a political and legal framework that facilitates migration. Milia (1997) showed, however, how free mobility alone may not explain greater migrations from non-sovereign states as today's largescale emigration from the French DOMs finds its roots in the French government's 1960s decision to recruit emigrants through a national bureau, the BUMIDOM (cf. 
Constant 1987; Condon and Ogden 1991). These studies suggest the need for further research on the processes triggered by independence and non-sovereignty and their effects on migration. Therefore, I elaborate further on two areas: i) colonialism, the processes of decolonisation and how these periods were important for migration; and ii) the processes that led to changes in rights of movement and the establishment of border regimes.

\subsubsection{Colonisation styles and decolonisation processes}

Colonialism had a profound and long-lasting impact on vast areas of the world. Colonial powers had specific interests and strategies to administer their colonies and precise perspectives on the role of their overseas populations (Heffernan 1995; Lucassen 1995; Byron and Condon 2008). Only certain segments of the colonial population within a colony were brought into the European sphere, typically the elite and urban professionals, but specific economic interests may have led to the migration of migrant labourers and rural agricultural workers. In Africa, colonial administrators gradually brought rural areas into the national economy and ruralurban migration systems emerged (Mabogunje 1970). Samers (1997) described how the French state deliberately concentrated its recruitment of Algerian workers for the automobile industry in the Kabylie region, where households had traditionally relied on regional migration. As men became fully incorporated into the migration systems with France, migration from this region became central to the livelihood of the population beyond colonial times. In the Caribbean, however, societies had been formed by international migration, making migration a frequently used strategy for social mobility, even among rural populations, as early as the late 18th and early 19th centuries (Insanally, Clifford et al. 2006). Such different embodiments of colonialism would have led to very different perceptions of migration and different degrees of people's readiness to migrate.

Similarly, the process of decolonisation should not be seen as homogeneous across and within former empires. Two strongly inter-related aspects of decolonisation must be noted: decolonisation as a transition of the former colonial state from an imperial power to a state with much more limited scope, and the process of decolonisation and the meaning of independence in the former colony. Decolonisation occurred over several decades in various parts of the world and the strategy followed by former colonial states was influenced by the former empire's ideological position towards independence as well as its previous experiences in granting independence. Byron and Condon (2008) showed the different objectives of the French and British states, particularly in relation to whether and how to retain connections to the colonies and their populations after decolonisation. The decolonisation strategies also provide key insights into how migration evolved following independence or with non-sovereignty. The violent path to Indonesia's independence shaped the Netherlands' desire to promote a 
'model decolonisation' in Suriname's independence process (Buddingh' 2001). But Suriname's independence was also closely linked to immigration fears in the Netherlands in addition to growing ambivalence within the Dutch government and the Dutch population on how to deal with socio-economic tensions in their former colonies, i.e. 1960s riots in the Dutch Antilles. Within this context, the Surinamese government gained negotiating power concerning citizenship and migration rights (discussed in Chapter 5). Similarly, Britain's 1962 Commonwealth Immigration Act was part and parcel of Britain's decolonisation process, as it restricted the entry of Commonwealth citizens, who up till then had rights of abode in Britain and were a potentially vast source of permanent immigration, including the populations of the entire Indian subcontinent, several African countries and most of the Caribbean colonies. Thus, these processes of imperial transformation had great influence on decolonisation as well as on how migration was perceived and migration policies would be designed in this period and beyond. However, although these overarching decolonisation strategies undoubtedly shaped migration policies by former colonial states, colony-specific issues also played important roles in the process. For example, Guyana's independence was greatly influenced by the choice of its leading politicians to follow Marxist ideals, which plunged Guyana into the midst of Cold War politics (Chapter 4).

In former colonies, different views were held on decolonisation and independence. Although generally independence created expectations of high levels of change as newly independent governments could determine their own future, history shows that this was not always the case: in Suriname, the Dutch government continued to retain strong influence on domestic affairs (Janssen 2011). For the population, the meaning and expectations associated with independence would have depended on whether independence was obtained peacefully or through conflict. Moreover, in the former colonies the frame of reference for independence may have been very different from that held by the former colonial state. For example, while the Dutch government's frame of reference was Indonesia, for the Surinamese population the spectre of neighbouring Guyana's post-independence tensions had great influence on their perceptions of the high uncertainties introduced by independence (Chapter 5). ${ }^{19}$

Consequently, independence may have been perceived as a time of heightened uncertainty or of promise and change, stimulating more or less emigration, respectively. Moreover, even with a positive outlook, former colonies would have suddenly faced restricted access to resources and human capital as a

\footnotetext{
${ }^{19}$ I thank Edo Mahendra for directing my attention to the fact that the former colonies and the former colonisers may have acted according to different frames of reference.
} 
result of the separation from the former colonial state. Thus, independence may introduce uncertainties in terms of the institutions upon which individuals have come to rely (e.g. banking system, unemployment insurance, free education, health services), encouraging migration by individuals eager to reduce future risks. Beyond economic factors, individuals may have concerns about representation, legitimacy of expected future governments and security and protection of private interests. Expectations may also be influenced by developments in other newly independent countries, e.g. pre-independence Suriname's close watch on the developments in neighbouring independent Guyana. Ultimately, these socioeconomic and political transformations and the policies put in place at independence may make the population consider emigration as a risk-spreading solution.

\subsubsection{The establishment of border regimes}

Independence generally results in the establishment of a border regime. This generally includes a new citizenship, which removes the freedom of movement previously guaranteed to 'colonial subjects'. However, there are no standard rules on how these processes occur. In fact, it is often assumed that independence and the end of freedom of movement occur at the same time, yet, border regimes may be introduced before or after independence. The circumstances in which independence occurs as well as pre-existing migration anxieties in the former colonial state may determine the timing of border regime establishment. For instance, low migration between the colony and the colonial state may make border regimes a low-priority policy and lead the former colonial state to the slow implementation of restrictive immigration policies. Contrarily, anxieties about growing immigration may encourage the early establishment of a border regime, even before independence. Independence and the introduction of border regimes are expected to produce interacting effects; moreover, the sequence of these events is likely to generate additional effects. Neither of these occurrences has been given consideration in migration research.

It is also generally assumed that non-sovereignty results in the absence of a border regime between the non-sovereign country and the metropolitan state. However, freedom of movement may not necessarily be retained. When former colonies become fully incorporated into the former colonial state (e.g. French Overseas Departments and Hawaii), citizens are granted full citizenship and migration is totally unregulated, making it essentially internal migration..$^{20}$ The Dutch dependencies have a middle-path status between independence and

\footnotetext{
${ }^{20}$ The lack of a border regime does not mean that the state is not involved in regulating migration. In fact, the state may engage in labour recruitment programmes, as we have seen with France's BUMIDOM, and may significantly alter emigration patterns.
} 
complete integration as they are officially an 'equal' part of the Kingdom of the Netherlands, ${ }^{21}$ and their populations retain full Dutch citizenship, which grants freedom of movement to the Netherlands (Oostindie 2006). The British overseas territories, on the other hand, held a specific citizenship, i.e. British overseas citizenship, which did not grant them automatic right to live and work in Britain. It was only in 2002 that Britain restored the right of abode in Britain for its citizens residing in the non-sovereign countries (Clegg 2005). Hence, although benefitting from the political and economic stability often associated with non-sovereignty, inhabitants of these non-sovereign countries were barred from migrating to their metropolitan state. Thus, analyses that consider the effects of non-sovereignty on migration should take into account the openness or closure of border regimes with the metropolitan state.

\subsection{Post-colonial ties as a migration determinant}

Migration literature commonly utilises the notion of 'post-colonial ties' or 'postcolonial links' to refer to the post-independence connections between former colonial states and their former colonies, which allegedly lead to a greater propensity to migrate to former colonial states.22 Very little conceptualisation has occurred since the early 1990s, when Fassmann and Munz (1992) identified that migration was affected by 'cultural and political affinities rooted in history', including a common language and the fact that former colonies' 'economy, transportation systems, and culture are still oriented toward London, Paris, Amsterdam, and Lisbon' (Fassmann and Munz 1992). Current research refers to post-colonial ties as: enduring linguistic, ideological, intellectual and cultural ties; administrative and educational systems; military presence, direct transport links and communication; and the presence of migrant networks (Thielemann 2006; Hooghe, Trappers et al. 2008; Beine, Docquier et al. 2009; Constant and Tien 2009; Belot and Hatton 2010). While these connections are undeniable, no conceptual endeavour has evolved to explain how these factors affect migration and why we observe important variations in migration patterns between former colonies and former colonial states.

\footnotetext{
${ }^{21}$ Since the dissolution of the Netherlands Antilles in 2010, Bonaire, Saba, and St Eustatius are incorporated municipalities of the Netherlands.

${ }^{22}$ By using the hyphenated term 'post-colonial', I refer to the historical period after colonialism and the direct consequences of decolonisation and shifts in bilateral relations between the former colony and the former colonial state. In this study, I do not adopt the notion of 'postcolonialism', the unhyphenated term, which refers to the dominance of western culture and to the argument that the nations in Africa, Asia and Latin America are in a position of subordination and economic inequality in relation to Europe and North America (Young 2003). Postcolonialism is used in migration research to acknowledge that colonial legacies and hegemonic powers continue to dominate and influence migration even beyond direct post-colonial links, e.g. Latin American migrants in London (Mcllwaine 2008).
} 
The limited explanatory power of this catch-all notion can be observed in quantitative studies that operationalise postcolonial ties as a dummy variable to test whether countries with a colonial past show common migration patterns. While such studies find an overall positive effect of post-colonial ties, not surprisingly, when they look at the migration effects of specific former colonial states the findings are ambiguous. Hooghe, Trappers et al. (2008) analysed total migration flows to 21 European countries and showed a positive and long-term stable effect of the colonial past; however, their analysis of bilateral flows indicated that over time Spain, Portugal, Italy and France have become more attractive to former colonial migrants while the UK, the Netherlands and Belgium seem to have become less attractive. The authors suggest that such differences may be explained by language effects, favourable policies or exclusive transportation links, i.e. flights connecting the former colony only to the former colonial state. Constant and Tien (2009) also showed a positive effect of former colonial links, but their results partially differed from the previous study as Portugal exerts stronger attraction than Belgium, Germany and Italy, while historical links are not significant for individuals from former British, French and Spanish colonies.

Post-colonial ties have also been considered in relation to high-skilled migration from former colonies, based on the notion that these individuals possess 'educational proximity' and greater transferability of skills, which facilitate their migration to Western countries (Belot and Hatton 2010). Beine, Docquier et al. (2008) found that although post-colonial ties matter, they don't apply equally to all individuals. Finally, Neumayer (2006) suggested that post-colonial ties are significant in determining visa restrictions only if colonial links are combined with current membership in the Commonwealth. This suggests that post-colonial ties may weaken over time, but that they may also be renewed through new forms of membership.

Attention to the time dimension has been limited, but a weakening of postcolonial effects on migration should be expected. Head, Mayer et al. (2010) analysed the relation between colonial ties, independence and trade and suggested that independence of former colonies from former colonial states introduced not so much a sudden rupture, but a slow 'erosion' of a preferential position of the former colonial state. This is attributed to a weakening of the human capital and business networks over the 30 to 40 years since independence (Head, Mayer et al. 2010). While we could hypothesise that the same 'erosion' may occur for migration, we cannot ignore some important differences, principally that flows of migrants rely on family and community connections which may be renewed and deepened with each additional migrant, possibly making the preference for the former colonial state as a migration destination more resilient to time than trade. 
Time, however, may lead to changes in preferences. For instance, a former colony's decision to strengthen diplomatic and commercial relations with a state other than the former colonial state may impact migration opportunities, or an educational reform to adopt a more nationalistic curriculum (e.g. change of language, history or geography curricula) may diminish the cultural and language affinities and preferential status of the former colonial state. Overall, the various processes of transformation that took place in former colonies over time cannot be ignored if we truly want to understand the evolution of migration in post-colonial settings.

\subsection{The agency of migrants in a structured post-colonial environment}

The notion of post-colonial ties ignores the agency of individuals in former colonies, who are seen as pawns in an endlessly subjugated, powerless and dependent position. This seems to reflect more generally the way in which developing country states have been represented as 'relatively passive and ineffective' in relation to developed countries (Skeldon 1997: 26). Reacting to the forces of colonial history, these individuals are denied a sense of self-identity, individual preference, and the ability to introduce change in these structural conditions. This Eurocentric view denies the numerous forms of resistance to the destructive aspects of colonial history, the imposition of hegemonic values (Young 2003), and the negative migration experiences in the former colonial state, including the rejection of former colonial populations on the basis of racial differences despite equal citizenship (Fanon 1952). Thus, while there is an attraction to migrate to the former colonial state, forms of rejections may co-exist.

Newly independent states and their populations have also gradually developed a sense of national identity. In a study on identity, Médéa (2010) found that in Mauritius independence signalled the search for a new post-colonial identity that departed from the colonial period, while in Réunion, a French DOM, a neo-colonial identity emerged as the French state tried to superimpose French values and norms over a Réunionese identity. The new identity of Mauritius and the tensions between a French and a Réunionese identity are likely to influence the strength of post-colonial ties and their power to determine migration destination. Similar processes have certainly taken place in other post-colonial contexts.

Ultimately, individual agency influences the timing, direction, composition and rationale of migration. Some migrants may decide to migrate to the former colonial state because of its intrinsic values which they admire and associate with success (associative preference). However, other individuals may see the former colonial state as a stepping stone, a place of opportunity with facilitating features (e.g. language, transport) that could easily be exchanged for any other place with 
equal or similar opportunities (instrumental preference). These two types of preferences, and their underlying drivers, may explain why post-colonial ties operate strongly in some contexts and are ineffective in other instances.

\section{Conceptualising the migration effects of political status changes, border regimes and post- colonial ties}

The following four hypothetical scenarios help to unravel how independence and non-sovereignty may affect migration patterns in terms of timing, volume, direction and characteristics of migration. These scenarios aim to bring together the explanatory power of states, which determine the timing and conditions of political status and border regime changes, the various processes of decolonisation, the time dimension and also account for individual responses described in the previous sections.

Core to these scenarios is the understanding that the transition to independence creates a number of uncertainties, which may vary depending on factors including whether independence was achieved peacefully or through conflict, and whether the new state follows the development trajectories set by the former colonial state or carves out its own identity (e.g. education reform) and novel structures away from its historical roots. Independence may be experienced as a moment of great opportunities, particularly for groups of citizens close to the power structure, or as a moment of great anxiety generated by the transfer of power from a familiar colonial government to a newly independent government without a previous ruling history. The establishment of a border regime also contributes to feelings of uncertainty and anxiety, but its effects on migration may depend on its timing and the set of policies introduced. Overall, these changes would alter the set of opportunities and challenges faced by the population, with possible important consequences for migration.

The proposed scenarios also visualise how political status and border regime transformations may lead to specific migration substitution effects (de Haas 2011) and present four variations: (i) synchronous independence and border regime; (ii) border regime enacted before independence; (iii) independence occurring before border regime; (iv) non-sovereign status and open borders. When reading these hypothetical scenarios, note that the vertical scale is non-numerical and is meant to provide only a rough order of magnitude. Rather than measuring exact changes in migration volumes, the scenarios help us to understand shifts in 
migration patterns and identify possible migration diversification along intertemporal (e.g. the anticipation of migration), categorical (e.g. shift from work to family channels) and spatial (e.g. diversion to alternative destinations) distributions as a result of migrants' responses to structural and policy changes as well as their opportunities and aspirations.

\subsection{Synchronous independence and border regime establishment}

When border regimes and independence occur simultaneously, residents may react to high levels of future political and economic uncertainty and migrate preemptively. The anticipation of the establishment of a border regime may cause a spike in emigration, primarily to the former colonial state, right before and around the year of independence (see Figure 2.2). Ceri Peach (1968) observed that people from the British Caribbean, who had been migrating to Britain to take advantage of employment opportunities since the late 1940s, rushed to Britain a year before the introduction of the 1962 UK Immigration Act. Migration scholars have called this pattern 'beat the ban' migration (Peach 1968) or, more recently, 'now or never' migration and inter-temporal substitution effect (cf de Haas 2011). ${ }^{23}$ The striped area in Figure 2.2 represents emigration flows towards the former colonial state under free movement; the figure also shows that before independence, former colonies may have already experienced migration to alternative destinations (spatial substitution), notwithstanding the ease of migration to the former colonial state.

The composition of existing migration flows may also be altered. Uncertainties may vary along class, ethnic or political lines, leading to various propensities towards migration in the population rather than a collective preference for emigration. Allegedly, the population leaving pre-emptively may reflect more strongly the segments of the population that are most uncertain about the future (e.g. the political opposition) or who already had migration aspirations and want to ensure entry into the former colonial state (e.g. in search of job opportunities or family reunification). Migrants may, however, represent the wide spectrum of the population when tensions surrounding independence are heightened, as many families may send at least one individual to the former

\footnotetext{
${ }^{23}$ It could be argued that a strong inter-temporal substitution effect may be limited to small states, because of their greater ability to control and influence their small populations. Such ample intertemporal substitution effects may not materialise in countries with large populations, particularly if the state does not have full control over parts of the country, e.g. Democratic Republic of Congo or Nigeria. In this case, the announcement of independence or border regime establishment may have minimal inter-temporal substitution effects as large segments of the population may be unaware of the change or feel only indirectly affected. This, however, is an assumption that needs to be empirically tested.
} 
colonial state as a risk-spreading strategy. Thus, independence and border closure are likely to transform the composition of migration flows.

Figure 2.2 Possible effects of synchronous independence and the establishment of a border regime on international migration

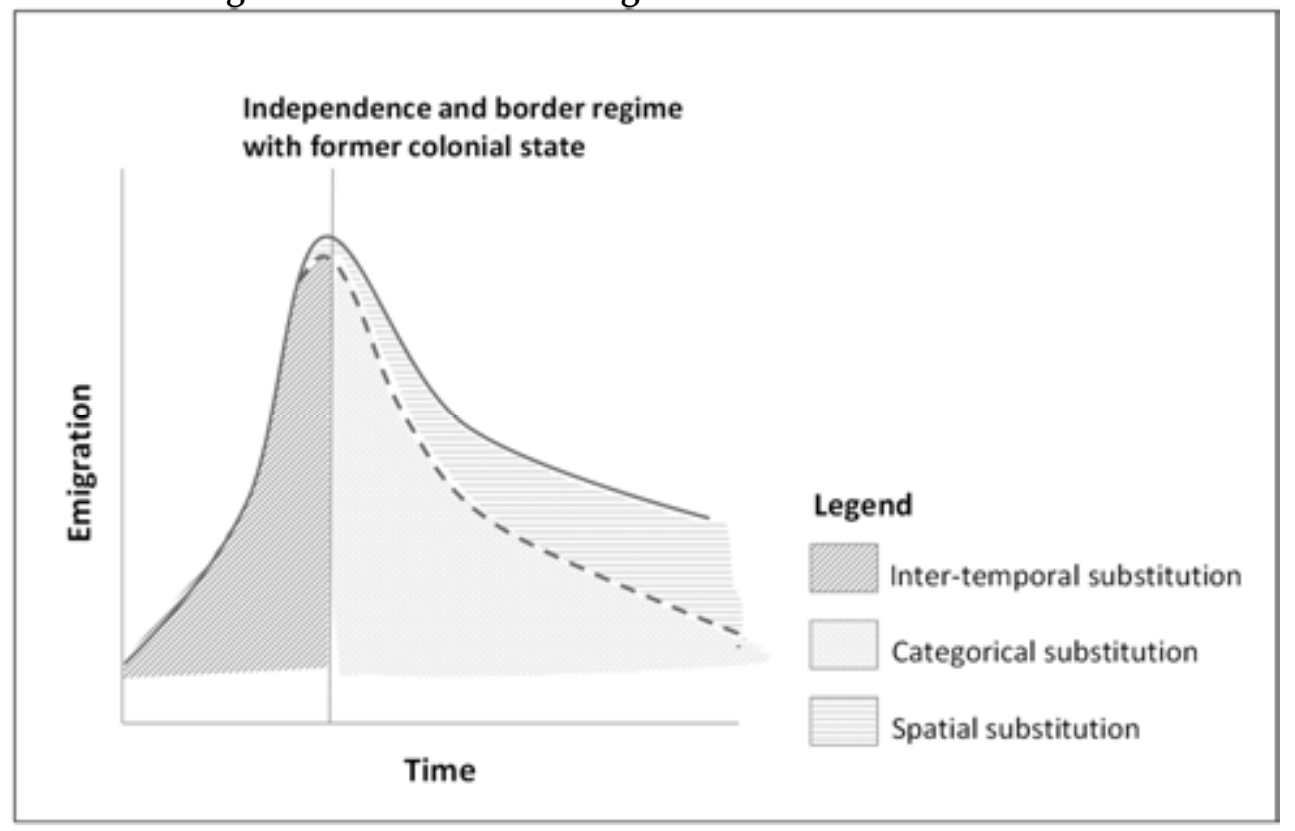

The border regimes introduced by the former colonial state and the migration policies implemented by other destination countries may further change the structure of migration and produce three additional unintended migration substitution effects: categorical, spatial and reverse migration (de Haas 2011). After independence and border closure, categorical substitution would occur because migrants, having acquired a new citizenship, would need to rely on diverse types of channels, legal or illegal, to emigrate. ${ }^{24}$ Aspiring migrants may explore family reunification, study, asylum and any other migration channels, causing categorical substitution. Immigration to Britain over the period 1965-1970 showed that 72-86 percent of Commonwealth citizens were entering as dependents using family reunification channels, ${ }^{25}$ although it was known that Caribbean spouses generally went to Britain to work. Categorical substitution, however, is not uniquely about the same individuals switching entry channels. Migration policy changes may inspire individuals who never intended to migrate to do so (e.g. elderly parents

24 However, former colonial states may purposely retain specific migration channels with former colonies as a way to satisfy potential labour demands, thus reducing the size of categorical substitution.

25 Immigration Bill: Memorandum by the Secretary of State for the Home Department, Cabinet, CP(70)126, 31 December 1970, The National Archives, Catalogue Reference: CAB/129/154. 
who become eligible for family reunification), while preventing other intending migrants (e.g. migrant workers), leading to a change in the composition of migration. Post-colonial ties may also explain categorical substitution as migrants may decide to rely on alternative migration channels, e.g. marriage of convenience, to reach the former colonial state.

Independence and border regimes may also lead to spatial substitution effects (de Haas 2011) when migration barriers to the former colonial state are too high, the attraction of post-colonial ties is not strong and when migrants have knowledge of alternative destinations and feasible access to them. Reorientation may be to neighbouring countries and other colonies that belong to the same colonial state or to alternative destinations further afield. After the enactment of the 1962 Commonwealth Act migration from the former British West Indies quickly shifted from Britain to North America, where migration policies were becoming more open to non-European migrants (Marshall 1987). Spatial substitution may occur more rapidly when alternative destinations were already a destination of choice before independence and the closure of the border.

Although not represented in Figure 2.2, a fourth migration substitution effect may occur: namely the reduction of return flows as a result of the stringent rules for (re-)entry in destination countries (de Haas 2011). From an origin country perspective, this effect would potentially reduce the volume of return and alter the composition of return flows. Empirical evidence shows that return is negatively affected when entry restrictions are high, as migrants prefer to stay put even when they may wish to return, because of the risk of being denied re-entry (Massey 2005; Flahaux 2014). In this and the following three scenarios, this risk may affect negatively the return of individuals who may see independence and the postindependence period as a time of opportunity.

Overall, after the independence peak, migration may taper off, particularly if socio-economic conditions are stable and feelings of uncertainty subside. Postcolonial ties may gradually lose their importance, while migration to new destinations may gain relative strength. Should post-independence conditions stabilise, emigration volumes would gradually decrease; in the case of persistent high levels of uncertainty or emerging conflict, growing migration would be expected. Regardless of the long-term post-independence conditions, however, these structural changes are expected to lead to a diversification of migration flows in terms of who migrates (e.g. class, rural/urban, ethnic group) and the migration channels pursued. 


\subsection{Asynchronous independence and border regime establishment}

Independence and the establishment of a border regime are not necessarily simultaneous events. In the British Caribbean, only Jamaica and Trinidad and Tobago obtained independence in 1962, within four months of the introduction of Britain's Immigration Act. The British citizens residing in the other former British Caribbean colonies, including the ten which gained independence between 1966 and 1983 and the five non-sovereign countries, were unable to migrate freely to Britain in the years leading to independence. By contrast, in the case of Suriname, the opposite timing took place: border control measures were introduced in stages with a final border closure in 1980, five years after political independence from the Netherlands. The asynchronous timing of these events is expected to affect migration patterns differently, as described next.

\subsubsection{Border regime establishment before independence}

When border regimes are put in place before independence, the levels of uncertainty may be less acute at each stage. Pre-emptive 'now or never' migration may occur before border closure (Figure 2.3); however, political continuity may reduce the perceived risks and large parts of the population may wait and see, particularly if independence is not expected in the immediate future. Thus, the first peak is smaller than in Figure 2.2. The nearing of independence may prompt another peak of migration as some groups of individuals may see emigration as a risk-reduction strategy (Figure 2.3), although the inter-temporal substitution effects caused by independence may not be as high as in Figure 2.2 because of greater migration policy constraints already in place. This second emigration peak may, however, be higher when the country is experiencing high levels of instability and: (i) the former colonial state maintains some non-restrictive immigration channels; (ii) individuals feel strong post-colonial connections (i.e. leading to categorical substitution); or (iii) alternative destinations offer favourable migration policies (i.e. spatial substitution). On the other hand, stability and positive future prospects in the newly independent country, but also the lack of migration opportunities (both in the former colonial state or alternative destinations) and weak postcolonial ties, may produce a less pronounced emigration peak at independence. 
Figure 2.3. Possible effects of the establishment of a border regime followed by independence on international migration

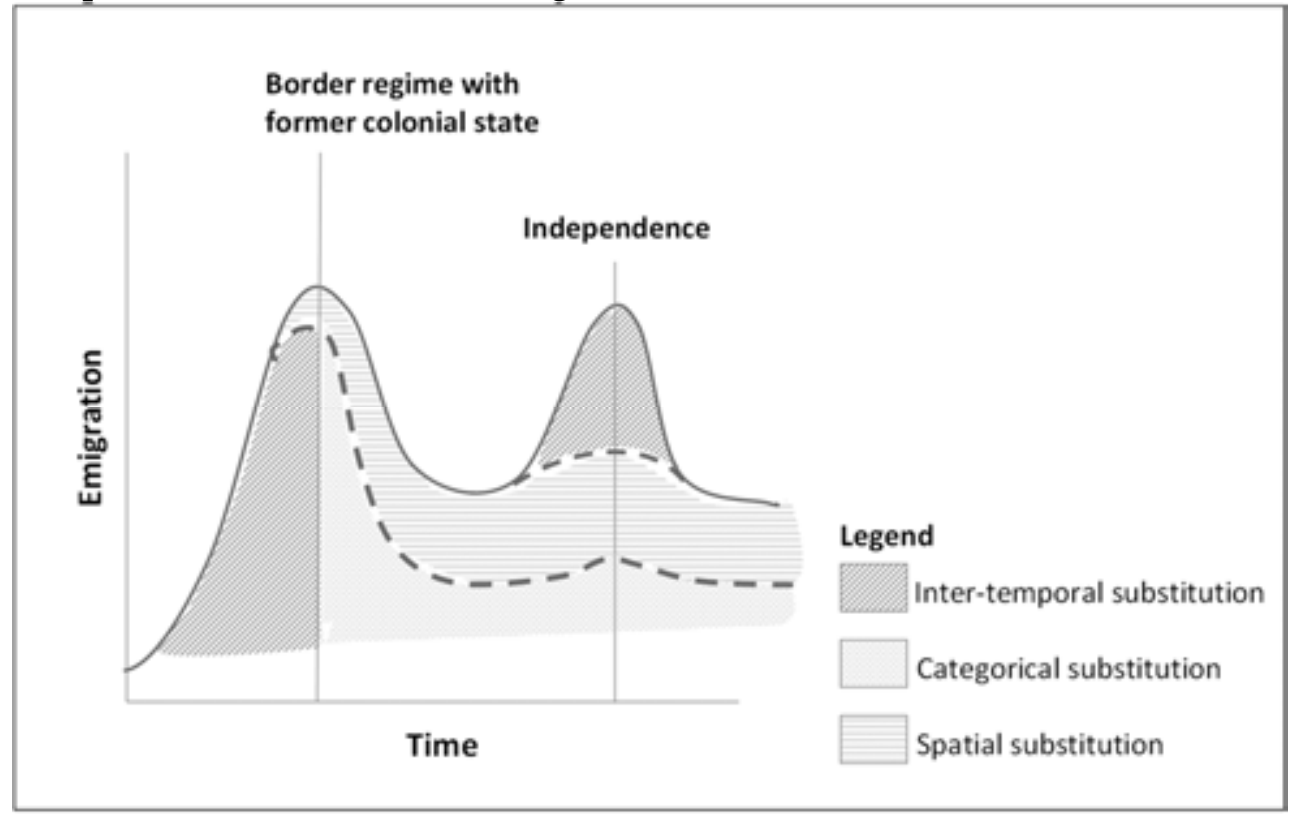

In the interim period between border closure and independence, migration patterns may diversify as migrants adapt to changes in migration channels (e.g. family channels rather than labour) and to the gradual reliance on alternative destinations. In contrast to Figure 2.2, alternative destinations may be well established by the time independence occurs, reducing the relevance of the former colonial state. Under these conditions, the effect of post-colonial ties may weaken rapidly. Nevertheless, a strong post-colonial identity may orient migrants towards irregular migration or to countries within the same colonial sphere (e.g. Commonwealth countries).

This timing of events may also alter the composition of migration flows. The first peak may be largely composed of the elite and the middle classes who enjoy access to resources and connections with the colonial government. The lower classes may be unable to migrate before the closure of the border due to limited resources. The second peak would trigger the migration of a different set of individuals fearful of the changes induced by independence. Such fears may encourage even individuals with limited resources to pursue migration, possibly to neighbouring countries or by relying on irregular channels. Nevertheless, the early closure of the border would limit emigration, lowering the overall volume of the second peak. 


\subsubsection{Border regime establishment after independence}

In the third scenario, independence occurs before the establishment of a border regime, leading to different migration effects. With the nearing of independence, parts of the population may hold expectations of greater opportunities, while other parts of the population may seize the opportunity to emigrate before the official transfer of power (first peak in Figure 2.4). The first emigration peak may, however, be higher than in the previous scenario given the uncertainties surrounding the impending political and economic changes and the possibility to migrate. Reflecting more closely the first scenario (synchronous independence and border regime), we may see a broader representation of the population among migrants, as more households try to establish a foothold in the former colonial state before the transfer of power and change of citizenship. Migration would be driven by political changes rather than fears of mobility constraints. However, the nature, terms and conditions of the free mobility agreement in the interim period (e.g. when it is announced, its clarity and fixity of terms) may influence migration decisions.

Figure 2.4. Possible effects of independence followed by the establishment of border regime on international migration

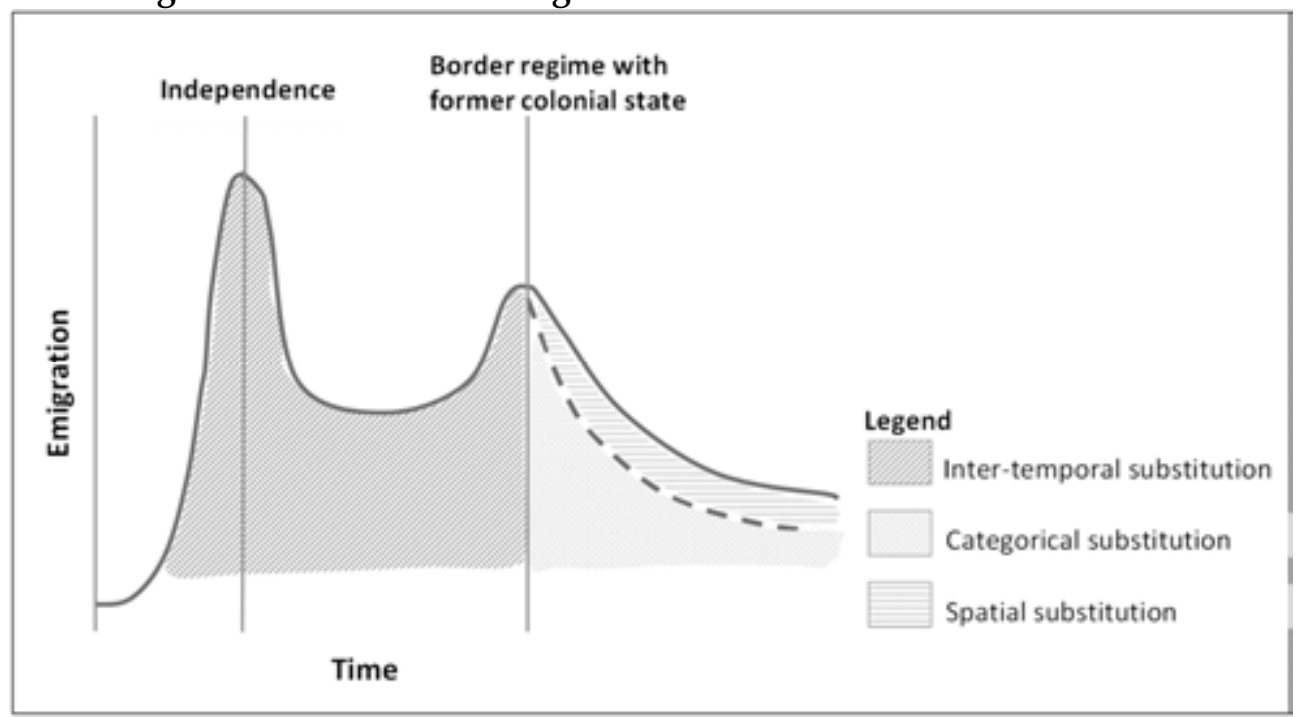

Throughout the interim period, some individuals may rely on the fixedperiod open borders to take a 'wait and see' attitude, resulting in lowered but sustained emigration. Political and economic developments in the newly independent country may greatly influence the confidence of the population in the country's future and their migration decisions. However, regardless of how stable the newly independent country is, the imminent closure of the border would lead to a last minute rush of 'now or never' emigration, particularly for those segments 
of the population unsatisfied by the performance of the newly independent government. However, the interim period provides citizens some time to witness positive signs of stability and growth, which may lower the urgency to emigrate. If, in addition, the attractiveness of the former colonial state is not high, emigration may actually decrease and settle at much lower levels. While it would be unrealistic to claim that the subsequent establishment of a border regime would not generate a 'now or never' effect, its volume may in fact be much weaker in a newly independent country with a bright outlook.

The second emigration peak may be lower than the first peak as the interim period provides ample opportunities to all those who would want and could emigrate to do so before the enactment of entry policies, leading to a degree of 'saturation' among most segments of the population. However, 'saturation' is short-term, as each year a new cohort of young adults enters the pool of potential migrants and new constraints may quickly generate new aspiring migrants unable to migrate. One certainty is that this sequence of events (independence followed by border regime) may lead to magnified post-colonial effects due to the long period of free mobility and the concomitant concentration of large migrant communities in the former colonial state.

After the implementation of a border regime, those seeking to emigrate would have to find the most permissive channel of entry in the former colonial state or look for alternative destinations. These choices may lead to categorical substitution effects and spatial substitution effects, respectively (de Haas 2011). In this scenario, spatial substitution may be less important than categorical substitution given the strong migrant networks concentrated in the former colonial state over the interim years. Thus, categorical substitution is expected to dominate after the establishment of a border regime.

The two asynchronous scenarios similarly forecast two migration peaks, but they differ in terms of estimated volume, with stronger emigration in this last scenario both at independence and in the interim period. The interim period between the two events is strikingly different in the two models. In the previous scenario (subsection 4.2.1), although interim migration is officially still internal migration (migrants are still citizens), individuals face the restrictions of international migration. When independence comes, in spite of the anxiety that the population may feel, a large number of people would not be able to migrate. In this scenario, although migration in the interim period is officially international migration as individuals have already acquired a different nationality, the absence of restrictions equalises it to internal migration. During the interim period, the population would be able to make an informed decision on whether the developments in the newly independent country are satisfactory. Qualitatively, individuals emigrating may be doing so less for the anxiety created by 
uncertainties and more for the dissatisfaction with developments in the newly independent country. Ultimately, the three models presented so far show that independence and the establishment of a border regime and their timing provide vital insights into the dynamism of migration responses to these structural changes. Section 4.4 and Table 2.2 provide additional comparative insights.

\subsection{Non-sovereignty and open border regimes}

Not all decolonisation results in independence. What migration effects should we expect, if any, when decolonisation results in non-sovereign status? Conceptually, non-sovereignty ensures continuity and avoids uncertainties and shocks normally associated with independence (i.e. shifts in ideology and economic model), because the metropolitan state largely retains control of political and economic developments. Non-sovereign countries may also benefit from a number of guarantees, including political relevance as an administrative unit (e.g. department, statehood), access to national resources and government support for administrative and developmental activities. Such continuity and stability may result in lower emigration and greater immigration (McElroy and Sanborn 2005; Mitchell and McElroy 2011). However, a dependent status may also disenfranchise the population, leading to strife, instability and emigration. Because nonsovereignty often corresponds with the acquisition of full citizenship, and in some cases freedom of movement, the population's perception of the new status may significantly affect emigration patterns, with on one hand opportunities, protection and access to employment and services in the non-sovereign territory resulting in low emigration and, on the other hand, unemployment, lack of social services, disenfranchisements in the non-sovereign territory and socio-economic opportunities in the former colonial state, potentially generating high emigration.

In this scenario (Figure 2.5) we consider a non-sovereign country for which the borders with the metropolitan state have remained open. In general, if the transition to non-sovereignty generates any emigration increase, it is expected to be much smaller than that observed during the transitions to independence and border closure with the former colonial state (Figures 2.2-2.4). Moreover, different dynamics underlie this small change in volume: while in countries facing the uncertainties of independence and border closure an inter-temporal substitution effect was visible before independence and border closure occurred, in the case of non-sovereignty the inter-temporal substitution effects may occur after the transition and result in lowered emigration in response to the expected improvement in quality of living. Under these conditions, emigration would be lowered, at least in the short term.

This figure shows that the ease of movement enjoyed by individuals in most non-sovereign countries may lead to spontaneous migration which does not 
present spikes such as those seen for independence or border regime establishment. The timing of emigration here may react to specific periods of transformation, such as the introduction of socio-economic reforms, the establishment of a university, the start of large development projects or more simply an economic downturn. In addition, full citizenship rights and the absence of a border regime suggest that most migration flows would be directed towards the metropolitan state, with weak emigration to alternative destinations. While alternative destinations may gain importance reflecting shifts in geopolitical and diplomatic relations, feelings of shared identity and access to opportunities in the metropolitan state would generally discourage spatial substitution. Thus, categorical substitution effects may not be relevant as people are able to freely migrate to the metropolitan state. ${ }^{26}$

Figure 2.5. Possible effects of status change from colony to non-sovereignty on internal and international migration

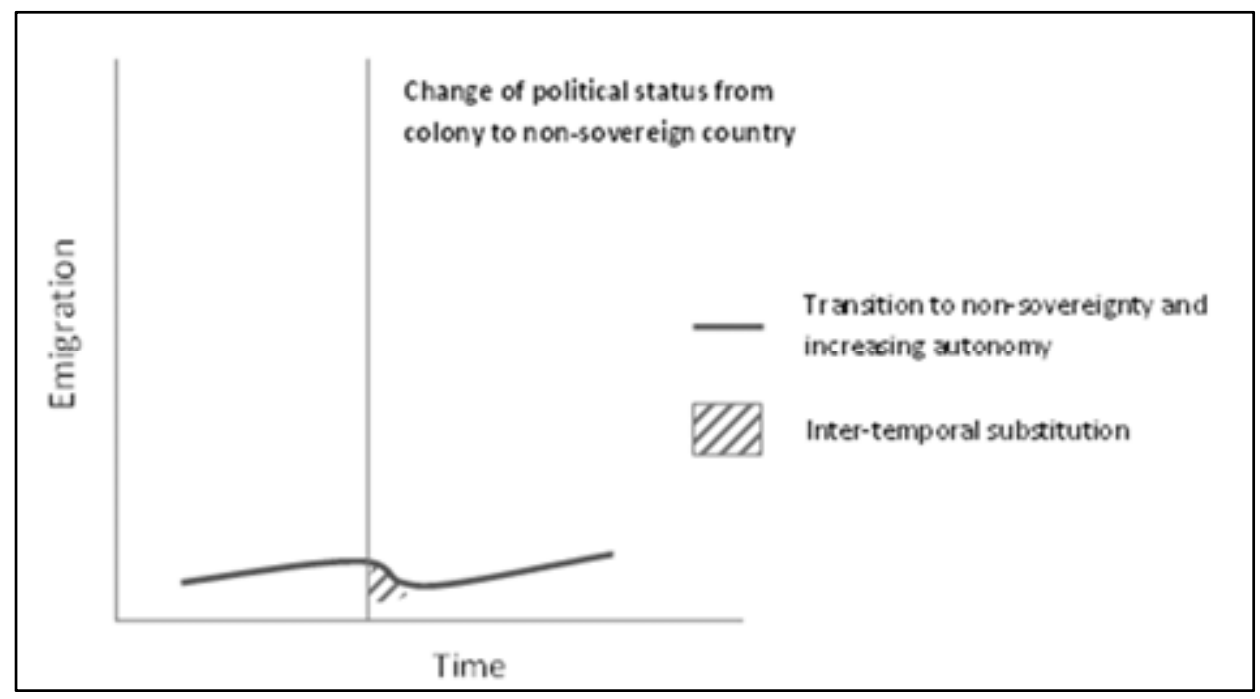

When we consider the composition of migration, open borders may lead to a more diverse migrant population, including greater numbers of less educated and rural migrants (Grosfoguel 1996). In addition, freedom of movement would permit high levels of circulation and return migration. Overall, the guarantee that borders are and will remain open may also lead the population not to rush into emigration, but to engage in migration only if and when needs arise. Moreover, because non-sovereign countries may reach high levels of political and economic stability, they may experience low emigration and become migration destinations,

\footnotetext{
${ }^{26}$ Nevertheless, we may observe shifts in preference to alternative destinations, in which case migrants may be faced with the need to engage in categorical substitution.
} 
particularly receiving immigrants from neighbouring independent countries with lower standards of living. The migration dynamics may be very different for nonsovereign countries which face border regimes and may show migration policy substitution effects, as these individuals may resort to category jumping or migrate to alternative destinations in order to overcome the migration policies imposed by their metropolitan state.

\subsection{Comparative migration effects}

The possible migration effects introduced with each of the scenarios are summarised in Table 2.2 so as to facilitate comparison. For each scenario, the table reports how the events and their timing may affect the volume and distribution of flows over time (i.e. inter-temporal substitution) and generate potential spatial and categorical substitutions. The table also provides specific information on how the composition of migration may change in each scenario by elaborating on shifts in the migrant population across class, age and ethnicity. These insights emerge from the hypothetical scenarios in combination with empirical evidence from elaborations on the cases of Guyana, Suriname and French Guiana. This analysis does not include a gender component because these historical events do not seem to produce atypical gender effects. As the table reflects previously explained concepts, I address only three important points concerning shifts in migrant composition.

First, both the non-sovereign country scenario and the scenario of independence followed by a border regime (Figure 2.4) stimulate all classes of people to migrate. Conversely, in the synchronous timing of events or when borders anticipate independence, migration is primarily of the higher and middle classes. Second, in non-sovereign countries and when borders close before independence, migrants may be overly represented by young people of working age (i.e. $20-45$ year-olds). This is based on the notion that these individuals may aspire to migrate to pursue work/career opportunities abroad. In the other two scenarios, the various political and economic motives may lead all age cohorts to engage in migration. Third, populations with high levels of ethnic diversity may witness specific shifts in the composition of migration along ethnic lines in reaction to independence. The transfer of power and potential fears of discrimination or even oppression may encourage certain ethnic groups to migrate pre-emptively. Conversely, the establishment of a border regime should not have any ethnicspecific effects, unless migration policies target specific ethnic groups or when migration policies target income, education levels and other traits that may exclude disadvantaged ethnic groups. 
Table 2.2. Comparative table of the effects of four scenarios on the volume, destination, migration category and composition of migration

\begin{tabular}{|c|c|c|c|c|}
\hline \multirow{2}{*}{$\begin{array}{l}\text { Migration } \\
\text { effects }\end{array}$} & \multicolumn{4}{|c|}{ CONCEPTUAL SCENARIO } \\
\hline & $\begin{array}{l}\text { Synchronous } \\
\text { (Figure 2.2) }\end{array}$ & $\begin{array}{l}\text { Border regime } \\
\text { then independence } \\
\text { (Figure 2.3) }\end{array}$ & $\begin{array}{l}\text { Independence } \\
\text { then border } \\
\text { regime } \\
\text { (Figure 2.4) }\end{array}$ & $\begin{array}{c}\text { Dependency and } \\
\text { weak border } \\
\text { regime } \\
\text { (Figure 2.5) }\end{array}$ \\
\hline Volume & $\begin{array}{l}\text { - High and } \\
\text { concentrated in } \\
\text { one peak } \\
\text { - Rapid decline } \\
\text { after } \\
\text { independence/ } \\
\text { border } \\
\text { establishment }\end{array}$ & $\begin{array}{l}\text { - Medium first } \\
\text { emigration peak } \\
\text { - Rapid decline in } \\
\text { interim period } \\
\text { - Medium second } \\
\text { peak }\end{array}$ & $\begin{array}{l}\text { - High first peak } \\
\text { - Sustained interim } \\
\text { emigration } \\
\text { - Medium second } \\
\text { peak }\end{array}$ & $\begin{array}{l}\text { - Low emigration } \\
\text { peak } \\
\text { - Continued low/ } \\
\text { gradual } \\
\text { emigration }\end{array}$ \\
\hline Destination & $\begin{array}{l}\text { - Towards former } \\
\text { colonial state } \\
\text { (FCS) before } \\
\text { independence } \\
\text { and border } \\
\text { regime } \\
\text { - Afterwards } \\
\text { some } \\
\text { diversification to } \\
\text { alternative } \\
\text { destinations }\end{array}$ & $\begin{array}{l}\text { - Towards FCS } \\
\text { before border } \\
\text { regime } \\
\text { - Diversification in } \\
\text { interim period } \\
\text { - At independence } \\
\text { diversification } \\
\text { established, } \\
\text { reduced } \\
\text { relevance of FCS }\end{array}$ & $\begin{array}{l}\text { - Towards FCS } \\
\text { before and after } \\
\text { independence } \\
\text { - Strong } \\
\text { emigration } \\
\text { towards FCS in } \\
\text { interim period } \\
\text { - Continued } \\
\text { migration to FCS } \\
\text { after } \\
\text { establishment of } \\
\text { border regime }\end{array}$ & $\begin{array}{l}\text { - Towards FCS } \\
\text { before and after } \\
\text { change of } \\
\text { political status } \\
\text { - Migration to } \\
\text { other non- } \\
\text { sovereign } \\
\text { territories of } \\
\text { FCS } \\
\text { - Low migration } \\
\text { to alternative } \\
\text { destinations }\end{array}$ \\
\hline $\begin{array}{l}\text { Migration } \\
\text { policy } \\
\text { category }\end{array}$ & $\begin{array}{l}\text { - After } \\
\text { independence } \\
\text { and border } \\
\text { regime, work } \\
\text { permits required } \\
\text { and heavier } \\
\text { reliance on } \\
\text { family } \\
\text { reunification, } \\
\text { study, asylum } \\
\text { and possibly } \\
\text { resorting to } \\
\text { undocumented } \\
\text { entry and stay }\end{array}$ & $\begin{array}{l}\text { - After border } \\
\text { regime work } \\
\text { permits required } \\
\text { and heavier } \\
\text { reliance on } \\
\text { family } \\
\text { reunification, } \\
\text { study, asylum } \\
\text { and possibly } \\
\text { resorting to } \\
\text { undocumented } \\
\text { entry and stay } \\
\text { - At independence, } \\
\text { possible } \\
\text { categorical } \\
\text { substitution also } \\
\text { in alternative } \\
\text { destinations }\end{array}$ & $\begin{array}{l}\text { - After } \\
\text { independence no } \\
\text { major change in } \\
\text { category } \\
\text { - After border } \\
\text { regime work } \\
\text { permits required } \\
\text { and heavier } \\
\text { reliance on family } \\
\text { reunification, } \\
\text { study, asylum } \\
\text { and possibly } \\
\text { resorting to } \\
\text { undocumented } \\
\text { entry and stay; } \\
\text { small categorical } \\
\text { substitution in } \\
\text { alternative } \\
\text { destinations }\end{array}$ & $\begin{array}{l}\text { - No categorical } \\
\text { substitution }\end{array}$ \\
\hline
\end{tabular}




\begin{tabular}{|c|c|c|c|c|}
\hline \multicolumn{5}{|c|}{ Composition } \\
\hline Class & $\begin{array}{l}\text { - Elite and } \\
\text { middle classes } \\
\text { - Lower classes } \\
\text { with migration } \\
\text { connections } \\
\text { - Most lower } \\
\text { class unable to } \\
\text { migrate }\end{array}$ & $\begin{array}{l}\text { At border closure: } \\
\text { - Elite and middle } \\
\text { classes } \\
\text { - Lower classes } \\
\text { with migration } \\
\text { connections } \\
\text { - Most lower class } \\
\text { unable to migrate } \\
\text { At independence: } \\
\text { - Most lower class } \\
\text { unable to migrate } \\
\text { - Alternative } \\
\text { destinations may } \\
\text { be viable for all } \\
\text { classes }\end{array}$ & $\begin{array}{l}\text { At independence: } \\
\text { - All classes, } \\
\text { including lower } \\
\text { classes } \\
\text { At border closure: } \\
\text { - All classes, } \\
\text { including lower } \\
\text { classes }\end{array}$ & $\begin{array}{l}\text { - Small elite and } \\
\text { middle classes } \\
\text { - Small lower } \\
\text { classes }\end{array}$ \\
\hline Age & $\begin{array}{l}\text { - All cohorts } \\
\text { (includes } \\
\text { younger } \\
\text { cohorts of } \\
\text { migration- } \\
\text { prone groups } \\
\text { and more } \\
\text { diverse cohorts } \\
\text { reacting to } \\
\text { independence) }\end{array}$ & $\begin{array}{l}\text { At border closure: } \\
\text { - Young working } \\
\text { age cohorts, } \\
\text { setting a foot in } \\
\text { the country } \\
\text { At independence: } \\
\text { - Greater } \\
\text { representation of } \\
\text { all cohorts }\end{array}$ & $\begin{array}{l}\text { At independence: } \\
\text { - All cohorts } \\
\text { At border closure: } \\
\text { - All cohorts }\end{array}$ & $\begin{array}{l}\text { - Primarily young } \\
\text { cohorts }\end{array}$ \\
\hline
\end{tabular}

\section{Conclusions}

This chapter explored the role of states in shaping migration patterns and developed a broader perspective on the migration relevance of state policies in both origin and destination countries. I introduced a simple categorisation, which considers two broad policy groups, migration and non-migration policies, and their migration and non-migration policy objectives and policy tools. Two main observations can be made. Although migration policies are often defined as policies with migration objectives, research on migration policies considers policies that do not have a migration objective but use a migration tool (e.g. residence permit for investors). Concurrently, policies that do not use migration tools (e.g. increasing university courses to decrease emigration for education) are largely ignored although they might have migration objectives. While these policies may appear marginal in comparison to the broad range of migration policies that have been created over time (cf. de Haas, Natter et al. 2014), this shows that policies that are unaccounted for may in fact promote migration. 
A second observation is that migration research remains focused on migration policies, largely ignoring other non-migration policies that do not utilise migration tools. Because these policies appear unrelated and irrelevant for migration they are overlooked, although they may lead to important migration effects. Among such policies are the privatisation of social care services or changes in university tuition fees, which may possibly affect individuals and have migration-stimulating effects both in origin and destination countries. By reassessing the role of the state in migration through both its migration and nonmigration policies, not only do we start to perceive it as more pervasive, but we suddenly see a realm of ways in which states in origin countries may also play an active role in migration. A broader perspective on the role of the state in migration invites us to explore whether some migration outcomes, which may not be explained by migration policies or other observable migration drivers, may perhaps be explained by non-migration policies. Thus, this contextualised perspective may shed light on why border regimes do not have the expected migration-reduction effects.

The second objective of this chapter was to understand the migration effects of the transition of former colonies into independent or non-sovereign countries. This has been achieved through a conceptual elaboration which accounts for the heterogeneity of the colonial and decolonisation experiences, the distinction between independence and the establishment of border regimes and their timing, the passage of time and contextual transformations, and the agency of individuals in the post-colonial environment. Four hypothetical scenarios elaborated upon the expected migration effects when: (i) independence and the border regime occur at the same time; (ii) border regime occurs before independence; (iii) independence occurs before the border regime; (iv) decolonisation results in non-sovereign status. This initial conceptual framework generated initial insights, showing that independence and border regimes may fundamentally shift the motivations and composition (i.e. class, age and ethnic group), the volume and concentration, migration policy channels and the direction of migration. The timing and the sequence of these events provide important clues to the development of migration patterns.

With these conceptual insights on the role of the state and the potential effects of independence and border regimes, we proceed to first explore how extraregional and intra-regional emigration from Caribbean countries differs according to border regimes and colonial sphere of influence (chapter 3). Then, the proposed scenarios will be used to understand how independence and border regimes, or alternatively non-sovereignty and open borders, and post-colonial ties have affected long-term emigration patterns from Guyana, Suriname and French Guiana (chapters 4-6). Throughout the analysis of the case studies, close attention will be 
given to state actions, mainly in the origin country but also at destination, and the variety of non-migration policies that may influence migration decisions. 


\section{Chapter 3 - Examining the role of border closure and post-colonial ties in Caribbean emigration ${ }^{27}$}

\section{Introduction}

Border regimes are generally seen as a necessity to control and limit migration. Open borders are associated with massive migration flows. However, empirical evidence on the effects of borders on migration does not seem to support these statements: while the opening of the EU borders to Southern European countries in the 1980s did not lead to massive flows from Southern to Northern EU member states, countries with allegedly restrictive immigration policies seem to have increasingly higher concentrations of immigrants (Czaika and de Haas 2014). The effects of border regimes appear to be misunderstood and border closure seems in fact to produce unanticipated effects. This chapter questions the general assumptions about border regimes by comparing emigration from countries that have experienced border closure and whose citizens have had their rights to settlement restricted by former colonial states, and those whose borders have remained open over time. It does so by focusing on the evolution of emigration from the Caribbean in the period between 1960 and 2000 and analysing the role of border regimes and post-colonial ties in shaping trends and patterns of migration in this region.

The Caribbean region includes countries that are commonly recognised as sharing a history rooted in colonialism, forced (slavery), indentured and voluntary migration which create a common heritage and regional coherence (Clarke 1978). Caribbean colonies underwent rapid political change after the Second World War. In the 1960s and 1970s some of these colonies became independent states, while others were transformed into non-sovereign countries, retaining dependence while gaining greater autonomy in local political and budgetary matters, including determining their own immigration policies. The colonial powers (France, the

\footnotetext{
27 This chapter is based on a joint paper by the author and Marie-Laurence Flahaux also entitled, 'Examining the role of border closure and post-colonial ties in Caribbean migration', which is currently under review by Population and Development Review.
} 
Netherlands, Britain and the US) showed important differences, not only in the decision to grant independence or non-sovereignty but also in whether to allow inhabitants of former colonies to retain rights of entry, residence and work in the former colonial state. Thus, the Caribbean region provides a lens through which to study not only whether there is an association between border closure and migration, but also whether migration patterns may be associated with specific former colonial states.

Previous literature that examined migration trends across the Caribbean region has distinguished between islands that show traits of immigration countries (the Bahamas Islands and the US Virgin Islands) and those displaying the characteristics of strong emigration countries (e.g. Anguilla and St Kitts and Nevis) (McElroy and Albuquerque 1988). Immigration islands generally show advanced socio-economic levels and dynamic economies due to economic diversification (McElroy 2011; Mitchell and McElroy 2011) and are also non-sovereign countries (McElroy and Sanborn 2005; McElroy and Pearce 2006). Conversely, emigration islands have not diversified their economies, experience slow economic growth (McElroy 2011; Mitchell and McElroy 2011) and are almost exclusively independent countries (McElroy and Sanborn 2005; McElroy and Pearce 2006). However, these regional analyses have largely disregarded the role of border regimes. A few case studies on non-sovereign countries with open borders with the metropolitan state have considered the effects of open borders and suggested that the freedom of movement leads to high emigration (Audebert 2007) and high emigration propensities of rural and less educated people (Grosfoguel 1996).

Evidence is lacking on how border regimes have affected emigration from the countries in the region and whether belonging to a specific colonial sphere - i.e. British, French, Dutch or US - is associated with different migration patterns, including diverse effects of post-colonial ties. This chapter first analyses the extent to which border regimes and post-colonial ties affect the intensity ${ }^{28}$ of emigration, in order to question the common assumption that closed borders limit emigration. Second, we will explore whether closing of the borders by the former colonial state also impacts migration to other destinations, leading to spatial substitution effects (de Haas 2011), diversifying migration to alternative extra- and intra-regional destinations where migration policies are less restrictive than in the former colonial state. By looking at the extent of spatial diversification, we may learn more about the conditions under which post-colonial ties endure and observe whether

\footnotetext{
${ }^{28}$ Emigration intensity is the share of migrants among all individuals born in a specific country or group of countries. This concept is explained further in section 3 of this chapter.
} 
variations can be explained by the former colonial state (e.g. former British, Dutch, French colonies or US possessions), or border regimes (open vs closed).

\section{Characteristics of Caribbean migration trends}

\subsection{Migrations before the Second World War}

The Caribbean is the region of the world most affected by a deep and continuous impact of international migration (Segal 1987). ${ }^{29}$ Caribbean societies have their roots in the continual labour requirements on the plantations, which were met initially with slave labour from Africa, and after Emancipation with indentured contract labour from Europe (e.g. Madeira Islands) and Asia, primarily from India, but also from China and Indonesia, depending on the colonial power. Emancipation, which Britain enacted in 1833, France in 1848 and the Netherlands in 1863, was of great importance for Caribbean migrations as around this time former slaves gained the freedom to seek alternative occupations. The planters' unwillingness to pay acceptable wages for work on the plantation and, concurrently, the stigma associated with plantation work, made peasants look for options away from the plantation in the cities and, in small island settings, this often involved emigration to other colonies in the Caribbean region. These emigrations were a statement of these peasants' 'freedom' from the planters, from the oppressive working conditions and from the rigid socio-economic structure from which they could not otherwise escape (Thomas-Hope 1978). This offers a prime example of the link Zelinsky (1971) makes between spatial and social mobility when he argues that moving spatially allows individuals to break away from the social structures that prevent upward mobility.

Along with the post-Emancipation migration of West Indian islanders ${ }^{30}$ to British Guiana and Trinidad (Chaney 1989), there are records of West Indian migrations to the Hispanic Caribbean: Panama offered work on the railroad and the canal in the 1850s-1880s, Costa Rica in the 1870s-1890s; Cuba, Haiti, Dominican Republic, St Croix and other Central and South American countries provided work

\footnotetext{
${ }^{29}$ Net migration rates for 2005-2010 clearly show the Gulf countries as the most affected by international immigration. Here, however, I refer to both immigration and emigration. Two Caribbean countries, Curaçao and the Bahamas, are in the top 20 immigration countries worldwide, while five countries, Jamaica, Puerto Rico, Grenada, Guyana and Saint Vincent and the Grenadines, are within the bottom 20 countries, indicating most emigration; many other Caribbean countries also show strong negative net migration rates. Data source: United Nations, Department of Economic and Social Affairs, Population Division (2013). World Population Prospects: The 2012 Revision, DVD Edition, File MIGR/1: Net migration rate by major area, region and country, 1950-2010 (per 1,000 population), Estimates, 19502010, accessed on July 25, 2015, available at http: //esa.un.org/unpd/wpp/DVD/.

${ }^{30}$ The term 'West Indian' refers to the former Caribbean British colonies.
} 
in forestry and cane cutting, while Venezuela, Aruba and Curaçao offered employment in the oil refineries as early as the 1910s (Thomas-Hope 1978). At this time, Caribbean migrants worked for US companies such as the American Fruit Company (later United Fruit Company) which provided an initial link to later seasonal migrations to the US (Chaney 1989). With the completion of the Panama Canal in 1914, the onset of World War I, the crash of sugar prices in 1921 and the advent of the Great Depression, migration decreased and many migrants returned to their origin country (Marshall 1987; Chaney 1989). Starting in the 1920s, Panama and later other Central American countries began to control the entry of West Indian immigrants, which heralded the end of this intra-regional phase of Caribbean migrations (Thomas-Hope 1978; Marshall 1987).

By the mid-20 th century, migration had become an essential part of Caribbean life, particularly in the British colonies. Emigration evolved into a social and cultural phenomenon embedded in the Caribbean colonial environment, where expectations of fundamental socio-economic change in the communities of origin were low, while migration 'offered an alternative to fundamental change' (Thomas-Hope 1978: 77). For French and Dutch Caribbean colonies migration was not as prevalent as for British colonies. Pre-Second World War migration from the Dutch Caribbean was much more limited and primarily consisted of students from the elite who pursued tertiary studies in the Netherlands, although small groups of working class migrants also moved from Suriname to the Netherlands (Oostindie 2009). Emigration from the French Antilles and French Guiana similarly comprised mainly students pursuing secondary and tertiary education in metropolitan France. In the British, French, Dutch and US cases young men were mobilised during the Second World War to support the war efforts and fight for the colonial state, a process that would make these young men aware of the opportunities available in the metropolitan state and would influence later migrations (Levine 1987; Peach 1991; Oostindie 2009). Generally, the absence of border regimes regulating migration (Hendry 2011) allowed Caribbean migrants to respond to the emergence of opportunities within the Caribbean region, in Central and South America.

\subsection{The development of extra-regional migrations}

From the mid-20 th century, Caribbean migration patterns underwent an important transformation, primarily through a spatial diversification towards overseas destinations. This important shift can be explained by a combination of economic, political and migration policy factors.

As Britain started its post-Second World War reconstruction efforts, West Indian migrants contributed to the rebuilding of the British transport and health systems, sometimes through recruitment programmes (e.g. Barbados and Jamaica) 
but also through spontaneous migrations. Concurrently, early recruitment programmes for seasonal workers by the US and domestic workers by Canada offered regular short-term migration opportunities (Thomas-Hope 2000) (see chapter 4), which strengthened the connections between the Caribbean and North America. Significant migration to France and the Netherlands from their Caribbean colonies started ten to fifteen years after West Indian migrations, with peaks in migration in the 1970s (Peach 1991). The rapid growth of migration from the French Antilles, less so from French Guiana, followed the introduction of a stateorganised recruitment system which attempted to reduce high unemployment and prevent social unrest in the French Antilles, while filling low-level civil service positions in France, which could only be taken by French citizens (Condon and Ogden 1991).

Migration from Dutch Caribbean colonies was not strongly associated with labour. Although small-scale recruitment programmes existed, emigration was tied to political anxieties in anticipation of Suriname's independence and the establishment of its border regime with the Netherlands in 1980 (van Amersfoort 2011). Puerto Rican migration to the US started many years before the Second World War, but peaked in the 1950s when on average 40,000 Puerto Ricans were migrating to the US per year, facilitated by the fact that neither passports nor visas were required. While many factors explain this intense emigration, research found a high correlation between Puerto Rican emigration and the US business cycles and US unemployment rates, linking this migration to migrants' search for better economic opportunities, higher wages and better quality of life (Levine 1987).

The literature acknowledges the importance of migration policies in redirecting (rather than curbing) migration in this period. The US Immigration Act of 1952, also known as the Walter/McCarran Act, restricted immigration to the US and is believed to have been partly responsible for a spatial substitution of migration from the US to Britain (Marshall 1987). Conversely, the 1962 British Commonwealth Immigration Act increased restrictions on West Indian immigrants who were required to obtain employment vouchers to be admitted to Britain. In the same period, the liberalisation of immigration policies in Canada (in 1962) and in the US (in 1965) towards non-European countries encouraged migration from the Caribbean as well as secondary migration of Caribbean immigrants already residing in Britain to North America (Palmer 1974; Thomas-Hope 2000) (see chapter 4$)$. 


\subsection{Evolution of political status and border regimes}

\subsubsection{General trends}

In the post-Second World War period, opposition to colonialism mounted, leading to a gradual move towards decolonisation. Decolonisation processes were not homogeneous and reflected national ideologies, as well as the economic constraints faced by many European countries after the devastation of war. While the US had already established free associated status for Puerto Rico and unincorporated status for the US Virgin Islands by the 1920s, the French government transformed its French Caribbean colonies into integral parts of the French state as Overseas Departments and the Dutch government made its Dutch Caribbean colonies countries within the Kingdom of the Netherlands. Britain, which had the strongest European presence in the Caribbean (Figure 3.1), was the first colonial power to concede independence, initially to Jamaica and Trinidad and Tobago in 1962 and followed by most of its Caribbean colonies (Christopher 2002; Rabe 2005) (see Figure A2 in appendix B for specific year of political status change). Among nonBritish Caribbean colonies, only Suriname gained independence from the Kingdom of the Netherlands in $1975 .{ }^{31}$

The establishment of border regimes did not always mirror the changes in political status. Although Britain initially did not introduce entry restrictions, it implemented policies to restrict residence and work for its colonial nationals, which were the first measures introduced to regulate immigration before independence. Travel visa requirements were introduced later by Britain and the Netherlands for citizens of some of their former colonies which gained independence. France and the US never implemented any travel visa restrictions on their Caribbean dependencies. In this study, closed borders refers to the set of measures implemented to restrict residence and work, not necessarily restricting the right to travel through travel visa requirements. This definition stands apart from the way 'closed borders' are often used in current parlance: while often undefined, closed borders tend to refer to attempts to 'seal' borders through travel visa requirements regulating entry as well as sets of policies that regulate residence and work. However, in this study it seems appropriate to use 'closed borders' to

\footnotetext{
31 The Kingdom of the Netherlands has evolved since 1954, when it included Suriname as one of its countries. After Suriname's independence and Aruba's separation from the Netherlands Antilles in 1986, the Kingdom was composed of three countries: (i) the Netherlands; (ii) Aruba; and (iii) the Netherlands Antilles, which included Bonaire, Saba, Sint Eustatius, Curaçao and Sint Maarten. Currently, it is composed of four countries: (i) the Netherlands, which include the European mainland and the three Caribbean municipalities of Bonaire, Saba and Sint Eustatius; (ii) Aruba; (iii) Curaçao; and (iv) Sint Maarten (all in the Caribbean). However, due to data limitations, in the following sections we refer to the pre-2010 setup since data are available only for Aruba and the Netherlands Antilles.
} 
refer to the regimes of tight regulations to prevent residence and work, which stood in reference and stark contrast to the previous regime of 'open borders'. And while it is true that potential migrants may still have been able to enter visa-free and overstay, indeed a well-known strategy, opportunities to migrate regularly were in fact closed.

Figure 3.1 shows that some countries retained an open border regime over time as they transitioned to non-sovereign status, while others (mainly British colonies) had their right of settlement curtailed in 1962, whether they gained independence or retained a non-sovereign status. Hence, the inhabitants of some non-sovereign countries did not enjoy freedom of settlement in their metropolitan state, while some independent countries experienced a time gap between border closure and independence. The figure shows the different approaches of former colonial powers towards free movement of their former colonial subjects. This also shows the necessity of investigating the association between border closure and shifts in migration in conjuncture with, but separately from, the effect of independence and non-sovereignty on migration, which has been the focus of most prior research.

\section{Figure 3.1. Evolution of political status and border regimes of Caribbean} countries, 1920-2014

Caribbean countries previously colonised by France:

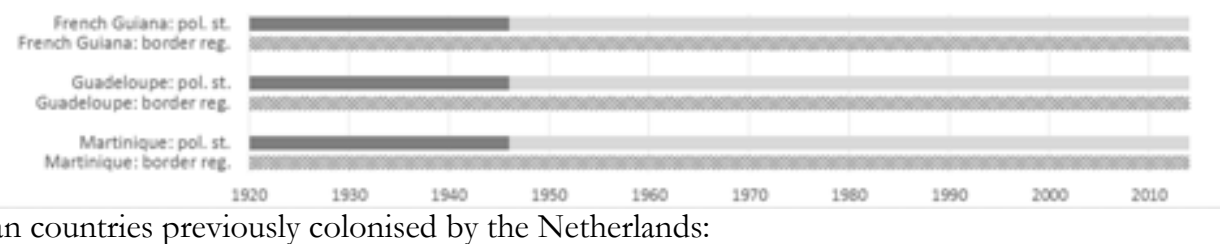

Caribbean countries previously colonised by the Netherlands:

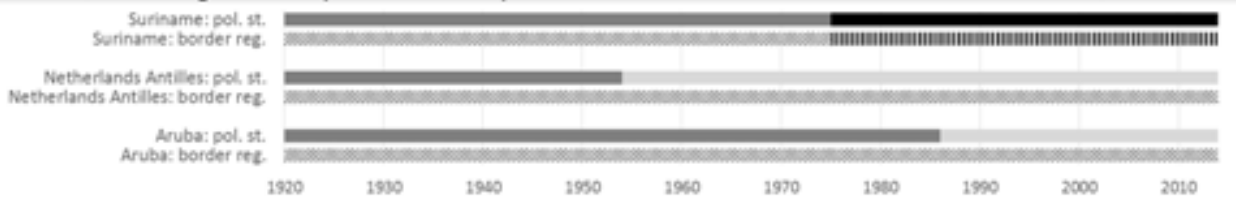

Caribbean countries previously colonised by the US:

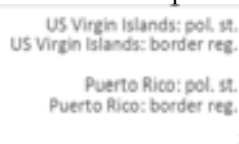

1920

2930

1940

1950

2960

1970

2980

1900

2000

$20: 0$ 
Caribbean countries previously colonised by Britain:

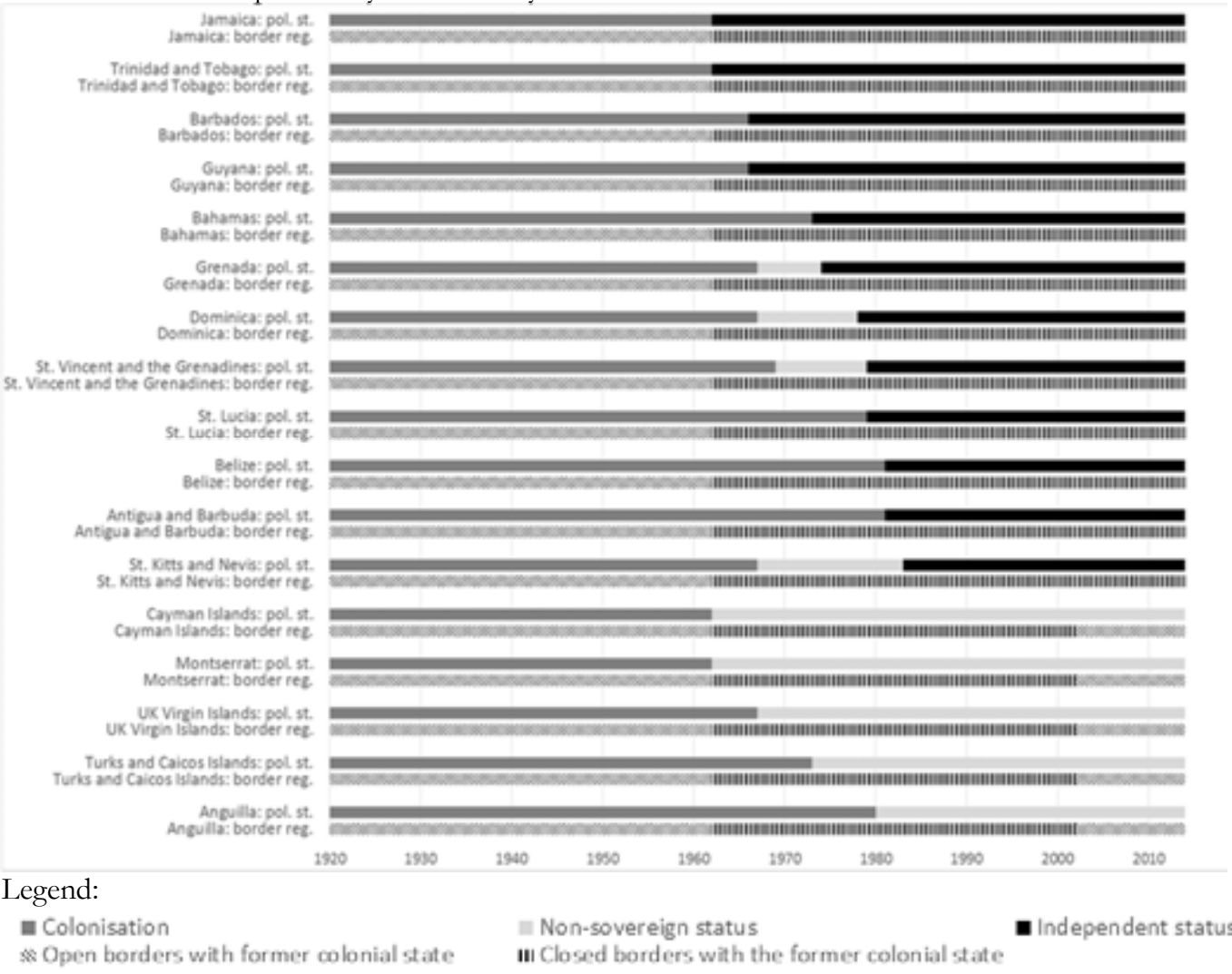

We can distinguish three main categories with regard to the evolution of border regimes of Caribbean countries (see Figure 3.2). To our understanding, all former Caribbean colonies had an open border regime during colonialism, giving the population full rights to circulate, work and reside in the colonial state (Hendry 2011). In trajectory A, the border regimes remained open during the entire period before, during and after colonisation (the so-called Open-Open-Open Borders, later referred to as open borders). This is the case for the Dutch, French and US colonies that transitioned to a dependent non-sovereign status and that have been guaranteed access to the metropolitan state through full citizenship and freedom of movement and settlement.

Trajectory B applies to Open-Closed-Closed Borders (later referred to as closed borders), which represent the evolution from open border regimes to closed border regimes applicable to all former British colonies, regardless of political status, as well as Suriname. In the early 1960s, British citizens in the colonies were subjected to partial closure starting with the Commonwealth Immigration Acts of 
1962 and 1968, which restricted the right of settlement, and the 1971 Immigration Act which restricted all rights to remain. Finally, the 1981 British Nationality Act created a British Dependent Territories citizenship, which did not give the right to abode and essentially gave the Dependent Territories citizens no legal status (Clegg 2005). Because of the immediate restriction on work and residence, all the former British colonies can be categorised as having passed from an open to a closed border regime in the 1960s. Similarly, in the case of Suriname where initial immigration barriers were introduced in 1975 and full immigration policies applied in 1980, border closure was recorded in 1975, when free movement and right to residence and work were curtailed.

Since 2002, a third trajectory (C, Open-Closed-Open Borders) represents the evolution in the border regimes applicable to British non-sovereign countries: the Monserrat crisis, triggered by the explosions of the volcano Mount Soufrière starting in 1995 and the departure of two-thirds of the population in the following years, brought to the surface the peculiar lack of a legal status of the inhabitants of British dependencies. By 2002 the British Overseas Territories Bill gave the five British non-sovereign countries the right to British citizenship upon request with matching right of abode in Britain, the right of free movement and residency in the EU and European Economic Area member states (Clegg 2005). However, the effect of this 'opening' of the borders on emigration cannot be analysed due to the lack of reliable data after 2000 .

Figure 3.2. Evolution of border regimes of former colonies towards their former colonial state: 3 trajectories among the 25 Caribbean states

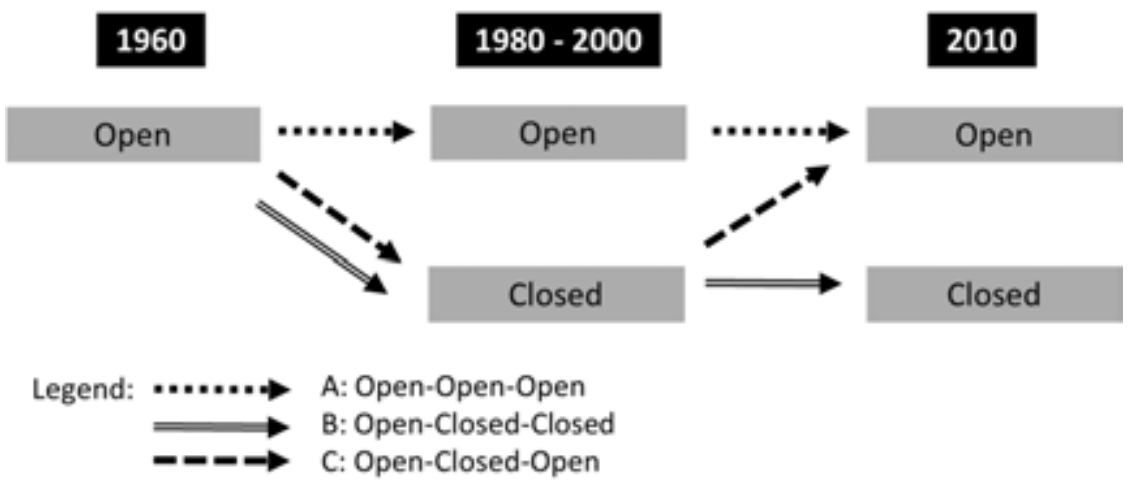

This categorisation of border regime evolutions is based exclusively on the full set of migration policies established by and with the former colonial state. It is meant to provide a lens to observe whether such drastic changes in policies seem to have an effect on migration intensity and destination choice or, conversely, whether the consolidation of full mobility and settlement rights is associated with 
any shifts in migration patterns. Hence, the open border category in Trajectory A is intended as freedom of settlement for countries within their own colonial sphere, including their respective former colonial state, not to countries outside of their colonial sphere, where they often face migration restrictions, e.g. French Antilleans migrating to Dutch-sphere Curaçao, Puerto Ricans migrating to the French Antilles or British-sphere Anguillans migrating to Canada. Hence, even open-border countries are affected by migration policies of other potential destination countries.

In particular, North American immigration policy shifts in the 1960s have been deemed important shapers of extra-regional Caribbean migrations: (i) shifts in Canadian policies to attract skilled migrants provided greater opportunities for Caribbean migrants, who generally possessed secondary and tertiary levels of education (Thomas-Hope 2000); and (ii) US policies dismantled racial criteria and opened migration opportunities for Caribbean people with an emphasis on family reunification, allowing Caribbean families to use extended family relations as a migration channel (Maingot 1983). This effect was so great that West Indian migration to Britain has been described as being 'sandwiched between two periods of migration to the Americas' (Peach 1991: 3), reducing Britain to just one of the many destinations for West Indian migrants. However, whether the opening of North American migration policies had an effect on migration from the Caribbean in general - i.e. from the non-British Caribbean sphere - remains unclear, particularly because of the freedom of movement and settlement enjoyed by many open border countries towards their respective metropolitan states, i.e. French Antilles and French Guiana to France, Aruba, the Netherlands Antilles to the Netherlands, and Puerto Rico and the US Virgin Islands to the US. In fact, the literature suggests that migration from the Dutch and French dependencies remained concentrated towards their relative European states (Peach 1991). For Suriname, however, the end of the negotiated preferential migration channels and the introduction of a travel visa requirement to the Netherlands in 1980 (van Amersfoort 2011) made US policies more relevant as migration towards the US gained some strength (Runs 2006) (see chapter 5).

Caribbean countries are also important migration destinations within the region. In fact, while Caribbean migration patterns shifted after the 1940s from intra-regional to extra-regional destinations (Thomas-Hope 1978), intra-regional migration also continues at a steady pace (Thomas-Hope 2000). Within the region, there is ample evidence of various forms of movement, which reflect migrations to work in niche areas such as tourism or off-shore financial services, fluid forms of migration that follow trade and networks of opportunities (Carnegie 1987), circulation and patterns of return, for retirement but also as active workers in Caribbean economies (Thomas-Hope 2000). However, it is unclear the extent to which these intra-regional migrations have been affected by border regimes and 
whether closed borders have in fact reduced overall emigration and open borders within the region have engendered large migrations.

\subsubsection{A closer look at visa requirements for nationals from Caribbean countries}

As previously mentioned, the proposed categories of open and closed borders are based on the bilateral relations between countries and their former colonial state. However, the establishment of a border regime by the former colonial state may also prompt changes in border regime by other countries which may also enact more restrictive policies towards citizens of countries with closed borders, who can no longer emigrate easily. One way in which countries have restricted entry is through the introduction of travel visa requirements, which may complement other immigration policies restricting settlement.

Travel visa requirements are thought to affect migration and have been used by states in destination countries as a way to prevent irregular immigration, asylum requests and potential overstaying (Czaika and de Haas 2014). By using travel visa requirement data from the DEMIG VISA database, which covers the 1973-2013 period ${ }^{32}$, we analyse the evolution of travel visa requirements for Caribbean nationals, in order to better understand (1) to what extent Caribbean nationals in closed and open border countries have been targeted by major destination countries, including their former colonial states, and also (2) how Caribbean countries have attempted to control travel and migration of Caribbean nationals of closed and open border countries. We calculated a visa restrictiveness index by computing the percentage of Caribbean countries that need a travel visa to enter a destination country for every year, distinguishing between closed and open border regimes. The following graphs reflect yearly changes of visa restrictiveness for all countries and for countries included in the closed and open border categories.

(1) Evolution of travel visas required by Britain, France, the Netherlands and the US for Caribbean nationals

Analysis of the evolution of travel visas required by Britain, France, the Netherlands and the US for all Caribbean nationals (Figure 3.3) shows a rapid increase in travel visa requirements coinciding with the period of independence over the 1960s to 1980s, but relative stability over the 1990s and a recent drop in 2010. Countries that have open borders with their former colonial state have seen a significant drop in travel visa requirements by France, the Netherlands, Britain and the US combined since 1990, while these destination countries have gradually

\footnotetext{
32 Data before 1973 are not available, as data were compiled from IATA Travel Information Manuals (TIM) reports available since 1973.
} 
increased travel visa requirements for countries with closed borders with their former colonial state, reaching levels around 80 percent in the 2000s (Figure 3.3). This suggests that the visa regimes of extra-continental migration destination countries partly mirror the former colonial state's choice to open or to close their borders to Caribbean countries. This could possibly indicate a fear that border closure by the former colonial state (e.g., Britain) would lead to a 'spatial substitution' of migration to other destinations (e.g., the Netherlands, France or the US).

Figure 3.3. Evolution of travel visa restrictiveness of France, the Netherlands, Britain and the US combined towards nationals from Caribbean countries, by border regime of Caribbean countries, 1973-2013

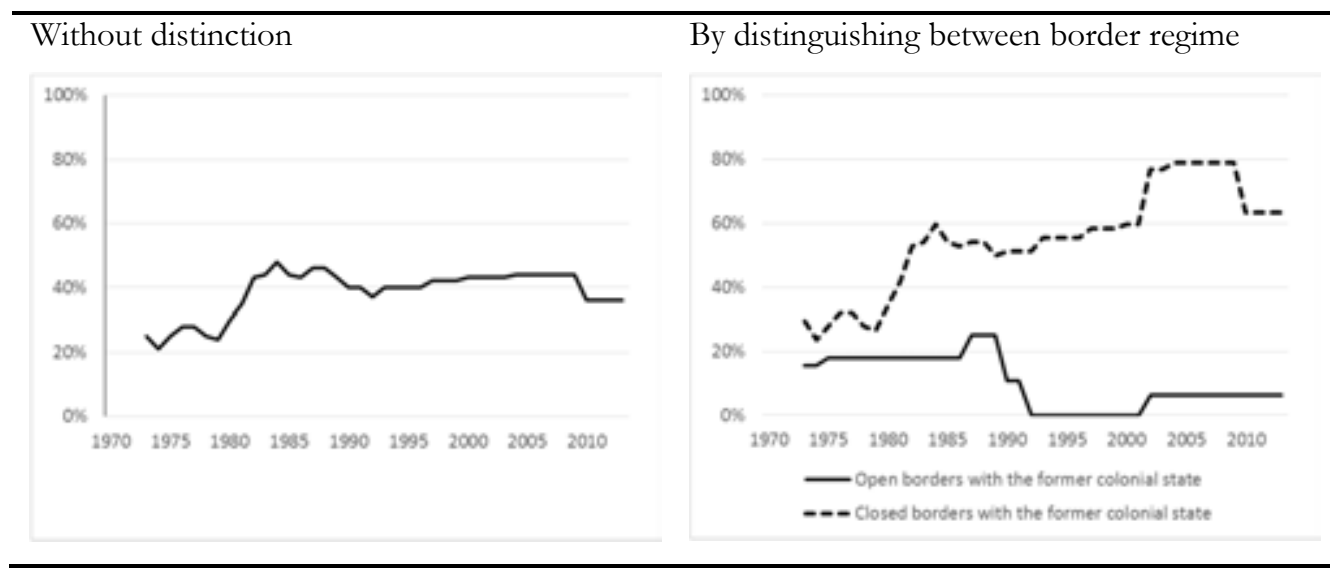

Source: DEMIG VISA ${ }^{33}$

When we disaggregate by each of the former colonial states (Figure 3.4), we find variation: France and the Netherlands introduced travel visa requirements for 60-70 percent of closed border Caribbean countries in the mid-1980 to 2000 period while requiring visas for all closed border countries between 2002 and 2010. On the other hand, they have almost universally exempted nationals from open border countries from visa requirements. Also the US has increasingly required travel visas for closed border countries, but visas were required also for 70 per cent of open border countries until 1990, when these requirements dropped. The US shows more ambiguity towards open border countries, over 20 percent of which require a travel visa to the US. This may be explained by the fact that either the US or its Caribbean territories are an important destination for all Caribbean countries.

${ }^{33}$ DEMIG (2015) DEMIG VISA, version 1.4, Full Edition. Oxford: International Migration Institute, University of Oxford. www.migrationdeterminants.eu. 
Figure 3.4. Evolution of visa restrictiveness of France, the Netherlands, Britain and the US towards nationals from Caribbean countries, in relation to border regime of Caribbean countries with their former colonial state, 1973-2013

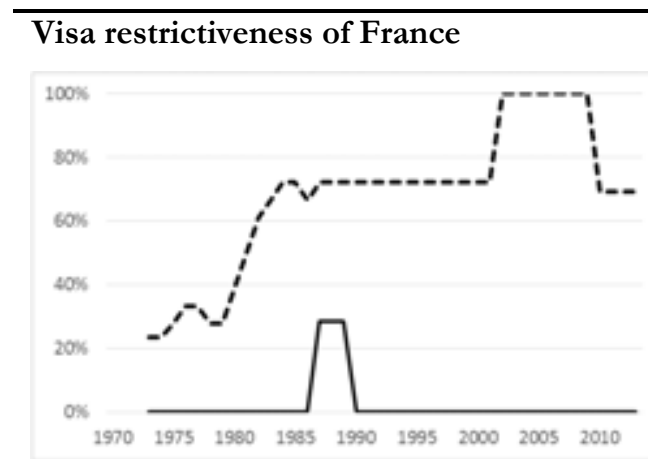

Visa restrictiveness of the US

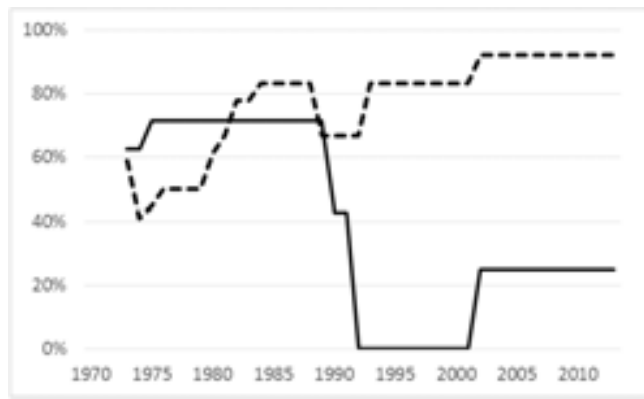

Visa restrictiveness of the Netherlands

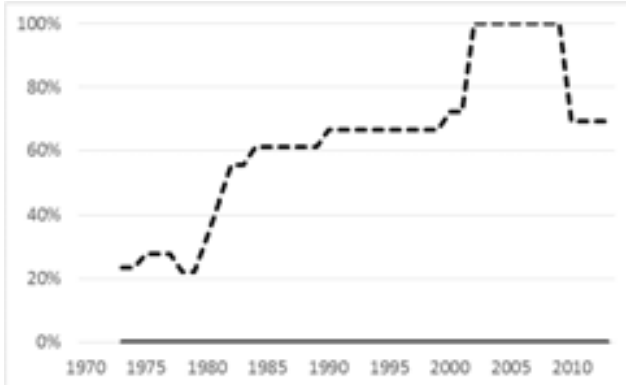

Visa restrictiveness of Britain

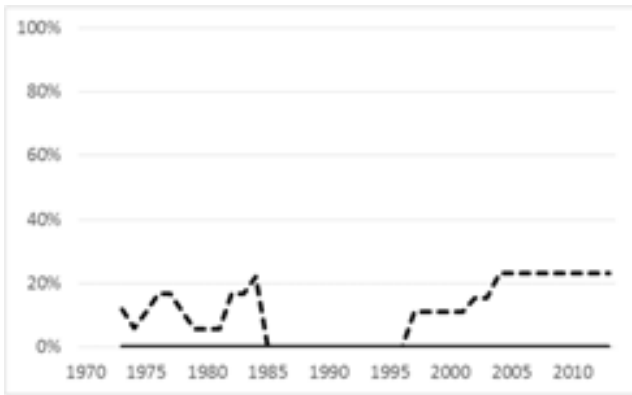

Legend:

Source: DEMIG VISA

Britain has historically required a travel visa for less than 25 percent of countries with closed borders, while never requiring travel visas for any of the open border countries. Considering the early immigration policy restrictions introduced by Britain already in the 1960s, it is somewhat surprising that the British government did not rely more strongly on travel visa requirements to regulate entry and possible overstaying. It appears that the British government used travel visa requirements in a targeted manner only for a few years around independence, which we see in the increases until 1984 (the last Caribbean country to obtain independence from Britain was St Kitts and Nevis in 1983) (Figure 3.4). This shows a clear awareness among British policy-makers of the sudden shortterm migration effects of independence through 'now or never migration' (intertemporal substitution) (de Haas 2011), when individuals may prefer to emigrate rather than facing the uncertainties brought about by independence, and 
represents an effort by the British government to try to prevent immigration exactly around these critical years.

When we considered travel visa requirements by France, the Netherlands, Britain and the US towards Caribbean countries by the border regime and the presence or absence of colonial ties, countries with colonial ties and closed borders experience high visa requirement, similarly to countries with no colonial ties (see Figure A3 in appendix B). In the case of Britain, this seem to support evidence that emerged from government documents which demonstrated that British politicians had greater concerns about immigration of Commonwealth citizens, given the assumption that they would be interested in long-term settlement, rather than that of other nationals not linked to Britain through colonialism. ${ }^{34}$ This seems to challenge the assumption that citizens of former colonies benefit from privileged migration policies of former colonial states.

(2) Evolution of travel visa requirements by Caribbean countries for Caribbean nationals

Figure 3.5 shows that visa requirements by Caribbean countries have been and continue to be higher for citizens of Caribbean countries which have closed borders regimes with their former colonial states and are lower for citizens of countries with open borders. However, the difference in travel visa requirements between these two groups of countries is small. This seems associated with two factors: (i) historically intra-regional migration has occurred from both sets of countries and Caribbean governments may react rather uniformly, introducing restrictions for both open and closed border countries when immigration is perceived as too high and economic conditions are not favourable; (ii) some Caribbean governments have promoted emigration to reduce unemployment and political tensions (Segal 1975; Segal 1987; Chaney 1989), which may have encouraged some Caribbean countries to introduce travel visa requirements for other Caribbean countries (Segal 1975: 10) regardless of their border regime.

\footnotetext{
34 Immigration Bill: Memorandum by the Secretary of State for the Home Department, Cabinet, CP(70)126, 31 December 1970, The National Archives, Catalogue Reference: CAB/129/154
} 
Figure 3.5. Evolution of visa restrictiveness of Caribbean countries towards nationals from Caribbean countries, by border regime of Caribbean countries of origin, 1973-2013

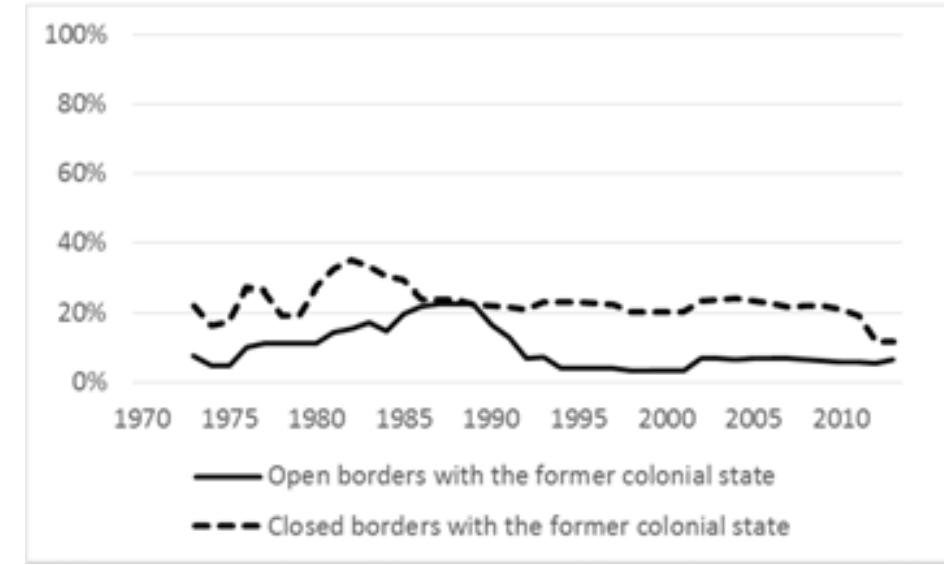

Source: DEMIG VISA

The generally low and decreasing visa requirements for independent countries may be associated with the Caribbean Community (CARICOM) and the creation of the CSME (CARICOM Single Market and Economy) in 1989 with its provisions of free movement of goods, services, capital, technology and skilled labour. Although this provision guarantees freedom to work and reside in any member state only to individuals possessing certain types of qualifications (e.g. university graduates, musicians, athletes, entertainers) (Pérez Caldentey and Schmid 2006), it has further reduced travel visa requirements among citizens of member states.

The evolution of travel visa requirements varies when Caribbean countries are disaggregated by colonial sphere (Figure 3.6), e.g. French dependencies or former Dutch colonies towards Caribbean nationals from closed and open border countries. (i) Unsurprisingly, the French dependencies implemented strong visa requirements for closed border countries and close to no visa requirements for citizens of open border countries, reflecting French national policies. (ii) Dutch sphere Caribbean countries had equal visa requirements for Caribbean countries with open and closed borders until the early 2000s, when citizens of open border countries saw an increase in visa restrictions. This reflects Suriname's introduction of visa requirements for a large number of countries worldwide in 2003. (iii) Countries in the US sphere have increasingly required travel visas for Caribbean countries with closed borders, while open border countries saw their visa requirements suddenly decrease in the 1990-2000 period, after which visa requirements have begun to increase again, although only to a limited extent. (iv) Countries in the British sphere have had relatively low travel visa requirements 
irrespective of border regime, strongly mirroring Britain's own travel visa requirements. British Caribbean countries were more restrictive towards nationals of closed border countries in the 1970s to mid-1980s, followed by a brief period between the mid-1980s to mid-1990s of higher travel visa requirements for open border countries, but they have since treated nationals from the two groups equally.

Figure 3.6. Evolution of visa restrictiveness of Caribbean countries towards nationals from Caribbean countries, by former colonial state and border regime of Caribbean countries of origin with their former colonial state, 1973-2013
a) Evolution of visa restrictiveness of
b) Evolution of visa restrictiveness of countries from the French sphere countries from the Dutch sphere

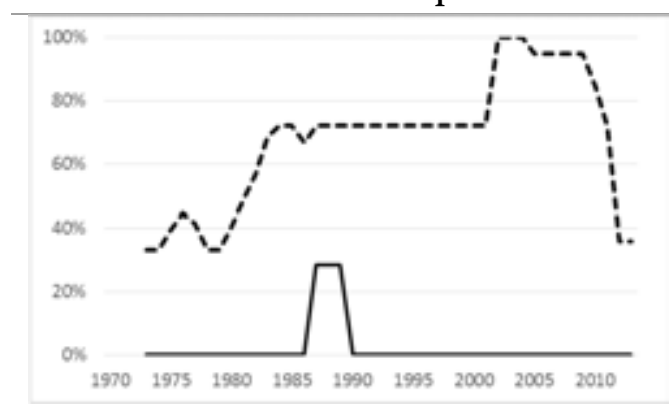

c) Evolution of visa restrictiveness of countries from the US sphere
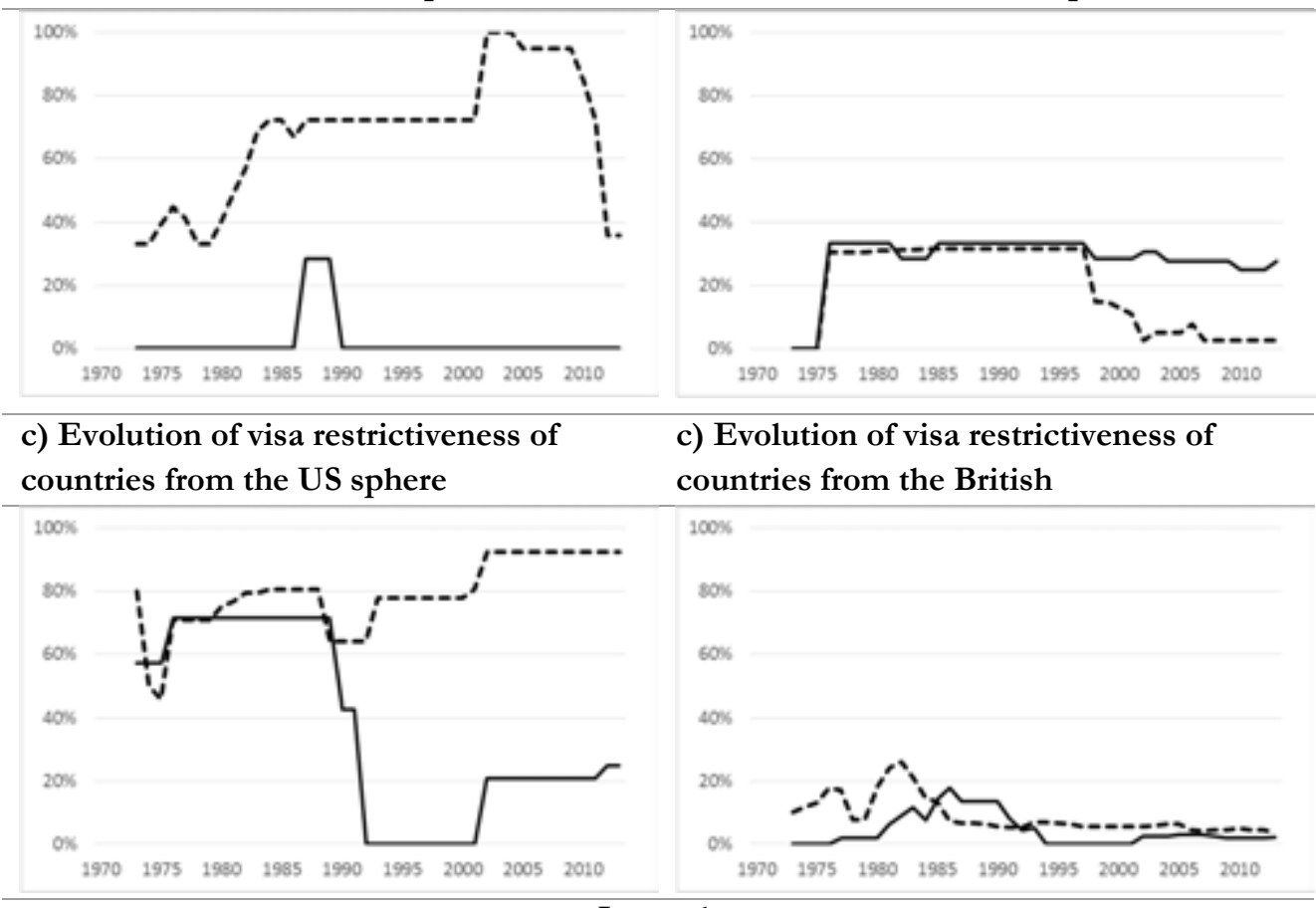

Legend:

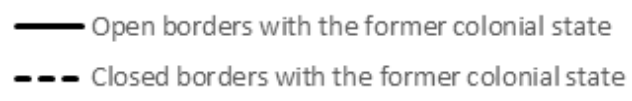

Source: DEMIG VISA

Caribbean countries with open borders with their former colonial state show greater visa requirements for closed border Caribbean countries, displaying a similar pattern as Figure 3.5, although about 40 percent of closed border countries require a visa, with a dip to 20 percent in the 2010s, while open border countries have almost no visa requirements since the early 1990s (see Figure A4 in appendix B). By contrast, closed border Caribbean countries have similar travel visa 
requirements for open and closed border countries, similarly to the trend of British sphere countries in Figure 3.6 (see Figure A4 in appendix B).

This analysis suggests that travel visa requirements largely overlap and reinforce border regime types. Thus, countries with a closed border regime with the former colonial state also experience the closure of other countries overseas and in the region as the introduction of travel visa regimes 'spreads' to other potential migration destinations. On the other hand, countries that have retained an open border with the former colonial state continue to benefit from a less restrictive visa regime even for countries outside of their colonial sphere. These findings broaden and strengthen the categories of closed and open borders beyond the bilateral border regime between Caribbean countries and their former colonial states. As such, these border categories allow us to test common assumptions that closed borders lead to lower emigration, and to examine whether the introduction of migration restrictions by specific former colonial states and countries in specific colonial spheres leads to any spatial substitution.

\section{Scope, data and methodology}

After having examined and confirmed the validity of the open and closed borders categories among these Caribbean countries, we proceed to analyse the evolution of overall, extra-regional and intra-regional emigrations from 1960 to 2000. The objective is to understand whether shifts in emigration intensity and destination may have occurred and how these may be related to the evolution of border regimes with the former colonial state as well as the nature of post-colonial ties.

To accomplish this analysis, migrant stock data were taken from the Global Bilateral Migration Database (GBMD) released by the World Bank. This database contains bilateral migration population ('stock') data for 226 countries, major territories and dependencies for each decade from 1960 to 2000 and is based on estimations from census data and population register records (when census data were not available) (Özden, Parsons et al. 2011). While the release of this database has greatly increased the potential to assess long-term migration trends, it has some limitations. For instance, immigration is likely to be underestimated for countries defining migration on the basis of 'citizenship' rather than 'birth' because of naturalisation. Moreover, if data was missing the values have been fully estimated and, as in most official migration datasets, irregular migrants are generally not taken into account. Because the 1970 data was inconsistent, we decided to use only 20 year intervals (ie, 1960, 1980 and 2000).

Other limitations affected particularly British data and former British colonies, whose values seem well below expected values, as well as data for the 
French DOMs, which are low and erratic compared to data reported in French statistics. Data for Surinamese in the Netherlands are also much lower than those reported by the Dutch statistical office. Despite these limitations, this database allows us to account for the presence of Caribbean migrants worldwide by origin and destination countries in a 40-year period, during which important changes in border regimes, political status and immigration policies occurred. The low quality of the 2010 migration stock data estimated more recently by the World Bank prevented us from utilising it, although it would have greatly improved our analytical purpose, as it would have allowed the analysis of the effect of the reopening of borders for emigration by Britain towards its non-sovereign countries (the 'opening' of the borders, Trajectory C in Figure 3.2. The United Nations database on international migrant stocks (United Nations 2013) was considered because of the availability of data for 1990, 2000, 2010 (and 2013); however, its total absence of data for residents of the French Overseas Departments (DOMs) and of some other non-sovereign countries made it unusable for this analysis.

Migrant stock data were utilised in conjunction with UN population estimates to calculate emigration intensities, namely the percentage of migrants of all individuals born in a specific country or group of countries. So for example, in 2000 the overall emigration intensity of countries which have had an open border over time with their former colonial state was 33 percent, that is to say 33 percent of all individuals born in these countries resided abroad.

\section{Results}

\subsection{Total migrations from Caribbean countries}

The Caribbean region displays high intensity of emigration, which was already visible in 1960 and has increased in all the countries over time, regardless of the border regime. Figure 3.7 shows how emigration intensity has grown in both those countries that have had constantly open borders (21\% of their population lived abroad in 1960, and 33\% in 2000) as well as those that have gone from open to closed borders (11\% of their population lived abroad in 1960, and $27 \%$ in 2000 ). However, countries that have had open borders with their former colonial state and within the colonial sphere experienced stronger growth in emigration intensity between 1960 and 1980, when it grew by 7 per cent, but emigration has since been decelerating. The countries whose borders have closed experienced weaker growth between 1960 and 1980 and a much more rapid growth in the following period, when emigration intensity grew by 12 percent. This delayed increase may be related to the establishment of border regimes which constrained emigration, but possibly also to the positive appeal of independence which took place in this 
period and may have encouraged people to stay and take part in the development of a new independent country (see chapter 4).

The growth of emigration between 1980 and 2000 has been associated with weak economic growth in many Caribbean countries (McElroy and Albuquerque 1988; McElroy 2011). However, it can be suggested that time is necessary for 'migration substitution' effects (de Haas 2011) to take hold. Rather than limiting migration, closing the borders of a country engenders migration to other destinations (i.e. spatial substitution) or through new channels, e.g. illegally or via family reunification (i.e. categorical substitution). However, time is necessary for migrants to identify new possible destinations and/or for new migration channels and for new networks to emerge. These trends challenge common assumptions that closing the borders limits emigration, as closed borders seem in fact to slow emigration only in the short term. ${ }^{35}$

\section{Figure 3.7. Evolution of total emigration intensities by border regime (\% of migrants among the population born in the countries), 1960-2000}

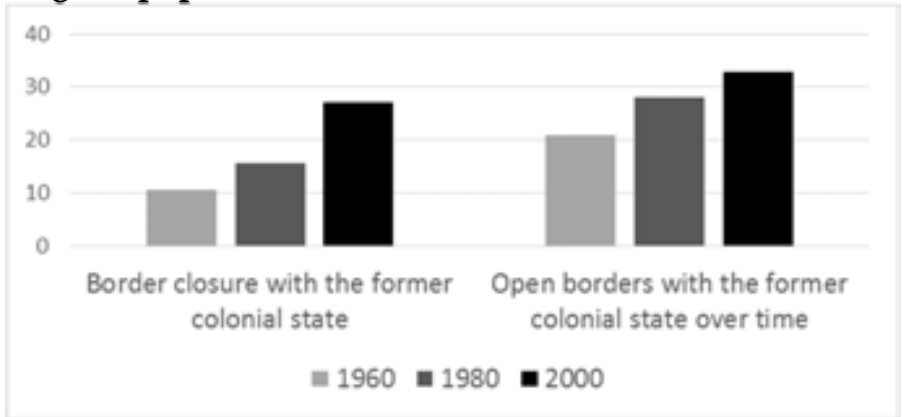

Source: Global Bilateral Migration Database, World Bank

Figure 3.7 also suggests that migrants from countries that experienced border closure may be pushed into settlement abroad. Stringent entry regulations in destination countries may indeed prevent re-entry, leading to the increase in settlement abroad (i.e. reverse substitution effects) (de Haas 2011), thus increasing the size of migrant stocks. Conversely, the absence of constraints to migration for people in countries with continuous open borders enabled higher levels of circulation and lower settlement patterns, represented by the decreasing levels of permanent settlement abroad. Nevertheless, Figure 3.7 shows high emigration intensity for open border countries as early as 1960, primarily due to the high emigration of US dependencies to the US, which alone accounted for over 17 per

\footnotetext{
${ }^{35}$ Being based on migration stock at 20-year intervals, this analysis can only generate observations of long-term trends. Therefore, we cannot observe the short-term effects of independence and border regime establishment hypothesised in the scenarios in chapter 2.
} 
cent of emigration intensity in 1960. The important contribution of US dependencies to this trend has continued over time, although French dependencies and to a lesser extent the Dutch dependencies have also shown some growth in overall emigration intensity.

\subsection{Extra-regional migrations and the relevance of the former colonial state}

The disaggregation of emigration by intra-regional and extra-regional destinations (Figure A5 in appendix B) shows the dominance of extra-regional emigration, which almost exactly replicates the patterns seen in Figure 3.7. This is well reported in the literature, which refers to an important shift in Caribbean migration patterns from intra-regional to extra-regional destinations after the 1940s (ThomasHope 1978).

When extra-regional emigration intensities are disaggregated to observe migration intensities in the respective former colonial state or the metropolitan state, e.g. Jamaicans towards Britain and Puerto Ricans and US Virgin Islanders towards the US, we observe (Figure 3.8) that migration to the metropolitan state is largely significant for US dependencies and it has grown in importance for the French and Dutch sphere countries towards their metropolitan state, which confirm that open borders contribute to the strengthening of migrant networks in the metropolitan state.

Figure 3.8. Emigration intensities in the former colonial states by border regime and former colonial state $(\%$ of migrants in their former colonial states among the population born in the countries), 1960-2000

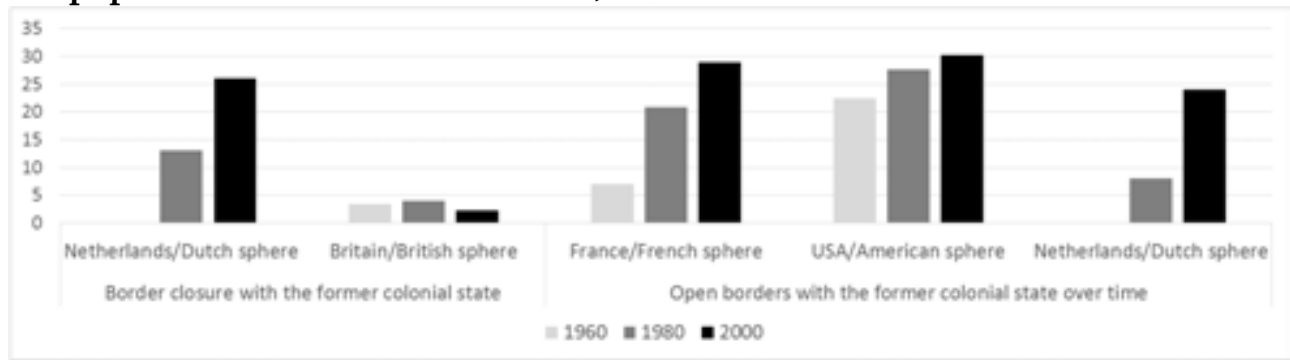

Source: Global Bilateral Migration Database, World Bank

The countries that have experienced border closure provide diverging examples of post-colonial effects on migration towards the former colonial states. Suriname, in the Netherlands' border closure group, shows strong post-colonial ties despite border closure. This is the result of the particular circumstances leading to independence and the closure of border regime, which encouraged the formation of large Surinamese communities in the Netherlands before border 
closure. These facilitated migration via family reunification and formation processes after Dutch policies became increasingly restrictive and stunted the growth of alternative migration destinations (see chapter 5). Conversely, we observe the rapid weakening of post-colonial effects on emigration from former British colonies towards Britain. Although emigration from British Caribbean countries to extra-regional destinations has grown from just over 7 percent in 1960 to almost 22 percent in 2000, it has not been directed to Britain, where the migrant communities have actually shrunk. This offers strong support for claims made in the literature which point to four concurrent patterns: i) reduction of immigration due to British immigration policies (Peach 1968; Marshall 1987; Peach 1995); ii) attraction of North America, where family reunification and skills allowed immigration and the formation of large communities, and where economic prospects were more positive (Palmer 1974; Maingot 1983); iii) the attractiveness of North America leading to step-wise migration of Caribbean people from Britain to North America; iv) post-retirement return, a trend known to be higher for Caribbean returnees from Britain than North America (Thomas-Hope 2000). A notable exception to this pattern is Montserrat, which saw a great expansion of emigration to Britain in the mid-to late 1990s following natural calamities.

As expected, when we consider emigration intensities from all colonial spheres towards North America (Figure 3.9), former British colonies, all of which have experienced border closure with Britain, display the strongest growth in migration. Among open border countries, only US dependencies show high emigration intensity to North America, while French and Dutch dependencies and Suriname have low emigration to North America. Although the hegemonic presence of the US in the Western Hemisphere is often seen as a strong migration determinant, this does not seem to have affected migration destinations except for its own dependencies and the Anglophone Caribbean. The high degree of spatial substitution of emigration of the former British Caribbean countries to North America seems tied to the shared English language. Also it is well documented that the countries in the British sphere have been historically highly migratory (Thomas-Hope 1978), which may have resulted in high levels of aspiration to find alternative destinations once borders were introduced by Britain. Contrarily, the French and Dutch were historically less migratory to start with and as migration developed, it did so within the colonial sphere where freedom of movement and settlement were guaranteed. 
Figure 3.9. Emigration intensities in North America by border regime and former colonial state $(\%$ of migrants in North America among the population born in the countries), $1960-2000$

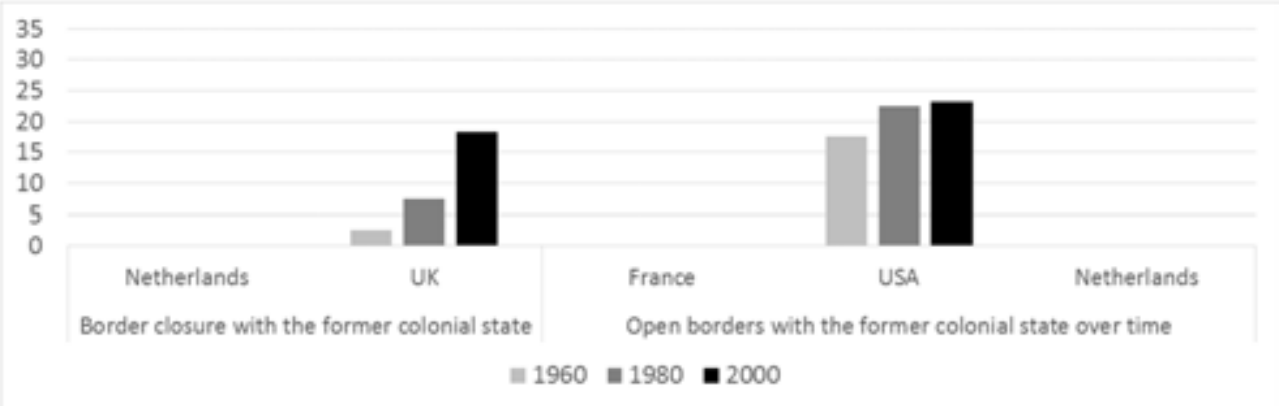

Source: Global Bilateral Migration Database, World Bank

Yet there are clear exceptions to these general patterns. For instance, emigration from the Netherlands Antilles was originally more oriented towards North America than to Europe (Oostindie 2009) and data show that these connections to North America remain stronger than for Suriname. This may be associated with the fact that English is commonly spoken in the Netherlands Antilles. However, growing interest in the US as a migration destination is emerging in Suriname, while French Guianese are increasingly interested in Canada, although in both cases the high costs of studying in these countries, particularly in comparison to lower cost or free education in the Netherlands and France, respectively, make the pursuit of these new educational destinations in North America exclusive to the elite (chapters 5 and 6). In the next decade, a growing expansion of 'worldviews' away from the Netherlands and France, may possibly lead to a greater diversification of non-Anglophone Caribbean emigration towards North America.

\subsection{Intra-regional migrations and the relevance of the colonial sphere within the region}

Intra-regional migration has remained steadily low (Thomas-Hope 2000), although it is probably higher than the 1 to 3 per cent shown in the results for 2000 (see Figure A5 in appendix B) when we consider the many forms of movement that occur among Caribbean island nations (Carnegie 1987), including 'replacement migration' of seasonal agricultural labour, particularly in the sugar sector in islands like Barbados, the Dominican Republic, Guadeloupe and Martinique (Segal 1987) and across the Guianas (chapters 4-6) which remain unaccounted for. Therefore, it is interesting to study the intensities and direction of intra-regional emigrations and assess whether border closure with the former colonial states impacted emigration within the region. 
We find strong evidence of spatial substitution associated with border closure. Caribbean countries whose borders with the former colonial state and with other countries within the same colonial sphere have been closed, display growing emigration towards countries in other colonial spheres. Contrarily, open border countries do not display any shift in destinations since 1960. With regards to the relevance of post-colonial ties, the data suggest that the closing of the borders by the former colonial state may weaken historical migration connections, while continuous open borders encourage migrants to continue relying on cultural and linguistic connections found in countries in the same colonial sphere. However, Suriname is an exception given its strong migration towards the Netherlands. In addition to language, this may be explained by the fact that independence was intensely contested and, concurrently, borders were fully closed only five years after independence (see chapter 5).

The data also suggest that French and US dependencies are strongly oriented towards other destinations within their own colonial sphere (Figure 3.11). For instance, French Caribbean people migrate to other DOMs while Puerto Ricans migrate primarily to the US Virgin Islands and vice versa. Interestingly, for US dependency citizens, British-sphere destinations are gaining some relevance, although at an irregular pace, suggesting the facilitating role of language as well as the growing attractiveness of specific British territories.

Figure 3.10. Evolution of destinations within the Caribbean region, by border regime of Caribbean countries of origin with their former colonial state and by colonial sphere (same or different), 1960-2000

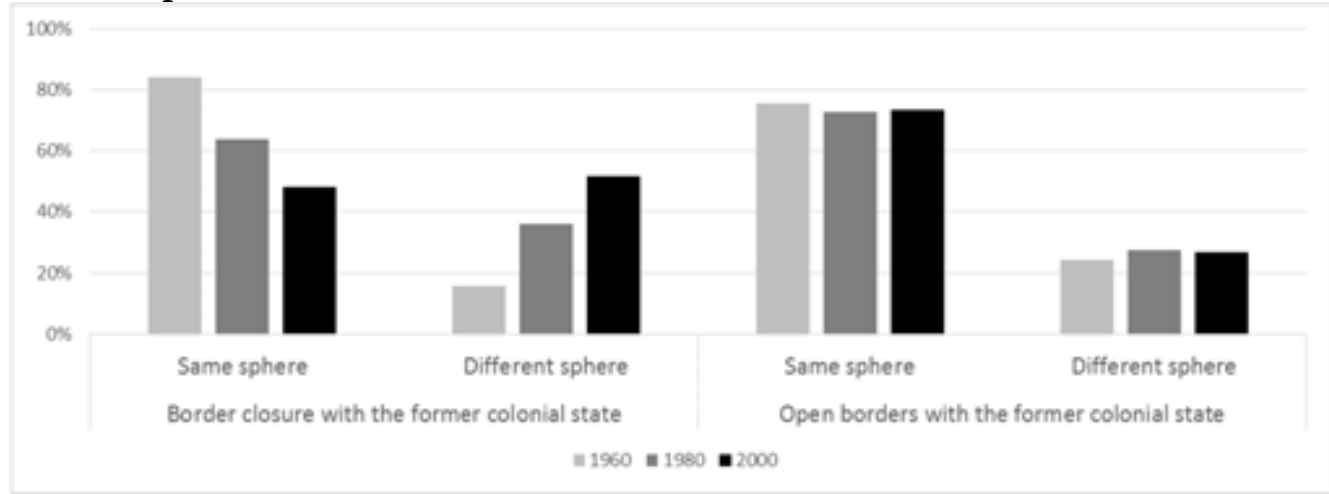

Source: Global Bilateral Migration Database, World Bank

Both British and Dutch sphere countries with border closure show a similar pattern as in Figure 3.10. For countries in the British sphere this follows the same trend of spatial substitution we see in extra-regional emigration. Conversely, for Suriname, this spatial substitution trend diverges from the continuous concentration of migration in the Netherlands. This is largely due to the strong 
emigration of Surinamese to French Guiana during the Interior War from 19861992 and the rapid growth of a Surinamese settled community along the Maroni River on the Suriname-French Guiana border (Piantoni 2009; Léobal 2013). Moreover, Guyana, Suriname's westerly neighbour, absorbed 15 percent of Suriname's intra-regional migration in 2000 (see Table A1 in appendix B).

The only group of countries not conforming to the observed pattern are countries with open borders in the Dutch sphere, i.e. Aruba and the Netherlands Antilles (Figure 3.11). However, a close examination of the data suggests that this pattern reflects some data inaccuracies, particularly the undercount of population exchanges among the Dutch dependencies in 1960 and 1980, often driven by the growth and later decline of the oil industry. Nevertheless, these countries have also been associated with important historical migrations with other colonial spheres in the region, such as between the Netherlands Antilles and Saint Kitts and Nevis. Overall, the open border countries within the Dutch sphere suggest that freedom of movement tends to reinforce migration within the same colonial sphere.

The French sphere countries have the least spatial substitution, which seems to be linked to high standards of living in the French Overseas Departments, while the highest level of spatial substitution is found among the Dutch sphere countries, with growing emigration towards the French dependencies. An interesting finding is that while the US was not an important destination in extraregional emigration from French and Dutch sphere countries, intra-regionally US dependencies clearly exert strong attraction. In fact, in 2000 all countries in the region had an important share of their intra-regional emigration directed towards Puerto Rico and/or the US Virgin Islands (see Table A1 in appendix B).

From this analysis, a number of factors emerge as important in determining patterns of intra-regional migration. First, the colonial sphere continues to be highly relevant for all countries within the region and particularly for countries that maintain open border regimes with former colonial states. Second, border closure is associated with a substitution of migration destinations and weakening post-colonial migration ties. Third, besides colonial ties and border regimes, geographical proximity and economic growth influence intra-regional migration. 
Figure 3.11. Evolution of intra-regional destinations of Caribbean countries, by border regime of Caribbean countries of origin with their former colonial state and by type of sphere and by colonial sphere of destination (same or different), 1960-2000

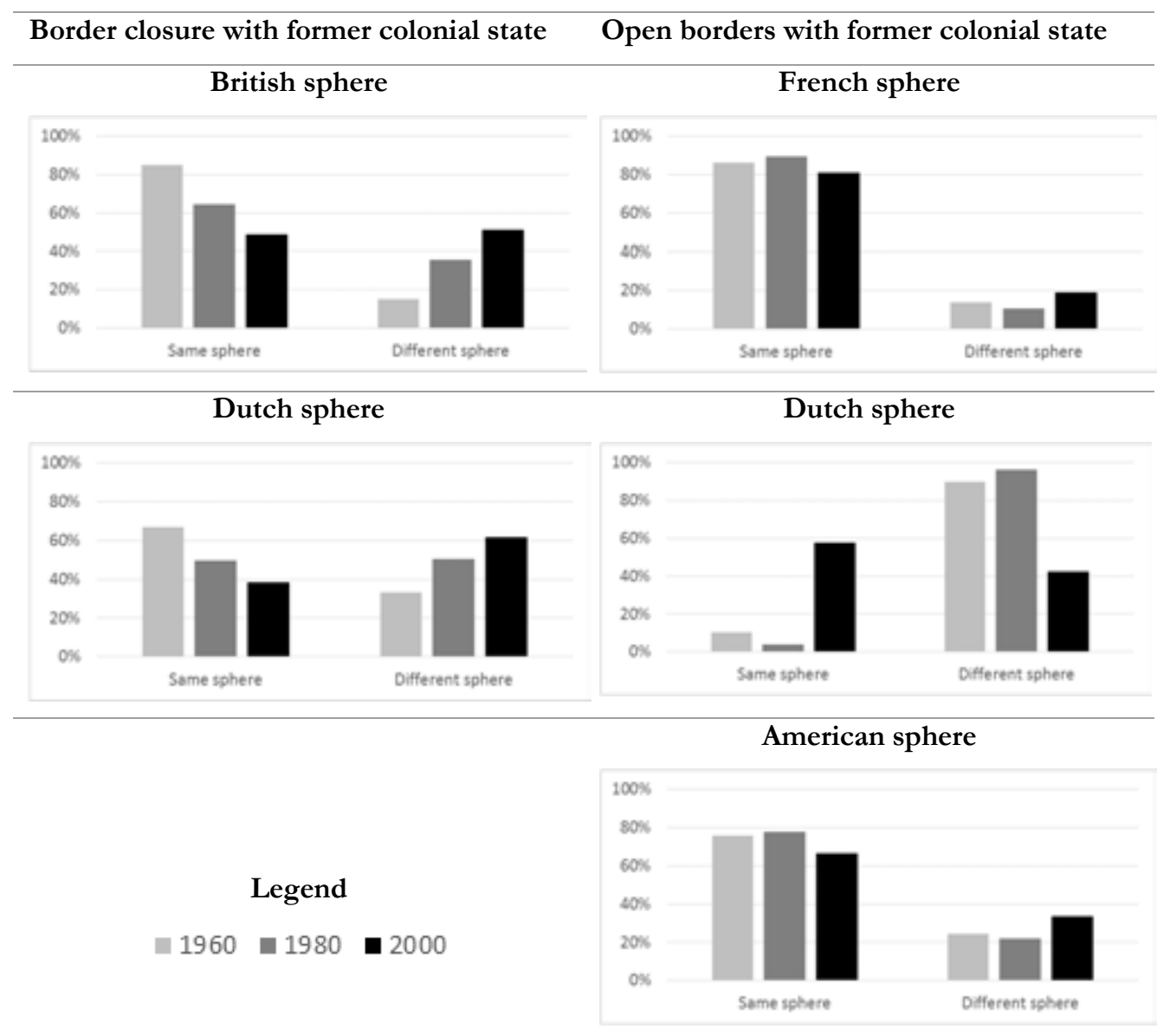

Source: Global Bilateral Migration Database, World Bank

\section{Conclusions}

During colonialism, colonial 'subjects' largely benefited from rights to free movement and settlement in the metropolitan state and in other colonies. After the Second World War, as the decolonisation movement gained strength, colonial powers gradually introduced measures to prevent settlement in the metropolitan state. Britain, in particular, fearing the mass arrival of Commonwealth citizens, adopted a pre-emptive immigration policy by introducing immigration restrictions before many of its Caribbean colonies became independent. Concurrently, former 
colonial states used travel visa restrictions as a tool to prevent entry not only for their own former colonial nationals but also for nationals from other Caribbean countries. Our analysis shows that when the former colonial state closed its borders, other former colonial states also tended to introduce travel visa restriction for the same origin country.

Yet this conceals considerable variation across former colonial states. While France and the Netherlands require visas for most countries having closed borders with the former colonial state, Britain has retained a very low level of travel visa requirements for Caribbean nationals, regardless of border regime type, despite the early restrictions to settlement placed on its own former colonial nationals. Different from the general visa restrictions by France and the Netherlands, Britain has made a more occasional, targeted and temporary use of travel visa requirements for its own former colonies, particularly around the time of independence. This suggests that the British government anticipated that these nationals would engage in 'now or never' migration if borders were open around independence. Regarding the visa requirements introduced by Caribbean countries, these generally reflect the policies implemented by their respective former colonial states. In sum, entry restrictions have increased both extra- and intra-regionally for countries with closed borders, while countries with open borders with their metropolitan state continue to benefit from lower travel visa restrictions.

The analysis showed that, paradoxically, emigration intensity in closed border countries is not only high, but has grown exponentially despite the closure of borders by the former colonial state and other extra-regional destinations through the introduction of travel visa restrictions. Border closure enacted by former colonial states has also encouraged migration from former colonial states towards alternative extra-regional and Caribbean destinations. Countries that have retained open borders and have thus not gone through the 'shock' of border closure, have not experienced a similar acceleration of emigration and have rather seen decelerating emigration. Moreover, when borders remain open, there is generally no diversification of destinations either extra-regionally or intraCaribbean.

Nevertheless, the results suggest that the border closure has been effective from a British perspective. However, state restrictions have not stopped migration, but rather deflected it to other destinations. In fact, the reasons for this deflection are not limited to the border regime, as other contextual conditions have been important. As Britain closed its borders, new labour and family migration opportunities opened in Canada (1962) and the US (1965). These permitted entry and settlement for several categories of migrants and marked the beginning of 
long-term patterns of family reunification from the Caribbean to the US. In addition, Britain was experiencing an economic downturn, while economic growth in the US offered better opportunities. Conversely, from a Dutch perspective, the closure of the border with Suriname was not effective given the high concentration of Surinamese in the Netherlands. In addition to the importance of language and cultural proximities, this reflects the sequencing of independence and the establishment of the border regime, which led to formation of large migrant networks before the borders were closed (see chapter 5 ).

The results also show that open borders are not associated with high emigration. This may be explained by the fact that when borders remain open there is no urgency for people to migrate in response to migration policy changes. However, this may also be related to the fact that several of these non-sovereign countries show either economic growth or the strong presence of the state, which may ensure high levels of living conditions and opportunities across the dependencies (see chapter 7).

Through the proposed innovative approach which categorised Caribbean countries by closed and open border regimes, this chapter has included a unique analysis of travel visa requirements and examined the association between types of border regimes with changes in extra- and intra-regional Caribbean migrations. While the analyses help us to confirm previous findings that migration policies do not decrease migration, but rather lead to diversification to alternative destinations, they do not allow us to fully explain how closed border regimes affect migration patterns in the short and long term. Moreover, it is unclear what may be the dynamics that influence migration, or lower emigration propensities, in open border countries. Furthermore, these findings suggest that post-colonial ties are not a strong predictor of continuous migration to the former colonial state when borders have been closed. However, we know that this does not apply for Suriname, which has closed borders and a high concentration of its migrant population in the Netherlands. To understand these specific trends, this study continues by presenting the three in-depth case studies of Guyana, Suriname and French Guiana. 



\section{Chapter 4 -Closing borders to citizens: the role of states and policies in the evolution of Guyanese emigration $^{36}$}

\section{Introduction}

Throughout its history Guyana, the only English-speaking country in South America, has had a small population, reaching just over 780,000 inhabitants in 2010. Its emigrant population however increased from about 6 percent of the total population in 1960, lower than many Caribbean countries, to an estimated 56 percent in 2010, one of the highest percentages of emigrant population in the world. ${ }^{37}$ Guyana's emigration began to increase in the early 1960s with great acceleration from the mid-1970s, a period that included both the establishment of a border regime between Britain and then British Guiana in 1962 and independence in 1966. Literature on historical Guyanese migration is limited (Roopnarine 2013; Kirton and Lewis 2015), with some research focusing on the large Guyanese communities abroad and their remittance and development potential (Orozco 2003). Britain's establishment of the border regime and the transition to independence have never been used as an angle to examine the evolution of Guyanese migration. This chapter examines specifically the sequence of border closure and independence and its effects on the shifts in the volume, timing, composition and direction of Guyanese emigration. The chapter also considers the wider role of the Guyanese state and main destination states in shaping emigration patterns over the years though a broad range of state actions and policies, including migration policies.

\footnotetext{
36 This chapter is based on the author's working paper, 'The Effects of Independence, State Formation and Migration Policies in Guyanese Migration.' In IMI Working Paper Series 94/DEMIG Project Papers 20: International Migration Institute, University of Oxford, 2014.

37 Source: World Bank Global Bilateral Migration Database, http: //data.worldbank.org/datacatalog/global-bilateral-migration-database; 2010 Estimates, http://econ.worldbank.org/WBSITE/EXTERNAL/EXTDEC/EXTDECPROSPECTS/0 „, contentMDK: 22803131 pagePK: 64165401 piPK: 64165026 theSitePK: 476883,00.html, accessed on August 25, 2013.
} 
To examine the evolution of Guyanese migration patterns from the early 1950s to the early 2010s (see Figure A1 in appendix C for complete emigration trend and major historical events over this period) this study uses two guiding questions: (i) what have been the short- and long-term migration effects of the establishment of a border regime and independence? And (ii) what has been the importance of post-colonial ties for migration and how did they affect emigration? This analysis relies on the conceptual framework developed in chapter 2, which theorised about the potential effects of the transition to independence and the establishment of a border regime which regulated settlement in the former colonial state. We test specifically the validity of the asynchronous scenario in which the early establishment of a border regime is followed by independence. The chapter examines the potential inter-temporal migration substitution, spatial diversion of migration to alternative destinations and variations in migration composition as a result of changing migration policies (de Haas 2011). Beyond the effect of border regimes and independence, this study explores the political, social and economic transformations that significantly affected living and working conditions in independent Guyana and analyses how these processes of transformation have affected the volume, timing, direction and composition of emigration from Guyana.

This chapter relies on scholarly articles, books and reports on the political and economic developments and migration from and to Guyana; historical documents issued by colonial and Guyanese governments reporting migration data and policy discussions; articles from 13 Guyanese newspapers between 1962 and 2013; and a limited number of historical articles from British newspapers. These sources were complemented with data from 32 interviews conducted in Guyana and Suriname between October 2013 and January 2014. The interviews explored individual migration trajectories, family migration, time and duration of migration, and return. Among the interviewees, 7 individuals were still abroad, 11 had returned to Guyana, and 13 never migrated from Guyana, although they may have travelled abroad. In addition, one in-depth interview was conducted with a government official who has held various positions in government since the 1970s and provided valuable insights into government debates on migration.

After a brief presentation of early Guyanese migrations, the chapter analyses migration patterns in parallel to broader processes of political, social and economic transformation across three broad historical phases that reflect important migration stages: 1953-1966; 1967-1985; and 1986-2013. For each of these phases, the chapter examines the actions of the state, its ideology, migration and nonmigration policies, to identify events or processes that have affected migration. Immigration policies of major destination countries are also part of this analysis. The chapter concludes by presenting insights on the migration effects of the border 
regime and independence, and briefly assesses the role of the state and major structural changes in shaping long-term emigration.

\section{British Guiana's historical migrations and ethnic diversity}

Within the British Empire, British Guiana was historically considered a colony of relatively low economic and strategic importance, with sugarcane and rice as the main economic activities (Standing 1977; Rabe 2005). British planters initially attempted to fill their labour demand on the plantations with local Amerindian populations, but these efforts were unsuccessful (Baksh 1978). From the mid-16 $6^{\text {th }}$ century, African slavery supplied the necessary labour; however, the abolition of slavery in 1834 reintroduced labour shortages. With Emancipation, planters attempted to retain former slaves through a system of apprenticeships, but low wages and poor working conditions sealed their fate (Baksh 1978).

Labour demands persisted and planters resorted to the recruitment of indentured labour from India, following the example of such recruitment in Mauritius, which resulted in 240,000 East Indians entering British Guiana in the period between 1838 and 1917, the year in which this system was abolished (Peach 1968). Indentured workers also came from the Madeira Islands and Hong Kong, but the 25,000 Portuguese and Chinese indentured workers quickly left the harsh conditions of the plantations and entered retail trade (Baksh 1978). At the end of their contract East Indian workers had the right to return to India; however, the majority remained on sugar plantations in the rural areas of British Guiana (Rabe 2005).

In the meantime, many former slaves had pooled their resources to buy abandoned sugar plantations and establish villages, where they could cultivate their own crops (Nicholson 1976; Baksh 1978). Plantation owners opposed this 'village movement', which they perceived as competition with the plantation system (Canterbury 2007), circumscribed their activities and ultimately contributed to the villages' unsustainability. Thereafter some villagers returned to work on plantations, while many others migrated to mining centres or to the city, where they gradually found occupations in low-level civil service positions, including teaching, law and medicine (Nicholson 1976; Rabe 2005). These internal migrations show clear similarities with emigration from other Caribbean islands, where postemancipation migration was not exclusively about earning better wages but significantly about escaping hierarchical structures in island societies (ThomasHope 1978). However, being a large colony, Guyanese migrants could migrate internally. British Guiana also received Caribbean immigrants looking for a fresh 
start on newly opened Guyanese sugar estates; they remained the only external labour source from 1917 to the late 1920s (Baksh 1978; Marshall 1987; Segal 1987; Chaney 1989).

These early labour migrations produced a diverse population, with East Indian and African populations comprising the two largest ethnic groups, plus smaller groups of Chinese, Portuguese, people of mixed descent and the autochthonous Amerindian populations (Premdas 1999). Colonial practices produced deep divisions between ethnic groups, rural-urban spaces and socioeconomic levels. Over the years, the African population became increasingly concentrated in skilled occupations in the civil service, the police and the mining sector, while the Indian population remained largely rural, with little access to education. Before 1961 all schools were administered by Christian denominations, which caused many Hindu and Muslim East Indians to turn away from education. The East Indian population suffered particularly from weak political representation, given their limited role outside of agriculture. However, rice farming proved to be a viable economic activity for this group, who were able to acquire small plots of land and develop a niche in rice farming and export, leading to the gradual improvement of socio-economic conditions in the East Indian communities (Rabe 2005).

\section{3 . The long road to independence and the closure of the British border (1953-1966)}

In the 1950s emigration from British Guiana was a minor phenomenon, but a rapidly increasing trend began in the early 1960s in correspondence with the introduction of the British Commonwealth Immigration Act in 1962 (Figure 4.1). In addition to a visible growth in emigration volume, emigration to new destinations gained greater importance and new motives for emigration gradually emerged from the 1950s into the 1960s, affecting the composition of emigration. The following sub-sections examine the political and socio-economic shifts taking place in this pivotal moment and their association with these shifts in migration. 
Figure 4.1. Emigration from Guyana by destination, 1953-196738

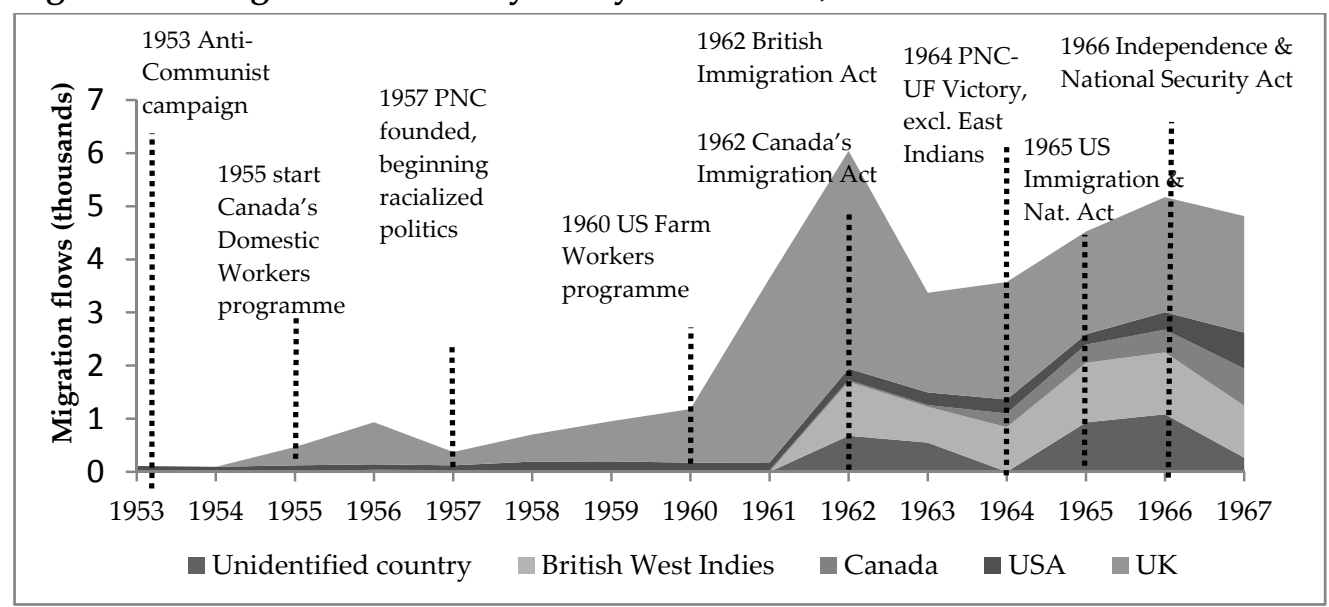

Sources: DEMIG TOTAL, DEMIG C2C, ${ }^{39}$ various annual labour reports ${ }^{40}$ and Peach 1968.

\subsection{Political transitions and the rush to beat the 1962 British Immigration Act}

In the early 1950s British Guiana's stable political and social conditions suggested a speedy passage to self-governance. However, the political and social conditions rapidly deteriorated with the first elections in April 1953, which resulted in the victory of the Marxist-influenced People's Progressive Party (PPP) led by Cheddi Jagan and Forbes Burnham. Under pretext of restoring order, the British

\footnotetext{
${ }^{38}$ Due to incomplete data, emigration figures may be underestimated: for instance, the peak in 1956 is not a real representation of an increase in emigration, but it is due to the fact that data were available in a more complete set in 1956. The same is true for data starting in 1962. This weakness in the data does not undermine the effects of border closure, as the trend is supported by Figure A1 in Annex which uses total outflows data.

${ }^{39}$ DEMIG (2015) DEMIG TOTAL, version 1.5. Oxford: International Migration Institute, University of Oxford; DEMIG (2015) DEMIG C2C, version 1.2, Full Edition. Oxford: International Migration Institute, University of Oxford. Both databases are available at http://www.imi.ox.ac.uk/data.

${ }^{40}$ British Guiana (1952), Annual Report of the Commissioner of Labour for the year 1950, Georgetown, Demerara, British Guiana; British Guiana, Annual Report of the Department of Labour about 1956 (approximate title and year, because report missed the title page); International Labour Office, Expanded Programme of Technical Assistance (1957) Report to the Government of British Guiana on Employment, Unemployment and Underemployment in the Colony in 1956, Geneva; British Guiana, Annual Report of the Labour Division of the Ministry of Labour and Social Security for the year 1964; Guyana (1967), Annual Report of the Department of Labour of the Ministry of Labour and Social Security, for the year 1965, Georgetown; and Guyana (1968), Annual Report of the Ministry of Labour and Social Security for the year 1967, Georgetown. All reports retrieved from the Walter Rodney Archives, Georgetown, Guyana.
} 
government revoked British Guiana's constitution in August 1953, removed the PPP from power and deployed British paratroops (cf. Hintzen and Premdas 1982), essentially bringing British Guiana into Cold War politics. Led by covert US operations, a pervasive campaign ensued against the PPP (Rabe 2005) and antiCommunist literature for youth and adult readers warned that British Guiana would be another Cuba. Nervousness and anxiety arose in the merchant class, generally middle- and upper-class Catholic Portuguese and Chinese Guyanese, who feared the possible loss of their assets and began to leave British Guiana.

In 1957 Forbes Burnham split from the PPP and founded the People's National Congress (PNC), which distanced itself from Communism and gained British and US support. However, this schism reproduced racial divisions sown during colonialism, leading to racialized politics as the Afro-Guyanese population began to follow the US-subsidized PNC and the Indo-Guyanese continued to support Cheddi Jagan's PPP. While in reality class divisions may have been as important as ethnic divisions, since the PNC was also supported by East Indian professionals, teachers and public servants (Jeffrey 1991), ethnicity became the prime determinant of party affiliation, a phenomenon which largely continues today. Between 1962 and 1964, ethnic violence broke out in Georgetown, British Guiana's capital, primarily perpetrated by Afro-Guyanese against Indo-Guyanese businesses and residents and by the end of 1964, 368 political and racial clashes, 200 deaths and 800 injuries had occurred in a country of about 600,000 people (Hintzen and Premdas 1982; Rabe 2005).

In the meantime, the arrival of large numbers of British 'subjects' from the colonies to Britain over the 1950s raised alarm in British society, especially in view of the vast pool of potential migrants, but also because of an economic slowdown, growing unemployment and housing shortages in Britain (Davison 1962; Freeman 1987). The British government appealed to Colonial governments to adopt measures to curtail migration to Britain: British Guiana's Executive Council discussed these appeals in 1961 and refused to enact any migration-reduction measures, citing that the size of the problem (migration) did not justify establishment of the machinery proposed' ${ }^{41}$ In fact, while migration from the British West Indies had reached important levels by the late 1950s, only a small number of British Guianese had migrated to Britain (Peach 1968; Marshall 1987). Nevertheless, in 1962 Britain introduced the Commonwealth Immigration Act, signalling the British government's first step towards an increasingly hostile

\footnotetext{
${ }^{41}$ Executive Council: Minutes and Papers, 18 November 1961, 311, retrieved from the Walter Rodney Archives, Georgetown, Guyana.
} 
approach vis-à-vis the movement of its colonial British 'subjects' (Byron and Condon 2008).

Reactions in British Guiana were strong and ranged between worries about Britain's treatment of its own citizens to appeals to keep migration channels open for those pursuing advanced education. In November 1961 British Guiana's Minister of Communications and Works assessed that the recent increase in emigration from British Guiana to the United Kingdom was due to the fear that legislation would be enacted in the United Kingdom prohibiting immigration; people wanted therefore to get in before such legislation was passed.' 42 According to official documents, the implementation of the Act in July 1962 resulted in a drop in emigration in 1963 'to about half that level and was almost restricted to next of kin, students and skilled workers'. ${ }^{43}$ This inter-temporal substitution effect was caused by an attempt to beat the immigration restrictions, with an immediate decline after policy implementation, as previously observed for British Caribbean migrations in general (Peach 1968; Marshall 1987). But while the closure of the British border may have propelled emigration, growing instabilities and ethnic threats in British Guiana may also partially explain the increasing volume of emigration. In addition, in 1962-63 British employers demanded less labour due to an economic slowdown, resulting in lower migrants' arrivals, the return of men and the arrival of women and children, marking a shift in migration composition (Peach 1968). The Act, in conjunction with lower employment opportunities in Britain, may have contributed to the diversification of migration destinations to the British West Indies and other unidentified destinations, suggesting possible spatial substitution effects. For instance, Portuguese-Guyanese families were reported to have resettled permanently in Canada, where there was a cultural affinity (being part of the British Commonwealth) and the opportunity to start a new life. As one interviewee eloquently stated, 'the longshot of it all was that it (the Act) somehow caused migrants to look for alternatives and they found them in the USA and Canada.' Figure 4.1 shows a gradual diversification in migration destinations starting in 1963.

\subsection{Independence and the rapid weakening of Britain's influence}

The 1964 election was won by a coalition between the PNC, led by Burnham, and the United Front, led by D'Aguiar. The coalition government largely excluded East Indians from senior positions in the new administration, while the largely AfroGuyanese police showed strong presence in East Indian communities, worsening

\footnotetext{
${ }^{42}$ Ibid.

${ }^{43}$ British Guiana, Annual Report of the Department of Labour for the year 1963, page 41, retrieved from the Walter Rodney Archives, Georgetown, Guyana.
} 
the country's racial tensions (Hintzen and Premdas 1982; Rabe 2005). Amidst concerns of ethnic violence, Britain felt pressure to proceed with independence because of its limited financial resources to administer the empire and a growing anti-colonial movement (Rabe 2005). Thus, British Guiana's independence talks resumed and independence was set for May 1966. Recollections of independence by the interviewees, regardless of ethnic group, were overwhelmingly positive: independence was widely welcomed by the population, who had demanded it.

Figure 4.2. Guyana-born individuals residing abroad, by country of residence and Guyana's population size, $1960-2000$

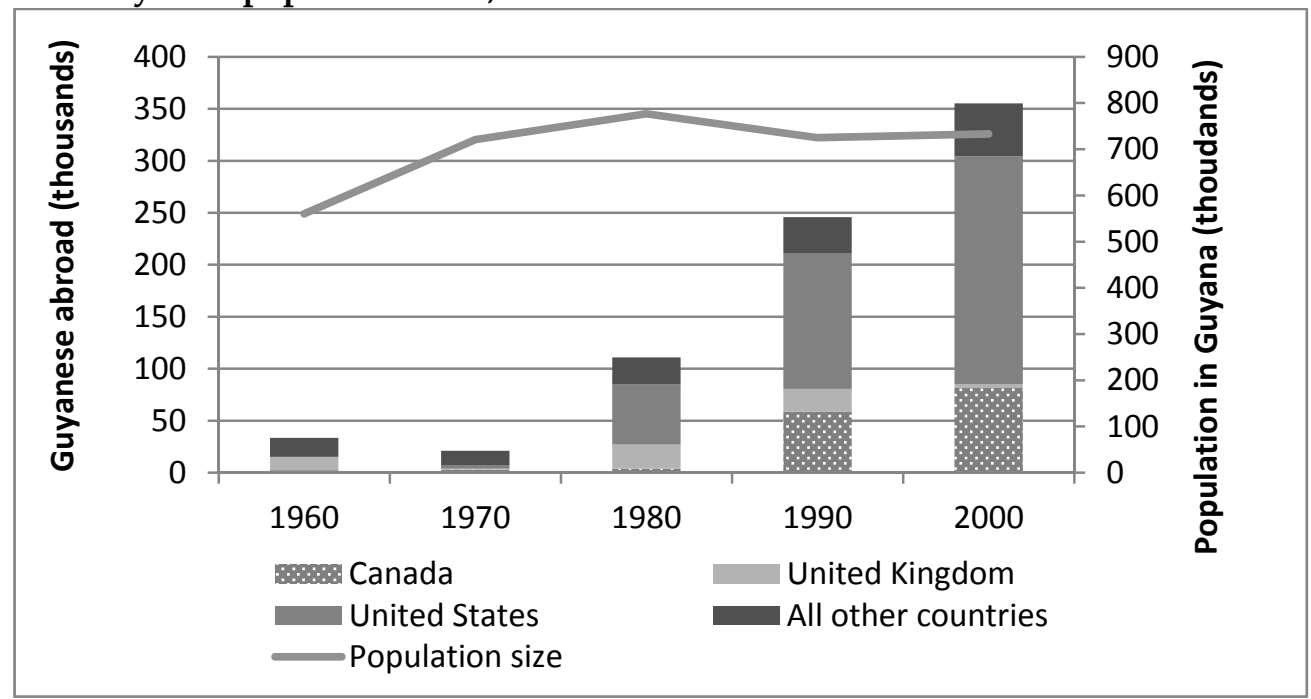

Source: World Bank Global Bilateral Migration Database and UN Population Estimates

Yet, emigration increased in 1965-66, suggesting a second inter-temporal substitution effect as segments of the population sought to leave the colony before it gained independence, possibly reflecting the disappointment of PPP supporters and uneasiness with ethnic-based discriminatory practices in the coalition government. However, while emigration in 1962 affected 1 percent of the population, in 1966 it was slightly lower at less than 0.8 percent of the population, pointing to a slightly stronger impact of border closure than independence. Migration stock data confirms a drop in the size of the Guyanese community abroad in 1970, a decrease particularly visible for the population in Britain (Figure 4.2). This may have also been associated with the 1967 Remigration (return/immigration) Policy which saw the return of national and non-national professionals placed in engineering, education, medicine, management, research and the social services by 1970 (Strachan 1980; Strachan 1983). Although few returned through this scheme, those who did were largely returning from Britain, 61 percent of total returns (Strachan 1983). While migration flows to Britain 
scarcely changed in the 1963-1968 period, emigration towards the British West Indies and other destinations, including Canada and the United States, continued to grow (Figure 4.1), suggesting sustained spatial substitution at least partially due to the increased difficulty in migrating to Britain. Nevertheless, although independence stimulated emigration, in no way did it fuel an exodus.

\subsection{The opening of North American migration policies and the diversification of migration destinations}

The geographical shift away from Britain was undoubtedly linked to Britain's establishment of a border regime with its colonies. Similarly, the gradual increase in migration to North American countries was associated with these countries' opening of new immigration channels: The US initiated small recruitment programmes, including from British Guiana in 1960, when '...the Minister of Labour, Health and Housing [...] received a letter from the B.W.I. Central Labour Organisation in Washington asking for a plane load of farm labourers for employment on United States farms.' 44 While this programme involved low numbers of temporary workers and absconding rates were low, ${ }^{45}$ it provided early labour migration connections to the United States. ${ }^{46}$ US immigration policy was eased further in 1965 with the enactment of the US Immigration and Naturalization Act, which removed European-biased national origin criteria and allowed channels for new groups of immigrants, including citizens of newly independent countries. The Act also introduced non-immigrant temporary visas for skilled, high skilled and temporary workers needed in the US labour force, channels heavily utilised by Caribbean health care workers, particularly Jamaican nurses (Nicholson 1985).

As early as the mid-1950s Canadian immigration policies also created new opportunities, although most Caribbean people could only access Canada as domestic workers. In 1955, the Canadian government introduced a recruitment programme for a few hundred Caribbean women each year (James 2007), a scheme that was active in British Guiana, where the colonial government provided the recruits with reimbursable funds for the cost of passages and incidental expenses, as well as training in home economics. ${ }^{47}$ Between 1956 and 1962, about 30 domestic

\footnotetext{
${ }^{44}$ Meeting of the Executive Council of British Guiana, 29th September 1960. 'Recruitment of Farm Labour for the United States of America.'

${ }^{45}$ Although officially return rates were high, an interviewee indicated that he met a Guyanese in Boston who was the son of one of these farm workers. He specified that a few of these farm workers settled in the Boston area in the 1960s.

${ }^{46}$ Meeting of the Executive Council of British Guiana, 29th September 1960. 'Recruitment of Farm Labour for the United States of America.'

${ }^{47}$ Meeting of the Executive Council of British Guiana, $8^{\text {th }}$ March 1960, L.56/147 IV. (10) 'Recruitment of Domestic Servants for Canada.'
} 
workers were recruited each year, but in 1963 and 1964 respectively 240 and 270 domestic workers left for Canada ${ }^{48}$; although these numbers were small, nonetheless, domestic workers would be eligible for Canadian citizenship at the end of their one-year contract. ${ }^{49}$ Hence, these women had access and regularly used family reunification channels already in the mid-1950s (James 2007). The 1962 Immigration Act of Canada finally eliminated racial discrimination and emphasised education and skills in an attempt to counteract the inflows of familysponsored unskilled immigrants. Although this Act is generally seen as the opening of Canadian immigration, the easing of restrictions was in fact true only for skilled individuals. Nonetheless, the notion of skills is time-dependent and the types of skilled workers sought in the Canadian economy in the 1960s were not highly educated scientists, but rather professionals, teachers, technical and semiskilled workers (Baksh 1978). Among the Guyanese population, clerical and white collar workers as well as teachers benefited the most from these policy changes. Interviewees stated that it was well known that there were jobs in Canada and since Guyanese did not require a visa to travel to Canada, they could easily go and 'explore' opportunities.

\subsection{Rapid diversification of migrants and their migration motives}

This period clearly marks the beginning of what would be Guyana's long and significant emigration history. Early emigration was concentrated on Britain and was frequently linked to the pursuit of tertiary education, which would guarantee a good standard of living and a prestigious social status upon return. As tertiary education was unavailable in the colony until the foundation of the University of Guyana in 1963, it emerged as an important motive for migration among the interviewees who described Britain as a preferred destination in their own migration trajectory or that of siblings, aunts and uncles who studied and became lawyers, doctors and nurses in Britain.

Labour migration to Britain was less prevalent among Guianese than from other British Caribbean colonies as the British Guiana colonial government never became directly involved in coordinating the emigration of labour, unlike the Barbadian and Jamaican authorities which invited the on-site recruitment of workers by London Transport, the National Health Service and British Rail (Mayor

\footnotetext{
${ }^{48}$ Various labour reports: British Guiana (1960), Annual Report of the Department of Labour about 1959; British Guiana, Annual Report of the Department of Labour for the year 1963; British Guiana, Annual Report of the Labour Division of the Ministry of Labour and Social Security for the year 1964; All reports retrieved from the Walter Rodney Archives, Georgetown, Guyana.

${ }^{49}$ British Guiana, Annual Report of the Labour Division of the Ministry of Labour and Social Security for the year 1964: 51.
} 
of London and Transport for London 2006). The low levels of emigration from British Guiana in the $1950 \mathrm{~s}^{50}$ may be explained by three factors: education was an important factor but the prerogative of a limited few; potential Guianese migrant workers faced higher costs and longer journeys to reach Britain than other West Indians; and British Guiana enjoyed a reasonably 'healthy' economy and good political and economic prospects, lowering migration aspirations (Baksh 1978). Nonetheless, colonial ties were key in attracting migrants: of the 34,000 individuals born in British Guiana residing abroad in 1960 (roughly 6 percent of British Guiana's population), about 37 percent resided in Britain and more than 26 percent resided within regional British possessions.

However, political changes and increasing uncertainties among segments of the population contributed to the emergence of new migration motives. The rapid increase in emigration in reaction to the impending closure of the British borders led to a clear 'now or never' migration effect; however, it may be argued that the initial growth of emigration starting in the mid-1950s was rooted in political reasons: The Communist scare of the 1950s and the violent outbreaks starting in the early 1960s made living conditions in Guyana difficult, particularly for upper class Portuguese and Chinese populations and the Indo-Guyanese population at large, while the closure of immigration channels into Britain in 1962 gave a clear signal of expiring migration opportunities.

While the closure of British borders created consternation among the population, not everybody could emigrate at this time due to lack of resources and contacts on whom to rely in Britain. This peak largely consisted of the middle and upper class and students. New migration opportunities were gradually opening in North America, allowing for the initial and long-lasting diversion of migration flows. Nevertheless, by independence in 1966 few Guyanese would have been able to migrate either through skilled or seasonal programmes or independently, as no strong migrant communities had yet formed in North America to provide initial support. This partially explains why the emigration effect of independence was lower than that of the implementation of the 1962 British Commonwealth Immigration Act.

In addition to the role of border regimes and independence in explaining the shift of migration from Britain to North America, we must consider four other important factors. First, the economy and employment conditions in Britain, while better than in Guyana, were not seen as so attractive as the opportunities in North

\footnotetext{
${ }_{50}$ Although data quality is sketchy, documents of the colonial government confirm low emigration trends from British Guiana to the United Kingdom (Executive Council: Minutes and Papers, 18 November 1961, 311).
} 
America. Second, the tense social atmosphere in Britain, exemplified by the Notting Hill riots in 1958, had shattered the notion of belonging to the British motherland instilled into the British subjects worldwide during colonialism. Third, Guyanese who pursued university education in Britain joined the ranks of other radically-minded intellectuals with anti-colonial, non-capitalist or non-alignment ideals, common in Guyana at this time, and preferred to take job opportunities in developing countries rather than remaining in Britain. Fourth, some Guyanese in Britain engaged in step-wise migration to Canada and the United States because their family had migrated from Guyana to Canada or the United States while they were in Britain and those countries allowed migration for family reunification. Informants provided examples of how siblings in Britain joined family members in Canada as most of the family had started a new life there. So rather than encouraging cumulative migration, Guyanese migration to Britain went through a rapid process of decline as migration to North America gained strength. This point supports previous observations made in the literature that Caribbean migration to Britain was just a blip, sandwiched as it was between a first phase of Caribbean migrations to North America in the 1930s-1954 period and then again after the mid-1960s opening of Canadian and US immigration policies (Peach 1991).

Ultimately, Britain rapidly lost its attractiveness as a migration destination. While some migration to Britain continued in smaller numbers in later years, it remained stunted in comparison to the growing migration trends within the Americas because of its continually restrictive policies that severely curtailed even family reunification (Segal 1998). Meanwhile, political uncertainties and insecurity in independent Guyana were felt more and more by the population, making emigration an increasingly preferred option.

\section{Co-operative socialism, authoritarianism and 'planeloads of emigrants' (1967-1985)}

The transition to independence brought some uncertainty and with it some emigration, but the importance of migration in the history of Guyana was just beginning. Migration flow data are highly imperfect, but when we combine total outflows reported by Guyana with immigration flows reported by the major destination countries we are able to approximate some missing flows and construct a better picture of the changes that took place between 1967 and the mid-1970s. After independence emigration continued at similar rates with a slight growth around 1968-1969 but then it followed a downward trend across the late 1960s to the early 1970s (Figure 4.3). 


\section{Figure 4.3. Emigration from Guyana by destination, 1966-1985}

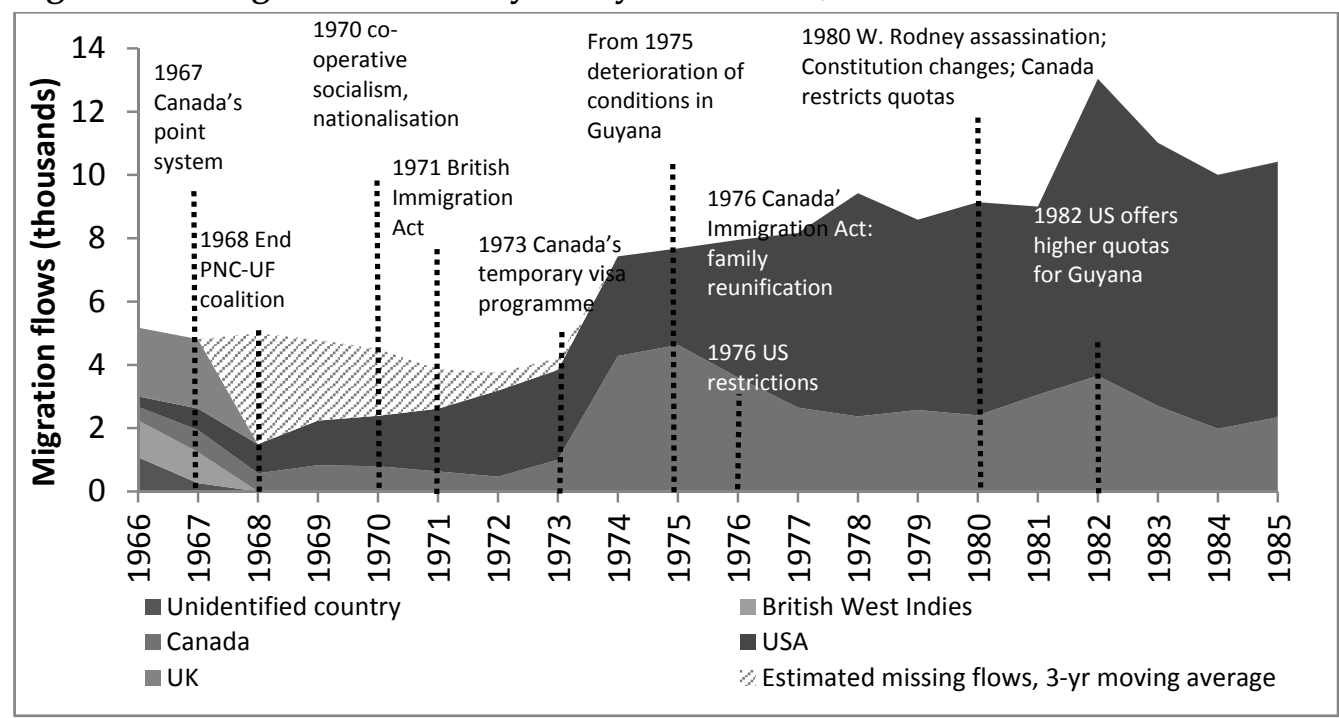

Source: DEMIG TOTAL, DEMIG C2C, various annual labour reports ${ }^{52}$ and Peach 1968.

This emigration would be directed partly to Britain, for which we do not have data and which is estimated in Figure 4.3, but also to regional destinations. The migration shifts in the 1966-1972 period pale in comparison to the almost doubling of migration between 1973 and 1974 and its continuous gradual growth into the late 1970s and 1980s, largely directed towards North America. In this period there is also a deep shift in emigration motives, composition and different rationales for destination choices, including important episodes of step-wise migration. Most of all, after independence Guyana underwent profound political and economic transformations, which affected the population's working and living conditions and their emigration decisions.

\footnotetext{
${ }^{51}$ Total outflows are reported by Guyana but are not available for every year during this period; as a result, the author calculated a 3-year moving average in order to have a rough idea of the flow during this critical period. While the direction of these flows is unclear, it is likely that these represent migration to Britain and even more so to the British West Indies, which is supported by the data that emerged from the interviews.

${ }^{52}$ See footnote 40 .
} 


\subsection{Widening authoritarianism and the growth of sudden emigration}

Troubling political developments arose as the Burnham government gradually introduced policies at odds with democratic principles, creating an atmosphere of fear and insecurity. Already in 1966, Prime Minister Burnham introduced the National Security Act, giving the police arbitrary power to search, seize and arrest anybody at will (Mars 2001). In 1968, the end of the PNC coalition with the United Front, a party that represented business interests, caused great political and economic uncertainty for middle- and upper-class Portuguese, other minority European groups and wealthy East Indian business people. For this segment of the population, emigration to Canada became increasingly attractive..$^{53}$

A system of overseas proxy voting, corruption, graft and political oppression led to rigged elections in 1968, 1973 and 1980 (Jeffrey 1991; Rabe 2005; Canterbury 2007), while in everyday life the government suppressed human rights, restricted freedom of movement and harassed political opponents. Attempts to stop the opposition culminated with the assassination of Walter Rodney, leader of the Working People's Alliance (WPA) in June 1980, while lawlessness reigned as scare tactics targeted the East Indian population and all critics regardless of ethnicity (Jeffrey 1991; Rabe 2005). The 1980 Constitution introduced the figure of a powerful executive president (Polity IV 2010) while on the ground politically-supported gangs, commonly called 'kick-down-the-doorgangs', used ambushes to attack wealthy businessmen, usually Indo-Guyanese, creating a state of terror (Owen and Grigsby 2012).

By the early 1980s discrimination, surveillance and violence either because of ethnic group or political affiliation were widespread. These conditions were strongly associated with sudden bouts of emigration: people did not discuss emigration, not even with their immediate family, and left with spouse and children, suddenly, from one day to the next. This secrecy may be associated with two motives: first, although the Guyanese government was largely pleased that dissenters were voting with their feet rather than voicing their opposition (Hirschman 1978), emigration was a financial concern for the government as many Guyanese emigrants possessed assets and their departure was 'draining wealth out of Guyana'. ${ }^{54}$ As a result, people did not want to publicise their plans to leave and

\footnotetext{
53 Unfortunately Canadian data for 1956-1973 are only available as an aggregate for the Caribbean region. However, in 1974, immigration figures were at 4277, higher than inflows to the US, 3153, demonstrating the high attractiveness of Canada in these early years.

${ }^{54}$ This statement was made by an interviewee who is an expert on Guyana's long-term economic development.
} 
risk being held before departure, under a law which prevented the export of even small amounts of foreign currency. Second, people wanted to keep a low profile with Canadian or US authorities as in many instances people, often entire families, left Guyana with tourist visas, intending to overstay and regularise their status once in North America.

\subsection{The unintended migration stimuli of socio-economic reforms}

The ominous political developments were matched by rapidly worsening socioeconomic conditions. After independence, the Burnham government introduced a radical ideological programme to uproot Guyana's economy from its colonial structure, create a self-reliant decolonised society and redress the imbalances created during colonialism (Standing 1977). Starting in 1968, 'cooperative socialism' aimed to give workers control of the economy and in 1970 the country became a Co-operative Republic, marking the introduction of cooperatives, price controls, imposition of a ban on imported foods, and in 1973 the start of a plan to feed, clothe and house the nation by 1976 (Canterbury 2007). Among the state-led development strategies implemented in the 1970s, four had long-term implications for Guyana as well as unintended migration effects: (i) nationalisation; (ii) the national agricultural plan; (iii) the educational reform; and (iv) the national service.

(i) Nationalisation emerged as an attractive ideological, financial and symbolic strategy to halt the leaking of profits earned by foreign-owned enterprises out of Guyana (Standing 1977; Rabe 2005). However, its implementation had severe effects on the nation's financial and human capital. First, the purchase of these companies at negotiated prices caused the national debt to treble between 1970 and 1975. Second, by 1976 the state controlled 80 percent of the national economy (Thomas 1982), resulting in the nationalisation of most jobs. Third, although the government indicated that no enterprise established after independence would be nationalised (Thomas 1982), nationalisation was perceived as a threat to private property, a sufficient reason to convince many business people to leave Guyana, as indicated in the interviews.

(ii) The national plan to reform agriculture focused on mechanisation and large-scale rice production to increase efficiency and competitiveness of Guyanese products on global markets (Canterbury 2007). However, mechanisation seems to have increased rural unemployment and underemployment (Standing and Sukdeo 1977) and rural-urban migration, mainly of the Indo-Guyanese population. Internal migration posed a growing threat to the urban economic base, because of the already high urban unemployment levels and because rural migrants encroached into sectors largely occupied by the Afro-Guyanese population (Hanley 1981). To curtail rural-urban migration, the government promoted agricultural training and encouraged rural settlement, with disappointing results as migration to the city 
continued uninterrupted (Standing and Sukdeo 1977). Affected by a number of difficulties, by the 1980s the national agricultural plan proved to be unsustainable and, most critically, food self-sufficiency was not achieved as large-scale production had supplanted small-scale mixed farming (Canterbury 2007). In an indepth study of the village of Ithaca, Nicholson (1976) found that the rural population was negatively affected by poor agricultural growth and poor access to services and was aware of the wider employment opportunities and services in the urban area. Family and friends in urban areas would facilitate migration and often determined migration corridors that linked specific rural areas to specific urban areas.

(iii) An important component of the government's plan to decolonise Guyana was to provide educational opportunities for the entire population as a means to lift the public's socio-economic status and to move away from colonial educational policy, which had created a privileged elite (Sackey 1977). By the 1970s, the government had diversified secondary schooling away from the traditional grammar system and towards technical secondary schools geared to teach the technical skills needed for the country's development. From 1975, university fees were abolished, students were financially supported and were obliged to serve in the National Services during the course of their studies. Free education resulted in a significant increase of enrolment and what Baksh (1978) called an 'education explosion'. Greater access to education was offered at a time when the population realized that education was the main avenue for occupational and social mobility (Baksh 1978). In particular, East Indian parents recognized that village life would not allow their children to advance socially and economically and began to make significant sacrifices to educate their children (Hanley 1981). Concurrently, mechanisation had freed up young men and women, who traditionally had helped their parents in rice production. An increasing number of children were sent to the capital, Georgetown, with good chances that they would not return to the village after completing their education, as their life aspirations were linked to the urban environment and its more prestigious employment market (Hanley 1981). This stimulated further rural-urban migration (Nicholson 1976). Hanley (1981) also observed that villagers were acutely aware of how acquaintances had managed to succeed through education and becoming doctors or lawyers enabled them to migrate to Barbados and North America.

(iv) Associated with free education was the National Service, established as a prominent state-led development strategy which required a compulsory year of para-military service for all university students, who were usually placed in the interior to work on agricultural projects. Meant to deprogramme neo-colonial values, instil pride in Guyana and help young Guyanese solve Guyana's problems in accordance with the government agenda, this initiative generated different 
responses: while for some it was an empowering experience, for others it was a deterrent to pursue tertiary education in Guyana. It was reported that parents of Indo-Guyanese female students generally resisted sending their daughters to the interior unsupervised. Moreover, the National Service was suspected to be a system for recruiting future government supporters. Thus, the programme contributed to divisiveness in society (Baksh 1978) and, as confirmed during interviews, it led some individuals to drop out of university and also pushed some to seek educational opportunities overseas in order to avoid the National Service.

Over time, the strategy to promote decolonisation and self-reliance engendered widespread difficulties for the population: frequent and long-lasting power outages, shortages of basic foodstuffs, dismantling of certain public services such as transport added to low wages and few job opportunities, leading the population to make lifestyle and dietary adjustments. These hardships, combined with an increasingly oppressive political environment, encouraged a growing number of Guyanese to pursue emigration.

\subsection{Worsening working conditions and the emigration of skilled workers}

Emigration was particularly enticing for skilled workers. Since independence, intellectual and public leaders raised concerns about the emigration of skilled workers (Sackey 1977) ${ }^{55}$ and when nationalisation was introduced, many more skilled professionals working in multinational companies left Guyana (Standing 1977). The government's failure to diversify the economy, stimulate the private sector and create sufficient jobs to meet the new occupational aspirations of an increasingly educated population meant that the only employment opportunities were in the public sector, which by 1970 employed nearly 44 percent of all Guyanese workers as teachers, in the police, the army or other public ventures. Working in the public sector was increasingly a problem, not only because wages were very low, but mostly because Guyana's bureaucracy was a centralised tool for advancing political interests. As the government engaged in a 'spoils system' which rewarded workers depending on their ethnic group and political position (Baksh 1978), civil servants who chose not to be a pawn in the authoritarian system

\footnotetext{
55 The Guardian, May 26, 1966, p13, 'The Economics', by Clyde Sanger, available at ProQuest Historical Newspapers The Guardian and the Observer (1791-2003), accessed on 12 February 2013; Guyana Graphic, Tuesday January 4, 1972, page 1, 'Move by Health Ministry to halt brain drain' available at Guyana National Library, Georgetown, Guyana; Sunday Argosy, February 25, 1973, p15, 'Too many young people leaving Guyana' by Humphrey Nelson, available at Guyana National Library, Georgetown, Guyana; Sunday Argosy, August 12, 1973, 'Brain drain: incurable cancer?', By R.O. Bostwick, available at Guyana National Library, Georgetown, Guyana.
} 
opted for emigration (Hope 1977; Thomas 1982). In 1968 and 1970, respectively 20 and 25 percent of high skilled emigrants were individuals who before departure held professional or technical positions such as doctors, lawyers, engineers, administrative posts and supervisors. Emigration of Indo-Guyanese was particularly noticeable, prompted by fear and insecurity generated by the increasingly uncertain political and economic future of Guyana (Sackey 1977). By the late 1970s the personnel situation in Guyana was so critical that there were hardly any qualified individuals able to lead or carry out the functions of the state, while poor recruitment policies and lack of proper manpower planning contributed to the frustration of those individuals who remained in Guyana (Hope 1977; Standing 1977; Standing and Sukdeo 1977). For most graduating students, a degree increasingly represented a ticket to occupational mobility abroad (Sackey 1977; Baksh 1978).

\subsection{Migration policies and the diversification to North American destinations}

As Guyana became progressively inhospitable, many Guyanese looked more and more to build a future abroad. British immigration control gradually widened and by 1973, when the 1971 Immigration Act came into force, Commonwealth workers no longer enjoyed the automatic right to remain in Britain. ${ }^{56}$ However, immigrants who had previously acquired permanent residence in Britain could return 'after an absence of up to 2 years and to bring in, or be joined by his wife, children under 18 and his elderly parents, free of conditions. ${ }^{57}$ As the conditions worsened in Guyana in the early 1970s, Guyanese returnees from Britain may have used this channel to re-emigrate to Britain, possibly explaining the strengthening of the Guyanese community in Britain in 1980 (Figure 4.2).

The overall weakening of migration flows to Britain is surprising nonetheless, since no travel visa was required until 1997 and Guyanese would have been able to seek asylum or overstay, strategies used to migrate to North America. Interviews offer possible explanations: First, the heightened levels of immigration controls in Britain may have made the Guyanese community hesitant to support further migration. A number of interviewees indicated that although they had family in Britain, these relatives never 'sent for them' even during the

\footnotetext{
${ }_{56}$ Immigration Bill: Memorandum by the Secretary of State for the Home Department, Cabinet, CP(70)126, 31 December 1970, The National Archives, Catalogue Reference: CAB/129/154

${ }^{57}$ This clause existed in the proposal of the Bill in December 1970, cannot be found on the 1970 Act, but is found in an extended form in the 1983 Statement of Changes in Immigration Rules, http: /www.official-documents.gov.uk/document/hc8283/hc01/0169/0169.pdf and in today's policy in a more limited version.
} 
harshest times in Guyana, while another interviewee pointed to the general perception that Guyanese in Britain lost their ties to Guyana. Second, interviewees pointed to the unattractive employment conditions in Britain by the 1980s. Third, interviewees recalled harsh political and socio-cultural conditions well-captured by Enoch Powell's 1968 'Rivers of Blood' speech, which advocated the immediate stop of immigration on the basis of Commonwealth immigrants' 'incompatibility' with British society. Such political propaganda may not have in itself deterred migration, but it certainly reinforced the negative experiences of West Indians living in Britain, making Britain a less desirable migration destination. Finally, the homogeneity of British society made Britain a place where it was difficult to 'blend in' and live as undocumented migrants, which deterred irregular immigration. While these factors alone may not have led to a migration decline, the availability of alternative destinations helped to sideline Britain and make Guyanese migration to Britain a temporary phenomenon.

On the North American side, after the introduction of skills criteria by the 1965 US immigration Act, the 1976 amendments to the Act restricted entry opportunities by requiring a job offer. Nevertheless, the amendments also allowed immigrants from the Americas already in the US with a temporary or even irregular status to adjust their status (e.g. through marriage). Entry quotas were reduced further in 1980; yet in 1982 the US Ambassador to Guyana announced that its government would offer Guyana 11,000 permanent visas and 6,000 visitor visas, up from 6,600 and 5,000 respectively in 1981. In 1982, US policy also introduced a new refugee category. ${ }^{58}$ Guyanese increasingly applied for permanent residence as spouses and children of US permanent residents, but irregular migration also gained importance. ${ }^{59}$ By this time, even rural Guyanese had become well-versed in regular migration regulations and how the regulations could be circumvented. For instance, during the Vietnam War, one could overstay and avoid deportation by volunteering for the US Army, a strategy reportedly used by Guyanese (Hanley 1981).

Canada's immigration policy followed a different path: While in 1967 Canada reinforced its emphasis on skills by introducing the points system, by 1973 labour shortages pushed the government to introduce a temporary work visa programme. The 1976 Immigration Act embodied non-discrimination, family reunification and refugee policy as the policy's three pillars, but also continued to emphasise skills, clearly expressing the Canadian government's concerns with the

\footnotetext{
${ }^{58}$ Express Thursday June 17, 1982, p 15, '11,000 Guyanese get visas to live in the States', available at Guyana National Library, Georgetown, Guyana.

59 Guyana Chronicle, Wednesday, 16 June 1982, pp1 and 7, 'Harsh measures demanded against US immigrants...', available at Guyana National Library, Georgetown, Guyana.
} 
composition of migration more than its volume. In the early 1980s Canada's policies became more selective by restricting temporary workers and introducing a labour market test for low-skilled immigrants, ${ }^{60}$ while migration for the highskilled and entrepreneurs was facilitated. For the rest of the 1980s, Canadian migration policies attempted to regulate flows through frequent adjustment of immigration quotas, which were lowered in 1983 and 1984. By 1985-86 Guyanese had become the top Caribbean nationality of asylum seekers, mainly composed of Indo-Guyanese applicants. Canadian authorities approved 40 percent of asylum seeking applications, but the majority of applications were rejected as the authorities considered applicants to be economic refugees. Remarkably, applications started to decrease in 1985, when Guyanese were obliged to obtain a visa to travel to Canada. ${ }^{61}$

\subsection{Greater diversification of emigration composition and regional destinations}

By the mid-1980s Guyana was on its knees (Rabe 2005). The promises of independence gradually gave way to dismal conditions which socially and politically included discrimination, oppression, victimisation, crime, violence as well as unemployment and food shortages, as Guyanese remember well. Emigration was staggering as 47,000 Guyanese ( $43 \%$ of natural population increase) migrated between 1970 and 1975 and 72,000 (70\% of natural population increase) migrated between 1976 and 1981 (Thomas 1982).62 This period marked the maturation of skilled emigration with the departure of all kinds of professionals who faced discrimination for not complying with political agendas. Increasingly skills were recognized not as a way to contribute to Guyana's development but to emigrate, leading more people to upgrade their skills to migrate (Thomas 1982).

Gradually all social classes engaged in emigration, increasingly also the lower classes (Canterbury 2007; Roopnarine 2013). North America was the chosen destination by many who perceived that jobs were available and salaries were high, although Guyanese frequently migrated through marriage or as family members of Canadian or US permanent residents or citizens. In 1982, Guyanese applied mainly as relatives of US citizens (71 percent) or US residents (20 percent), compared to skilled or unskilled workers needed in the US (6 percent) (Maingot

\footnotetext{
${ }^{60}$ Data source: DEMIG POLICY database

${ }^{61}$ Sunday Stabroek News. May 27, 2006 (missing year, 2006 assumed given the content) p3\&9, 'Guyanese still applying in droves to Canada, but only $10 \%$ granted refugee status' by Miranda La Rose. Unfortunately Canadian refugee data (Refugees Landed in Canada - RLC) is only available after 1990.

62 The sources of this data are Government of Guyana, IMF and World Bank and include all outflows, not only to main destination countries as in the data originating from the DEMIG C2C database.
} 
1983). By the early to mid-1980s the family reunification processes had been fully 'activated' and entire families, including members beyond the nuclear family, were 'sponsored' or 'sent for', as Guyanese colloquially refer to this process. This may partially explain why the introduction of a job offer requirement in the 1976 US policy had seemingly very little effect in constraining immigration from Guyana, as many individuals were able to 'jump category' and use family reunification channels. This strategy was also used by family members who had previously migrated to Britain, leading to emigration flows of Guyanese from Britain to North America. This process of gradual convergence of entire families in North America initiated a strong intra-familial cumulative effect whereby in some cases emigration from Guyana was pursued because no other family members were left in Guyana.

Interviewees described what could be called an 'intra-community' effect of migration: when barrels arrived filled with goods and relatives visited from abroad, everything from their demeanour, their accent and purchasing power filled the people in the community with awe and stimulated migration aspirations. By combining the rapid diffusion of migration aspirations and the greater obstacles to obtain regular access to North America, we can easily explain the growing reliance on irregular migration channels during this period. Interviewees indicated that it was a known fact that in North America, and in particular the US, one could 'disappear from the authorities' and lead a viable life without documents within the Guyanese community in New York City. This process was facilitated by the Guyanese communities in North America, which were perceived as 'welcoming' and willing to help Guyanese immigrants.

Regional migration to Suriname, Brazil and Venezuela and a number of Caribbean countries also gained strength (Canterbury 2007). The total emigration estimates cited by Thomas (1982) when compared to immigration reported by main destination countries (using the DEMIG C2C database) suggest that about 15,000 Guyanese migrated within the region in 1970-75 and about 20,000 in 19761981. Better wages and working conditions in a number of Caribbean islands in conjunction with easy access attracted teachers, medical professionals and staff and university recruits. Rural East Indian migrants began to work in the Surinamese sugar industry in the 1950s, but it was in the late 1960s and 1970s that they became an important part of the workforce in Suriname's sugar, rice and lumber sectors. A survey of these workers suggested that their migration was motivated by the poor living conditions in Guyana and the search for greater freedom. In fact, Guyanese took advantage of the opportunities created by Dutch aid in independent Suriname (Krishnadath 1983). While scholars hypothesised that Guyanese were interested in step-wise migration, mainly using Suriname to migrate to the US, only about 26 percent of Guyanese workers in the rice sector considered Suriname as a possible 
stepping stone to further migration, while 61 percent were interested in settling in Suriname (Menke 1983).

As living conditions remained difficult and hope for improvements dwindled, emigration became an 'escape valve' for a large segment of the population. It is over this period that a strong migration propensity developed and with that, the activation of multiple migration strategies taking advantage of and circumventing migration policies. It is over this period that the migration experience of Guyana seems to merge more closely with a culture of migration that has been recognized as a key factor in Caribbean migrations (Thomas-Hope 1996).

\section{Persistent instability and the gradual reduction of emigration (1985-2013)}

Guyanese emigration reached its apex in absolute terms in the mid-1980s with over 17,200 Guyanese recorded as immigrants in Canada and the US in 1987 alone. This figure is likely to be much higher when regional migration is considered, for which flow data are not available. The motives for such large outflows largely reflect previously mentioned political reasons and economic hardship. After the 1987 peak, emigration from Guyana progressively decreased, so much so that by the late 2000s emigration figures fell back to mid-1970s levels, reflecting some improvements in living conditions and emerging opportunities (Figure 4.4). Continuing emigration is associated with political factors, crime, lack of opportunities and unfair working conditions, as well as access to better education abroad. A remarkable feature is the important role of family reunification and migration policies in shaping the timing, composition and destination of migration. The major migration determinants and their evolution over this period are discussed in the following sub-sections. 
Figure 4.4. Emigration from Guyana by destination, 1986-2010

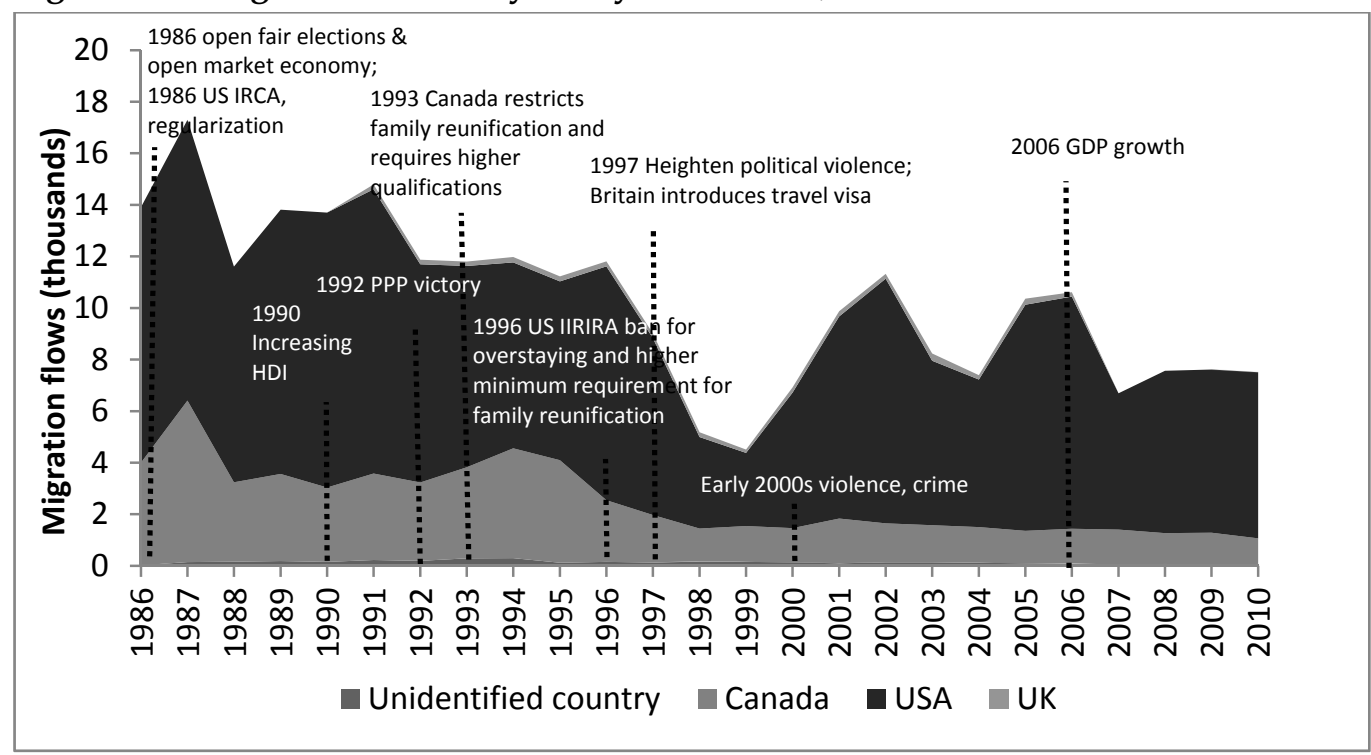

Source: DEMIG C2C

\subsection{Economic and ethnic-based uncertainties}

After Forbes Burnham's sudden death in 1985, Desmond Hoyte took leadership of the government and quickly opened discussions on free and fair elections. The first democratic elections in 1992 resulted in the victory of Cheddi Jagan's PPP. Guyana seemed to be set on a new path, but years of corruption, clientelism and oppression severely damaged national institutions (e.g. the police force and the education system). The population had also undergone deep changes: on one hand Guyanese had become demoralised and had learnt to cope by disregarding the government; on the other hand, twenty years of intense emigration had led to the departure of the bulk of experienced qualified workers, professionals and academics along with the majority of new graduates, a vacuum filled by people who often lacked the necessary preparation to serve vital national functions. Guyana experienced a shortage of strategic human resources needed for national political, social and economic reconstruction.

The 1997 electoral victory of the PPP/C (formerly PPP) ushered in a period of heightened violence. PNC supporters contested the election results leading to sporadic violent clashes between political factions and political gangs which targeted and killed supporters of the opposition. The police used force, intimidation and extreme policing measures such as extra-judicial killings and eventually deployed the army to enforce the law (Owen and Grigsby 2012). Ahead of the 2001 elections, the government took many precautions, but a delay in 
announcing the results raised renewed suspicion about the legitimate re-election of the PPP, leading once again to political violence (Polity IV 2010).

In the new millennium, criminal gangs came to dominate public and political life. Between 2002 and 2006 a string of robberies, murders and kidnappings turned into a political issue and brought to light the government's collaboration with international drug criminals (Owen and Grigsby 2012). For the past decade, drug trafficking has been a source of international concern particularly as estimates suggested that 20 percent of GDP in 2006 was earned through the trafficking in cocaine through the country (US Department of State 2006). Drug trafficking and the related escalation of violence may explain why in 2003 Guyanese were among Canada's top ten nationalities of asylum seekers, with 640 applications lodged, although only 17 percent were approved. ${ }^{63}$

Both the high level of violence and the corruption of government and its institutions did nothing to increase the population's confidence in the future of Guyana and its political class. Certain of its ability to hold onto power, the PPP/Cled government lost respect for the rule of law, engaged in corruption and established its own version of authoritarian rule (Canterbury 2007). If the PPP victory in 1992 sparked hope, by the turn of the millennium it was clear that Guyana had only experienced a shift in the ethnic group in power. Capturing a common feeling of hopelessness in the political system, an interviewee indicated that by this time 'there could no longer be grounds for persuading people to stay.'

In parallel, Guyana's economic performance became progressively weaker throughout the 1980s with rapidly deteriorating exports and falling GDP (Thomas 1982; Thomas 2013) (Figure 4.5). Under Hoyte's leadership, the PNC government opened the economy towards market-based principles, which brought the World Bank and the IMF to introduce structural adjustment programmes, including the privatisation of state-owned industries. Economic growth continued to be largely concentrated in agriculture, while other parts of the economy contracted: the public sector declined by 45 percent, bauxite operations decreased about 37 percent, and the sugar industry experienced a decline of 35 percent (Canterbury 2007). Economic reforms began to generate some growth in the 1990s, although in 1998 a combination of droughts, falling commodities prices and political tensions stunted further growth.

\footnotetext{
${ }^{63}$ Immigration and Refugee Board of Canada, IRB Refugee Status Determinations (1989-2011 Calendar Year), available at http: //www.cdp-hrc.uottawa.ca/projects/refugeeforum/projects/documents/REFUGEESTATSCOMPREHENSIVE1999-2011.pdf, accessed on June 1, 2014.
} 


\section{Figure 4.5. Guyana's total emigration flows (1953-2010) and GDP per capita} (1960-2010)

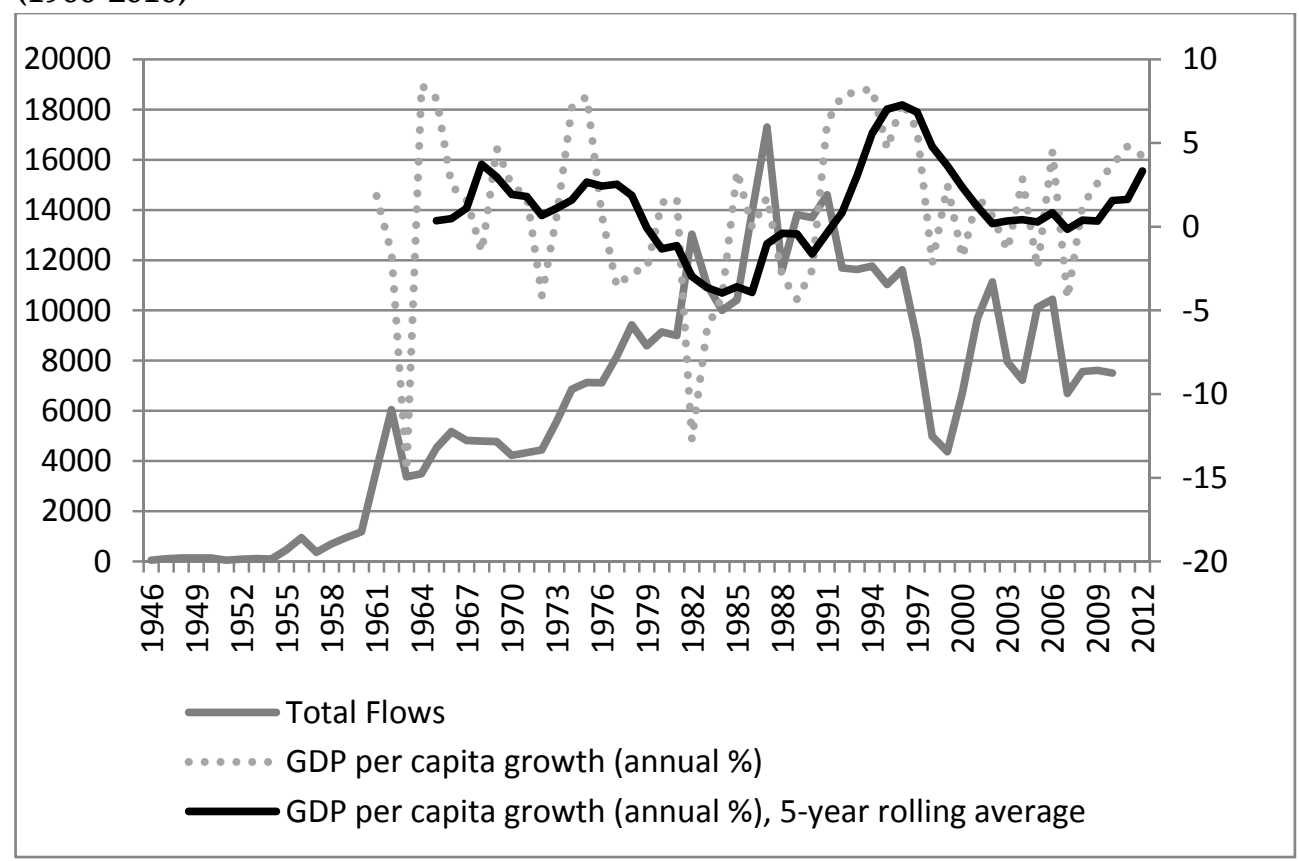

Sources: Migration flows - DEMIG TOTAL, DEMIG C2C, various annual labour reports ${ }^{64}$ and Peach 1968; GDP per capita - World Development Indicators (WDI) ${ }^{65}$

Starting in 2006, Guyana's economy grew with GDP figures expanding, public indebtedness decreasing and progress of Guyana's rating from a highlyindebted poor country to low-middle income status (Economist Intelligency Unit 2013). However, Thomas (2013) warns that the GDP figures reported since 2006 (Figure 4.5) reflect a data measurement change which occurred when the Bureau of Statistics officially rebased the National Accounts series, replacing the previous 1988 series with the 2006 series. Consequently, GDP estimates were 62 to 77 percent larger than those obtained with the former base year, resulting in an impressive 7 percent growth rate for 2007. Similarly, the debt-to-GDP ratios were also lowered (cf. Thomas 2013). In fact, even when we consider human development levels, after an increase in 1990 they have remained at around 0.61-

\footnotetext{
64 See footnote 40.

65 World Bank's World Development Indicators (WDI), available at http: //data.worldbank.org/datacatalog/world-development-indicators, accessed on May 6, 2014.
} 
0.63 in 2005-2012, slowly driving Guyana below medium development levels and challenging the reported GDP growth. ${ }^{66}$

Nonetheless, there are some reasons to be optimistic about the country's future economic prospects. In addition to agricultural output, gold mining, logging and the potential discovery of oil could set Guyana on a real development path. However, important challenges remain, such as corruption, discrimination and weak state capacity (Clegg 2014). The centrality of the political and governance factors in stimulating further migration was perfectly captured in the interviews of two individuals who for have shown strong commitment to Guyana and its development over the past three decades; they ended their separate interviews questioning how much further the government may continue down this path and wondering whether they may feel compelled to emigrate in the future.

\subsection{The selectivity of North American migration policies}

Destination countries' migration policies underwent multiple changes over the 1985-2013 period. Figure 4.6 shows the average score of all migration policy changes introduced independently by Canada, Britain and the US, with a score above 0 indicating that the number of restrictive policy changes introduced was larger than the number of less restrictive policy changes in that particular year, while a score below 0 means that less restrictive changes dominated. ${ }^{67}$ Canadian immigration policies wavered in their level of restrictiveness, generally targeting irregular entries although all migrant categories, including investors and skilled migrants, were restricted at times. For Guyanese citizens, movement to Canada was significantly restricted starting in 1985, when Canada introduced a travel visa. ${ }^{68}$ This went along with a general increase in border controls and fines for the transport and smuggling of undocumented migrants. Even for family migration, Canada introduced more rigid rules to reduce fraudulent applications, starting in 1993. However, in 2000 a series of regulations made common-law partners eligible for family sponsorship and parents and grandparents enjoyed a Super Visa from 2011. Family channels were once again made more restrictive in 2012, when time limits were set to limit sponsorship of subsequent spouses. Although since 1993 higher qualifications were required of skilled workers and new procedures limited quotas for specific immigrant classes, Canada was generally favourable to skilled immigration in the 1994-2008 period, although starting in 2010 quotas were again

\footnotetext{
${ }^{66}$ United Nations Development Programme, Human Development Index (HDI), accessed on May 18, 2014, available at http: //hdr.undp.org/en/data.

67 This graph displays an average of all policies and does not distinguish across different policy areas and migrant groups.

${ }^{68}$ Data source: DEMIG VISA
} 
reduced and new requirements, such as language abilities and adaptability, introduced. 69

Figure 4.6. Overall changes in restrictiveness in migration policy in Canada, Britain and the US, 1953-2013, 5-year average

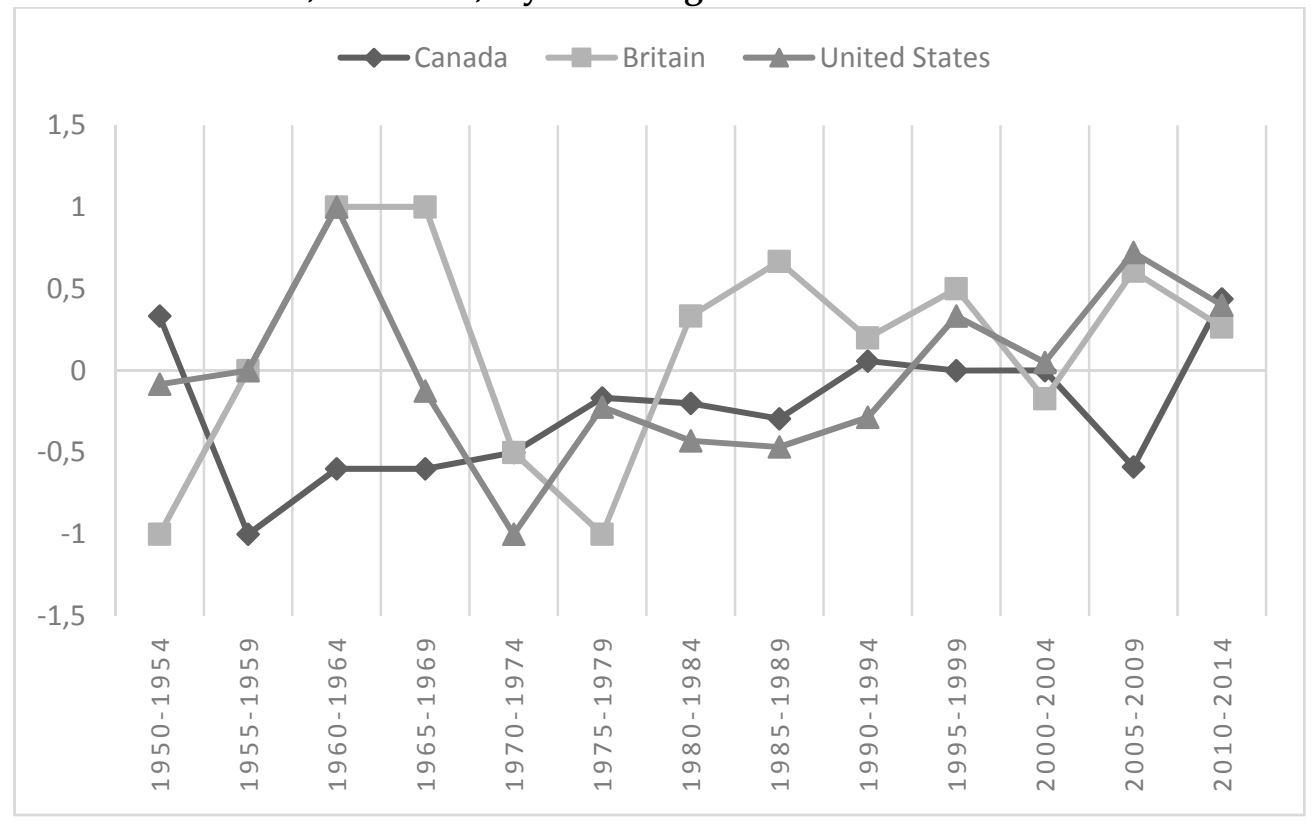

Source: DEMIG POLICY

US immigration policies changed towards less restrictiveness until the mid-1990s, generally facilitating the entry of professionals and health care workers and protecting family member categories. The 1986 Immigration Reform and Control Act (IRCA) acted as a regularisation, impacting inflows from 1989 to 1998, although its effect on Guyanese immigration does not seem substantial (Figure 4.7). Starting in 1996 however, new policy measures increased restrictions: The Antiterrorism and Effective Death Penalty Act of 1996 effectively allowed border officers to 'accept or reject' asylum claimants at the border and expedited the backlog of asylum applications. This may have affected the rejections of Guyanese asylum applications, as Guyanese no longer had a legitimate case for political asylum after the restoration of democracy in $1992 .{ }^{70}$

${ }^{69}$ Data source: DEMIG POLICY

${ }^{70}$ Guyana Chronicle, Sunday, June 22, 1997, p3, 'Guyanese asylum seekers to be deported from US' by Vishnu Bisram in New York, available at Guyana National Library, Georgetown, Guyana. 
Figure 4.7. Total inflows from Guyana to Canada and the US, 1946-2010

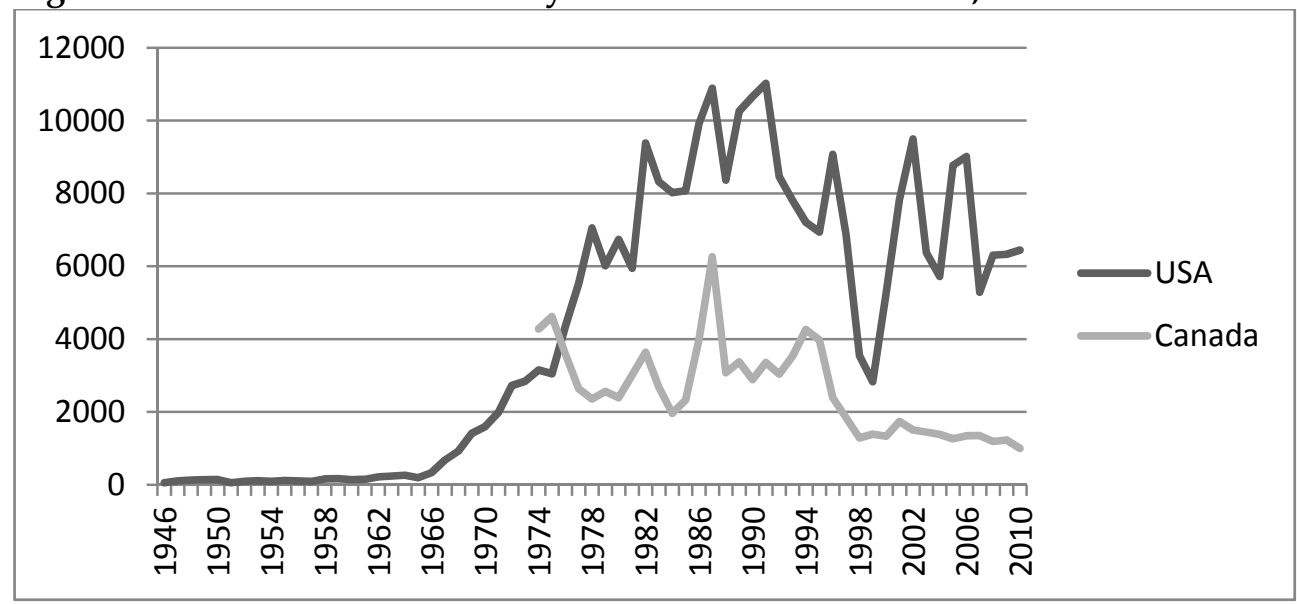

Source: DEMIG C2C

The 1996 Illegal Immigration Reform and Immigrant Responsibility Act (IIRIRA) also introduced bans for irregular immigrants who were deported or were leaving the country voluntarily. Overstaying could lead to a 10-year entry ban, while re-entering irregularly would earn an irregular migrant an indefinite ban. ${ }^{71}$ The same Act also increased the minimum income requirements for family sponsorship and strengthened its enforcement. Many US-based Guyanese were thought to be unable to meet this threshold. ${ }^{72}$ By 1999 the new forms and complex process created large backlogs ${ }^{73}$ and up to 90 percent of Guyanese immigrant visa applications had been turned down,74 while before 1996, 90 percent of Guyanese immigrant visa applications were approved. ${ }^{75}$ These policy requirements and logistical difficulties seem to have led to a stunning immigration drop in 1997-98 (Figure 4.7). Since 2001, US policies have continued to move towards more

\footnotetext{
${ }^{71}$ Guyana Chronicle, Tuesday, April 8, 1997, p1, 'Guyana monitors new US immigration law', available at Guyana National Library, Georgetown, Guyana.

72 Guyana Chronicle, Monday, April 28. 1997, p11, ‘New immigration law impact: Tougher for Guyanese to join relatives in US' by Vishnu Bisram in New York, available at Guyana National Library, Georgetown, Guyana.

73 Sunday's Chronicle, June 14th, 1998, 'Guyanese affected by new delays for Green Cards' by Vishnu Bisram, available at Guyana National Library, Georgetown, Guyana.

${ }^{74}$ This was recognised as a global problem as the rate of refusal went up from about 15 percent to 90 percent on average.

75 Stabroek News, Friday April 16, 1999, p3, 'US immigrant visa refusals over 90\%: Affidavit of Support posing major problems' by Courtney Jones, available at Guyana National Library, Georgetown, Guyana.
} 
restrictiveness, targeting border controls and surveillance measures, expanding grounds for deportations and limiting entry of workers and refugee rights. ${ }^{76}$

\subsection{Migration as an integral part of everyday life}

The ups and downs of political and economic developments created an unstable environment throughout the 1990s and the 2000s. This led to the consolidation of emigration patterns that had started to take shape in the 1970s and 1980s. A number of factors pointed to continued uncertainties for the population: references to the political situation particularly stressed the disappointment following the transition of leadership to the PPP after the initial hope for real changes in governance, and the escalation of violence and close ties between the government and criminal groups; economically, while foodstuffs were available once again, unfair distribution of scarce opportunities made living conditions still difficult for large segments of the population. In the 1990s and 2000s, interviewees spoke of relatives emigrating because it was at this time that they finally were able to acquire the necessary financial resources. This suggests that economic changes were in fact benefitting parts of the population.

The dominant factor shaping migration in this period was family reunification. While in previous periods, developments in Guyana were the clear stimuli and migration policies were a filter of migration, in this period, family reunification became a motive in itself. Stories of the emigration of family members abounded as a well-established sponsorship process enabled adult children to sponsor their parents and siblings, while siblings themselves began to sponsor other family members upon meeting eligibility requirements. During this period the emigration of entire families was 'completed' as parents, numerous adult children and respective spouses relocated to Canada or the US in cycles that took up to 11-12 years. ${ }^{77}$ Among the interviewees, some individuals waited up to 15 years for their permanent visa, a process that created unusual dilemmas. While waiting for US permanent residence permit, some individuals started life projects in Guyana which brought them satisfaction; however, once they finally received the permit, their life was put into question. Although their desire to emigrate had weakened, they felt a certain 'pressure' to start a new life in the US, as giving up the opportunity to migrate to the US regularly was a rather unpopular choice, particularly when so many Guyanese would still go to great lengths to have that right.

\footnotetext{
${ }^{76}$ Data source: DEMIG POLICY.

77 Guyana Chronicle, Sunday, December 6th, 1998, p13, 'US releases visa availability for Guyana' by Vishnu Bisram, available at Guyana National Library, Georgetown, Guyana.
} 
Heavy family migration also produced another dilemma when only one or two family members were left in Guyana. These individuals expressed a feeling of pressure as the family abroad encouraged them to migrate, yet they referred to 'not wanting to go'. Some people eventually gave in, while others resisted the pressure to 'be sent for' or to 'overstay' during each visit to Canada or the US. Among these individuals were grandparents needed by their adult children in the US to care for their grandchildren. These grandparents often engaged in 'partial' or 'pendulum' migration (de Haas and Fokkema 2010) and they returned to Guyana in wintertime. The trend of older women migrating to support their children and grandchildren was also observed by Karran (2007) among Indo-Guyanese women in Britain.

For people without access to regular migration channels, emigration often involved entering with a tourist visa and overstaying, obtaining fraudulent documents or utilising smuggling services. In the late 1980s, individuals, sometimes middle-aged and with relatively good jobs, chose to migrate to the US with their entire family by overstaying on a tourist visa, aware of the risks but also of the possibility to go undetected and find job opportunities in the Guyanese community. Irregular migration was a common topic in the Guyanese press from the late 1980s to the mid-2000s, with reports of yearly deportations from Canada and the United States, the reasons for their deportation including overstaying and summary descriptions of how the irregular status came about. Throughout this period, United States and Canadian diplomats in Guyana provided information on new policy rules introduced by their respective governments and long articles were published in national newspapers to announce any changes in visa procedures, fee changes, and visa processing times, often warning individuals that no exception to the queuing systems would be made under any circumstances. The ensemble of migration news reported in the Guyanese press raised the population's awareness of the available migration channels and the consequences of irregular migration, often supplemented by information they received from relatives abroad.

Since the late 1990s, migration to Canada has been decreasing in contrast to stronger emigration to the US (Figure 4.7). This may be due to the public perception that Canada's policies have become more restrictive; interestingly, this perception seems to be confirmed by the long-term trends of Canadian migration policies shown in Figure 4.7. Canadian authorities also announced in 2008 that skilled applicants would have to wait 3-4 years for their permit, a 50 percent 
increase over previous processing times. ${ }^{78}$ The gradual reduction of migration to Canada may indicate lower emigration of the East Indian population, since 80 percent of Canadians of Guyanese origin are East Indian (James 2007), but since most Guyanese migrating within CARICOM destinations are East Indian, this may in fact suggest that the family connections that have been able to support family reunification to Canada are exhausted and that the increasingly restrictive Canadian migration policies are limiting new Guyanese migration. ${ }^{79}$

Concurrently, intra-regional migration of Guyanese has continued to grow (Figure 4.8). Neighbouring Suriname is the easiest and cheapest destination, particularly for Guyanese living in the eastern regions of Guyana. These flows are facilitated by a porous and loosely patrolled border. In 1992 Suriname introduced strict immigration regulations that pushed employers to regularise the immigration status of foreign workers. ${ }^{80}$ The doubling of Guyanese-born residents in Suriname from 1990 to 2000 may reflect this regularisation process. A similar function is played by Venezuela for Guyanese living in the western regions of Guyana, while for Guyanese living in the south-western areas of the interior, Brazil has been the destination of choice. Given the limited infrastructure, for many of these individuals, reaching Boa Vista in Brazil is easier and cheaper than looking for economic opportunities in Georgetown. Further destinations gained popularity from the 1990s, including Antigua, Barbados and the British Virgin Islands, where higher wages and the tourist industry attracted Guyanese to work in hospitality and the service sectors (e.g. security, gas station attendants). French Guiana has also recorded an increase of Guyanese residents from 1650 in 1990 to 2400 Guyanese in 1999 (Granger 2007), figures that are much higher than those reported by the World Bank (Figure 4.8).

\footnotetext{
78 Stabroek News on Feb 26, 2008, 'Fewer Guyanese will be admitted to Canada under the Skilled Workers category', accessed on 11 August, 2013.

${ }^{79}$ I thank Prof Elizabeth Thomas-Hope for bringing my attention to the dominance of Indo-Guyanese in CARICOM migration and to possible effects of the exhaustion of family reunification channels.

${ }^{80}$ Guyana Chronicle, Wednesday, July 8, 1992, pp. 6 \& 8, 'Guyanese in Suriname: An Analysis by Daniel da Costa', available at the Guyana National Library.
} 
Figure 4.8. Guyana-born individuals residing in the Caribbean region, by country of residence, $\mathbf{1 9 6 0 - 2 0 0 0}$

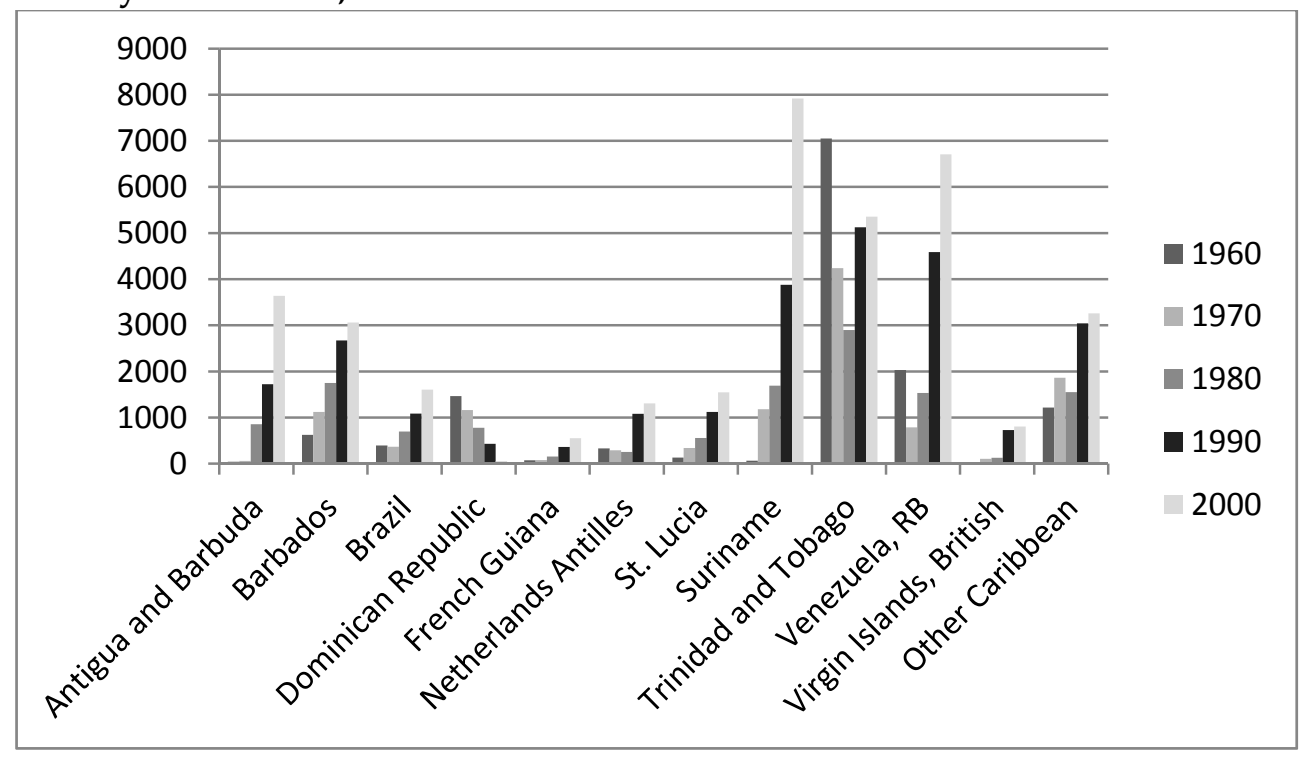

Source: World Bank Global Bilateral Migration Database

The growth in regional migration may partially be a spatial substitution effect of Canadian and US policies that have become more restrictive since the 1990s. However, regional migration has a long history and has been pursued by skilled workers such as teachers, carpenters and electricians, small traders (i.e. suitcase traders) as well as those with lower levels of education, limited financial resources and perhaps no family overseas, who look for earning opportunities within reach. However, even within the region, migration is often irregular, as despite promises of freedom of movement within CARICOM, privileges have largely remained for individuals with degrees or specific professions. As a result, migrants may work without permits (i.e. in Suriname, Venezuela and Brazil) or overstay tourist visas (e.g. Barbados and Trinidad). Over the years, deportations of Guyanese for irregular migration activities (e.g. entry, false documents and smuggling) were reported from the entire Caribbean region and Guyanese have earned a negative reputation, leading to Guyanese travellers regularly experiencing discrimination at the hands of border officers. 


\section{Connecting the state, structural changes and long-term migration: a discussion}

\subsection{The effects of a border regime and independence}

After a relatively small emigration throughout the 1950s, the introduction of the border regime and migration restrictions between Britain and British Guiana in 1962 stimulated an initial migration rush as about 1 percent of the population tried to 'beat the ban' that year. Independence encouraged a second emigration peak in 1965-1966, but in both years emigration was lower, about 0.7 percent of the population. The absence of a large outflow coinciding with independence suggests that the population did not largely perceive this event as a threat, which was confirmed in the interviews and by the fact that among Caribbean countries Guyana was the only British colony with an independence movement (Laing 1979). However, some pre-emptive emigration took place and this small emigration peak may be the result of the closed border regime, which prevented large emigration to Britain. In fact, we observe some spatial diversification of migration towards North America, where new immigration policies gave increasingly easy access to diverse populations, including Caribbean migrants, who found growing employment opportunities in North America (Peach 1968; Palmer 1974; Freeman 1987; Marshall 1987). Hence, although overall a large portion of the population welcomed independence and did not perceive it as a threat, had Britain not closed its borders four years prior, it is highly likely that the volume of the second emigration peak would have been higher, although probably not excessively so.

While significant, independence and the closure of the British border may have had a short-lived impact on Guyanese migration if political and economic stability had followed. In fact, emigration seemed to be on a downward trend by the end of the 60s and may have followed a similar trend as Barbados, which experienced a similar peak in 1960-1962 and then another smaller peak in 1967, after its 1966 independence, but migration in the 1970s was gradual and about half the size of its 1962 migration peak. Conversely, the migration patterns stimulated by the establishment of a border regime and independence in Guyana further developed as political and socio-economic conditions worsened and migration aspirations grew; hence, these initial patterns of migration would provide the background for long-term migration dynamics. 


\subsection{Weakened post-colonial ties}

While the linguistic and cultural similarities engendered by colonialism may produce a strong preference for migration towards the former colonial state, Guyanese migration offers a clear example of weak post-colonial migration effects. We can explain this development on the basis of a mixture of policy and cultural factors. First, the small emigration from Guyana before 1962 means that by the time borders closed Guyanese had not built up sufficiently large communities and concomitant strong network ties to counteract the increasingly restrictive migration policies. In fact, migration to Britain spans a short period sandwiched between the closing of US immigration in 1954 and the opening of Canada in 1962 and the US in 1965. The momentum built in this short period was insufficient to overcome British barriers to immigration, and by independence alternative destinations were becoming well established, making the former colonial state rapidly irrelevant. Moreover, as it emerged from the interviews, family members in Britain were allegedly reluctant to support further migration of relatives in Guyana, making regular or irregular immigration particularly challenging. Second, Guyanese, like other West Indian immigrants, may have been negatively affected by both the slumping British economy and British discriminatory attitudes towards former colonial 'subjects' mentioned above (the 'Rivers of Blood' speech being cited by two interviewees).

Concurrently, not only were immigration policies in North America opening new avenues for migration, but North American influence was perceived through North American television programmes (Byron 1999) and visits from migrants to North America displaying their relative wealth. The family reunification policies combined with the knowledge among Guyanese that, unlike in Britain, one could go to the US and live comfortably without a regular status, led to the rapid shift in major migration destinations, making Britain the ninth migration destination in 2000, hosting less than 1 percent of Guyana-born migrants, while the same year the US had almost 62 percent and Canada just over 23 percent of Guyana-born migrants.

Guyanese emigration offers a strong case to challenge the assumptions built into post-colonial ties and the embedded notion of a positive connection of former colonial citizens with the former colonial state. In this case, little categorical substitution occurred although Guyanese could travel visa-free to Britain and potentially remain irregularly or pursue other channels, such as asylum seeking. Linguistic connections with North America and cultural links with Canada, which is also a Commonwealth country, made these two destinations good substitutes for Britain. Moreover, the Guyanese government made visible efforts to distance itself from a post-colonial society, making important changes to the constitution, 
removing the clause that appeals of court cases would be heard in London (Laing 1979), 'decolonising' the education system, contributing to the building of a Guyanese national identity. Undoubtedly, however, the lack of a strong migrant network in Britain had an important effect in preventing, on a practical level, the pursuit of migration to Britain by 'jumping' across policy categories.

\subsection{Policy influence on migration composition}

The composition of Guyanese migration has undergone transformations over time reflecting changes in the conditions in Guyana, migration policies and attitudes towards migration. While in early years migration was closely linked to young people pursuing an education, the growing threat of a Communist takeover resulted in increasing emigration of the merchant class, composed of Portuguese and Chinese Guyanese. As evidenced in some of the interviews, uncertainties about the country's future stimulated entire families to emigrate after liquidating their assets, with the intention to start a new life in North America, never to look back. These individuals along with students and a small number of workers, who may have feared that they would be prevented from entering Britain in the future, largely made up the 1961-1962 emigration peak. Hence, this event affected a rather confined segment of the population.

Independence slightly expanded the representativeness of the population engaged in migration. Now emigration was the solution for those who were afraid of the changes that may be introduced in the country after independence, once again affecting the middle classes and particularly those Indo-Guyanese disappointed with the country's political developments. Therefore, independence led to a shift in the ethnic composition of migration: while pre-1964 emigration was primarily of Afro-Guyanese, along with early Portuguese and Chinese emigration, after the PNC victory in 1964 emigration of the Indo-Guyanese population gained strength (Menke 1983; Mhango 1983). In both events, only those with access to financial means and useful connections would have been able to migrate.

Emigration would become a widespread phenomenon from the 1970s onwards, including all classes and various ethnic groups, as a result of domestic policies. Emigration of young adults pursuing advanced education continued over the decades, but increasing numbers of Guyanese with tertiary education emigrated to escape discrimination, unfair treatment and the low wages prevalent in the nationalised economy. The increasing focus on skilled migration channels of North American migration policies made emigration for these individuals fairly straightforward. Intra-Caribbean emigration of teachers, skilled tradesmen, such as electricians, and traders gained strength as other Caribbean countries offered stability, higher wages and better opportunities. 
The most diffused channel to leave Guyana's hardship behind was family reunification to Canada and particularly to the United States. Similar findings on the dominance of family reunification emerged in a small study of migration determinants from the rural areas of Black Bush Polders (Gahunde 2012). Over the years, Guyanese emigration through family channels became dominant, supporting the emigration of skilled and unskilled, young and old, men and women, leading to the emigration of entire families. This cycle of family reunification led to emigration pressure among people, such as the elderly or the illiterate, who at times are 'forced' to emigrate to be with close family members. Altogether, such strong family reunification practices have resulted in a very strong and continually renewed awareness of family connections between Guyanese in Guyana and those overseas: on one hand the policies require the sponsor to be responsible for the physical and financial welfare of the grantee for a number of years after residence has been granted; on the other hand, evidence emerged that those 'sponsored' by relatives in North America also feel a long-term moral and financial 'obligation' towards their 'sponsors'.

Although family reunification opportunities have also allowed individuals in the lower class to emigrate, the interviews produced evidence of individuals who, in the past as much as in the present day, have been unable to emigrate due to a lack of connections, skills and resources. Interestingly, being born out of wedlock could be at once the source of adverse financial conditions and being left outside of the family reunification system. Among the poor, the difficulty in even obtaining a tourist visa, which alone is seen as a high-risk financial investment, prevents even the pursuit of irregular migration. However, for young adults without particular skills or family connections but some financial resource, irregular migration to North American and Caribbean destinations was a welldocumented practice from the 1980s to the early 2000s: while many overstayed tourist visas others used fraudulent practices such as fake passports or marriages of convenience. Today, however, many young Guyanese claim they would not engage in irregular migration unless they felt threatened in Guyana, suggesting that at present the risks of irregular migration may outweigh the risks of remaining in Guyana.

\subsection{Migration motives over 60 years}

Over the past 60 years, Guyanese emigration has been affected by five broad factors: education; political and ideological conditions, including politically-incited violence; economic factors in Guyana and abroad; migration policies; and family connections. These factors have already been discussed at length in this chapter; it remains to point to shifts in their relevance over the past 60 years. Education was closely linked with early emigration as students left for Britain or North America 
in the pursuit of advanced education, often with the support of a scholarship. Today, education is also a motive for emigration, but it is often in reference to the education of children, who are believed to have better chances in life if they pursue even the lower levels of education in North America. Family members abroad would encourage the sponsorship of siblings for the benefit of nieces and nephews' education.

Political and economic factors were clearly the stimuli for emigration for an extended period and to a certain extent they contribute to migration aspirations today as limited job opportunities, low wages, weak workers' rights and widespread corruption make living in Guyana difficult for the lower and middle classes. For many Guyanese, emigration is an escape from these conditions and an opportunity to build a life that goes beyond basic survival. Although emigration is perceived as a risky investment, Guyanese are also aware of successful migration stories and migrants' ability in accessing better job opportunities, higher wages, high-level educational programmes and better living conditions.

Over the years, this rich migration history has strengthened migration propensities and produced unique effects. While in the past emigration was a means to an end, e.g. to study, to work, to escape poor living and working conditions and start anew elsewhere, with the passage of time emigration may have become an end in itself. Along with some dependency on remittances in cash and in kind, evidence emerged of people who upon entering the 'migration cycle' put their life 'on hold' in anticipation of the arrival of their residence visas and the start of a new life abroad. Such migration became disconnected from and unresponsive to other political, economic, educational factors and solely linked to family connections and migration policy changes which could speed up or delay the visa. Since the 1980s, family and household dynamics help to explain unique forms of migration: elderly parents emigrating to care for grandchildren abroad; the last few family members left in Guyana who emigrate so that the entire family is abroad; the migration of entire young families because relatives abroad insist that education is better abroad; pressure to remain abroad when visiting migrant relatives; and the disappointment of family abroad when Guyanese decide to resist the pressure to stay abroad, and return to Guyana. Hence, while family reunification has provided emigration opportunities for many who seek them, one can also perceive a certain 'family reunification pressure' that has been enabled by migration policies but has in itself become an important migration motive.

\section{Conclusion}

From the analysis of the border regime and independence effects to the examination of migration motives, destinations and migration composition in the 
post-independence period, we observe the multiple ways in which the Guyanese state has had a long-lasting impact on Guyanese development, engendering a deep reliance on emigration: the creation of heavily politicized ethnic tensions and political violence and crime, authoritarianism and constitutional changes, deep economic and educational reforms. However, an analysis of Guyanese emigration cannot ignore two external factors: first, the role of migration policies of destination countries; second, the intervention of external governments in Guyana's internal affairs during Cold War period, which contributed to Guyanese emigration by undermining the formation of the post-independence Guyanese state, generating anxieties and the instability which endured until the late 1980s and reinforced persistent governance problems. These issues underscore the unfailing importance of the state in origin and destination countries in combination with immigration policies at destination.

Despite these ongoing conditions, Guyanese migration has been decreasing over the last two decades. This paradox may be explained by the increasingly restrictive immigration policies of major destination countries that target family reunification and the low- to medium-skilled categories that are significantly important for Guyanese. Then again, Guyanese migration may have switched towards irregular channels, or alternatively, to regional destinations. Yet, what we observe may be a real shift in migration patterns. In fact, despite the hardship and the fact that many people would migrate if given a chance, there are also positive reflections about changing opportunities in Guyana: young people with skills and some financial resources perceive Guyana as a place which offers some opportunities, particularly for the self-employed. The immigration of Brazilians and new Chinese immigrants, who occupy specific economic niches, and visible Trinidadian investment in commercial ventures have raised awareness of Guyana as a place of economic opportunities. As a result, when migration is considered, it is no longer exclusively associated with a one-way trip out of Guyana, a pattern that prevailed since the late 1960s. Rather, some young Guyanese express the desire to work outside of Guyana for a short time and return to Guyana to invest their savings in small business ventures. Whether these are early signs of a real shift in migration patterns remains to be seen. 


\section{Chapter 5 - The evolution of Surinamese emigration across and beyond independence ${ }^{81}$}

\section{Introduction}

The South American country of Suriname is little known outside the Dutch sphere of influence, partly due to its small population size - just under 525,000 in 2010 and partly because of its almost exclusive geopolitical orientation towards the Netherlands, its former colonial state. Yet, Suriname is a remarkable case because of the large volume of emigration during the period of political status change, i.e. the years around independence in 1975 and the establishment of a full border regime with the Netherlands in 1980. The consequences of these events persist as in 2000 Suriname was among the top ten emigrant countries, with 56.3 percent of the total Surinamese population residing abroad (Koser and Laczko 2010), almost three quarters of whom were concentrated in the Netherlands (see Figure A1 in appendix D). The literature commonly associates the uncertainties of independence with emigration, yet little attention has been given to the fact that independence was followed by a five-year period of minimally-regulated migration before borders were fully closed, a rather unique sequence of events which affected not only the volume, timing and composition of migration, but also its concentration in the Netherlands. This chapter specifically examines the sequence of independence and border regime closure and its effects on Surinamese emigration and then considers more broadly the role of the Surinamese and Dutch states in shaping emigration patterns over the years, not only through the enactment of migration policies, but through a broad range of policies and state actions.

This chapter draws from literature by primarily Dutch and Surinamese scholars who have examined specific periods of Surinamese migration (SedocDahlberg 1984; Bovenkerk 1987; van Amersfoort 2011), the impact of Surinamese

\footnotetext{
${ }^{81}$ This chapter is based on the author's working paper, 'The Evolution of Surinamese Emigration across and Beyond Independence: The Role of Origin and Destination States.' In IMI Working Paper Series 106/DEMIG Project Papers 28: International Migration Institute, University of Oxford, 2014.
} 
emigration on the country's development (Kalpoe 1983; Krishnadath 1983; Menke 1983; Mhango 1983; Monsels 1983; de Bruijne and Schalkwijk 1994; Hassankhan 1997; Dulam and Franses 2011), the welfare of Surinamese migrants in the Netherlands and their remittance behaviour (Reubsaet 1984; Gowricharn and Schuster 2001; Gowricharn 2004; van Niekerk 2005) and return migration (Bovenkerk 1981). A few very valuable academic papers also discuss political, demographic and socio-economic changes and their migration effects (Lamur 1973; Dew 1978; Chin and Buddingh' 1987; Menke 1990; Jeffrey 1991; Menke 1991; Menke 1998). This chapter adds to this literature by presenting an analysis of Surinamese emigration based on the conceptual framework developed in chapter 2 , which considers the migration effects of independence, border regimes and postcolonial ties and potential migration substitution effects (de Haas 2011).

This chapter relies on two sets of sources: (i) secondary literature and primary sources such as newspaper articles from De Ware Tijd to reconstruct the political, economic, social and legal transformation in Suriname and the policies designed to manage migration to the Netherlands and other destinations; (ii) 32 interviews conducted in Suriname and French Guiana between December 2014 and April 2015 to explore individual migration trajectories and motives as well as conditions associated with staying behind. Among the interviewees, 9 were migrants still abroad, 11 were returnees and 11 had never migrated from Suriname. One additional in-depth interview was conducted with a scholar with great familiarity with government policies and perspectives since independence.

As with the analysis of Guyanese emigration in the previous chapter, this chapter focuses on the role of the state in the evolution of Surinamese migration patterns from the early 1950s to the early 2010s (see Figure A2 for complete migration trend over this period) and relies on two main guiding questions: (i) what have been the short- and long-term migration effects of independence and the establishment of a border regime? And (ii) what has been the importance of post-colonial ties for migration and how have they affected migration? After a brief presentation of historical Surinamese migration up to 1954, the chapter examines the evolution of migration patterns in association with political, social and economic factors in Suriname in four broad phases which reflect distinctive patterns of emigration: 1954-1972; 1973-1982; 1983-1994; and 1995-2010s. The chapter concludes by presenting insights on the main patterns of Surinamese emigration and elaborates on the role of the state and structural changes in shaping long-term emigration. 


\section{Early migrations and population diversity}

\subsection{Early labour immigrations and the formation of a diverse population}

Suriname was acquired in 1667 by the Dutch after a brief colonisation by British settlers in 1630. Populating the colony proved to be a challenge as Dutch settlers preferred to pursue more lucrative opportunities in the East Indies; consequently the Dutch government invited European planters from the Caribbean to settle in the colony, an invitation taken up by a small number of British planters. Planters relied on slave labour transported from Africa until the abolition of slavery in 1863, when 95 percent of the population in Suriname was of African origin; the remaining European population included Dutch but also Portuguese Jews and other Ashkenazim populations (Oostindie 2008).

In 1873, after a ten-year period of compulsory work on the plantations, former slaves began to gradually leave the plantations and enter the urban areas and mining sectors. To satisfy labour demand on the plantations, planters resorted to recruiting indentured labourers: between 1853 and 1873, small numbers of Chinese were brought to Suriname from the Dutch East Indies, Hong Kong and Canton; from 1873 to 1917 around 34,000 British Indians were recruited, while about 33,000 Javanese migrant workers were brought to Suriname between 1890 and 1940 (Hoefte 1987). The arrival of indentured workers marked an important shift in the ethnic composition of the population of Suriname, as by the mid-20th century the population was 47 percent of African descent, 35 percent East Indian and 14 percent Javanese (Oostindie 2008). Small autochthonous Amerindian populations as well as Maroon populations descending from escaped slaves continued to reside in the interior, largely untouched by the political and socio-economic colonial activities taking place in the coastal areas (Taylor and Bers 2010). The population in the interior was also largely untouched by the programme of 'Dutchification,' which encouraged assimilation of Dutch customs and values and safeguarded the endurance of colonial influence (Meel 2001: 129-130).

In the 1933-44 period, Governor Kielstra softened Dutch assimilation policy and encouraged each group to express its cultural identity. Diverse religious and cultural traditions emerged as well as a rich language diversity with Dutch coexisting with Sranan Tongo, i.e. the language of the creolised Afro-Surinamese as well the lingua franca in Suriname, Sarnami Hindi, Surinamese Javanese, Hakka Chinese and a number of Amerindian and Maroon languages (Meel 2001; Taylor and Bers 2010; van Amersfoort 2011). The early assimilation programmes exposed the population of African descent to European customs and values, leading to the formation of a Creole Afro-Surinamese population with early connections to 
European cultures and power, while the East Indian, commonly referred to as Hindustani, and Javanese populations retained greater ethnic distinctiveness and a weaker adoption of Western values (Oostindie 2008). However, such distinction and closeness to Dutch culture and values were less visible among the lower classes, regardless of ethnic group. ${ }^{82}$

\subsection{A gradual shift from immigration to emigration}

In the first half of the $20^{\text {th }}$ century, Suriname experienced both immigration and emigration. In addition to the arrival of labourers from India and Java, cohorts of these workers were also repatriating. Between 1878 and 1920, about 11,600 British Indians were repatriated to India with much smaller repatriation figures in the 1920s, while about 7,600 Javanese were repatriated during the 1896-1939 period with the strongest returns between 1928 and 1938 (Hoefte 1998). In fact, 2383 returned between 1928 and 1931, 2254 between 1935 and 1939 and 756 left in 1947 to return to Indonesia (Lamur 1973), while a group of 1,000 Javanese returned as late as 1954 (Hoefte 1998). These peaks are visible in Figure 5.1.83

In the meantime, forms of emigration to the Netherlands were gradually emerging. Emigration occurred among urbanites who belonged to privileged classes, e.g. planters, merchants and their relatives, mainly of Jewish and (often light-skin) African descent. The children of the elite often left to study as education was a way to obtain a prestigious position in the bureaucracy in Suriname; not everyone returned and it was estimated that in the 1950s only up to one quarter of these individuals returned (Bovenkerk 1981). Although the Creole population was more heavily represented in these early emigrations, the interviews showed that some Hindustani also emigrated as the Netherlands was perceived to offer better education and more opportunities for social mobility.

\footnotetext{
${ }^{82}$ I thank Rosemarijn Hoefte for bringing my attention to the importance of class.

${ }^{83}$ This figure and Section 3 rely heavily on data from Humphrey E. Lamur's 1973 doctoral thesis entitled The Demographic Evolution of Surinam 1920-1970: A socio-demographic analysis. This work uses immigration and emigration data which originate in Surinaams Verslag for the 1922-1948 data, while post-1949 data was collected from registers of 'Arrivals and Departures', statistics collected and registered by the Departments of Civil Affairs of the various District Commissariats, on the basis of residence change forms. Lamur compared the data from the continuous registers with that of the Aliens Branch of the Ministry of Justice, which registers all persons who leave or enter the country, regardless of the duration or purpose of their stay. This data compared reliably with the continuous registers of the District Commissariats, with the exception of the years 1950-1963 for which data from continuous registers was not used (Lamur 1973: 11, 22).
} 
Figure 5.1. Total immigration to and emigration from Suriname, 1922-1950

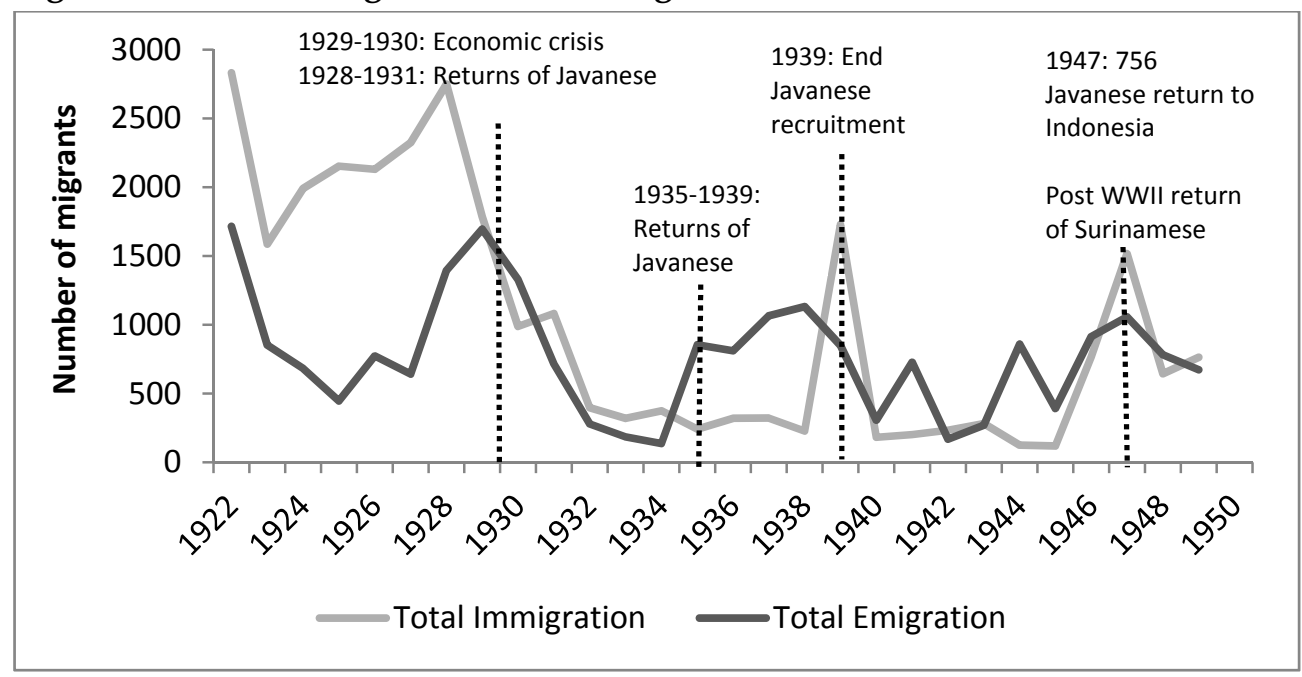

Source: Lamur 1973

Another group of migrants consisted of low- and middle-class workers, often unemployed, who left Suriname in the late 1920s and early 1930s to work in the oil industry in Curaçao and Aruba, and manual workers and seamen in Cuba, Panama and the US (Lamur 1973; Menke 1983; Gowricharn and Schuster 2001; Runs 2006; Oostindie 2008). Other small migrations included Dutch officials, businessmen and military personnel returning to the Netherlands at the end of their tour of duty (Lamur 1973) and small numbers of people who married or retired in the Netherlands (Gowricharn and Schuster 2001). Concurrently, Surinamese men who had been fighting for the Netherlands during the World Wars (Hassankhan 1997) as well as migrants from the Netherlands returned to Suriname, contributing to the immigration peak in the mid-1940s (Lamur 1973).

\section{From autonomy towards independence: social changes and growing emigration (1954-1972) ${ }^{84}$}

Dutch and US immigration statistics combined recorded a significant change in emigration volume between 1964 and 1971 when they received over 41,300 Surinamese immigrants (Figure 5.2). However, emigration was also changing in character, driven by a number of socio-economic and political transformations explained in the following subsections.

${ }^{84}$ Ibid. 
Figure 5.2. Emigration from Suriname, 1954-197385

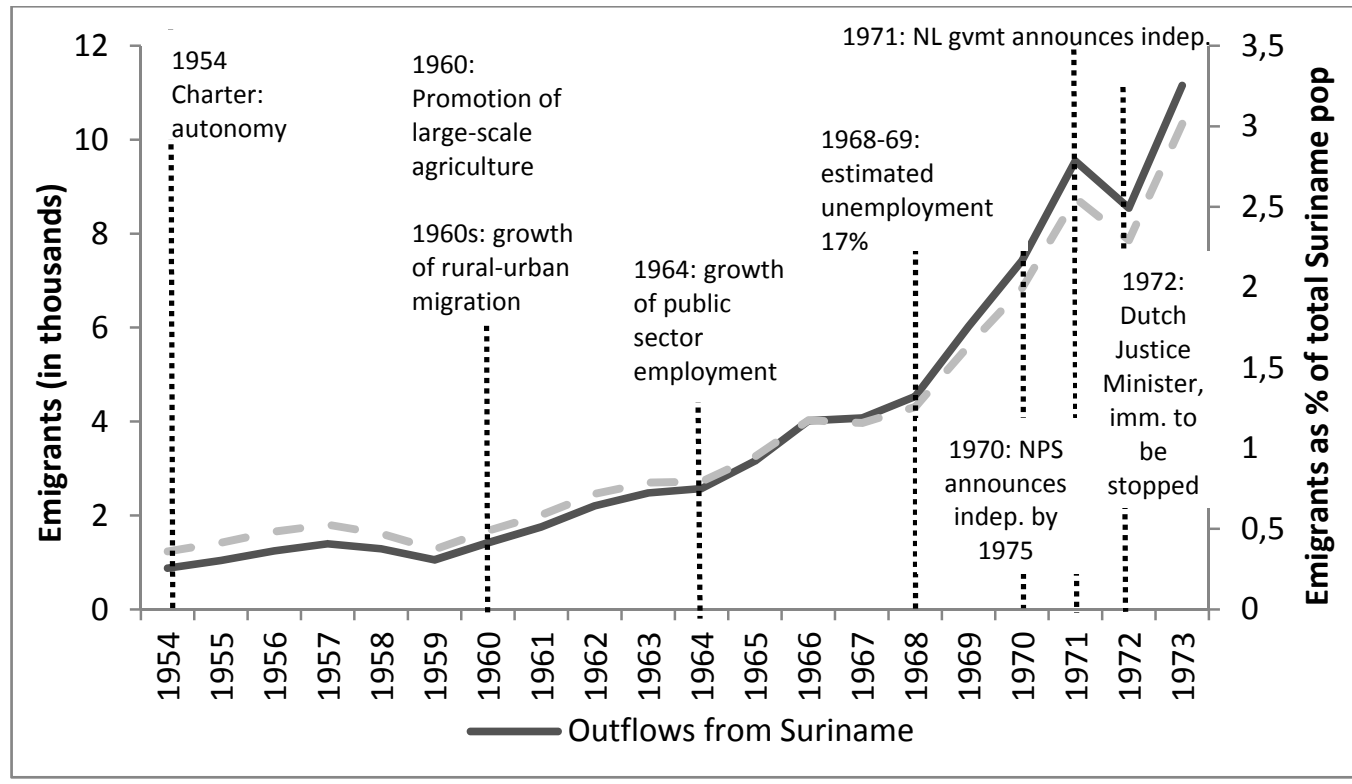

Sources: World Bank Global Bilateral Migration Database and UN Population Estimates.

\subsection{Labour market shifts and labour displacement}

Lamur (1973) associated the growth of emigration from the mid-1960s with Suriname's deteriorating economic conditions, while other literature linked emigration to education and to a sense of 'adventure' of members of the middle and higher classes, and suggested that only a marginal numbers of individuals emigrated in search for a better life (Gowricharn 2004). Indeed, the economic conditions were undergoing some transformation: on one hand Dutch-led economic plans had failed to diversify the Surinamese economy through industrialisation and continued to rely heavily on bauxite production, which contributed up to one third of Suriname's GDP from the mid-1940s to 1975; on the other hand, a new agricultural strategy stressed large-scale production and the export of rice and bananas (van Dijck 2001). Technological innovation and mechanisation increased land cultivation and yields, but reduced the need for seasonal labour and, by the 1970s, large-scale agriculture effectively supplanted the previously self-sufficient small-scale rice production (Menke 1983). Surinamese farmers and labourers left agriculture and migrated to the capital Paramaribo or began to join the growing flow of migrants to the Netherlands (Lamur 1973; Menke

\footnotetext{
${ }^{85}$ From here onwards, whenever the source of emigration data is DEMIG C2C, it was compiled using Dutch, Canadian and US immigration figures combined, unless otherwise indicated.
} 
1983), while rice planters filled their seasonal labour demand with low-cost labour from neighbouring Guyana (Menke 1983).

Surinamese leaders encouraged economic growth by attracting foreign investors for large infrastructural works (Sedoc-Dahlberg 1990; Buddingh' 2001) such as the Alcoa-financed Brokopondo project to build facilities to convert bauxite into alumina and aluminium. The project was accompanied by high hopes of economic growth and employment for many Surinamese; however, both effects were short-lived. The low contribution of this industry to national employment and the lack of other important foreign investments meant that structural unemployment remained high (Buddingh' 2001). The Surinamese government attempted to alleviate this problem by creating public service jobs and joint ventures largely owned by the Surinamese state (i.e. 51 and 60 percent, respectively) (Menke 1990) leading to an increase in public sector employment from about 6 percent of total employment before 1960 to 25 percent in 1964 (de Bruijne 2001). Public employment was largely concentrated in the capital Paramaribo and benefited primarily the urban Creole population, while the Hindustani population was more heavily concentrated in commerce, partly contributing to their advance into the middle class, both in rural and urban areas (Menke 1990; de Bruijne 2001). The government also promoted social projects on education, housing and health, which in addition to their social benefits were also meant to reduce emigration to the Netherlands (Sedoc-Dahlberg 1990). Still, negative economic growth, 17 percent estimated unemployment (Dew 1978) and social unrest contributed to the rapid increase in emigration starting in the late 1960s (Menke 1998).

As conditions were deteriorating in Suriname, Dutch companies in the Netherlands needed workers and advertised job vacancies in Surinamese newspapers. An interviewee explained how some companies offered work-study programmes, which required young adults to work in factories while pursuing their technical studies. Teachers were in high demand in the Netherlands and Surinamese teachers were ideal recruits because of their knowledge of the Dutch language and their training in the Dutch curriculum. A combination of lack of employment opportunities in Suriname, increasing gaps in standards of living between Suriname and the Netherlands and a period of labour demand in the Netherlands suggests that the growth of emigration may be at least partly explained by economic and employment motives.

\subsection{The pursuit of education}

Rural-urban migration was also linked to the pursuit of education (Lamur 1973). Secondary education was often not available in rural areas, forcing students to go to Paramaribo, where they might remain at the end of their studies. However, the 
Netherlands was the main destination for higher education: since higher technical schools were not available in Suriname until the 1970s (Buddingh' 2001), individuals who wanted to become mechanics, civil engineers or other technical professions were obliged to go abroad. Scholarships were available for professional development in the service sector, such as for the police force (Bovenkerk 1981) and in health services. Among the interviewees, two men left for the Netherlands to pursue higher technical studies and two women learned about nursing training programmes from magazines. The interviewees recalled many of their friends being 'recruited' in this manner. University education was facilitated by Dutch government-funded scholarships, which were initially available only for children of the elite, many of whom were light-skin Creoles and, starting in the 1950s, were extended to the entire Surinamese population (Gowricharn and Schuster 2001). The Surinamese government also funded fellowships to train Surinamese teachers in the Netherlands, ${ }^{86}$ while medicine students received some of their education in the Netherlands. ${ }^{87}$ Gradually migration for education stopped being exclusive to the elite, although the population benefiting from these opportunities was still not fully representative of Surinamese's ethnic diversity (Bakker, Dalhuisen et al. 1993: 117 in Janssen 2011: 8).

\subsection{Emerging political motives}

In 1954, the Charter of the Kingdom of the Netherlands (Statuut voor het Koninkrijk der Nederlanden) gave Suriname and the Netherlands Antilles internal autonomy. 88 Negotiations for the Charter underlined different perceptions on the desirability of Dutch control among the different ethnic groups in Suriname, with many Creoles seeing autonomy as the anticipation of independence and the Asian groups generally desiring a long preparatory path towards sovereignty (Janssen 2011). Political discussions gradually centred along these divergent visions: the Hindustani VHP party rejected independence while the Creole NPS party demanded independence by 1974 (Dew 1978; Moore 2001:243). The Hindustani population's position was based on fears of discrimination and continued exclusion from political and economic participation, while the Creole population feared that the growing Hindustani population would take over the country (Menke 1990; Hassankhan 1997).

\footnotetext{
${ }^{86}$ This information emerged from an interviewee who received a similar fellowship.

${ }^{87}$ The husband of one of the interviewees studied in a joint programme offered by the University of Leiden.

${ }^{88}$ The Charter granted specific traits of sovereign states, such as the right to issue currency (Giacottino 1995), while the Dutch government retained control over international defence, budgets and development plans (Janssen 2011; Oostindie 2006; Sedoc-Dahlberg 1990).
} 
Despite the tense atmosphere, in 1971 the Dutch government reacted to the public debate in the Netherlands which questioned the benefit of its colonies by unilaterally announcing that it would give independence to its autonomous territories (Moore 2001). Three issues were salient: (i) growing Surinamese immigration; (ii) the Dutch military intervention in Curaçao's 1969 riots, which was perceived internally as a financial burden, and externally as a Dutch neocolonial intervention; (iii) discomfort with the long-term Dutch commitment to secure the territories' economic viability (Janssen 2011; Moore 2001; Oostindie 2006; Sedoc-Dahlberg 1990). The Dutch political agenda moved rapidly forward and in late 1972 the Dutch Minister of Justice van Agt indicated that immigration would be limited, either by introducing quick changes in nationality or by changing the Dutch Constitution. Prospects of independence and barriers to migration generated growing anxiety among both the Hindustani and Creole populations, contributing to the growth of emigration in the late 1960s and early 1970s.

\subsection{Shifts in the composition of emigration}

In this period, the majority of emigrants were Creoles from the middle and lower classes, but Hindustani emigrants doubled from about 12 percent of total emigration in 1962 to about 24 percent in 1970 (Figure 5.3). Each ethnic group was increasingly affected by emigration, although the Creole population remained the most migratory over the 1964-1970 period (see Table A1 in appendix D) (Lamur 1973).

In addition to the specific political motives just mentioned, an economicbased explanation can be proposed for the ethnic and class shift in emigration: on one hand, a large number of Hindustani farmers were displaced by processes of mechanisation in agriculture, leading to migration to urban areas and overseas; on the other hand, the advancement of the Hindustani population into the middle class may have increased the aspirations of this segment of the population to emigrate for education or other endeavours, while their increased financial capabilities may have facilitated emigration. Concurrently, the Hindustani youth gained eligibility for Dutch-funded scholarships, possibly giving further impulse to emigration for education. 
Figure 5.3. Emigration by ethnic group, 1964-197089

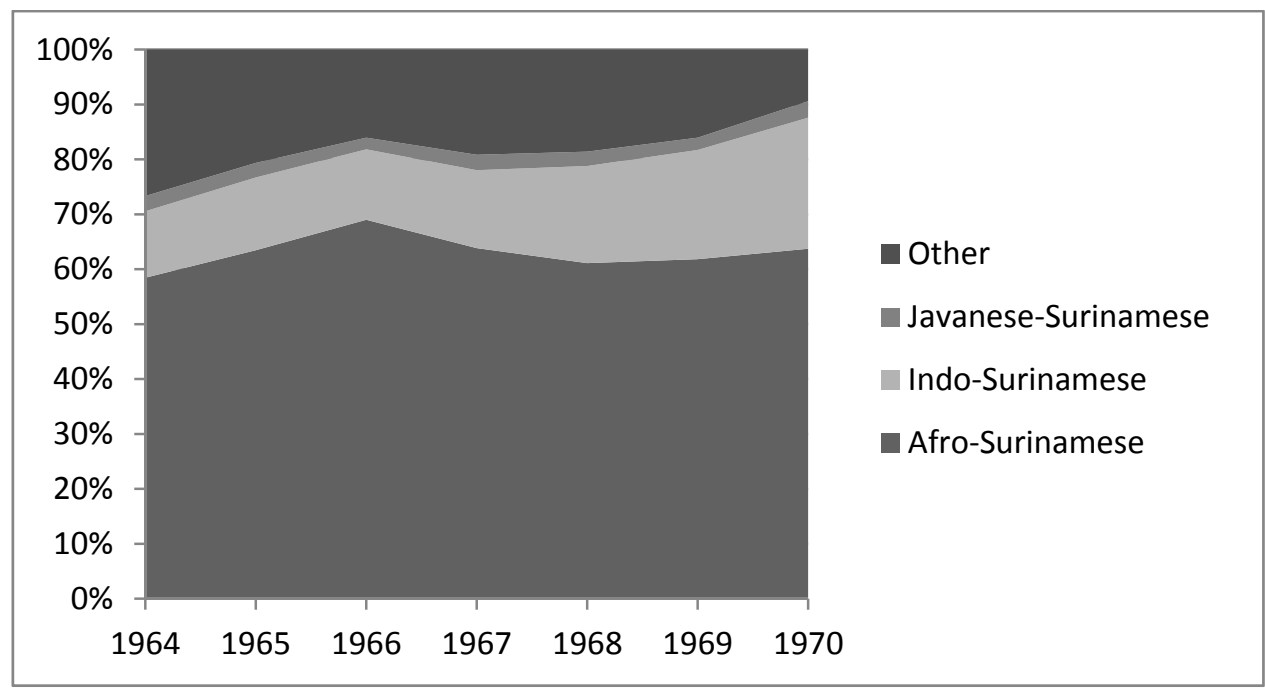

Source: Figures elaborated from data in Tables 51 and 54, Lamur 1973

Shifts in age composition of migrants were also taking place at this time: age-disaggregated data shows the rapid growth of emigration among 0-14 year olds, suggesting the importance of emigration of entire families of all ethnic backgrounds (Lamur 1973; Krishnadath 1983). This was supported in the interviews: in this period, three women were brought to the Netherlands by their parents at the ages of 3, 5 and 12 years. Interestingly, the gender composition of Surinamese emigration was also shifting: starting in 1970 women were just above 50 percent of all emigrants (Lamur 1973), marking the beginning of a long-term prevalence of women emigrating from Suriname. Women went to the Netherlands to become nurses or teachers, to leave unpleasant relationships and in some instances they were sent to the Netherlands by the parents (i.e. to prevent relationships), but in some cases it was the generous Dutch welfare system that stimulated migration. ${ }^{90}$

By 1972, the Surinamese population in the Netherlands was representative of the ethnic background, class and gender distribution of the population in Suriname, including small numbers of Maroons, Chinese, whites and Amerindians (Bovenkerk 1981; Gowricharn and Schuster 2001). The pervasiveness of emigration was apparent in the narratives of the interviewees, who in almost all cases had at

\footnotetext{
${ }^{89}$ The 'Other' category includes Dutch, other Europeans, Chinese and Amerindian, with the Dutch being the largest group.

90 Across the periods of Surinamese migration, women discussed personal and sentimental issues as migration reasons, e.g. to stop an abusive relationship and to escape cultural traditions.
} 
least one relative abroad and in a few cases indicated that most of their family was already abroad. Almost inevitably, relatives in the Netherlands provided initial migration support, enabling most migrants to emigrate.

\section{Emigration peaks across independence and the establishment of a border regime (1973-1982)}

Over 18,000 individuals born or residing in Suriname left in 1974 and almost 40,000 in 1975, the year of independence, when the migration rate jumped from 5 to 11 percent of the population in Suriname. Emigration to the Netherlands decreased significantly after 1975, but it increased again in 1979-1980, when over 37,000 Surinamese emigrated (Figure 5.4). ${ }^{91}$ These emigration spikes can be easily associated with independence and the establishment of a border regime with the Netherlands, but interwoven are other deep processes of political and economic transformation which shaped the timing, volume and composition of migration in this period and are discussed in the following sub-sections.

Figure 5.4. Migration from and to Suriname, 1970-1985

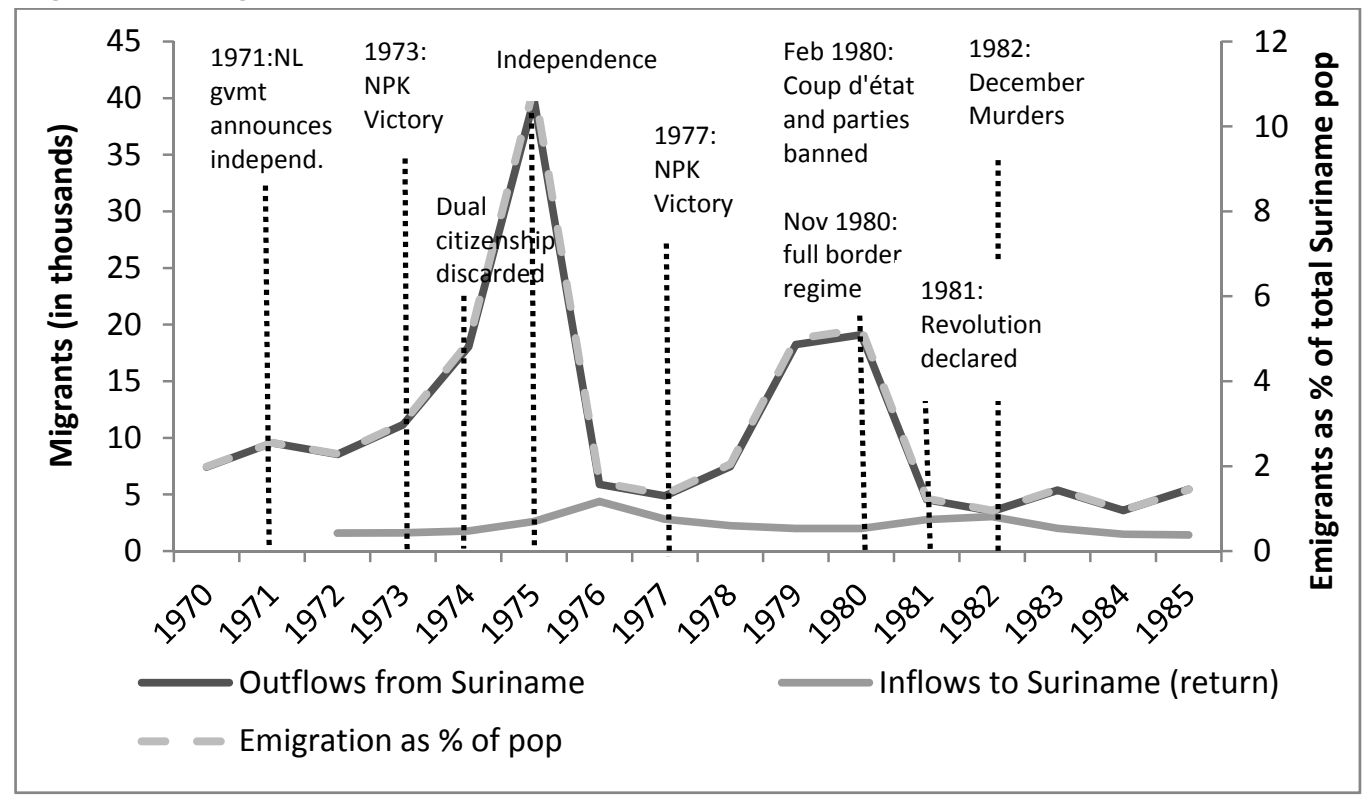

Sources: World Bank Global Bilateral Migration Database and UN Population Estimates

${ }^{91}$ Based on combined immigration figures by the Netherlands, Canada and the US, reported in the DEMIG C2C database. 


\subsection{Uncertainty and growing anxiety as migration drivers}

\subsubsection{Divergent positions on independence and citizenship}

The year 1973 started with strikes and demonstrations led primarily by Creoles in labour unions (Dew 1978). A tense electoral campaign followed these events, as the Hindustani VHP party leaders warned that a Nationale Partij Kombinatie (NPK) victory would result in great insecurity and terror. The NPK was a Creole and Javanese coalition which included radical parties such as the pro-independence PNR (Dew 1978; Menke 1990; Moore 2001). VHP party members suggested that the PNR leader Eddy Bruma would call for independence and push the Hindustani population to leave Suriname as the East Indians had been forced to leave Uganda (Dew 1978: 170). Nonetheless, the NPK won the election, the VHP was relegated to the opposition (Dew 1978; Chin and Buddingh' 1987; Menke 1990; Moore 2001) and in February 1974, Minister-President Arron announced that Suriname would become independent by the end of 1975 (Chin and Buddingh' 1987), generating such anxiety that an Hindustani organisation even sought to create a separate Hindustani state in Western Suriname (De Ware Tijd, June 18, 1974 cited in Dew 1978: 178). However, opposition to independence also gradually emerged within the NPK (Dew 1978: 181) and the Creole population.

Unable to stop independence, the VHP focused on citizenship and proposed the retention of Dutch nationality through dual nationality for an indefinite period (De Ware Tijd, July 4, 1974 and August 8, 1974 cited in Dew 1978: 179). The NPK counter-proposed that only the Surinamese in the Netherlands should be allowed to choose their nationality, while in Suriname the population would become automatically Surinamese. This position was viewed favourably by the Dutch government (De Ware Tijd, August 10, 1974 cited in Dew 1978: 179), whose strong objective was to halt Surinamese immigration (Sedoc-Dahlberg 1984). Throughout 1975, dual nationality became a point of contention: Hindustani politicians claimed that Surinamese unable to travel to the Netherlands to secure Dutch citizenship would suffer social injustice, while Javanese politicians threatened to take planeloads of constituents to the Netherlands (De Ware Tijd, November 14, 1975 cited in Dew 1978: 190). The Dutch government refused motions for dual citizenship (Dew 1978: 188-189), while it threatened to introduce measures, e.g. visas, to stop the growing emigration flow, although none of these measures were introduced (van Amersfoort 2011). In the meantime, the Surinamese government saw emigration as a 'safety valve' to deal with a poor economy, structural unemployment and reduce social tensions (Moore 2001: 245).

The Dutch government's immigration obsession and rush to grant independence gave the Surinamese government ample room to negotiate unique migration and, as we will see later, economic privileges. A few days before 
independence the Dutch and Surinamese governments reached agreements: First, Suriname's new constitution largely extended the previous constitution and provided some guarantees against ethnic discrimination (Giacottino 1995). Second, regulations on citizenship and migration were adopted: all Surinamese on Dutch territory on independence day would be able to retain Dutch citizenship (van Amersfoort 2011); after independence, all Surinamese nationals enjoyed the right 'to obtain a three-month residence permit in the Netherlands and, on conditions that he/she be self-supporting, could obtain Dutch citizenship' until November 1980 (Chin and Buddingh' 1987: 139); and Surinamese nationals enjoyed visa-free travel to the Netherlands until November 1980. Starting in November 1980, Surinamese citizens required a travel visa to enter the Netherlands and those who wanted to stay for a longer period would need a work permit, issued upon demonstrating access to adequate housing. Although these were very favourable conditions compared to border regimes established by other colonial states, for many Surinamese who saw migration as 'normal' (Sedoc-Dahlberg 1984), these restrictions seemed harsh.

While independence is always bound to raise uncertainties, in Suriname it generated heightened levels of anxiety, possibly associated with two factors: First, throughout this process, independence remained a movement of the elite and intellectuals and never reflected a widespread desire for self-determination (Chin and Buddingh' 1987; Moore 2001). Moreover, while the Creoles perceived independence as the end of Dutch oppression, other ethnic groups did not share such feelings (Hassankhan 1997) leading the Asian population to perceive independence more as an uncertainty than a cause for celebration. Second, feelings of uncertainty were worsened by the unstable conditions in neighbouring Guyana (Moore 2001: 246), which was held up as an example of the possible dangers of independence in a similarly ethnically-diverse society (Hassankhan 1997; Meel 2001). De Ware Tijd frequently reported on Guyana's socialist agenda, its worsening conditions and irregular Guyanese immigrants involved in various criminal activities in Suriname. ${ }^{22}$ Hindustani interviewees talked about Guyana's difficult political and socio-economic conditions, the discrimination suffered by the IndoGuyanese population and the strong fear of similar outcomes in Suriname. Chaos, discrimination and fear of loss of hard-earned family property were used to explain why their families and relatives left in 1973-1975.93 This multi-layered sense of insecurity, in contrast to the certainties guaranteed by Dutch citizenship

\footnotetext{
${ }_{92}$ Based on a review of De Ware Tijd in 1973 and 1979.

${ }_{93}$ Interviews with Indo- and Javanese-Surinamese non-migrants showed that not everybody felt a great degree of fear as some individuals separated political agendas from reality. Although some of these individuals had the contacts and opportunities to emigrate, their priority was to keep their businesses going and their family united.
} 
and opportunities in the Netherlands, contributed to the mass emigration anticipated by the newspaper De Ware Tijd (De Ware Tijd, August 14, 1974 cited in Dew 1978: 179-180), as many Surinamese rushed to secure Dutch citizenship before November 1975.

\subsubsection{The 1980 coup and the 1982 December murders}

Political tensions subsided in the post-independence period, but the 1977 electoral campaign reignited VHP alerts against Arron's coalition. Once again the VHP lost and was left out of government, protracting anxieties among the Hindustani population (Giacottino 1995). This time, political discontent had grown among the population at large and in February 1980 a group of non-commissioned officers led by Colonel Bouterse carried out a successful coup d'état, justifying it as a necessity to resolve corruption and inefficiency, change the economic model and eliminate ethnic conflict (Bovenkerk 1981). Some members of the Dutch military also saw the coup as a necessity and offered covert support, while the Dutch government speedily provided 'an unprecedented volume of aid' in 1980-1982 (Sedoc-Dahlberg 1990). ${ }^{94}$

The coup initially enjoyed the support of large parts of the population, who saw it as a possible source of change (Chin and Buddingh' 1987; Menke 1990; Thorndike 1990; Gowricharn 2004). However, signs soon appeared that the coup's leaders were unprepared to fulfil their promises (Bovenkerk 1981). On the contrary, in 1980 the military junta banned party activities (Chin and Buddingh' 1987) and became increasingly repressive, leading the population to turn to the streets of Paramaribo in a number of strikes in late 1982 (Thorndike 1990). The junta increasingly repressed political opponents, eventually leading to the murder of 15 opponents who were former supporters and now wanted the restoration of democracy (Sedoc-Dahlberg 1990). The murders, commonly known as the December Murders, shocked the population, shattered the Dutch government's belief that democracy would be restored (Buddingh' 2001) and led to a sudden halt of Dutch financial aid (van Dijck 2001).

It remains debated how much the coup contributed to the 1979-80 wave of emigration. While some believe that this was the case, three reasons suggest the contrary: (i) the increase in emigration started in 1977; (ii) the difference in total outflows between 1979 and 1980 is only 870, about 4.5 percent of the 1980 total emigration, which does not suggest panic, like that witnessed at independence (there the difference in outflows between 1974 and 1975 was almost 22,000!); and (iii) the literature and several interviews suggest that initially the coup was

\footnotetext{
${ }^{94}$ The Dutch government's initial support relied on its understanding that the civilian government created by the ruling military junta guaranteed a speedy return to democracy (Buddingh' 2001).
} 
welcomed by many Surinamese (de Bruijne 2001). Conceivably, the second loss of the VHP in the 1977 elections may have stimulated emigration as it strengthened feelings of anxiety linked to possible future discrimination against the Hindustani population. ${ }^{95}$ Moreover, evidence shows that visible patronage and nepotism produced discontent and hopelessness across ethnic groups, making emigration increasingly desirable (Thorndike 1990).

\subsection{Economic conditions and development aid}

In 1975, per capita income in Suriname was US\$1,000, making it a 'middle income country'. However, notwithstanding the government's expansion of the public sector and growing emigration, unemployment remained between 15 and 30 percent, exacerbated by continuous rural-urban migration. Economic prospects were enhanced by a development aid package based on the 'Treaty for Development Cooperation', often referred to as the 'golden handshake', negotiated with the Dutch government before independence. It included the cancellation of Suriname's debts and financial assistance over a period of 10-15 years of Nf 4 billion (US\$1.6 billion) (Dew 1978: 185), an amount that accounted for a large part of Suriname's national income (Sedoc-Dahlberg 1990).

Notwithstanding its economic character, scholars observed that this deal was a political tool: first, it was meant to convince the Hindustani politicians to accept independence and, concurrently, to reduce the large outflow of migrants (Buddingh' 2001). Second, the 'golden handshake' strengthened dependency on the Netherlands, giving the Dutch government the right to intervene in Suriname's budget plans (Sedoc-Dahlberg 1990). Third, this aid package also had a moral function as reparation for 300 years of colonialism. This aid package enabled the development of a patronage system and the accumulation of great amounts of wealth among the upper classes, while the poorest 10 percent of the population effectively experienced an income reduction of almost 25 percent between 1968 and 1980 (Buddingh' 2001). Although per capita annual national income grew to US\$2,200, economic growth was inflated by aid-funded government investment, concealing stagnation and a 6 percent shrinkage in national income. For the majority of the population the post-independence period was a great disappointment: the agricultural sector weakened, industry failed to grow and the government's only solution to unemployment was the further expansion of the public sector. Yet, the unemployment situation would have been even worse without emigration, a fact that did not escape the Arron government (Chin and Buddingh' 1987: 46).

\footnotetext{
${ }^{95}$ I thank Jack Menke for bringing my attention to the VHP's loss in 1977 and its possible relevance for migration.
} 


\subsection{Combining uncertainty, migration policies and the role of migrant networks}

Chaos in Suriname, large numbers of departures, families selling property as a result of the political uncertainties tied to independence were images painted in many interviews. After independence, however, worsening economic developments in conjunction with disillusionment with corrupt politicians produced most uncertainties, particularly for the middle and lower classes. The reality of these sustained political and economic uncertainties was in direct opposition to two key certainties: the Netherlands offered employment opportunities and social assistance (i.e. housing, clothing and funds), even for families with many children; and, the opportunity to start a new life in the Netherlands would expire in November 1980. A quote by an interviewee summarised this contrast, 'they were very uncertain about what was coming to them with independence and a lot of them, well you know, thought, "well, let me go to Holland because in that case I am at least sure about the system and things like that".'

After 1975, migration to the Netherlands remained easy, albeit with some constraints, in comparison to any other destination. Those with financial means could freely travel to the Netherlands, obtain a three-month residence permit, find a job, secure housing and gain access to Dutch citizenship. But not everybody could leave, as highlighted in one interview, 'Some relatives were able to send some money and they, they [people] just needed the tickets. People were thinking, "God, if I could just have one ticket, one ticket to Holland, then everything will be fine." And there was this man who even stole the ticket of his brother-in-law just to go to Holland.'

Thus, the role of family and friends already in the Netherlands was very important in many of the stories recalled in the interviews. Family and friends in the Netherlands provided information on Dutch employment and services, while some families provided full assistance to new arrivals by offering accommodation and walking them through the various procedures to start a new life in the Netherlands. A couple of individuals reported being the catalyst for the migration of their entire family in just a few years, while some families focused on sending at least one family member to the Netherlands before 1980, in order to secure access to the Netherlands once the border closed.

\subsection{Migration diversification across class and ethnic groups}

This period of Surinamese emigration has been generally associated with a shift in ethnic composition: while pre-1973 migration was mostly of Creoles, thereafter it was strongly represented by Hindustani as well as Javanese who 'voted with their 
feet' (Chin and Buddingh' 1987; Hassankhan 1997). In fact, Creoles continued to emigrate, but the rate of Hindustani emigration grew more rapidly, while Javanese emigration rose sharply only in late 1975 (Dew 1978:179, 183), suggesting a last minute rush of 'now or never' migration. Migration figures disaggregated by ethnic group are not available, but Dutch immigration figures disaggregated by religious affiliation suggest that the emigration of individuals with religions generally associated with the Hindustani population increased by over 135 percent between 1973 and 1974, while at the same time an increase of over 37 percent was recorded for Surinamese of all other religions linked to the Creole, Chinese and European populations (Table 5.1), confirming that the desire to secure Dutch citizenship was widespread across all ethnic groups (van Amersfoort 2011). The unsatisfactory economic developments also suggest that emigration was multiethnic. Contrasting with the initial emigration linked to elite and middle classes, from the early 1970s and into the early 1980s emigration became very much a lower class phenomenon (van Niekerk 2005).

Table 5.1. Surinamese arrivals to the Netherlands, by religious affiliation ${ }^{96}$

\begin{tabular}{lcc}
\hline Religion & $\mathbf{1 9 7 3}$ & $\mathbf{1 9 7 4}$ \\
\hline Hindus, Mohammedans and Buddhists & 3362 & $\mathbf{7 9 3 0}$ \\
\hline All other religions & 5391 & 7421 \\
\hline
\end{tabular}

Source: Dew 1978, citing data from Centraal Bureau voor de Statistiek

Peculiar emigration outcomes emerged in this period: for instance, among emigrants were many low-educated individuals of a mature age, particularly of rural Hindustani and Javanese background (van Amersfoort 2011), suggesting that entire families were starting a new life in the Netherlands but also reminding us that the provision of old age pensions in the Dutch welfare system made this type of migration possible. Menke (1983) found that in the 1972-1980 period emigration was particularly high for women in the 15-19 age group and suggested that this may have been part of been a strategy to send daughters away to protect them or to prevent them from getting 'in trouble'. A Javanese interviewee indicated that his brother had gone to the Netherlands because he had seven daughters and he did not want them to get involved with boys in Suriname; he felt that in the Netherlands he would face fewer difficulties raising them. A Hindustani woman was sent to the Netherlands to contract an arranged marriage and an Amerindian

\footnotetext{
96 The first category roughly includes Indo-Surinamese, while the second category includes AfroSurinamese as well as Chinese and Europeans (Dew 1978: 179).
} 
woman was encouraged to go to the Netherlands in order to halt a relationship with a man the family rejected. While such socio-cultural motives may have played an important role, this emigration may also have been associated with high demand for teachers and nurses in the Netherlands, professions often filled by women.

It is only logical that the Netherlands remained the primary destination of Surinamese migrants throughout this period, given the favourable migration and citizenship policies until 1980 and the obvious language and cultural connections. Nevertheless, some Surinamese found alternative destinations: records of the immigrant population in French Guiana showed that in 1974 a population of 600 to 700 Surinamese individuals resided there, 80 percent of whom were reported as being Javanese. ${ }^{97}$ France's statistical data show a larger Surinamese population of over 1,200 (Granger 2007). Concurrently, while immigration to the US accounted for about 80 Surinamese immigrants on average per year in 1973-1982, the size of the Surinamese population in the US had rapidly increased from under 100 in 1970 to almost 1,600 in $1980 .{ }^{98}$

In the meantime, Suriname was receiving immigrants. Among these were Guyanese and Haitians (de Bruijne 2001) and Surinamese who returned and often circulated between Suriname and the Netherlands (Bovenkerk 1981) (Figure 5.4). A few interviewees talked about their own migrations back and forth in response to professional or family needs: among the interviewees, three Hindustanis (two men and one woman) returned right before independence, one to experience the transition to independence and contribute to the country, one because of a job opportunity and one because of the desire to return after several years in the Netherlands. These personal trajectories suggest that despite the uncertainties and the alarmism promoted by politicians, some individuals felt patriotism and aimed to take part in nation-building in an independent Suriname.

\section{Internal political and economic crises driving migration (1983-1994)}

A new wave of migration took place from the early 1980s to the mid-1990s: its volume was small in comparison to the previous decade, but emigration was once again on the increase, reaching 2.2 percent of Suriname's population in 1993 before

\footnotetext{
${ }_{97}$ Guyane Action, Jan 1975, no. 31, p. 4, retrieved from the Departmental Archives of Guyane (Archives départementales de la Guyane) in Cayenne.

${ }_{98}$ Immigration flow data from DEMIG C2C and stock data from World Bank Global Bilateral Migration Database.
} 
halving in 1994 (Figure 5.5). Two political events created high levels of instability: the growth of military control and abuse; and a guerrilla war waged in the interior. Concurrently, a weak economy and worsening living conditions were partially responsible for the re-strengthening of emigration, which was undoubtedly facilitated by the presence of a sizeable Surinamese community in the Netherlands. However, different emigration strategies emerged: first, a new segment of the population engaged in migration; second, new migration channels were utilised in reaction to Dutch immigration policies; and third, new migration destinations emerged.

Figure 5.5. Migration from and to Suriname, 1982-1996

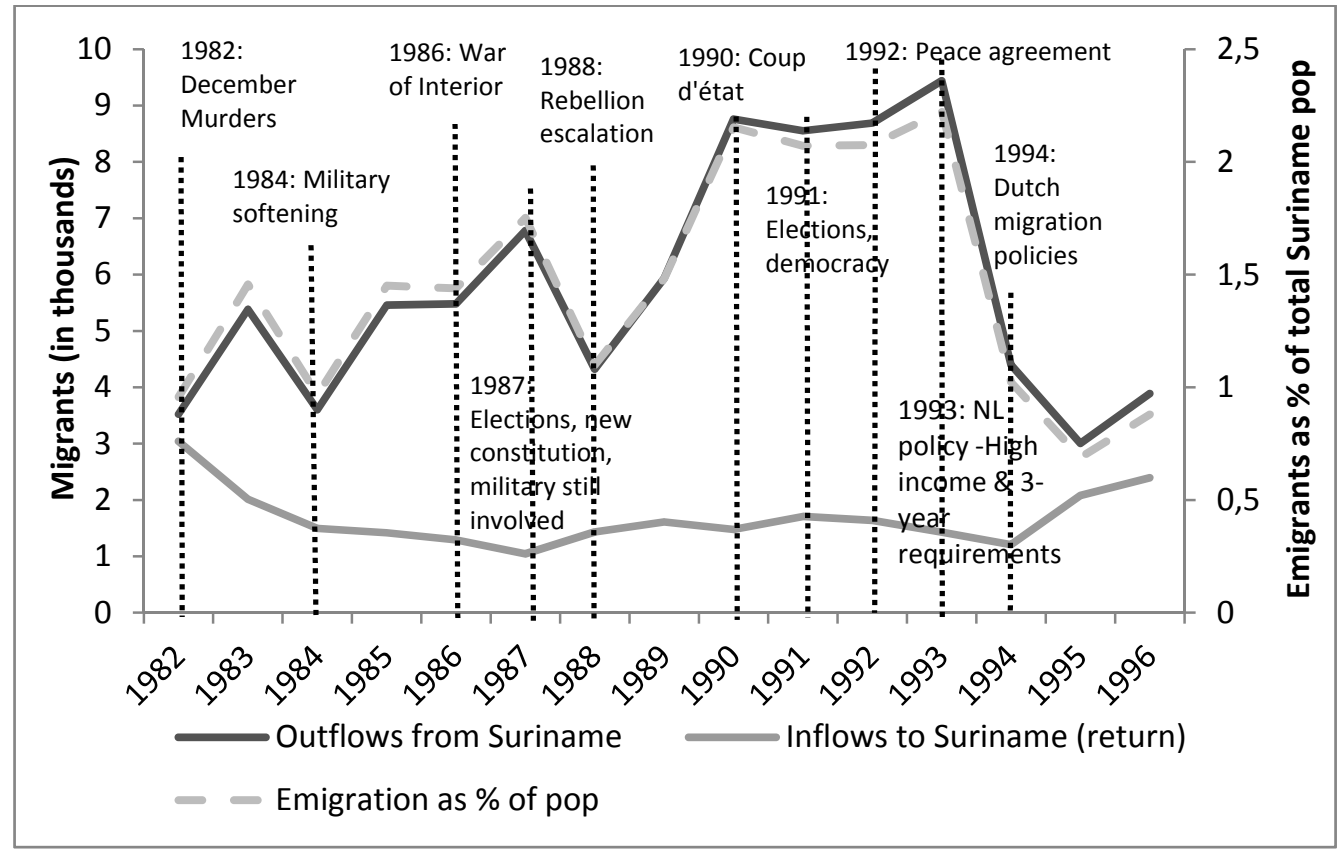

Sources: World Bank Global Bilateral Migration Database and UN Population Estimates

\subsection{Political emigration drivers: From a military dictatorship to the War of the Interior}

The 1982 December Murders marked the start of a period of heightened tension. Interviewees indicated that no widespread violence occurred in the streets, but the military implemented a system of surveillance, including phone tapping, warnings and police questioning, which instilled fear in the population. Coping mechanisms included staying away from politics and 'keeping one's mouth shut', but some people, particularly professionals and academics, felt directly under threat and 
compelled to emigrate. Acknowledging this situation, the Dutch embassy eased migration entry requirements and provided support for people threatened by the military and their dependents (Sedoc-Dahlberg 1984: 6). Over 1,400 Surinamese left with a Dutch visa, the majority Creole and Hindustani professionals, trade unionists, former commissioned officers and students; yet the Dutch embassy refused 65 percent of the visa requests. Moreover, those who arrived with visas were not granted long-term permits, leading many Surinamese, among whom many students who had participated in demonstrations against the military junta, to remain irregularly (Sedoc-Dahlberg 1984).

By 1983 the military junta lessened its authoritarian approach, lifted the ban on party activities (Thorndike 1990), opened dialogue with civilian groups (Menke 1990) and by November 1987 it allowed the approval of a new constitution by referendum. The 1987 general elections resulted in the defeat of the militarybacked National Democratic Party (NDP), although the party managed to retain significant power (Thorndike 1990). A second coup occurred in December 1990 (Meel 2001) once again orchestrated by Sergeant Major Bouterse, but swift elections followed in early 1991. The victory of President Ronald Venetiaan of the New Front for Democracy and Development coalition marked the return to a democratically elected government (Giacottino 1995; Taylor and Bers 2010), the reopening of Dutch-Surinamese relations (Giacottino 1995) and the return to Dutch intervention in Surinamese domestic affairs (Janssen 2011). In 1992 the two governments agreed to the Framework Treaty for Friendship and Closer Cooperation which included economic development and collaboration against drug production and related criminal activities (Meel 2001).

In the meantime, a guerrilla rebellion grew in the interior (Menke 1990). Starting in 1986 Ronnie Brunswijk and the Jungle Commando, composed of Maroon groups living in the interior, conducted an armed struggle, the so-called War of the Interior, against the military government (Taylor and Bers 2010). The rebellion rapidly degenerated (Thorndike 1990) and the rebels and the military perpetrated grave human rights violations on a wide scale, such as the 1986 Moiwana massacre of 50 unarmed Maroons (Meel 2001). In December 1988 violence escalated again (Thorndike 1990) and degenerated further as the government became involved with guerrilla groups until, in August 1992, a peace agreement was finally negotiated between the government and the Jungle Commandos to end the war (Taylor and Bers 2010).

The War of the Interior generated a large movement of the Maroon population across the Marowijne (Maroni) river into French Guiana (Gowricharn 2004) with estimates indicating that 13,000 refugees settled in the north-west of the country, contributing to the massive growth of the Maroon population in French Guiana from about 37,000 in 2002 to about 67,000 in 2014 (Price 2013), making the 
Surinamese the largest foreign population in French Guiana and changing the character of migration from Suriname to French Guiana (Piantoni 2015 forthcoming).

\subsection{Collapsing economy, shortages of goods, remittances and emigration}

In the early 1980s two events converged to affect the Surinamese economy negatively: the fall of global bauxite prices and the halt of Dutch development aid (Thorndike 1990). Bauxite contribution to Suriname's GDP fell from 20 to 12 percent between 1980 and 1985 (Menke 1990), reducing foreign currency earnings and government revenues (Menke 1998). Dutch development aid, which had become vital in the 1975-1982 period, was suspended after the December murders, weakening an already dwindling economy (Menke 1998). The economic crisis of the 1980-1987 period eventually led to a GDP decline of -6.8 percent, real per capita incomes declining at -23 percent (Menke 1998) and unemployment figures skyrocketing from 10 to 30 percent in 1980 and 1987 respectively (Thorndike 1990). Resuming development aid was imperative upon return to democracy in 1988 (Buddingh' 2001), but the Dutch government requested the introduction of the IMF's structural adjustment programmes (SAPs) to release the 1500 million Dutch guilders left in the 'golden handshake' agreement (Menke 1990; Buddingh' 2001). Aid discussions continued amongst difficulties and aid resumed from 1990 to 1996 upon the condition that all imports be conducted through a Dutch purchasing agency (Thorndike 1990).

By the early 1990s the population faced hyperinflation, increasing exchange rates, shortages of basic goods and price increases of basic goods (Menke 1998; van Niekerk 2005). A 1998 study based on surveys conducted in 1978 and 1993 in Greater Paramaribo, reported a shift away from public employment to precarious self-employment. The informal economy rapidly absorbed students, housewives and retired people unable to find formal employment, particularly in

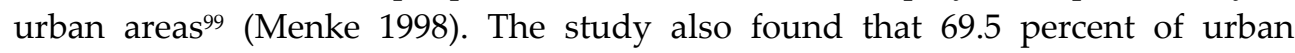
household were below the poverty line in 1993, a proportion that increased by 10.3 percent if remittances were excluded, showing that remittances had the highest effect on poverty alleviation (Menke 1998). The study also showed that non-poor households relied on four main survival mechanisms: commodity remittances, cash remittances, additional jobs and emigration (Menke 1998). Many interviewees also described their own situations of economic struggle and survival, recalled

\footnotetext{
${ }^{99}$ In the 1970s and 1980s, Paramaribo doubled in size due partly to rural-urban migration and partly to the extension of the city to include surrounding farming lands (de Bruijne 2001).
} 
queues to buy foodstuff and heavy reliance on barrels and packages from relatives in the Netherlands which included clothing and household equipment (Buddingh' 2001; Gowricharn 2004; van Niekerk 2005). Emigration became an important 'escape valve' among the interviewees: individuals who had returned in the 19751982 period re-migrated, helped by their Dutch nationality; adult children left for the Netherlands with the intention to improve their lives but also to send money to Suriname to support their ageing parents; others reported relatives who chose to try their luck by migrating irregularly to the Netherlands.

A less known fact about Surinamese emigration is that economic hardship contributed to an increase in emigration to French Guiana. Hindustani, Javanese, Chinese and mixed background Surinamese settled in French Guiana for rice cultivation ${ }^{100}$ and other agricultural production, forestry and retail businesses, but also to provide services such as dentistry and medicine in the under-served western part of French Guiana (Piantoni 2009). Interviews carried out by Piantoni (2009) showed that these individuals left Suriname due to the unstable political and economic conditions but also because of good investment opportunities in French Guiana, while the proximity allowed these migrants to remain connected to Suriname. These migrants held Surinamese or Dutch nationality and some were returnees that decided to resettle in French Guiana (cf. Piantoni 2009). In some cases, migration to French Guiana may have been a 'spatial substitution effect' due to the increasing barriers to migration to the Netherlands. The number of Surinamese migrants remained low, however, until the displacements caused by the War of the Interior.

\subsection{Dutch migration policies and Surinamese migration strategies}

While the Surinamese government adopted a laissez-faire attitude as it watched undesirable political opponents emigrate voluntarily (Sedoc-Dahlberg 1984), the Dutch government took stronger positions with its migration policies. Starting in the 1980s, family reunification policies gradually reduced entry rights, particularly through income requirements for second generation migrants (introduced in 1983). In 1993, income requirements were increased up to 70 percent of social welfare levels, a 3-year residence was required for family reunification eligibility and these requirements were extended to all, including Dutch citizens. ${ }^{101}$ In the late 1980s the Dutch Ministry of Justice began to repatriate over 5,000 irregular Surinamese immigrants as Suriname was deemed to be a safe country; this measure was halted

\footnotetext{
100 These immigrants successfully re-launched rice production in French Guiana after several failed attempts of previous development projects supported by the French government (Piantoni 2009a).

${ }^{101}$ Data source: DEMIG POLICY.
} 
by Minister of Foreign Affairs van den Broek, who acknowledged Suriname's uncertain conditions due to the war in the interior (Thorndike 1990).

Given the importance of family migration (Sedoc-Dahlberg 1984; Gowricharn and Schuster 2001), the increasingly restrictive immigration measures seem to have re-directed potential migrants to enter as tourists or to pursue marriages of convenience (Gowricharn and Schuster 2001). Interviewees' recollections of this time included recurrent references to marriage: siblings, daughters, nieces and nephews were marrying Dutch nationals, sometimes out of free will and at other times in arranged marriages, while Surinamese in the Netherlands with Dutch nationality were using this channel to help friends regularise their situation. Dutch authorities began to give travel visas more reluctantly (Gowricharn and Schuster 2001) and in 1994 the Dutch government introduced three policies which targeted these migration strategies: the introduction of new identification requirements to prevent irregular migrants accessing social services; requirements to obtain a 'provisional residence permit' before arrival in the Netherlands; and, the Law on Prevention of Marriage of Convenience, requiring Immigration Services to certify the genuineness of marriages. ${ }^{102}$ This gradual restriction of commonly used channels undoubtedly helped to generate the perception that the Netherlands was becoming inaccessible. 


\subsection{Class, ethnicity and diversification of migration destinations}

A survey conducted in Greater Paramaribo in 1992 found that 75 percent of the population in Suriname had relatives in the Netherlands, representing all segments of Surinamese society (de Bruijne and Schalkwijk 1994 cited in van Niekerk 2005). The economic and political turbulence caused a significant part of the executives in the civil service and the private sector to leave the country: an estimated 25 percent of individuals educated in Suriname between 1970-90 migrated in this period (van Dijck 2001: 66). The middle classes were also well-represented (Gowricharn 2004), but the poorer population had fewer relatives in the Netherlands (de Bruijne and Schalkwijk 1994 cited in van Niekerk 2005). Facing severe financial constraints, poor individuals were often unable to emigrate; a couple of interviewees shared details of their inability to emigrate over the years linked to their poverty and low levels of education.

Differences were also found across ethnic groups: more than 80 percent of European, African and mixed descent Surinamese had relatives in the Netherlands; between 60 and 80 percent of people of East Indian, Javanese and Chinese descent had relatives in the Netherlands; and only between 35 and 50 percent of Maroons and Amerindians had relatives in the Netherlands (de Bruijne and Schalkwijk 1994 cited in van Niekerk 2005). However, the emigration of Maroons became much more significant over this period given this population's displacement to French Guiana.

Emigration gradually expanded, albeit weakly, to the US, Brazil and the Dutch Antilles (Gowricharn 2004) in addition to French Guiana. Astrid Runs (2006) studied Surinamese emigration to the US and suggested that this spatial diversification was linked to changes in geopolitics, tourism and the difficulties in obtaining a Dutch visa. She specified that the migration to the US occurred before the military regime, but it was confined to the elite; after the 1987 elections the Surinamese middle class began to visit Miami and New York, where Surinam Airways flew for relative cheap fares. The US, particularly Miami, became a tourist destination as well as a place to purchase goods to import to Suriname. Gradually, some Surinamese decided to stay after their holiday and regularise through marriage, asylum, employment, family or other programmes such as the diversity lottery. Although Suriname's socio-economic and political conditions were important reasons for migration, individuals also mentioned a sense of adventure and family reunification (Runs 2006). Figure 5.6 shows that total migration figures to the US are very small, but that these gained strength starting in 1983, which corresponds to the year in which the Netherlands introduced income requirements for family reunification. Figure 5.6 also shows that, in contrast to neighbouring Guyana, Canada's attractiveness remained low. 
Figure 5.6. Immigrants to the US who previously resided in Suriname, 1946-2010, and immigrants to Canada who were born in Suriname, 1973-2010 ${ }^{103}$

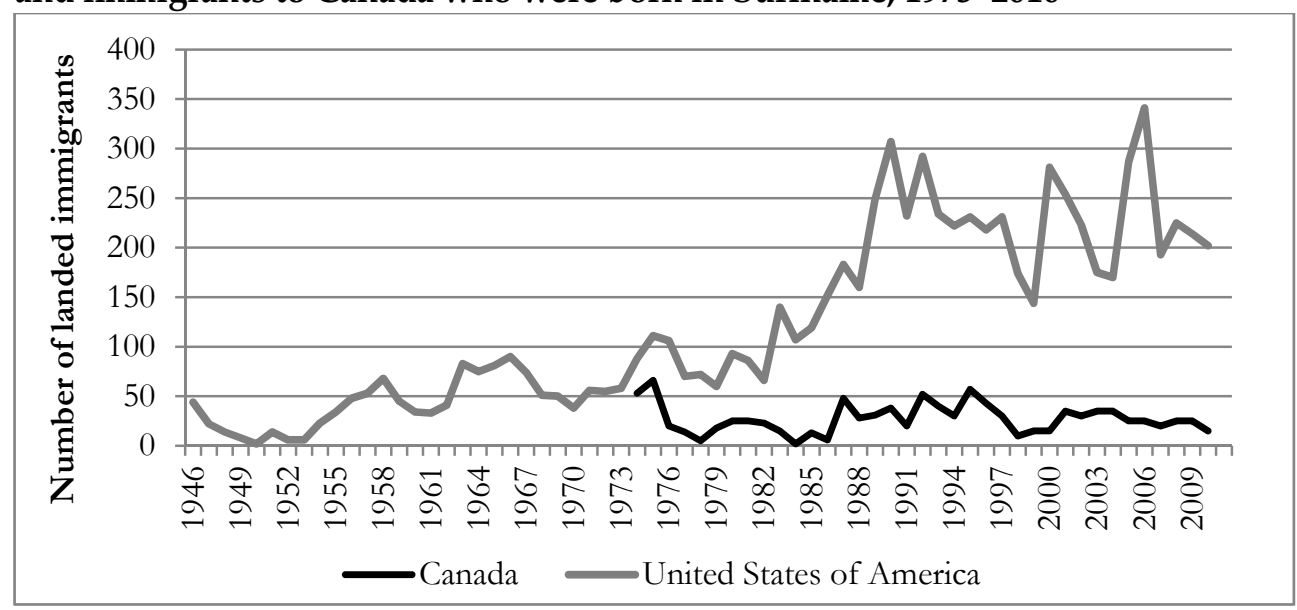

Source: DEMIG C2C

\section{Gradual return to stability and low emigration (1995-2010s)}

While the 1982-1993 period saw a gradual emigration increase, thereafter emigration followed a downward trend halving from about 1 percent of the population in 1994 to less than 0.5 percent in 2010 (Figure 5.7), approximately the emigration rate of 1956 (Figure 5.2). This decline has been associated with the restrictiveness of European migration policies as it was observed that migration aspirations remained high: the Surinamese population continued to perceive Suriname as a country with few opportunities; and migrant networks raised awareness of lifestyles and opportunities in the Netherlands (de Bruijne 2001). In addition to Dutch policy changes, I would argue that political and economic stability in Suriname over the course of the 2000s and worsening economic conditions in the Netherlands may have also contributed to a greater sense of wellbeing in Suriname leading to some changes in attitudes towards emigration.

${ }^{103}$ Country of birth data for Canada and country of residence data for the US. 
Figure 5.7. Migration from and to Suriname, 1994-2010

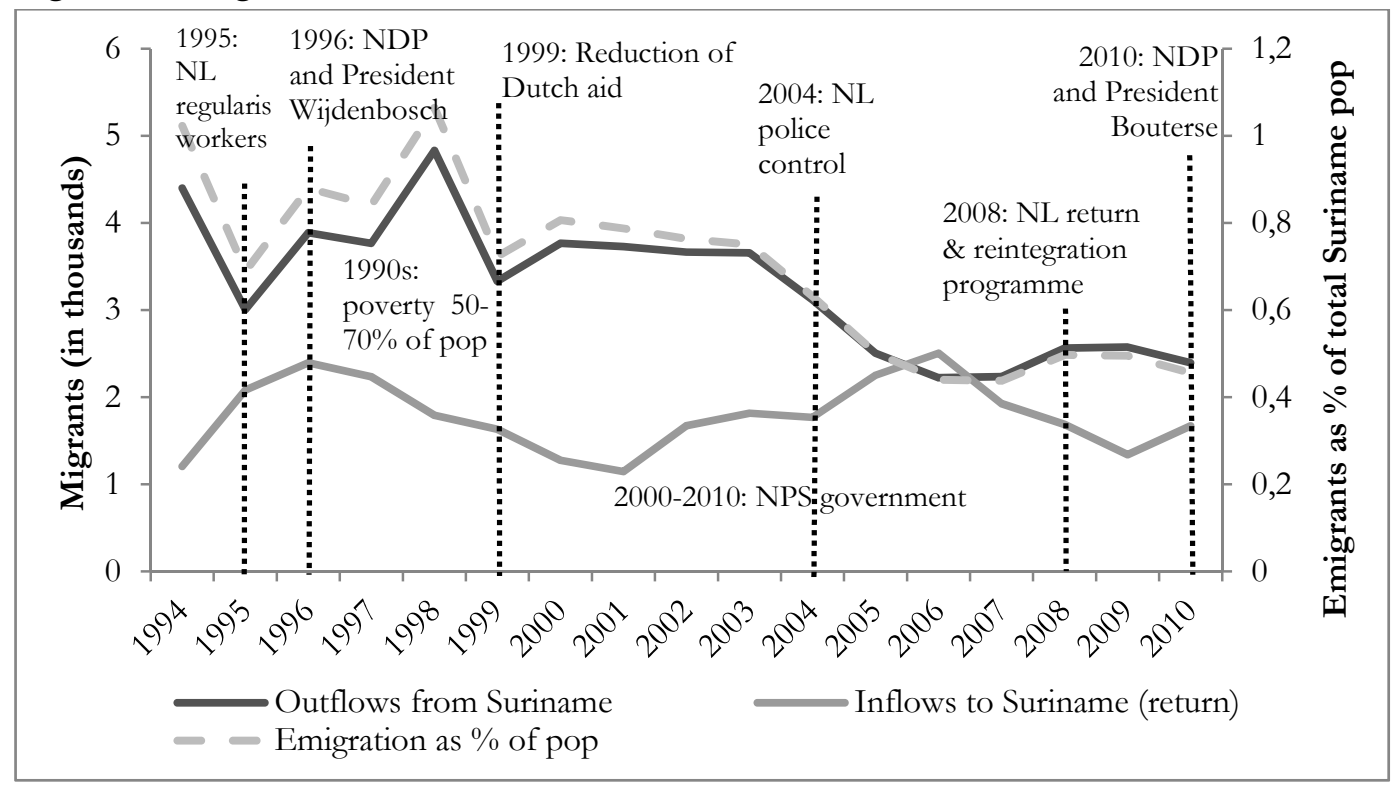

Sources: World Bank Global Bilateral Migration Database and UN Population Estimates

\subsection{Democracy and political stability}

The 1996 victory of the NDP and the nomination of Jules Wijdenbosch, an associate of Bouterse, as President (Meel 2001), led to the suspension of Dutch-Surinamese relations in 1997 by the Surinamese government (Buddingh' 2001) on account of two issues: the pursuit of macro-economic policies (van Dijck 2001) including SAPs; and Bouterse's prosecution for drug trafficking in the Netherlands, which eventually led to his conviction and sentence in absentia to 11 years imprisonment and US\$2 million in fines (Meel 2001). The Dutch government reduced aid to 40 million Dutch guilders (US\$20 million) in 1999, but a deep economic crisis forced President Wijdenbosch to request aid in 2000, which the Dutch authorities rejected on account of lack of 'good governance' (Buddingh' 2001).

Four free and fair elections have taken place since 2000: President Venetiaan led an NPS government for 10 years until the 2010 victory of the Mega Combinatie, a coalition that included Bouterse's NDP, which was followed by another victory by the NDP in May 2015. Bouterse's Presidency in 2010 surprised many people, not only for his role in the December Murders, but also because of his Dutch drug trafficking condemnation and peculiar governmental decisions, e.g. including appointing his son Dino Bouterse in the Counter-Terrorism unit in spite 
of his 2005 charges on drug and weapons trafficking. ${ }^{104}$ Yet, amidst voices of dissent, Bouterse received support particularly among historically disenfranchised groups, such as lower class people as well as Amerindian and Maroon populations, who interpret the construction of new roads, some access to housing and electricity as signs of inclusion which no previous government granted them. Notwithstanding the accusations against Bouterse, the high level of corruption in politics and business, a high degree of bureaucracy and, as one interviewee put it, the fact that 'there has been no real change' - those who were in power in 1980 are still in power today, this period's political stability has reduced the importance of political factors as migration determinants.

\subsection{Economic stabilisation but slow development}

In this period, Suriname's economy was again in crisis as a result of the fluctuation of bauxite prices and the 1997 suspension of development aid. While mining remained central to the economy, gold production gradually replaced bauxite and oil, contributing an estimated 20 percent of GDP in 2000. Although overall living conditions improved in the 1990s, poverty still touched 50-70 percent of the population and income inequality increased (van Dijck 2001). But by this time, ethnic and income divides no longer ran in parallel. The Maroon and Amerindian populations in the interior remained the poorest groups with lower standards of living (de Bruijne 2001; Taylor and Bers 2010), while the Hindustani and Javanese populations continued to represent most of the rural population, including a large proportion of the poor. However, the Asian groups also became largely employed in government jobs and some Hindustani businessmen gained great wealth (de Bruijne 2001). The middle class, mainly civil servants, struggled to retain their social position in the 1990s as their income decreased but the cost of imported goods increased (de Bruijne 2001). For such individuals, employment opportunities in the Netherlands motivated migration in the late 1990s, as indicated in interviews.

Over the 2000s socio-economic conditions improved. From 2001 annual GDP per capita growth remained positive (Figure 5.8), education and health indicators improved with literacy rates at 89.6 percent, net primary school enrolment at 96 percent ${ }^{105}$ and reduction of child mortality (Taylor and Bers 2010). Nearly all goods became available in Suriname, whether expensive Dutch and US

\footnotetext{
104 Ironically, in 2013 Bouterse's son was charged by the US for planning to build a Hezbollah base in Suriname, in addition to additional drug and arms trafficking charges.

105 Taylor and Bers (2010) remind us that in the interior literacy rates can plummet as low as 36 percent, many indigenous and Maroon children only reach grade 5 (64.5 percent) and schools in the interior lack qualified teachers, infrastructure and materials.
} 
products or low-cost Chinese-made alternatives (van Niekerk 2005). Heavy reliance on imported goods raised criticism of visible signs of modern consumerism, while real economic and employment prospects remained scarce leading some young people to resort to 'hustling' (de Bruijne 2001). Studies suggest that poverty has been mitigated by the informal economy, informal mining (especially gold), and drug- and trafficking-related money in addition to remittances from the Netherlands (van Niekerk 2005). Illegal activities are estimated to comprise approximately 20 percent of Suriname's economy (Taylor and Bers 2010).

Figure 5.8. Long-term migration and GDP per capita growth rate, 1950-2010

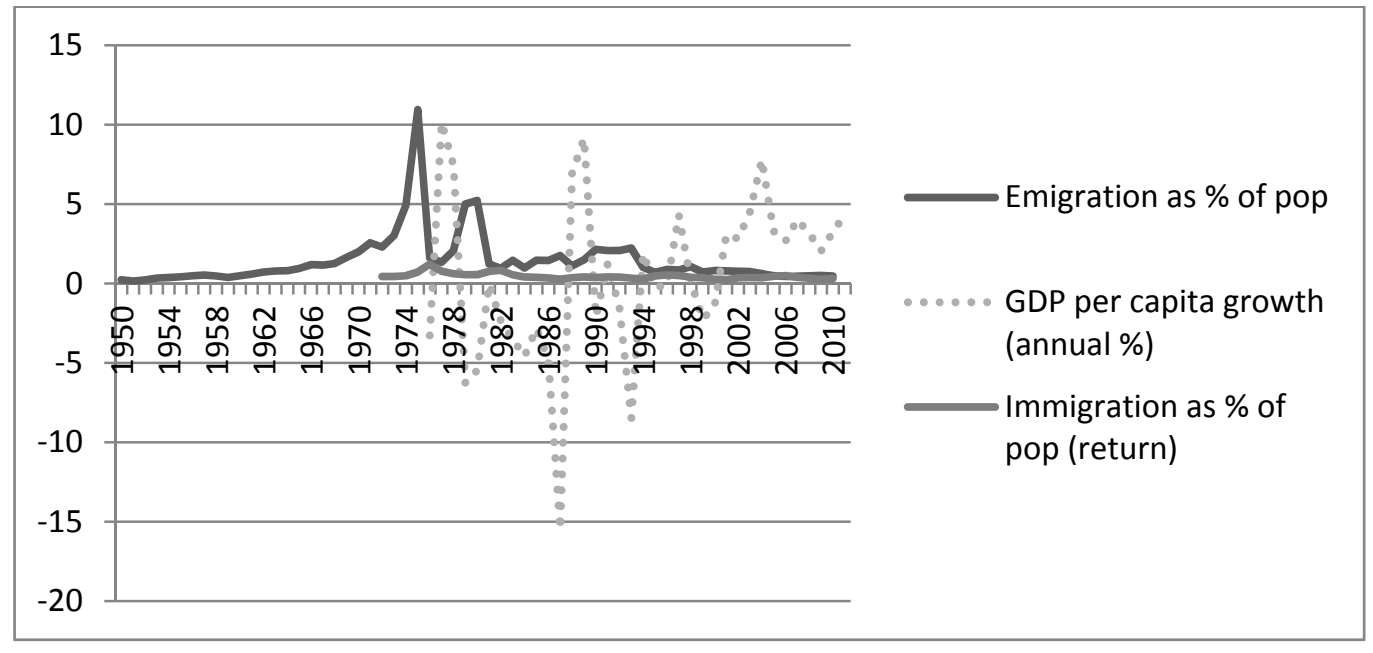

Source: DEMIG C2C and World Development Indicators ${ }^{106}$

Today an average worker in a construction company earns about 1200 1500 SRD (US\$360-450) per month and would struggle to pay rent, meet basic expenses and purchase a car. ${ }^{107}$ Yet, as another interviewee who owns a small business indicated, in a two-income household with an average salary the quality of life can be good. In spite of the lack of industrial development, young people from the lower and middle class shared positive thoughts about the availability of jobs for people, even for those not lucky enough to have received an education, and some shared enthusiastically their future plans to open a business in Suriname. Similarly, increasing numbers of returnees have made their way back to Suriname, attracted by business and employment opportunities, e.g. optical

\footnotetext{
106 World Bank's World Development Indicators (WDI), available at http: //data.worldbank.org/datacatalog/world-development-indicators, accessed on May 6, 2014.

107 This information was provided by a returnee interviewed who worked as a manager in a public works company and was aware of various levels of employment and salaries within the company.
} 
specialist, specialised shoe-making, developing counselling programmes for troubled youth. This is not to say that emigration for economic reasons is no longer occurring: for example, two daughters of a Hindustani elderly woman migrated to the Netherlands in the 2000s through family reunification because they reported being unable to meet basic expenses in Suriname, while a few individuals expressed their desire but inability to emigrate.

\subsection{The effect of Dutch migration policies}

In the 1990-2004 period, when we consider all migration policies changes introduced by the Dutch government, i.e. border control, entry, integration and exit policies, on average they consisted of restrictive policy changes (Figure A3 in appendix D). However, Dutch migration polices from the 1990s to the 2010s were a mixed bag of restrictive and non-restrictive changes. Policies targeting irregular migration included the 1995 regularisation of migrants working legally and the 2007 regularisation for failed asylum seekers; on the other hand policies led to the opening of deportation centres in 2003, the strengthening of police control in 2004 and return and reintegration programmes in 2008. Labour migration policies eased entry and residence requirements for graduating students and skilled workers. ${ }^{108}$

For family reunification, income requirements fluctuated, a one-year minimum residence requirement was introduced and civic and language requirements were tightened, although with little expected consequence for Surinamese as in general they are Dutch-speaking. The tightening of entry requirements for family reunification built upon already significant restrictive changes (i.e. the 1993 income and 3-year residence requirement for family reunification and the 1994 Law on Prevention of Marriage of Convenience) and contributed to a general perception that the Dutch border is closed. In many interviews and in casual conversations people commented that migration rules are now very strict and it is difficult to migrate to the Netherlands. Some said that the only way to migrate to the Netherlands is to marry a Dutch citizen; others gave examples of individuals who entered regularly and overstayed but eventually returned because it is difficult to stay. One interviewee indicated that one needs money and a contact to make it in the Netherlands, while another added a third condition, education, as the only way to ensure a decent standard of living in the Netherlands. The difficulties of migrating regularly to the Netherlands are visibly part of public knowledge.

\footnotetext{
${ }^{108}$ Migration policy data originates from the DEMIG POLICY.
} 


\subsection{Current emigration motives and growing immigration}

Surinamese statistics report a decrease of emigration flows to all destinations (Figure 5.9), suggesting that shifts in Dutch immigration policies may not fully explain decreased emigration. Two motives emerged from the interviews which may offer some explanation: the economic crisis in the Netherlands starting in 2008; and sustained exposure to the Dutch lifestyle through trips to the Netherlands. While still associated with a certain prestige, many individuals no longer saw the Netherlands as the 'promised land' amidst evidence of economic hardship, inclement weather and a stressful life. Young people, whether working class or among the university student population, did not see emigration as the only path to success.

Figure 5.9. Emigration by country of future residence, 2000-201109

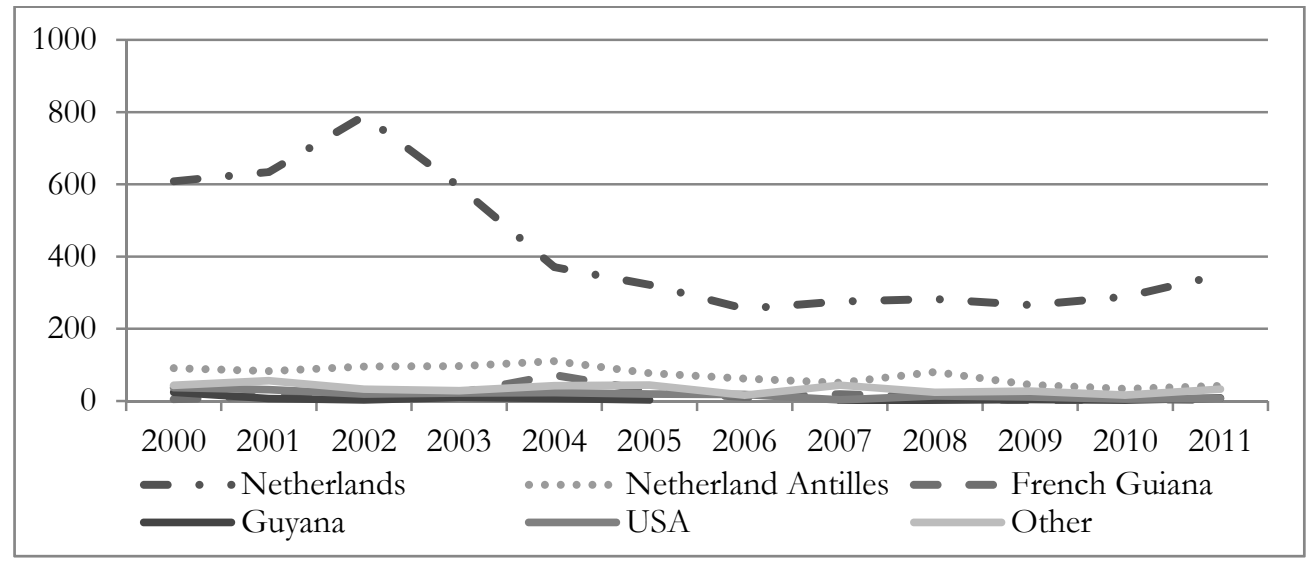

Source: Demografische Data Suriname 1998-2011110

Suriname's latest census shows that emigration motives changed for migrants who left over the 2004-2012 period (Figure 5.10). The importance of marriage has slightly decreased, while emigration for family migration or reunification gained some importance. Emigration for work reasons was the most stable, while emigration to study slightly decreased, supporting observations made by two faculty members at the University Anton de Kom that students are generally not eager to leave. One must note, however, that although Surinamese

\footnotetext{
109 The data reported by the Surinamese statistical office are much lower than the immigration figures reported by the Dutch and the US statistical offices (DEMIG C2C). However, these data include emigration to regional destinations.

110 Data from the demographic yearbook, Demografische Data Suriname for the years 1998-1999, 2000, 2003-2004, 2005, 2006-2007, 2008-2009, 2010-2011, published by Ministerie van Binnenlandse Zaken, Centraal Bureau voor Burgerzaken $(\mathrm{CBB})$, retrieved from the Algemeen Bureau voor de Statistiek in Suriname (ABS) in Paramaribo.
} 
students qualify for EU-resident tuition fees in Dutch universities, the financial guarantees required by Dutch universities cannot easily be met by middle- and low-class Surinamese families. Moreover, aware of the difficulties embedded in migration, it is possible that young Surinamese have stopped considering it a real option. ${ }^{111}$

\section{Figure 5.10. Surinamese emigrants by year of departure and main reason for emigration, 2004-2012 112}

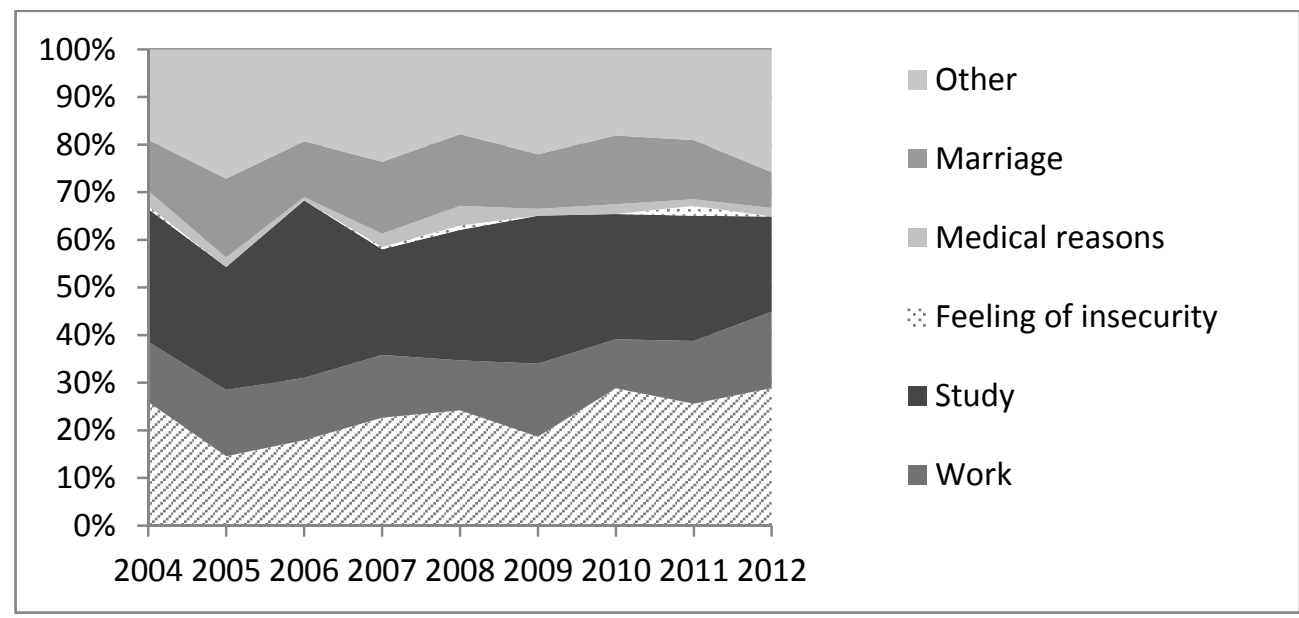

Source: Eighth Census of Suriname, published September $2013^{113}$

When we match emigration motives with the country of destination (Figure A4 in appendix D) the data shows continuous preference for migration to the Netherlands, primarily for family reunification, study and other unspecified reasons. Contrarily, migration to the US is linked to the pursuit of education, while French Guiana offers family connections and work opportunities, ${ }^{114}$ similarly to Curaçao and other minor regional destinations.

As emigration declined, immigration to Suriname increased. Figure 5.11 presents immigration of foreign-born immigrants as well as of Suriname-born returnees. Since the mid-1990s we see a gradual increase of Suriname-born migrants and a much more rapid growth of foreign-born immigrants. Census figures indicated that about 33,000 people of foreign nationality resided in Suriname. Among these, over 10,000 people had Dutch nationality, just over 8,000

\footnotetext{
111 I thank Professor A. de Bruijne for this observation.

112 Data of emigrant stock that may include emigrants who left before 2004 but did not know or did not answer what year they emigrated. These categories which are not disaggregated in Table 32.

113 ABS, 2013. Resultaten Achtste (8e) Volks- en Woningtelling in Suriname: Demografische en Sociale karakteristieken en Migratie. Censuskantoor, Vol. I. Paramaribo.

114 This emerged from interviews with a couple of Surinamese migrants in Cayenne.
} 
were Guyanese, Brazilians accounted for about 5,000 individuals followed by just over 3,700 Chinese nationals. Other studies suggested that these figures grossly undercounted the foreign population as Brazilians were estimated to be 13,000, or 2.64 percent of the Surinamese population, when Brazilians who work in the interior are included (Jubithana-Fernand 2009). Interestingly, some young Surinamese interpreted the presence of foreign individuals who find work and investment opportunities in Suriname as signs that Suriname may, through hard work, offer them good opportunities in the future too.

Figure 5.11. Period of return of Suriname-born population and period of immigration of foreign-born population, 10-year intervals

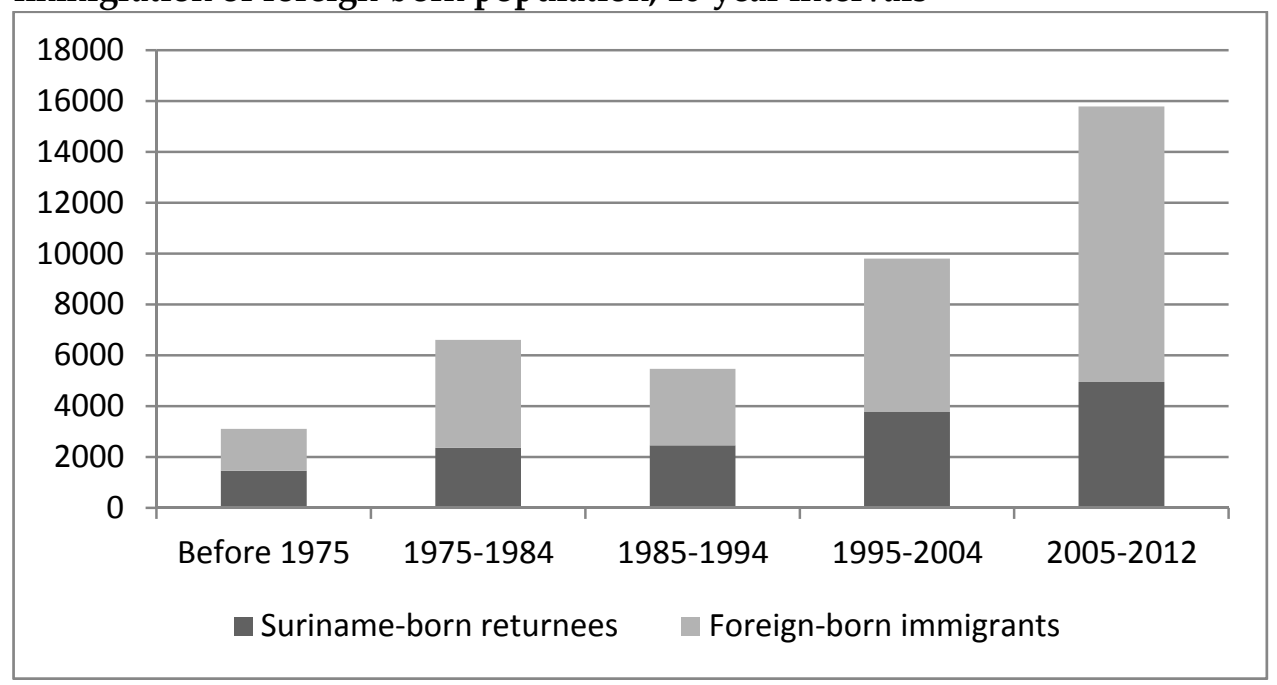

Source: Eighth Census of Suriname, published September 2013

\section{Connecting the state, structural changes and long-term migration: a discussion}

\subsection{The effects of independence and a border regime and their sequence}

The immediate impact of independence could not be more evident as 10 percent of Suriname's population emigrated in 1975 alone. As we have seen, however, specific circumstances surrounded Surinamese independence with political and ethnic tensions generating great levels of anxiety; amidst these uncertainties, parts of the population felt that the only secure option was to obtain Dutch citizenship in the Netherlands. The delay in border closure became itself a strong migration 
determinant as it provided a last window of migration opportunity for those dissatisfied with developments in independent Suriname and those who wanted to 'beat the ban' and ensure access to education, employment and the lifestyle offered by the Netherlands.

These initial migration reactions created strong migrant communities and numerous Surinamese organisations that provided the financial and human capital to support further migration, but also enabled the transfer of remittances which ensured the subsistence of family members during recurrent economic crises in Suriname from 1983 to the late 1990s. Today, strong Suriname-Dutch connections exist at various levels, i.e. organisational, commercial, inter-personal, which are likely to continue influencing emigration in the medium term.

The sequence of independence followed by border regime closure is likely to have repercussions in the longer term, particularly in the selection of the Netherlands as a migration destination. However, future emigration may depend also on a number of factors such as continued Dutch interests in Suriname, ${ }^{115}$ the interests of the Surinamese diaspora and the Surinamese government's position towards the diaspora. Moreover, future migration will be influenced by the Surinamese government's efforts to build relations and create economic opportunities with neighbouring countries (e.g. with Brazil) and regional organisations (e.g. with CARICOM). Ultimately, these changes, combined with sustained political and economic stability, may alter migration patterns, strengthening already observable returns of Surinamese and encouraging significant immigration of foreign nationals as well as opening new potential migration destinations.

\subsection{Enduring post-colonial ties}

The events surrounding independence and the delay in establishing a border regime strengthened post-colonial ties to such a level that even when Dutch immigration policies became restrictive, migration remained largely focused on the Netherlands. When I asked interviewees why other destinations were not explored even as Dutch policies tightened, I received a puzzled look and realised that no consideration had been given to this option. Why not? I suggest that initially postcolonial ties were embodied by language, strong cultural and educational links, feelings of belonging, e.g. individuals powerfully stating 'I was born Dutch!', the fact that the Netherlands was 'for most Surinamese the most important window on

\footnotetext{
${ }^{115}$ Some interviewees as well as experts indicated that Suriname is not as present in the Dutch media and public discourse as it was in the past, suggesting a gradual weakening of Dutch interests in this country.
} 
the world' (Buddingh' 2001: 71) or, as an interviewee suggested, 'the promised land'. Moreover, although independence may be associated with a wide range of transformative processes of legal, institutional, economic and even social and class structures, Suriname remained closely influenced by its colonial past and reliance on Dutch development aid, which reinforced the traditional patron-client framework and gave the Netherlands power to continue determining Suriname's socio-economic progress as well as influencing commercial, public and sociocultural aspects of life in Suriname (Janssen 2011). Furthermore, ties with the Netherlands were strengthened at the family and societal level, increasing the influence of Dutch lifestyles and keeping the Surinamese perspective almost exclusively on the Netherlands. Hence, post-colonial ties have not just survived the passage of time, but they have been nurtured and have evolved over time.

While the continued role of the Netherlands in Surinamese life is of utmost importance, I suggest that four additional reasons may have reduced the motivation to seek alternative destinations: (i) an important percentage of the population continued to migrate in spite of restrictive Dutch policies, renewing migrant communities; (ii) a level of 'saturation' of emigration must have taken place as most people who wanted to emigrate did so; (iii) remittances helped many families access goods that were not available in Suriname and face the worse aspects of the crises (Gowricharn and Schuster 2001; Gowricharn 2004; van Niekerk 2005), reducing the need to migrate and find alternative migration destinations; and (iv) information on the most likely alternative destination, the US, was scarce and negative, e.g. irregularity after many years, business owners without residence rights, the inability to visit Suriname, and the risk of being banned permanently from the US.

Ultimately, the strong post-colonial ties in Surinamese migration seem to be the outcome of language and cultural affinities, strengthened by institutional networks and the import of Dutch lifestyle models on one hand and, on the other hand, the reduced willingness of Surinamese to take risks in exploring alternative destinations as Dutch migration policies became restrictive because the conditions in Suriname gradually improved. However, as the Surinamese government attempts to expand diplomatic relations to Brazil, China and India, which not only have business interests but also historical diasporas, alternative destinations may emerge, weakening the effect of post-colonial ties. 


\subsection{Migration composition}

While early emigration was overly represented by the European and AfroSurinamese elites, the 1960s ushered in a gradual expansion of migration of all ethnic groups and social classes. The political, economic and citizenship changes introduced by independence caused further diversification, particularly by stimulating the migration of individuals who would not have migrated otherwise, i.e. less educated, rural and older individuals, as well as the departure of entire families after having liquidated most or all of their assets. Even individuals with few financial means were helped to migrate either by their friends and relatives abroad or by acquaintances in Suriname. Nevertheless, the literature and the interviews emphasised that the poorest individuals faced greater obstacles to migration: a combination of poverty, low education levels and lack of support by family members in the Netherlands prevented these individuals from emigrating in the past just as today.

An important and understudied aspect is the prevalence of women in Surinamese emigration since the 1970s. The prevalence of female migration may be associated with social and cultural motives, including accessibility to Dutch social welfare for women with children (Menke 1983; Ypeij), the selectivity of certain professions such as teaching and nursing (Jubithana-Fernand 2009) or for personal reasons such as to finalise a relationship or a divorce. Moreover, evidence from interviews suggests that some Surinamese women prefer to live in the Netherlands, where they have fewer cultural constraints and more rights than in Suriname. Further research is necessary to explore specifically the migration of Surinamese women.

\subsection{Migration motives over 60 years}

Over the past 60 years Surinamese migration has been influenced by five broad factors: education, economic factors, including employment opportunities in the Netherlands and socio-economic conditions in Suriname, political tensions in Suriname, family connections in the Netherlands and Dutch migration policies. Education emerged as a strong factor shaping migration in the pre-1972 period, its importance reduced radically in the period around independence, before reappearing in the 1980 s and regaining importance most recently. Existing literature concurs on the importance of education for migration in the 1960s, but it also cautions that education became a standard justification based on early migrations of the elite who returned with a Dutch diploma (Bovenkerk 1981), but in fact many Surinamese who claimed an education motive in the 1960s did not actually pursue it (Menke 1983). Aware of the symbolic meaning of education, when it emerged as a migration reason among the interviewees, I attempted to understand migration trajectories once in the Netherlands to verify whether they 
actually pursued an education. In most cases this was confirmed and further validated by their careers.

Socio-economic conditions both in the Netherlands and in Suriname played an important role. In the Netherlands, migrants found employment opportunities throughout the 1960s into the late 1970s, as well as greater stability and security, including social benefits, which gained importance after independence and into the early 1980s. In the 1980s to early 1990s, employment and other social benefits in the Netherlands seemed less important, but employment re-emerged particularly in the late 1990s. In Suriname, socioeconomic conditions were not strong migration drivers up until the 1970s, but they remained one of the two major reasons for migration in the three following periods. Economic crises were linked to development strategies, including SAPs, lack of economic diversification, and fall of global bauxite prices, and were frequently linked to development aid suspensions in 1982-87, 1990-91 and after 1997. Suriname's unstable economic conditions and the lack of employment opportunities remained migration drivers until the early 2000s. Political and economic issues in Suriname often went hand in hand, but unlike socio-economic factors, political factors were concentrated between 1973 and 1992. Political factors peaked during independence, the December Murders, the War of the Interior and the escalation of violence in 1988-1989. Once the political tensions subsided, economic hardship tended to grow, mixing the significance of these two important migration drivers.

The role of Dutch migration policies varied over time. They had no significance at all up to the early 1970s, but they became a migration stimulant in the 1973-1980 period, when the time limits to obtain Dutch citizenship (1975) or to gain entry into the Netherlands (1980) encouraged emigration. From 1980, however, migration policies become an 'intervening obstacle' (Lee 1966): as continuous political and economic hardship which stimulated migration unfolded in Suriname, migration policies prevented many people from emigrating. Migration was directed into family reunification policies with marriage (family formation) and irregular channels as ways for non-family to migrate, leading to strong categorical substitution effects in this period, when high levels of migration aspirations were met with the gradual closing of migration policy channels. In the recent decade, it is safe to say that common knowledge on the high level of restrictiveness of Dutch migration policies, combined with the worsening Dutch economy and promising Surinamese, has reduced overall migration levels.

The importance of family connections in the Netherlands is undeniable and was already visible in the 1960s. It was really around and after independence, however, that family connections and migrant networks strongly emerged as strategies to overcome migration policy barriers. Interviewees who migrated to the 
Netherlands as children recalled how their parents provided temporary housing for numerous family members and friends over the years, while more recently family members could provide the initial link to migrate. Family connections have remained constantly important over the past 60 years, although not always the most important factor as joining family members never seemed to be the driving force behind most Surinamese emigration.

\section{Conclusions}

From education to the economic strategies and the politicisation of ethnic relations, the migration-relevant factors discussed were heavily influenced by the Surinamese state through its policies, political actions, diplomatic relations and geopolitical preferences resulting in political and socio-economic transformations in Suriname. Concurrently, the Dutch state also played a visible role over the years, most strongly thorough its migration policies, but also through its influence on economic models, ideological principles (e.g. 'good governance') and its decisions on development aid. Today's reduced emigration has been associated with increasingly restrictive Dutch immigration policies, although the economic downturn in the Netherlands and some improvement in political and economic stability in Suriname seem to play as much of a role in discouraging emigration.

Lastly, Surinamese migration could be easily discussed as a textbook example of the migration effect of post-colonial ties, given the strength and endurance of the Suriname-Netherlands migration corridor. This chapter shows that post-colonial ties have been nurtured since independence and the factors that have mattered over time have shifted: while language, culture, educational and institutional links were determinant in the early period, economic dependency on Dutch aid, family connections and influence of Dutch lifestyle have become more dominant. However, with the economic crisis in the Netherlands in the late 2000s, the improved conditions in Suriname and the Suriname government's attempt to diversify the economy and strengthen regional ties, Suriname's 'window on the world' is expanding beyond the Netherlands. This may result in a gradual weakening of post-colonial ties as Surinamese migration destinations slowly diversify. 



\section{Chapter 6 - Emigration from French Guiana: the effects of non-sovereignty, open borders and state policies}

\section{Introduction}

In 1946 French Guiana (Guyane) was transformed from a French colony to a French Overseas Department (Département d'Outre-Mer, DOM), thus becoming an integral part of France and also a piece of Europe in South America. This process set Guyane apart from its continent and regional Caribbean environment in socioeconomic and migration terms. In relative terms, Guyane has high per capita GDP and growing immigration (Calmont 1994; Granger 2007; Calmont 2008; Piantoni 2009; Hurpeau 2012). This distinguishes it from the high emigration and low immigration rates that have historically characterised its neighbouring countries. With just over 22,000 Guyane-born emigrants in metropolitan France in 2006, emigration is seen as rather unimportant with only about 10 percent of all Guyaneborn people residing abroad, ${ }^{116}$ a low rate when we consider that in 2000 neighbouring Suriname and Guyana had between 48 and 50 percent of their population abroad and that same year Guadeloupe and Martinique, also French Caribbean DOMs, recorded over 57 and 44 percent of their respective populations away from the islands (i.e. in metropolitan France, other French territories or abroad). ${ }^{117}$ Guyane's low emigration is surprising considering that in becoming a DOM the French Guianese ${ }^{118}$ were granted full French citizenship and freedom of movement to metropolitan France and its territories, as well as ease of movement to the rest of the world. This chapter examines the role played by political incorporation and open borders in shaping long-term emigration patterns from French Guiana.

\footnotetext{
${ }^{116}$ Data from French statistics and literature; if migrant stock data from the World Bank Global Bilateral Migration Database were used, the percentage of Guianese abroad would fall to below 5 percent of the total Guianese population.

117 Data from the World Bank Global Bilateral Migration Database and UN Population data.

118 For simplification, in the rest of the text I will abbreviate French Guianese to Guianese. This must not be confused with Guyanese from Guyana (former British Guiana).
} 
Guyane has often been discussed in terms of its difficult settlement history: the multiple attempts by the French state to increase its population through a number of immigration programmes and create a sufficient labour force to support sustainable economic growth in its large unexploited territory (Ho-Choung-Ten 1978; Ho-Choung-Ten 1980; Redfield 2000). Even today most migration research on Guyane focuses on the rapidly growing immigration trends (Guengant 1993; Piantoni 2009; Hurpeau 2012), while research on emigration has been and continues to be limited (Calmont 1978; Calmont 1981; Calmont 1988) ${ }^{119}$ with the exception of observations on broad migration trends reported by a number of demographers (Guengant 1993; Rallu 1997; Marie and Rallu 2004; Breton, Condon et al. 2009; Marie and Rallu 2012; Marie, Temporal et al. 2012). Guianese emigration offers an interesting case to examine whether its distinctive migration patterns are associated with its incorporation and continuous open border regime with metropolitan France or perhaps with other functions of the state beyond migration policies.

This chapter analyses the evolution of Guianese migration from the late 1940s to the early 2010s and relies on two main guiding questions: i) how did the transition from colonial status to department, i.e. departmentalisation, and the absence of a border regime affect internal and international migration? And ii) how have the colonial past and continued association with metropolitan France affected Guianese migration? Through the exploration of these developments, this chapter seeks to improve our knowledge about the effects of non-sovereignty and open borders on emigration, applying the last conceptual scenario presented in chapter 2. By relating changes in the volume, timing, direction and composition of emigration to specific state-driven political and socio-economic transformations and individual migrants' narratives, this chapter aims to uncover potential migration substitution effects (de Haas 2011) linked to migration policies but also other state-promoted policies. With this inquiry, we aim to uncover links between state actions and migration dynamics which have so far been left unexplored. Because the non-sovereign status and its open border regime have important ramifications beyond emigration, a brief section of this chapter presents insights on return, circulation, non-migration and immigration.

This chapter relies on two sets of sources: (a) secondary literature and primary archival sources to reconstruct the political, economic, social and legal transformation in French Guiana and the policies designed by the French state to regulate mobility; (b) 20 interviews carried out in February-April 2014 with Guianese migrants, returnees and non-migrants in French Guiana and Martinique,

\footnotetext{
${ }^{119}$ Calmont 1978 has not been consulted because of this article's inaccessibility.
} 
who described emigration motives, timing and destination decisions. For the purpose of this study, Guianese are the people who see Guyane as their home, who enjoy French citizenship and live their life in reference to Guyane and not to another 'origin country'. This includes descendants of British West Indians and Asians with French citizenship and the French Antillean population with longterm attachment to Guyane, but excludes people who may have lived in Guyane most of their lives but do not possess French citizenship and the rights it grants, particularly freedom of movement and access and state services, including stateled migration initiatives. ${ }^{120}$

Before we continue, a note is necessary. Guyane's absolute emigration figures have been and remain so low as to appear insignificant, e.g. about 6,200 Guianese in metropolitan France in 1975 and about 22,000 in 2006. This partly reflects the fact that French Guiana's population was just under 58,000 in 1975 and about 197,000 in 2006. However, these small absolute figures actually correspond to about 11 percent of the population, similar to the proportion of Moroccan or Mexican populations abroad. As a result, seemingly contradictory messages appear in this chapter as, on one hand, the chapter seeks to explain how political status and border regimes have led to low emigration volumes in comparison to neighbouring Guyana and Suriname; on the other hand, these relatively low emigration volumes are given great attention to understand the shifts and longterm slow rise of Guianese emigration. Both aspects of inquiry provide valuable insights and help us to understand better the effects of non-sovereignty and open borders on the evolution of emigration patterns.

\section{Guyane's early immigration history and diverse population}

Population size and labour supply have been two central concerns of the French state since its occupation of Guyane in 1676. Primarily intended for cash crop production (Jolivet 1982), Guyane was populated mainly by slaves until the abolition of slavery in 1848 . Thereafter, planters attempted to replace slave labour with contract labourers from the African continent, China, India and the Madeira

\footnotetext{
${ }^{120}$ A Guianese researcher with whom I discussed this issue admitted her own ambiguity, eventually deciding that Guianese are those people who consider themselves to be Guianese and who have at least one parent who is Guianese; however, the same researcher indicated that in practice in her own research she included people without Guianese parentage who grew up or lived in Guyane and felt Guianese. Given this study's objective to understand the effects of open borders, the most appropriate definition included a Guianese identity and, most crucially, access to rights to movement granted by French citizenship.
} 
islands, but recruitment numbers remained small (Redfield 2000). East Indian contract workers contributed an estimated 8,000 workers between 1860 and 1880, a low number compared to neighbouring Suriname and Guyana (Ho-Choung-Ten 1978). French settlement remained small as well: the ill-fated Kourou expedition saw the arrival of 12,000 colonists in 1763-1765 followed by the rapid death of at least half of them, giving Guyane the unfortunate reputation of being a European tomb. The establishment of a penal colony in 1852 had the objective of providing productive labour, but ultimately only served to reinforce the image of Guyane as a harsh and dangerous tropical land (Redfield 2000).

Nevertheless, spontaneous immigration occurred as thousands of French Antilleans and British West Indians migrated to Guyane during the first gold rush of 1880-1916. Although most returned to the Antilles (Piantoni 2009), they remained the largest immigrant group until the mid-1950s (Granger 2007). By the mid-twentieth century, Guyane's population included three main groups: the Creoles, namely descendants of African slaves, early Europeans and Caribbean immigrants, who were the largest portion of the population; the Maroons, descendants of African slaves who escaped, largely from Dutch plantations in Suriname, to the interior over the $17^{\text {th }}$ and $18^{\text {th }}$ centuries; and various Amerindian populations. Historically, both the Maroon and Amerindian populations have primarily occupied Guyane's interior (Redfield 2000).

\section{Exploring Guyane's long-term emigration motives}

Guyane's emigration remained very low until the 1960s, when Guyane-born migrants in metropolitan France were estimated at just below 3000 (Marie and Rallu 2004). By 1982 this figure had risen to about 10,000, representing approximately 12 percent of Guyane's population (see Figure A1 in appendix E) and nearly a doubling of the growth of Guianese settled in metropolitan France between the 1968-1975 and the 1975-1982 censuses (Figure 6.1).121

\footnotetext{
${ }^{121}$ A note must be made on the patchiness of data and the heavy reliance on stock figures which are reported inconsistently over the years and make longitudinal analysis problematic. However, the data are of sufficiently good quality to observe overall trends, which is the main focus of this study.
} 
Figure 6.1. Intercensal net migration of Guyane-born individuals recorded in metropolitan France and net migration as percentage of Guyane's population, 1954-2006 ${ }^{122}$

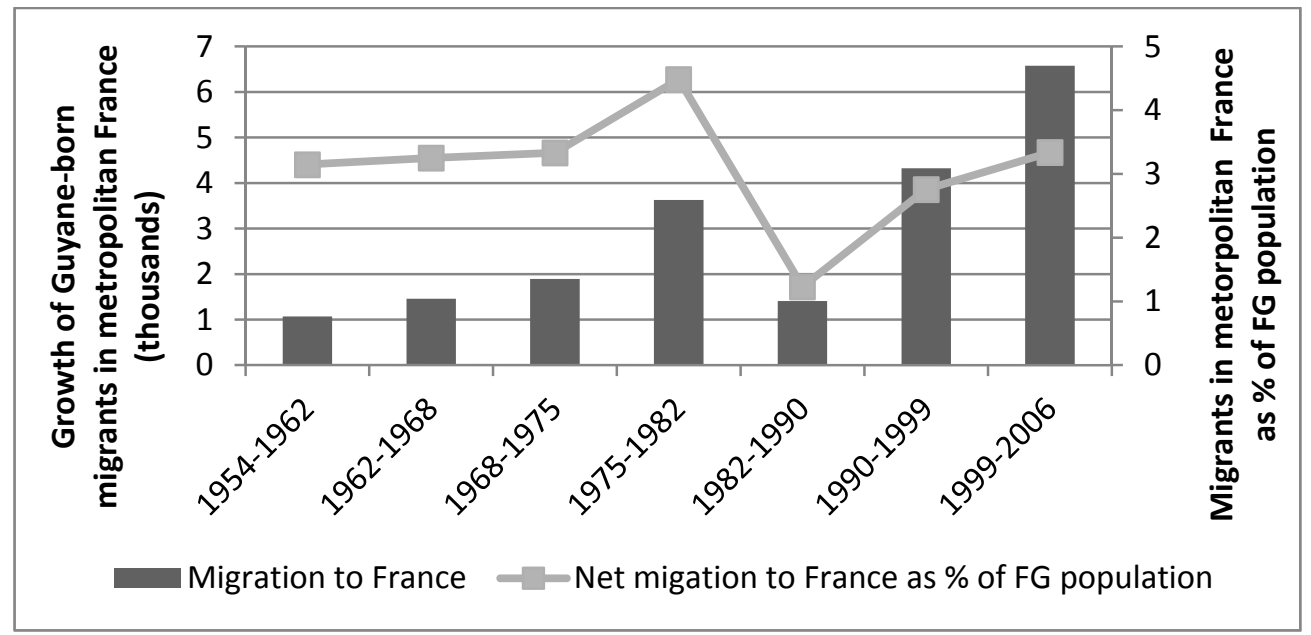

Source: Censuses of metropolitan France, Marie et Rallu 2004, INSEE data. ${ }^{123}$ Intercensal figures calculated by author.

However, a visible slowdown in emigration occurred between 1982 and 1990, followed by renewed emigration growth since 1990 when the Guyane-born population residing in metropolitan France grew from about 9,900 in 1982 to over 22,000 in 2006. Data from the 2007 census and survey data from 2009/2010 (Table 6.1) suggest that around 42 percent of the population in the 18-79 age group engaged in migration to metropolitan France, among whom around 15 percent have returned, while around 42 percent of the population has had short-term stays in metropolitan France of less than 6 months (Temporal, Marie et al. 2011). It has been suggested that multiple reasons have been driving this long-term trend of growing emigration. Régine Calmont (1981) argued that growing Guianese emigration to metropolitan France was driven by four main determinants: shortage of employment in Guyane, mismatch between job offer and aspirations among

\footnotetext{
122 This figure, and figures 6.3 and 6.4, represent the change in migrant stock, i.e. difference in Guyaneborn individuals residing in metropolitan France between census periods. In French statistics this is sometimes called 'net migration'. These figures cannot provide as good an understanding of migration patterns as migration flow data may do, but they are the primary figures used in all French statistics. Because the French census only accounts for Guianese present in the metropole, these figures do not account for any Guianese who may have migrated to other DOMs or abroad. However, occasionally, migration stock figures are derived from the Guianese census, in which case exits and returns would account for movements to destinations other than metropolitan France. The source listed for each graph will indicate whether the figures originate from the census of Guyane or metropolitan France.

${ }^{123}$ Data available at http: //www.insee.fr/fr/insee regions/guyane/themes/ter/ter2010/ter2010 03 gy.pdf, accessed February 2014.
} 
Guianese, cultural attraction of France, and education. The following sections consider these factors as well as political and institutional determinants, particularly non-sovereignty and open border regimes, in an analysis of the evolution of Guianese emigration.

Table 6.1. Migration history of Guyane-born individuals, based on residence in Guyane or in metropolitan France (\%)

\begin{tabular}{rlllll}
\hline $\begin{array}{r}\text { Migration } \\
\text { history }\end{array}$ & $\begin{array}{l}\text { Natives } \\
\text { who never } \\
\text { left }\end{array}$ & $\begin{array}{l}\text { Natives who } \\
\text { left for short } \\
\text { stay abroad } \\
\text { (less than } 6 \\
\text { months) }\end{array}$ & $\begin{array}{l}\text { Returnees } \\
\text { (long-term } \\
\text { migration) }\end{array}$ & $\begin{array}{l}\text { Natives still } \\
\text { abroad } \\
\text { (long-term } \\
\text { migration) }\end{array}$ & $\begin{array}{l}\text { Total } \\
\text { natives }\end{array}$ \\
Age group & & 40.0 & 12.4 & 30.3 & 100 \\
\hline Aged 18-34 & 17.3 & 42.1 & 15.4 & 26.2 & 100 \\
\hline Aged 18-79 & 16.4 & & & & \\
\hline
\end{tabular}

Source: Merged data from two tables in Temporal et al. 2011, original sources are Ined-Insee, MFV 20092010 and 2007 census data.

\subsection{Incorporation as a French department and institutional shifts}

When the French government incorporated French Guiana, as well as the French Antilles and Réunion, as an Overseas Department in 1946, some opposition to this transition emerged (Belenus 2006). However, the majority of the Guianese population supported departmentalisation (Mam-Lam-Fouck 1979), which implied the incorporation of the former colony into the French republic in a similar administrative category as other French departments, e.g. Provence or Brittany. As a department, Guyane's existing relations with the French government and institutions were reinforced: Guianese secured full French citizenship, the economic links with metropolitan France were strengthened (Redfield 2000) and French Guiana began to adopt limited versions of the French social security system (Horowitz 1960).

By the mid-1950s, a desire for greater autonomy emerged, particularly among left-wing parties (Redfield 2000). Discontent led to the rise of independence movements, which peaked in the early 1970s (Jones and Stephenson 1995), prompting harsh reactions by the French state which arrested a number of militants (Redfield 2000). Eventually, the French state reduced tensions by gradually granting more autonomy (Alexandre 1977; Giacottino 1995). The rise to power of the Socialist party in France in 1981 raised hopes that the French state would improve its relations towards the DOMs. A process of 'decentralisation' granted Guyane the status of mono-departmental region in 1982: along with greater autonomy in the management of its public finances (Blancodini and Tabarly 2010), fiscal policies were introduced to reduce taxes and promote investment (Piantoni 2009). Overall, decentralisation meant that important political 
and economic decisions could finally be made within the department, fulfilling some of the population's wishes for greater self-governance. ${ }^{124}$

The 2000s would introduce two other important institutional changes that altered the position of Guyane, and the other DOMs, in relation to metropolitan France and Europe. In 2000, the French Orientation Law (loi d'orientation) recognized the different institutional and legal needs of the DOMs and granted Guyane responsibility for the exploitation of some of its resources (i.e. biological resources of the sea, although it excluded gold) (Piantoni 2009). The second shift occurred at the European rather than at the French national level. In 2009 Guyane, like other overseas territories of European member states (e.g. the Azores, Canary Islands), became an 'outermost region' (région ultrapériphérique). This status, recognized in the 1992 Treaty of Amsterdam, grants special funding to peripheral regions because of the economic disadvantages linked to their distant locations (e.g. small local markets, high transportation costs) (Blancodini and Tabarly 2010). Through this status, Guyane became eligible for European funds for projects, e.g. the POSEIDOM programme, whose overall objective was to raise Guyane's socioeconomic standards to European levels. This process reinforced the already-strong orientation towards metropolitan France and Europe (Piantoni 2009).

Over the years, the political scene in French Guiana became heavily controlled by a few Creole families who gained power during the early years of decentralisation (Piantoni 2009) leading to clientelist practices (the filon). Almost all interviewees described how the majority of the population cannot enter the political system and access resources, e.g. land. The filon was mentioned particularly by young people who described their inability to access opportunities and showed a general sense of hopelessness and disbelief that they could have a fair chance. As a result, several interviewees expressed the desire to emigrate in order to leave this mentality behind.

Institutional and political reasons provide some explanation for the observed emigration, particularly the lack of emigration peaks which would have resulted from the transition to independence and the establishment of a border regime. Moreover, the important growth of Guianese abroad recorded in the late 1970s to early 1980s, equal to 4.5 percent of Guyane's 1982 population (Figure 6.1), can be associated with a general disappointment with the governance of Guyane, which also led to the growth of independence movements. This has resonance with Hirschman's arguments on people's reactions to dissatisfaction either by voicing their discontent or leaving the country (Hirschman 1978). Furthermore, the drop in emigrants in the 1982-1990 period to less than 1,500 suggests a potential decrease in

124 Phone conversation with Régine Calmont in March 2014. 
emigration aspirations at a time when institutional changes were gradually introduced by decentralisation, carrying the promise of socio-economic development and greater self-governance. However, we must also consider interwoven socio-economic factors to fully explain these trends.

\subsection{Economic developments and employment opportunities}

After the incorporation of Guyane as a department, the French state implemented new initiatives to improve working conditions in the country. Economic initiatives were launched both in agriculture and other sectors to reduce severe unemployment and poverty (Redfield 2000). Between the 1940s and early 1970s many initiatives were tied to immigration recruitment, revealing the French state's strong historical preoccupation with Guyane's underpopulation (Vizot and Chevalier 1947). Among these initiatives, which were usually linked to agricultural development, we find the following: the Bureau Intéressant les Personnes Immigrées en Guyane (BIPIG) was created in 1950 to resettle refugees located in France and Algeria (Milia 1997); Javanese immigrants settled in Sinnamary between 1955 and 1968 (Calmont 1979); in 1963, the Society of Technical Assistance and Social Credit (SATEC) assisted in the resettlement of about 10 Martinican families to Matoury (Milia 1997); and in 1970, a group of Hmong refugees who had fled the conflict in former Indochina were resettled in Guyane to start horticultural production (Redfield 2000; Piantoni 2009).

A major new initiative began with the decision to build the Guianese Space Centre (Centre spatial guyanais, CSG) in Kourou in 1964. This project required major infrastructural developments that generated labour demand in construction, forestry and other low-skilled jobs. Contract workers were recruited directly from metropolitan France, Colombia and Brazil and supplemental workers arrived spontaneously from Suriname and other Caribbean locations. These jobs did not appeal to the Guianese population, who preferred well-remunerated and stable employment in the public sector (Jolivet 1982). Once in operation, the CSG offered more prestigious employment opportunities. However, because these positions required advanced specialised technical education, they were filled primarily by employees from metropolitan France $(60$ percent). For the local population, employment opportunities were mainly confined to administrative positions (Redfield 2000).

In August 1975, the French state launched the Plan Stint, commonly known as Plan Vert, to promote large-scale agricultural development, including paper production, via the recruitment of 30,000 French colonists (Schwarzbeck 1982; Redfield 2000). Eventually, the fall in paper prices on the world market, combined with local opposition to such a large immigration plan (Guyane's population in 1975 was about 57,000 ) convinced the French government to recruit a 
much more modest number of farmers (Piantoni 2015 forthcoming) and the envisioned large-scale agricultural production never materialised (Redfield 2000).

Along with these initiatives, the French state expanded the size of Guyane's public administration. Keen to attract public officials from metropolitan France to the DOMs, a 40 percent bonus on the metropolitan salary scale was introduced in 1957 for those serving in the overseas departments. Although by 1960 the public sector employed 40 percent of the working population, this still left 60 percent with few employment possibilities (Calmont 1981). Lack of attractive employment opportunities in agriculture and the space industry meant that employment aspirations were concentrated in the public sector, which became a symbol of social distinction (Redfield 2000). In the meantime, emigration gained importance as an increasing portion of the population left in search of alternative employment opportunities. This labour migration has been described not necessarily as the result of lack of employment but of the mismatch between the jobs on offer and the aspirations of the Guianese population (Calmont 1981).

Until the early 1960s emigration was spontaneous and migrants relied on their resources and contacts in metropolitan France to migrate. In 1963, the French state established the Bureau for Migration from the Overseas Departments (Bureau pour le développement des migrations dans les départements d'outre-mer, BUMIDOM) to facilitate state-promoted migration, and settlement, from the DOMs to metropolitan France to fill shortages in labour in the low ranks of the public sector (cf. Constant 1987; Condon and Ogden 1991).125 In Guyane, BUMIDOM was less focused on emigration and more on the immigration of French citizens whose skills could promote the Guianese economy (Calmont 1981: 25). Yet, BUMIDOM offered an opportunity to access public sector employment, even if at the lowest levels, matching the growing employment aspirations in Guyane. BUMIDOM supported the emigration of 1,900 Guianese in the period between 1962 and 1977, a small percentage of Guyane's population and a tiny figure compared to the assistance given for the emigration of 30,000 Martinicans in the same period (Calmont 1981).

However, BUMIDOM emigration represented a changing trend and an increasing reliance on this service in the mid-1960s, as neither agricultural nor space-centred initiatives were fulfilling the population's aspirations (Figure 6.2). BUMIDOM did not increase emigration, but data suggest that it partially diverted spontaneous emigration. BUMIDOM's services had a three-fold benefit: i) they reduced emigration risks; ii) they made migration possible for people who may not

${ }^{125}$ Other motives justified such a programme in the French Antilles, where mass unemployment and social unrest were fuelling a growing independence movement. 
have been able to afford the costs of travel and accommodation; and iii) they gave people training and access to public work in metropolitan France, albeit at the lowest levels of the public sector. In fact, these were attractive positions for a workforce that was primarily low-skilled: data show that almost 35 percent of the Guyane-born population working in metropolitan France did not have any diploma of formal schooling and 72 percent did not possess any certificate of professional or technical education (Calmont 1981). However, after receiving training and work experience in metropolitan France, often as domestic and hospital help for women or as mechanics for men, these workers could attempt to obtain a transfer (mutation) to Guyane. BUMIDOM's role in Guianese emigration was limited: in fact, the 1973-74 emigration increase, which may have been associated with the rise of unemployment rates to 35-40 percent (Movement Guyanais de Decolonisation (MOGUYDE) 1977), followed spontaneous channels (Figure 6.2). The rapid drop in spontaneous emigration in 1975 may also be associated with the economic crisis and decrease in employment opportunities in metropolitan France linked with the 1973 Oil Crisis.

In the 1980s, financial contributions resulting from the process of decentralisation enabled new infrastructural projects and the further expansion of public employment. Additional employment opportunities seem associated with the decrease of emigration in the period 1982-1990 (Figure 6.2). However, by the mid-1990s financial constraints affected the Guianese economy and led to the slowdown of public works. Guyane experienced a period of social protests in reaction to these economic conditions but also to political and socio-cultural crises (Piantoni 2009). In 1999, unemployment rates again reached 30 percent, with 26.4 percent of the population living below poverty level. At the other end of the socioeconomic spectrum were public sector employees, representing 44 percent of all salaried workers in Guyane in the 1990s (Attali, Moriame et al. 2008), who benefitted from a gross bonus of 65 percent over public officials working in metropolitan France (Piantoni 2009). A widening gap divided the privileged permanent public employees and the rest of the population with limited and precarious employment opportunities. This would demarcate two different propensities to emigration: while the former would face few constraints to emigration, benefitting additionally from the possibility of job transfers (mutations), the latter would be less and less able to emigrate while increasingly perceiving emigration as a good option. 
Figure 6.2. Total emigration and BUMIDOM/ANT ${ }^{126}$ migration as percentage of total population in French Guiana, 1962-198427

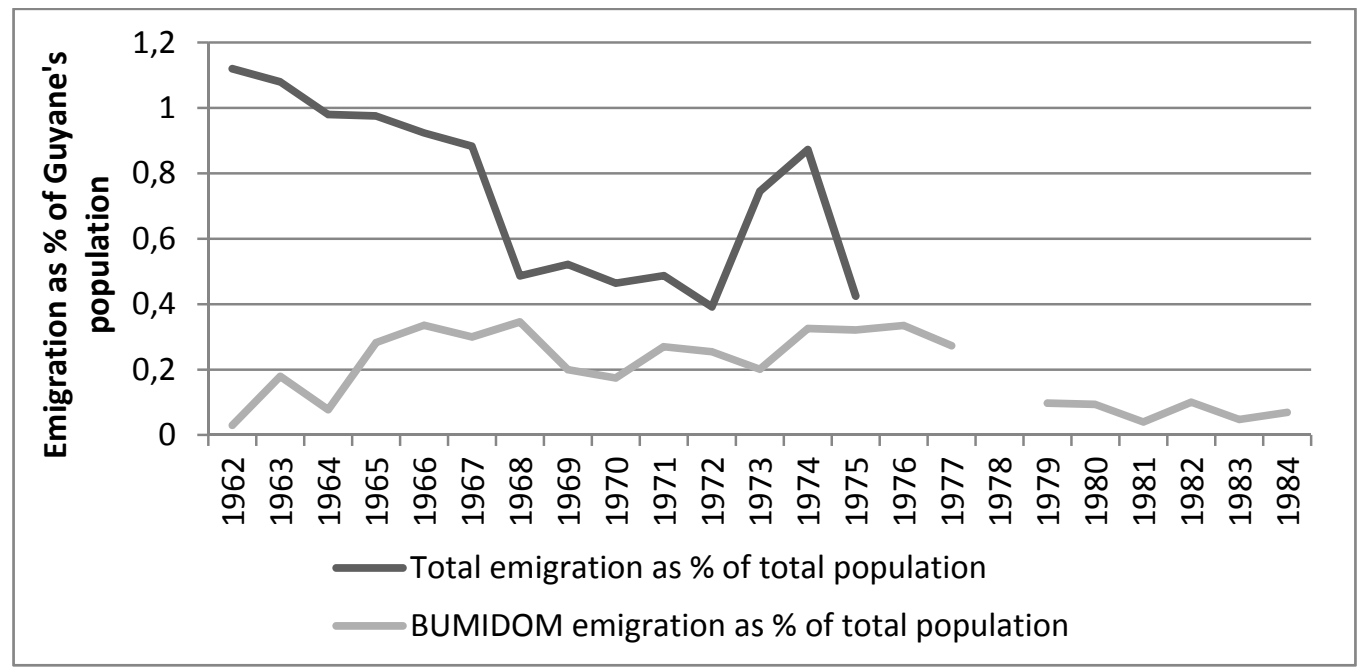

Source: French census 1975, 1982 and other sources in Calmont 1981 and Calmont 1988

By 2009, the population aged 15-24 had an unemployment rate of 40 percent, 128 compared to 24 percent in metropolitan France for the same age group, although qualified workers faced better employment prospects in Guyane than in metropolitan France (7 vs. 15 percent unemployment respectively) (Temporal, Marie et al. 2011). This difficult employment situation influenced migration propensities, as suggested by a survey carried out in 2009/2010 (Migrations, Famille et Vieillissement), which revealed that 56 percent of Guianese aged 18-34 were ready to leave Guyane if they were given a job (or a more interesting job for those with a job) outside the country.

Guianese emigration has clearly responded to employment needs (Calmont 1988). Interviewees shared stories of brothers, sisters, cousins and other relatives who migrated for work and professional reasons over the 1990s and 2000s, some to pursue careers as cooks, beauticians and hairdressers in metropolitan France where they would have better opportunities. Others emigrated because Guyane did not offer employment for workers with technical

\footnotetext{
126 ANT (Agence nationale pour l'insertion et la promotion des travailleurs d'outre-mer) was BUMIDOM's successor agency.

127 Total emigration figures for 1962-1967 were available only as an aggregate of 2500; this figure was simply averaged over these six years.

128 While high, this is much lower than the unemployment rates in Martinique, Guadeloupe and Reunion, which show figures of 61 percent, 57 percent and 52 percent respectively (Temporal, Marie and Bernard 2011).
} 
skills, either because their skills were too specialised or because they lacked the proper connections (filon) to secure employment. Interestingly, data from the Migrations, Famille et Vieillissement survey representing all DOMs ${ }^{129}$ also showed that 57 percent would leave only upon condition of being able to return and only 8 percent would leave without intending to return. Individuals willing to emigrate were generally the unemployed without a family, or students (Temporal, Marie et al. 2011), indicating that reasons tied to social welfare and education, which we explore next, have been among the primary reasons influencing migration patterns.

\subsection{Social welfare and educational opportunities}

At incorporation, the French state established a network of clinics and introduced DDT spraying to fight malaria and reduce health risks in French Guiana (Redfield 2000). Guyane would also be gradually included in the national social welfare system starting in 1946 (Horowitz 1960), but it was really in 1962 that the welfare state was extended to the DOMs with the introduction of social transfers and the threefold increase in family welfare benefits (Constant 1987). In 1973 family benefits were aligned to those in metropolitan France (Piantoni 2009). The reinforcement of social benefits continued in the 1976-1980 period (Constant 1987) with the introduction of a family supplement, making family benefits a monthly provision, establishing professional training, unemployment and housing benefits, social support for social integration and salary adjustments aligned with those in metropolitan France (Piantoni 2009).

The alignment and strengthening of social services occurred at a time when the Guianese population was undergoing a demographic transition and, as we saw previously, unemployment rates were reaching 35-40 percent and independence movements were becoming very active. This was also a period when emigration was gaining strength (Figure 6.1). By improving financial, social and educational assistance, the French state aimed to improve the quality of life in Guyane, but it also promoted more 'departmentalisation' in an attempt to prevent the further radicalisation of independence movements, as Constant (1987:14) observed for the French Antilles. The population's ability to rely on social benefits, including unemployment, training and housing, may have contributed to the drastic reduction in the emigrant population in the period 1982-1990 (Figure 6.1), a time when the outlook was positive as the Guianese were assuming greater control over internal matters.

\footnotetext{
129 The author was unable to access these data for Guyane alone.
} 
The provision of education also improved over time: while in the early 1970s only one high school (lycée) was available and students could obtain only basic professional training such as secretarial skills, the establishment of the University Centre of the Antilles and Guyane (Centre universitaire des Antilles et de la Guyane, CUAG) in 1970, which became the University of the Antilles and Guyane (Université des Antilles et de la Guyane) in 1982, began to expand educational opportunities for Guianese youth. However, a few interviewees indicated that they were sent by their parents to study in metropolitan France as teenagers, where education was believed to be better. Moreover, because course options remained limited at this time, the majority of the students continued their studies in metropolitan France. Several interviewees indicated that their siblings, who were in the school system in the 1960s and 1970s, had to go to metropolitan France, frequently to the university cities of Bordeaux, Paris, Toulouse and Montpellier, to advance their education. For the bourgeoisie, temporary migration to metropolitan France, typically to earn a degree, was important not only for the education objective, but also because spending time in France was associated with becoming modern, mastering the French language and culture, and ultimately securing a place in the elite (Jolivet 1985).

Educational opportunities for Guianese youth continued to develop over the years as the numbers of secondary schools increased and university courses were expanded with the opening of the University Institute of Technology (Institut Universitaire de Technologie, IUT) in Kourou in 1988 and the Guyane Institute of Higher Teaching (Institut d'enseignement supérieur de la Guyane, IESG) in 1991. However, in the 1980s students were a major component of Guianese emigration (Thery 1986). Since then, the numbers of Guianese with degrees who emigrate has been on the rise. In a recent survey among 16-25 year-olds, one third displayed strong mobility, frequently associated with education or professional development. ${ }^{130}$ Such high emigration seems to be linked to the fact that although availability of education has increased in Guyane, it remains limited to the first levels, leading students who want to pursue post-graduate degrees to go to metropolitan France (Temporal, Marie et al. 2011: 561). Moreover, interviewees often referred to perceptions that Guyane's education is inferior to that of metropolitan France, leading to a continuous preference to pursue degrees in metropolitan France.

Evidence of migration for education purposes was strong among the interviewees: a non-migrant interviewee indicated that about half of his high

\footnotetext{
${ }^{130}$ The source of this information is a synthesis of an unpublished report based on a survey (Démarche Jeunesse) of Guianese aged 16-25 carried out in 2012 by F. Piantoni.
} 
school friends went to metropolitan France in the 1980s, while another interviewee who went to study in Bordeaux in the mid-1990s indicated that almost all her friends pursued their studies in metropolitan France, but acknowledged that she attended a private school and that students in the public school system were less oriented towards going to university in metropolitan France. It transpired that among the elite, as for the interviewee, going to metropolitan France to study was part of a natural progression: it occurred without question as a result of the lack of educational options in Guyane and a belief in the superiority of French universities, factors that in combination acted as stimulants of student migration. The preference of studying in metropolitan France is also nurtured by significant information and support provided to students during their secondary studies to obtain scholarships and financial help to study in metropolitan France, which create a very interesting financial proposition for potential students. L'Agence de l'Outre-Mer pour la Mobilité (LADOM) (see more below), provides financial support to students who pursue advanced degrees in metropolitan France, through their Passeporte Mobilité Etudiant programme.

Migration for education is not confined to university studies. Professional training has been promoted since the 1980s, first by ANT (l'Agence nationale pour l'insertion et la promotion des travailleurs d'outre-mer), which was BUMIDOM's successor agency, and since 2010 by LADOM. Young Guianese can obtain a technical diploma by attending a variety of training programmes in metropolitan France. To be eligible, candidates must hold French citizenship or have a 10-year residence permit, have sufficient and relevant preparation, appropriate family circumstances, e.g. few or no children, and choose training programmes that allow future professional employment in Guyane. While the officials responsible for LADOM's activities claim that this agency does not generate emigration aspirations, their services enable a few hundred young people to migrate to metropolitan France at very low costs and low risk, making migration and further education, whether academic or technical, possible for individuals who may not have the financial means to do so personally. Through this eligibility-based programme, LADOM - and the French state - contributes to a small emigration stream, albeit meant to be temporary, to metropolitan France.

The financial support provided by LADOM was relevant in the migration processes of the interviewees. Two interviewees benefited from the Passeporte Mobilité Etudiant programme, while other interviewees mentioned having requested themselves or knowing people who requested LADOM's assistance to pursue technical and professional training in metropolitan France. An official indicated that LADOM receives large numbers of requests, approximately 5000 per year, although they honour only about 500 . The reasons given by applicants for requesting LADOM's services range from work and professional reasons (e.g. 
changing from secretarial work to bakery) to personal reasons such as pregnancy, domestic violence or simply wanting to join a partner in metropolitan France. Among the 15 young people interviewed by LADOM officers in March 2014, there were 9 young men and 6 young women with diverse backgrounds, including a Surinamese young man with a 10-year residence permit, all with specific career objectives - from caretaking to restoration and house-painting. The officials commented that there has been growth of requests from the Maroon population, which they associated with the fact that Maroons are increasingly exposed to the financial benefits of migration through the previous migration of community members. This, however, may also be linked to other transformations: first, investments along the Maroni river have resulted in greater interaction of the Maroon communities with coastal communities and the French state; second, the younger generation has been schooled in the French educational system, learning values and life course objectives that are distinct from the Maroon tradition of village life in the rainforest, and increasing their aspirations for education. ${ }^{131}$ Conversely, requests for overseas training by the Amerindian population have been limited.

Since incorporation as a French department, the levels of health, social services and education improved greatly in Guyane, making it the country with the highest quality of life in South America by the 1980s (Schwarzbeck 1982). This alone largely explains why emigration from French Guiana is much lower than from neighbouring Suriname and Guyana. Nonetheless, a number of factors are also generating growing emigration, particularly among young adults. Employment remains an important reason for emigration for graduates who find that Guyane does not offer them the employment opportunities to which they aspire given their areas of specialisation. And despite having made great strides, the availability of advanced education remains limited in formal academic areas and focused on technical skills, leading to growing student migration. These insights show that the role of the state is central in shaping Guianese emigration: on one hand it reduces emigration by providing basic social protection as well as offering educational options; on the other hand, education is increasing aspirations for further education or more specialised employment, which can only be achieved through emigration. Moreover, programmes such as those offered by LADOM provide the French state with a tool to channel and manage at least some emigration, e.g. selecting the candidates and reminding students of their return ticket. I would also argue that these programmes generate expectations that emigration should be 'low-risk', engendering hesitation in engaging in spontaneous emigration which relies on personal funding and contacts. Thus,

\footnotetext{
${ }^{131}$ I thank Frédéric Piantoni for bringing my attention to this important factor.
} 
while LADOM's programmes facilitate a small mobility stream, they concurrently may reduce spontaneous emigration. Evidence of this emerged in the interviews as some individuals described the conditions under which they would emigrate, which invariably included forms of state assistance, i.e. a secure job and housing.

\subsection{Additional emigration motives}

Emigration decisions have been influenced by the presence of the filon, mentioned previously, as well as by military service. Interviewees cited the filon and their personal lack of access to these contacts as an obstacle to gaining employment and access to resources in the 1960s as much as today. Emigration was described as an escape from these limitations, which the interviewees described as restricting their life opportunities, and from the mentality associated with the filon. Going to metropolitan France would open access a wider range of opportunities that were denied to them in Guyane.

Military service and army conscription had an emigration-facilitating role for young men. A number of individuals left Guyane for military service, while others enrolled in a military career, some remaining in the armed forces and others opting out once in metropolitan France. On two occasions the men admitted they would have probably emigrated nevertheless and one man indicated that he 'used the military service' to go to metropolitan France, as it made emigration cost-free for his parents. With the end of compulsory military service in 2001, this migration motive became much less prevalent, although young men still leave Guyane after joining the army.

\section{Characteristics of emigration}

\subsection{Destination choices}

Migration was described as a means to experience the world. A sense of adventure accompanied the migration of young military men as much as that of students pursuing a degree in metropolitan France. Migration was described as a way to expand their horizons, enter a new world of opportunities and even access the path to achieve success. Metropolitan France was preferred because it was considered intellectually stimulating, 'cultured' and overall superior, confirming what had been observed in earlier periods (Calmont 1981; Jolivet 1982). ${ }^{132}$ This was

\footnotetext{
132 Despite the dominance of metropolitan France as migration destination, not all perceptions of the metropole were positive: grievances about France's cold weather, people's individualism, excessive work schedules and discrimination (e.g. being treated like foreigners) emerged. Nonetheless,
} 
usually contrasted with description of Guyane as limited, not only in terms of employment but also in reference to cultural events and sources of entertainment.

In more practical terms, metropolitan France clearly gave and continues to give a number of advantages starting from language, familiarity with institutions (i.e. educational, administrative, legal), including access to all services and benefits (e.g. public employment, scholarships). Moreover, the presence of family members and friends, including Guianese and Antillean networks in Paris, Toulouse and Montpellier ensure some support, although the interviews revealed that reliance on these networks is limited. For instance, a young migrant indicated that it is good to rely on someone in metropolitan France for housing, but emphasised how friends' accommodation should be just as a short-term place to sleep while you are out looking for a job and a place of your own. Another woman who emigrated as a young woman in the 1970s shared how she had to find alternative housing because her brother could no longer keep her at home, and another who migrated in 2014 had to return after a few months because she could no longer stay with her sister, while her brother could not offer her any accommodation in his studio flat. This may be linked to having citizenship and the ability to circulate between Guyane and metropolitan France or perhaps to the fact that the state provides support for migration (i.e. scholarships or transfers for public employees). Thus, if the conditions are not appropriate for a migrant to remain in Paris, there is no pressure to remain at all costs. Rather, it may be preferable to return to Guyane and reemigrate to metropolitan France at a later time when better opportunities arise.

Despite the importance of metropolitan France as a migration destination, Guianese migration has been historically less concentrated in metropolitan France than for French Antilleans. This was confirmed in the 1990 census, which showed that only 68 percent of migrants returning to Guyane resided in metropolitan France in 1982, compared to 91 percent and 88 percent of returnees to Guadeloupe and Martinique respectively (Guengant 1993). Although these data do not indicate where the remaining 32 percent of Guianese previously resided, it can be assumed that the French Antilles were important destinations. This is confirmed by the findings in chapter 3 which showed a high concentration of intra-regional migration towards other countries within the French colonial sphere. Among interviewees, Guadeloupe had a significant role both for temporary and long-term migration: some interviewees went there in the 1990s in search for work while others went to stay with family members. Marriage and family relations were often a reason for migration to the French Antilles and other French territories: a couple

interviewees indicated that even an important aspect such as discrimination would not result in negative feedback and the reduction of migration to metropolitan France. 
of Guianese women married Guadeloupean men and lived in Guadeloupe for a few years, one of them migrating from metropolitan France to Guadeloupe before returning permanently to Guyane; a young man migrated to New Caledonia, a French territory in the Pacific, for personal reasons and later returned to Guyane; evidence emerged of children of Martinicans settled in Guyane who are now returning to Martinique. Migrants show a clear preference for remaining within the French sphere of influence, even when it involves long-distance emigration to the Indian Ocean, i.e. Reunion and Mayotte, and the Pacific Ocean, i.e. New Caledonia.

This can be contrasted with emigration to the Latin American and Caribbean region, which is nearly absent outside of the French Antilles. The high standards of living in Guyane seem to explain the lack of interest in places like Paramaribo $^{133}$ in Suriname and Georgetown in Guyana, but there is also little knowledge of places that offer high living conditions such as the Bahamas or the British and US Virgin Islands. It is undeniable that transport connections, which are limited to Paris and the French Antilles, Paramaribo and Belem in Brazil, are constraining the further diversification of destinations beyond the French sphere. Nevertheless, a new range of destinations are fanning out in Europe, i.e. Belgium, the United Kingdom and the Netherlands, and in North America, particularly Quebec in Canada, which was mentioned on multiple occasions as a desirable destination for students and young professionals. This suggests that although the preference for francophone destination remains strong, young Guianese are gradually exploring alternative migration destinations outside of the traditional French circuit.

\subsection{Age, gender and class composition of emigration}

Emigration to metropolitan France has primarily affected the 18-30 age group over the years. Some emigration among the over-30 group was observed in the 1960s1970s, motivated by family reunification in metropolitan France (Calmont 1981). BUMIDOM data confirmed the growing importance of family reunification in the 1970s (Calmont 1981; Calmont 1988). This partly explains the increase in women's emigration in the 1975 French census data, a trend confirmed in the 1982 census. However, this trend may have also been linked to the growing participation of women in education and their higher unemployment rates in Guyane, which in this period were double those of men in the 25-29 age cohort (Calmont 1988).

\footnotetext{
${ }^{133}$ With economic growth in Suriname and the improvement of roads and services in Paramaribo, this city has become a popular holiday destination and one interviewee shared his desire to buy a house and move to Suriname after retirement.
} 
Net emigration figures in the 1990-2006 period continued to be driven by high emigration rates among the population between the ages of 18-34, while emigration decreased after the age of 30, when returns became larger than outflows (Figure 6.3) (Temporal, Marie et al. 2011). Surveyed returnees indicated education as a strong motive for their initial emigration, even more important for women than for men (Marie, Temporal et al. 2012). Between 1990 and 1999, women in the 18-22 age group more than doubled their contribution to migration (from 7.6 to 17 percent of all Guianese emigration), while men's emigration grew particularly in the 28-32 age group. ${ }^{134}$

Figure 6.3. Intercensal net migration, Guyane-born individuals by age group ${ }^{135}$

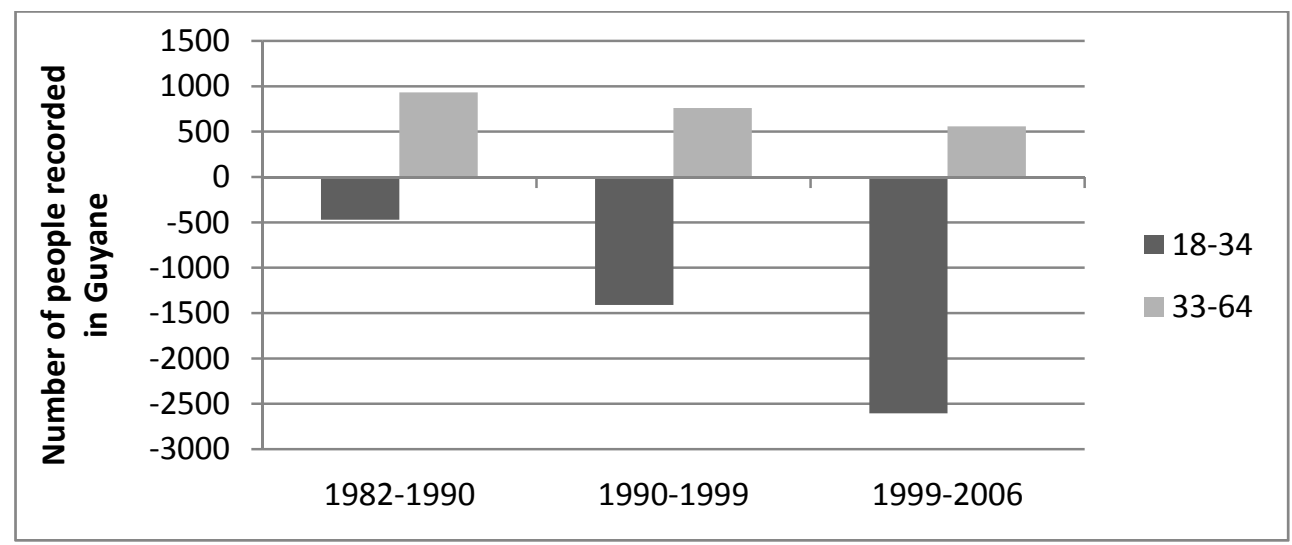

Source: Guyane censuses 1982 and 1990 (Rallu 1997; Marie and Rallu 2004); Censuses of metropolitan France (Marie and Rallu 2012)

Confirming the fact that emigration is primarily a phenomenon of the middle and upper classes are survey data from migrants from all DOMs, which indicated that migrants in metropolitan France and returnees from metropolitan France tend to have higher education levels, while individuals who never left the Overseas Departments tend to have high unemployment rates, low education levels and high levels of poverty. This contradicts previous research which suggested that Caribbean countries with open borders with the metropolitan state permit the emigration of various segments of the population, including less educated and rural migrants (Grosfoguel 1996). Evidence emerged that young persons from St Laurent-du-Maroni, on the western border with Suriname, are

\footnotetext{
134 These data are extracted from Table 4 in Rallu 1997 and Table 2 in Marie and Rallu 2004, as well as Guyane census 1982, 1990 and 1999 (measuring exits from Guyane).

135 The overlap in the age groups is due to the fact that over the years the data have been grouped according to shifting age groups. The groups presented here include the range of ages that have been used in the literature over the years to represent each group.
} 
often unable to independently afford accommodation and living expenses to attend professional training in Cayenne. However, the services of LADOM are important as they provide opportunities to experience life in metropolitan France even among this socio-economic group. This points to the importance of statesponsored initiatives in allowing the mobility of citizens in the lower socioeconomic classes. Thus, despite the absence of policy barriers to migration, migration is a phenomenon of the educated, because economic constraints reduce mobility for short stays abroad (Temporal, Marie et al. 2011) and even, as we have seen, internal mobility.

\section{Beyond emigration: the effects of open borders and non-sovereignty on other forms of mobility}

So far we have explored long-term emigration, one of the potential migration effects of the transition to non-sovereignty and the retention of open borders. Other forms of mobility, such as short-term mobility, return, re-emigration, immigration as well as decisions not to emigrate have also been affected. We now turn to a brief exploration of these trends.

\subsection{Return and circulation}

Open borders allow high levels of circulation, including short-term stays, and return migration, permitting migrants to respond flexibly to personal or structural conditions without feeling constrained by migration policies. For example, faced with unemployment, a migrant might prefer to return to the origin country either to look for employment there or to reorganise until she is able to secure new employment in the destination country. In the past, such flexible responses were thought to be uncommon because of Guyane's few opportunities for specialised technicians and professionals who returned with degrees from metropolitan France (Vizot and Chevalier 1947; Calmont 1981). However, the interviews provided ample evidence of return as early as the 1960s and throughout the period under study. Moreover, five of the 11 returnees interviewed returned when they were 30 or below, indicating that return was not associated with retirement. Among returnees we find those who always aimed to return and returned on multiple occasions, those who returned after perceived permanent emigration as well as those whose return was in response to changing opportunities and family needs. Two interviewees separately described the experiences of their friends who went to metropolitan France to study and returned because of various life decisions including family formation, parenthood and professional development. Sometimes return was the result of failed objectives (e.g. no degree). Evidence of high levels of mobility was also confirmed by a recent survey showing significant 
numbers of returns and short-term stays (see Table 6.1) (Temporal, Marie et al. 2011).

All returnees described their return and reintegration in Guyana as fraught with difficulties: they reported episodes of discrimination, being seen as a threat or outsiders even by family members and unable to have the right connections to reenter the job market (filon). A high-skilled specialist indicated that many obstacles were put in her way upon her return, hampering her motivation. Among the interviewees, return often led to re-migration to metropolitan France, where remigrants indicated they could find work and better working conditions. Interestingly, it was common for Guianese to migrate between the French Antilles and Guyane, sometimes migrating for a few years to Martinique or Guadeloupe for work or because of an Antillean spouse, before returning to Guyane.

Although return generally appeared as a 'fluid', unobstructed process, a number of reasons prevented return: for some emigrants return depended on a public post transfer (mutation) to Guyane, while for others it was not possible because of embarrassment (e.g. failure to obtain a degree and low-status job), financial constraints or because they felt they would no longer be able to fit into Guianese society.

\subsection{Non-migration}

The low levels of Guianese emigration are surprising when we consider that over 43 percent of the population is under 20 and unemployment rates were at 31 percent for the 15-64 age group in 2011. ${ }^{136}$ Moreover, although Guyane's GDP per capita is the highest in the region, it has not kept pace with the growth in metropolitan France, as observed for the other DOMs (Attali, Moriame et al. 2008). In 2010, Guyane's per capita GDP was just over $€ 15,000$, while Guadeloupe's was about $€ 18,700$ and that of metropolitan France was about $€ 30,700$ (Insee 2015). Given the lack of barriers to emigration, what factors are keeping emigration aspirations low? A number of factors were raised by interviewees, which point to a combination of inability and unwillingness to emigrate.

A first group of motives suggested the lack of financial means and contacts to support migration, which affected individuals who wanted to study in metropolitan France as well as young unemployed individuals unable to take advantage of state services (e.g. LADOM). This is in agreement with previous studies showing that people in socio-economic difficulties are less represented

\footnotetext{
136 Data published by Insee, Chiffres clés: Département de La Guyane (973), available at www.insee.fr, accessed on May 5, 2015.
} 
among migrants from the DOMs in metropolitan France (Temporal, Marie et al. 2011) and shows that even without the logistical and financial obstacles introduced by migration policies, migration is an expensive endeavour particularly when costly air tickets and housing are involved.

A second group of motives suggested the unwillingness to migrate. Some individuals discussed their commitment to family and their unwillingness to leave family members, particularly elderly parents. Many interviewees displayed a general reluctance to take on the risks commonly associated with emigration, be it in facing life in metropolitan France, e.g. finding housing, employment, investing financial resources to face new challenges, or in leaving 'certainty' behind, e.g. a job, stability, forms of social protection and possibly informal means of selfsupport (e.g. family-provided child-care). An interviewee who held a public post and had a previous short-term residence in metropolitan France, indicated that he would only migrate to metropolitan France if he was guaranteed a job, housing and a car. Another interviewee clearly indicated that she had thought of emigrating, but she would have had to leave her job in the public sector with the risk of not being able to access the same post, which she found overall satisfactory, upon return. This suggests that stability, certainty and social protection play a significant role in lowering emigration aspirations, even when people have rightful access to higher wages and better employment opportunities available in metropolitan France.

The aversion to taking emigration-related risks extended to possible alternative foreign destinations. A young man shared his intention of emigrating to the United States, but after discussing the procedures for obtaining a US work permit, he exclaimed, 'you say that I have to go through the same hell (galère) that Brazilians and Georgetonians have to suffer here?!?' This suggests that risks normally associated with international migration, i.e. financial investment, risk to be returned at the border, loss of investment and irregular work, seem to be real deal-breakers, reducing emigration aspirations. This risk-avoidance behaviour is reasonable given the fact that Guianese can emigrate to a number of destinations worldwide without any linguistic or legal barriers. However, at the very core of this outlook is the fact that Guyane offers a high quality of life, leading to no strong desire to emigrate at any price.

\subsection{A brief word on immigration}

Guyane's employment opportunities, the possibility of earning wages in euros and Guyane's high quality of life, including social services, have made French Guiana a very attractive regional destination. Immigration is much more present in Guianese consciousness than any consideration of emigration. This is justified by the absolute numbers of immigrants (born outside of Guyane) in comparison to 
much smaller numbers of Guyane-born emigrants (Figure 6.4). This section briefly touches upon two types of immigrants: French citizens from outside Guyane and foreign nationals.

Internal immigration of French nationals is long-standing ('Born in metrop France' in Figure 6.4): French nationals arrived in greater numbers in the 1960s and 1970s to serve as technical staff in the space centre and work in agriculture and forestry (e.g. Plan Vert) (Domenach and Picouet 1988) as well as to serve as civil servants on short-term assignments (2-4 years) (Guengant 1993). In 1982, almost 7,800 people from metropolitan France and just over 5,000 French nationals from other DOMs and French Overseas Territories (TOMs), mostly from Martinique and Guadeloupe, resided in Guyane (Domenach and Picouet 1988). Since the turn of the millennium, there has been a decrease in metropolitan France-born and DOMborn immigration (Figure 6.4).

Immigration of foreign nationals also began to gain strength in the 1960s with the arrival of Brazilians in particular. While until the early 1980s, immigration flows were largely associated with development initiatives, from the mid-1980s the motives for immigration became more varied and included political instability in the region, most notably in Haiti and Suriname. Surinamese immigration gained particular importance as a result of Suriname's violent War of the Interior between 1986 and 1992, which transformed the border region of the Maroni river and led to the arrival of between 8,000 and 10,000 Surinamese refugees in 1987 alone (Domenach and Picouet 1988). While Surinamese, Brazilians and Haitians together accounted for 85 percent of all immigration in 2009, other immigrant groups exist: Guyanese (from Guyana) comprised 5.2 percent of all immigrants, while Chinese, Saint Lucians and Hmong each comprised less than 2 percent of the total immigrant population (Hurpeau 2012). Since the late 1990s, the growth in the absolute number of people born in foreign countries ('Born abroad' in Figure 6.4) has raised concern and overshadowed the growing emigration figures. 
Figure 6.4. Intercensal changes in the population in Guyane by place of birth, 1982-2006

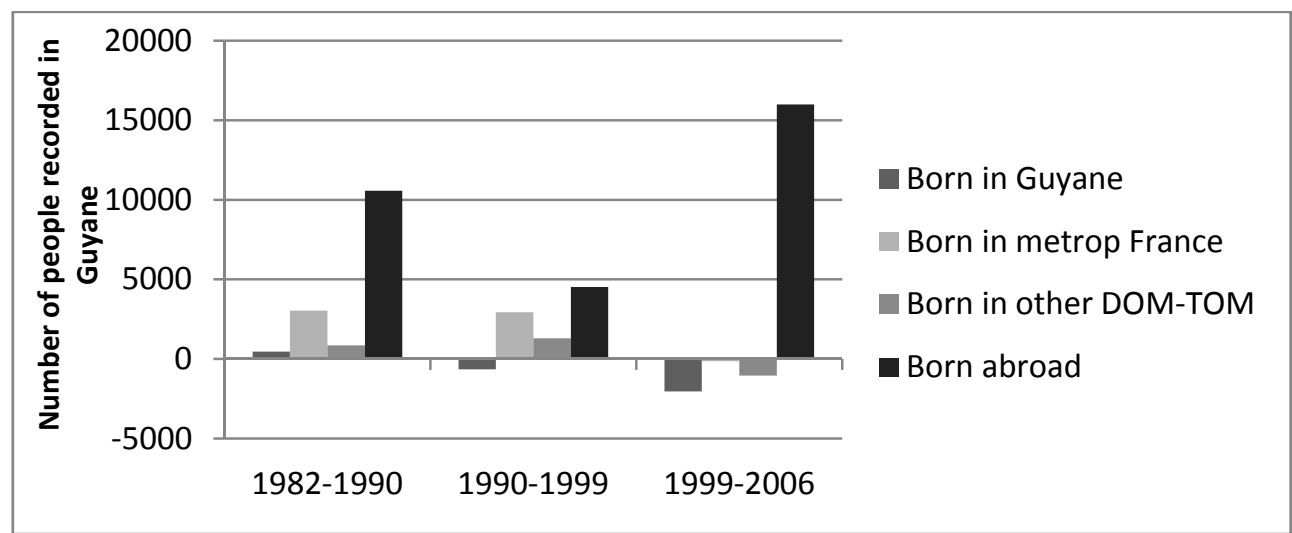

Source: Intercensal net migration data derived from Guyane censuses 1982 and 1990 (Rallu 1997; Marie and Rallu 2004) and Censuses of metropolitan France (Marie and Rallu 2012)

\section{Connecting the state, structural changes and long-term migration: a discussion}

\subsection{The emigration effects of non-sovereignty and open borders}

The first observation from the analysis of French Guiana and its transformation into a French Overseas Department with open borders within the French sphere is the absence of strong emigration peaks. In neighbouring Guyana and Suriname emigration grew significantly as these countries' inhabitants feared that the closure of the borders with the former colonial state would impede their future emigration and that independence would generate instability and worsened living conditions. By contrast, Guyane's emigration has been growing gradually, albeit with some fluctuations.

Guyane's incorporation as a French department has resulted in interventions at the institutional and economic levels. Unlike the uncertainties created by independence, the French state's socio-economic plans created greater stability through job creation and service provision, resulting in the overall reduction of emigration. The important institutional and socio-economic changes introduced by decentralisation in the 1980s resulted in a visible reduction of emigration in the 1982-1990 period (Figure 6.1); thereafter a re-alignment to longterm emigration trends has occurred. This seems associated with the fact that employment and education have been the main determinants of emigration from Guyane and increasingly Guianese seek specialised employment and advanced levels of education, which are not always available in the small Guianese economy. 
However, because living conditions in French Guiana are relatively good and there is a high level of stability, there is no strong motivation to emigrate.

The slow growth of Guianese emigration seems also to be associated with the absence of a border regime, which allows spontaneous forms of migration and mobility more generally. In fact, while forms of permanent migration are low, levels of circulation are high. The 'anxieties' and constraints associated with travel, residence and work visas and concerns with visa eligibility, fees, waiting periods and visa durations are eliminated. Two important effects resulted: first, the unfamiliarity with the 'world' of visas, which was a stark difference with Guyana and Suriname, where familiarity with visa regime types, fees, durations of application processes and eligibility was substantial in the general population (e.g. random conversations with taxi drivers, at shops, at events). Second, emigration occurs in a relatively 'low-stress' and 'low-key' fashion. Emigration is not rushed, it is not seen as a big event, as it may be in Guyana when someone finally obtains a US visa after waiting for 10-15 years or even a moment of celebration for having obtained a US travel visa. Emigration from Guyane to metropolitan France or one of its territories is rather the result of a personal decision, embarked upon when a person is ready and the conditions are conducive. The timing of emigration therefore is not concentrated, not resulting in strong emigration peaks.

The absence of visa constraints also explained why travel, short-term stays, returns and re-emigration were frequent among the interviewees. Unconstrained by migration policies, Guianese were able to follow employment and educational opportunities, visit family and return in relation to their personal timing. However, this case study shows that even without the barriers of migration policies, people facing difficult socio-economic conditions are unable to emigrate, internally as well as to overseas destinations.

Incorporation into the French state and freedom of movement have encouraged emigration towards metropolitan France. Departmentalisation resulted in the strengthening of French institutions, regulations, services as well as the cultural assimilation and admiration of ideals found in metropolitan France, including its 'modernity'. Unsurprisingly, metropolitan France is an important migration destination. However, it is also important to note that unlike the French Antilles, where emigration is strongly directed to metropolitan France, Guianese migration to metropolitan France remains dominant but a range of countries in the French sphere of influence are considered as potential migration destinations: Guianese individuals migrated in the past and continue to show interest in the French Antilles, Réunion, Mayotte, New Caledonia and increasingly in Quebec, Canada where institutional and linguistic ties suggest easier migration, as well as neighbouring Suriname. This may be due to a combination of factors: first, some 
migration is motivated by family and personal connections to the French Antilles as a result of previous immigrations to Guyane; second, although Paris and metropolitan France undoubtedly exert attraction, several interviewees saw emigration as a way to experience the world outside French Guiana and metropolitan France was important but not the sole destination that could satisfy this need. This was particularly noticeable among the potential re-emigrants, for whom future emigration was associated with the exploration of new destinations.

\subsection{Guianese emigration and the French state}

Guianese emigration provides a prime example of how states may shape migration without specifically resorting to migration policies. To start with, the reason why in Guyane emigration is not generally seen as a necessity is because of the presence of the state. Yet, the reason why some people emigrate is also linked to policies implemented by the state. Thus, the French state acts as a mediator as it creates opportunities in Guyane as well as giving Guianese alternative prospects in other parts of France which they can access through internal migration. Let us look more closely at the dynamics that emerged from this study.

There are three main factors that have affected Guianese emigration, in either direction: employment, education and social welfare. Employment and education have both been important emigration motives since the 1960s. Over the years, the French state's socio-economic plans have attempted to address the shortfalls in employment and educational prospects in Guyane. While employment in the private sector still offers limited options, the public sector has contributed to employment and over the years public jobs have become highly desirable because of the security of permanent placement and their high remuneration. Obtaining such a job may have the effect of fixing people to a place, particularly if the public official is satisfied with the placement.

However, public posts also allow migration through transfers. These transfers often occur with some delay, as an appropriate post may not be available in the desired location for a significant amount of time, sometimes years. A few individuals indicated how they tried to be transferred to France, Martinique, Réunion but this did not come through and so they gave up the idea of leaving Guyane, while another young women intends to migrate through a transfer to Réunion although she is aware that it may take years. Thus, public employment offers safe and risk-free migration opportunities, but the difficulty in securing a transfer to the desired location seems often to result in non-migration.

The provision of secondary and tertiary education in Guyane reduced the need for young Guianese to leave for metropolitan France. However, by increasing education aspirations, an increasing number of students aspire to pursue advanced 
degrees in metropolitan France, which are perceived to be of superior quality. The dissemination of information on scholarships throughout the secondary cycle plays a role in encouraging attendance of university in metropolitan France. Still, not all potential migrant students are financially able to access such services. In addition to transfers and scholarships, the French state has encouraged and continues to encourage migration to metropolitan France and other DOMs through the services of LADOM and its predecessors BUMIDOM and ANT. The mission of these state agencies has evolved over the year and they no longer support permanent relocation to metropolitan France. Yet their services still allow the departure of young people for university study or professional training and work experience in metropolitan France, making short-term emigration possible particularly for lower class young adults.

I would argue that the services of LADOM as well as the possibility of job transfers (mutations) have contributed to framing migration and the conditions under which people are willing to migrate in different terms: migration may be considered when some outside financial and logistical assistance is provided and personal financial risk is minimized. Interviewees consistently indicated that the state should provide assistance and financial support for those who want to emigrate as well as for the reintegration of those Guianese migrants who want to return. These expectations seem to affect both the volume and composition of migration: while the limitations of the state-funded programmes may reduce the overall volume of migrants, they also allow some people with socio-economic difficulties to migrate. However, this 'risk-avoidance' behaviour towards migration and the seeming reduction of emigration aspirations is linked to this specific context where stability and standards of living are high, and in fact is no different from what we may observe in many other countries where migration is not seen as a necessity. In French Guiana, lower emigration aspirations seem associated with the provision of a solid package of social welfare, the third factor that has shaped Guianese emigration. The improvement of livelihood conditions and reduction of household risks seem to have reduced emigration propensities in the 1980 s as well as today.

In the end, the provision of employment, education and social services provide strong evidence of the importance of the state and its policies in reducing emigration aspirations, while the state's involvement in providing emigration support contributes to directing emigration into specific channels that can be monitored and managed. This delicate balance, however, would not exist as such if it was not accompanied by the 'security' of the freedom of movement and the continued ability to emigrate should the need arise, which create a low anxiety environment with overall low emigration. Nevertheless, as the large young population reaches working age and the aspirations of the educated classes 
increase, both employment and education available in Guyane are unlikely to be sufficient, potentially resulting in important rises in emigration. Similarly, changes in social benefits may also shift emigration patterns in the future. As indicated by a young teacher, the potential loss of his 40 percent salary 'bonus', which has been in discussion, would make him consider leaving Guyane again, probably through a transfer to Réunion or Mayotte. However, given past responsiveness of emigration to state-supported initiatives in Guyane, it is not unlikely that renewed socioeconomic interventions may lead to a slowdown in emigration. 


\section{Chapter 7 - A comparative analysis of the effects of independence, border regimes and post-colonial ties on migration in the Caribbean and the three Guianas}

\section{Introduction}

I started this study with the desire to better understand the role of the state, its migration and non-migration policies and their effects on emigration. Migration has been increasingly perceived as a problem in need of control, and policy-makers have generally responded to this by implementing restrictive immigration policies and increasing border controls. However, the effectiveness of their measures have been contested in the literature. The 'Determinants of International Migration' (DEMIG) project, in the framework of which this study took place, has researched the role of states and their migration policies in affecting international migration (de Haas 2011). More particularly, this research aimed to contribute to the debate on the effects of border closure on emigration by looking at the Caribbean region, where the establishment of border regimes was linked to the transition to independence. This region and the three case studies of Guyana, Suriname and French Guiana provided a unique angle to observe the effects of the state's actions on migration during this important historical period. Albeit this study adopted an origin country perspective, the very nature of border regime establishment and transition to independence involved interactions between states in origin countries and those in destination countries, allowing insights on the role of origin and destination states and the effectiveness of their migration policies.

In the post-Second World War period the process of decolonisation generated important changes in border regimes in the Caribbean. The region underwent varied geo-political transformations as the various colonial powers adopted different strategies towards their colonies: Britain, with its large number of Caribbean colonies, primarily pursued independence while gradually transforming a small number of colonies into overseas territories; in 1954 the 
Netherlands established a Charter transforming its American colonies into countries with internal autonomy as part of the Kingdom of the Netherlands, although in 1975 Suriname attained independence; and in 1946 France incorporated its American colonies into the French state.

Citizens of former colonies were also granted various rights to movement, with incorporated colonies benefiting from full citizenship and freedom of movement and, at the other end of the spectrum, independent countries seeing their borders largely closed by highly regulated border regimes. Thus, the Caribbean region as a whole offered a unique opportunity to examine how the establishment of open and closed border regimes with the former colonial states altered pre-existing migration patterns. In-depth research of the evolution of emigration from the three Guianas provided an expansive understanding of the dynamics and underlying motives that link independence and border regimes to shifts in emigration. While Guyana and Suriname offer insights on the effects of independence and the establishment of border regimes on migration, French Guiana presents a counterfactual enabling the study of the effects of incorporation and ongoing freedom of movement with metropolitan France and its territories.

This chapter contains insights that emerged throughout this study, from the development of the conceptual framework on the role of migration and nonmigration policies and the hypothesised effects of border regimes and independence, presented in chapter 2, to the analyses of overall, extra-regional and intra-regional migration intensities of Caribbean countries, presented in chapter 3 , and the collection and analysis of data from archives, newspapers, academic literature and 84 interviews carried out in Guyana, Suriname and French Guiana, presented in chapters 4-6. The following sections incorporate all evidence from the various conceptual and empirical analyses.

\section{Understanding the migration effects of independence, border regimes and their interactions}

This study highlights the necessity to disentangle the migratory effects of independence from the establishment of border regimes with the former colonial state. First, the motives for migration associated with these two events differ, leading to distinct migration effects. Second, differences in the timing and sequencing of independence and the establishment of border regimes have significant effects on migration patterns. Third, the duration of their effects is different, with border regimes having more extended effects than independence. 
Independence carries the potential of strong short-term emigration peaks. However, the migration effects of independence are largely dependent on the support for independence amidst the population. Independence may cause political and socio-economic uncertainties, depending on the political environment: the presence of a peaceful and collaborative political atmosphere or political tensions, nepotism, oppression and/or competing ideologies that create a sense of uncertainty over the country's direction. Strong disagreements about the country's future prospects within the population due to ideological rifts or ethnic group divisions may lead certain segments of the population to feel uneasy about upcoming independence and encourage emigration. In Suriname, there was no strong independence movement and many Surinamese thought that the country was unprepared for independence. Support for independence was linked to ethnicity, access to power and resources, which made the groups in a weaker political and socio-economic position nervous about proceeding towards independence. When independence talks continued despite the many efforts by the opposition parties to stop or change the course of events, anxieties grew: the groups less close to the centre of power feared discrimination and potentially the loss of their assets in independent Suriname. Such a disputed and tense process to independence was the source of a staggering emigration flow (Figure 7.1), composed of people who felt threatened by this political change. This included entire families, including the very young, the elderly and the low-educated.

Conversely, Guyana's independence was the result of home-grown aspirations and 13 years of political negotiations between Guyanese and British politicians. Similarly to Suriname, ethnicity was closely associated with the power structure and access to resources. However, in contrast to Suriname, Guyana's economic prospects seemed very favourable and the majority of the population supported independence. Independence resulted in some emigration, but at much lower levels than those seen in Suriname (Figure 7.1). To a small extent, this reflects the fact that Britain had already closed its borders and most of the population could not easily emigrate. However, independence was not a particularly tense moment as it even led to some return migration by people wanting to participate in Guyana's development as an independent country.

The transition to non-sovereignty does not generate large emigration peaks and may overall leave emigration patterns unchanged in the short-term. However, by reducing uncertainties and engendering stability, non-sovereignty carries the potential of decreasing emigration. With its incorporation as a French Overseas Department, French Guiana underwent a process of stabilisation. On one hand, French Guiana's Creole-dominated society perceived their stability and power distribution to be 'under threat' by the arrivals of French citizens from metropolitan France and the French Antilles. On the other hand, by becoming a 
department Guyane inherited a strong political framework based on liberal democracy and norms of basic socio-economic standards. Through full incorporation into the French state, the Guianese population could access greater employment opportunities and increased security, leading to the lessening of emigration aspirations among its population (Figure 7.1).

Figure 7.1. Schematic representation of migration trends of Guyana, Suriname and French Guiana with respective moments of transition

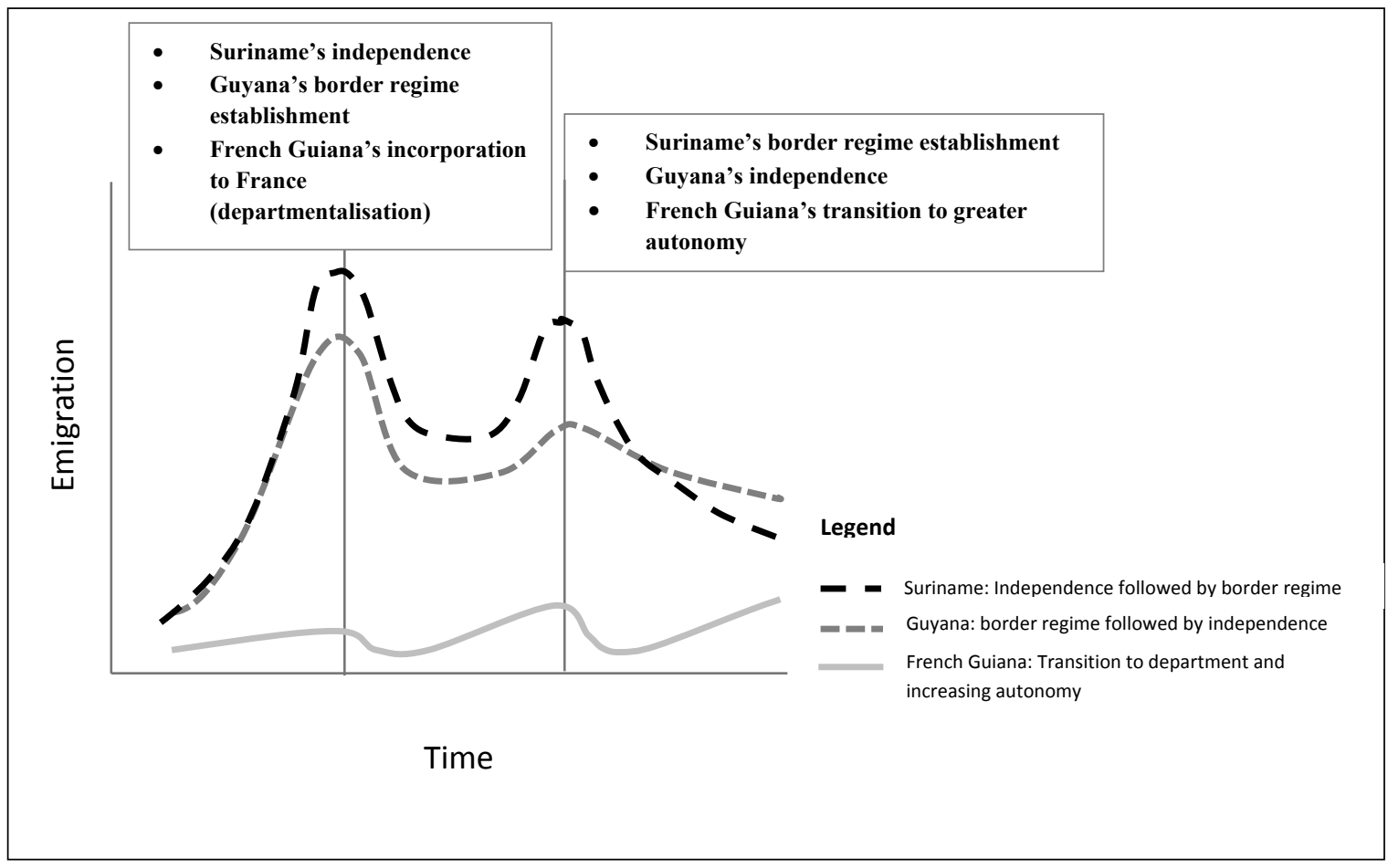

The establishment of border regimes with the former colonial state generates short-term emigration peaks, while the guarantee of free movement to the metropolitan state leads to lower and stable migration patterns (Figure 7.1). The introduction of border regimes seems to affect most strongly people already inclined to emigrate, encouraging them to emigrate within a short period of time in a rush to 'beat the ban'. This results in a sudden short-term peak in emigration. Young migrants would be strongly represented in this emigration hike, while the other segments of the population would remain largely unaffected. Guyanese and Surinamese emigration displayed such short-term inter-temporal substitution effects. In Guyana, this peak largely reflected the emigration of workers and students who wanted to take advantage of opportunities in Britain. However, the 
case of Suriname shows that when the establishment of a border regime occurs in the shadow of independence, this may diversify the emigrant population. Surinamese independence preceded the introduction of a comprehensive border regime with the Netherlands by five years. As a result, among emigrants who left before the introduction of the Dutch border regime there were not only young Surinamese, but also those engaged in family reunification in the Netherlands or those Surinamese dissatisfied with the standards of living in independent Suriname. Both in Guyana and Suriname, the 'beat the ban' emigration peak was followed by a rapid decrease in emigration, once the border regime with the former colonial state was enforced. This suggests that border closure has a migration-reducing effect, but this is a short-term effect, as revealed in chapter 3. On the other hand, the absence of the closure of borders in French Guiana explains the lack of a large emigration peak. Rather, emigration patterns have remained stable and seem mainly to respond to educational, employment and professional opportunities.

The sequencing of independence and the establishment of border regimes with the former colonial state generate substantial categorical and spatial migration substitution effects. One of the main findings of this study is that the sequencing of independence and border regime introduction generate significant categorical and spatial migration substitution effects. The case of Guyana illustrates this perfectly: the early closure of borders with Britain led to the search for alternative migration destinations and by independence Guyanese emigration had already started to orient away from Britain, mainly through increased settlement in North America. The degree of spatial diversification from the former colonial state strongly depends on the availability of alternative destinations, which may include neighbouring and regional countries. In Suriname, independence was followed by the introduction of a comprehensive border regime only five years later, a sequence that facilitated emigration and extended the period of 'beat the ban' emigration. While other potential destinations were possible, e.g. North America as demonstrated by Guyanese migrants, emigration continued to be directed to the former colonial state and led to the formation of large migrant communities which eased emigration even after the closure of the borders. Thus, Surinamese emigration did not undergo spatial diversification, but it displayed strong categorical diversification as potential Surinamese emigrants searched for alternative migration channels, such as family formation, to reach the Netherlands.

In the long term, countries with closed borders with the former colonial state experience increasing emigration intensity while countries with continuously open borders with the former colonial state show slower growth or stability of 
emigration intensity. Measuring emigration intensity as the share of emigrants of the total native population of a country, Caribbean countries ${ }^{137}$ with continuous open borders with their former colonial state experienced some growth in emigration intensity between 1960 and 1980, when it grew by 7 percent, but since then the growth of emigration intensity has been slowing down. On the other hand, the closed border countries experienced weaker growth between 1960 and 1980 and a rapid growth of emigration intensity by 12 percent in the following period. These trends are strongly related to the introduction of border regimes, which initially triggered 'beat the ban' emigration peaks, followed by a drop in emigration as border regimes were enforced. However, with time other migration substitution effects became prominent through the reorientation of emigration to other destinations (spatial substitution) or through new legal (or irregular) channels, such as family reunification (categorical substitution).

The dynamics observed in countries that have maintained open borders with their metropolitan state challenge the assumption that open borders necessarily lead to massive and uncontrollable emigration. These cases display emigration that is not responsive to migration policies, which do not apply to such internal migration, but to a variety of other political and socio-economic migration determinants. When states are unable to provide satisfactory socio-economic opportunities and high living standards, the right to movement may result in high emigration. For example, when Suriname was incorporated as a country of the Kingdom of the Netherlands (along with the Netherlands Antilles) between 1954 and 1975, it benefited from freedom of movement to the Netherlands, a political status similar to that of French Guiana today. In this period, Suriname was undergoing important structural changes in the agricultural sector, which led to increases in unemployment. It is exactly at this time that emigration from Suriname first began to grow as rural Surinamese began to look for employment in the capital Paramaribo and increasingly in the Netherlands. Nevertheless, even when stability wavers, emigration flows from open border countries are far from massive and uncontrollable.

\section{Wider migration effects of border regimes}

The border regimes with their colonies set up during the independence period by Britain and the Netherlands differed not only in the timing and sequence, but also in what forms of mobility they restricted. While Britain acted early to prevent work

\footnotetext{
137 The analysis focused on 25 Caribbean countries, including all independent and non-sovereign countries in the Caribbean Sea, plus Belize, French Guiana, Guyana and Surinam, but excluding Cuba, Haiti and the Dominican Republic.
} 
and long-term settlement, it was much more relaxed about allowing entry; it generally did not introduce travel visa requirements for its former Caribbean colonies (see chapter 3) and when it did for Guyana, it was in 1997, 31 years after independence. On the other hand, the Dutch government was initially more tolerant of settlement, but when the border regime with Suriname was fully introduced it included a travel visa requirement, which was never removed. Since then, however, old migration policies have been adapted and new policies have been introduced, with potential effects on emigration.

The border regimes of other destination countries have also affected emigration. While British and Dutch immigration policies had a great effect on emigration from Guyana and Suriname respectively, US and Canadian policies were extremely important for Guyanese emigration and to a lesser extent for Surinamese emigration. A diverse array of migration policies have been implemented by these four main destination countries: on one hand, there were policies aiming to control borders, to limit entry by reducing quotas, to raise requirements for family formation and reunification, to punish and deport those with irregular status; on the other hand, quotas were also increased, categories of caregivers were facilitated entry, students and high-skilled migrants could have easier access and the Canada and the US promoted seasonal workers programmes. This study has not pursued an in-depth analysis of these immigration policies and their objectives, so no claims can be made about the effectiveness of each of these policies, specifically the extent to which they have reached their intended objective (Czaika and de Haas 2013). However, this study has gathered evidence on the impact of some of these policies on migration, thus allowing us to identify some of their interesting and unintended effects.

Both in Guyana and Suriname, strategies of adaptation to migration policy included using fake documents, overstaying tourist visas and marrying family members, precisely reflecting Castles' (2004) description of 'policies as opportunity structures' and migrants' refusal to accept migration obstacles just because a destination state implemented these rules. This attitude towards migration policies is strengthened when the labour market offers opportunities (Castles 2004), but also when a sense of entitlement to migration comes from having been colonised. An older Surinamese interviewee, when asked why she wanted to migrate to the Netherlands, replied 'I was born Dutch!' referring to what for her was an inalienable right to retain Dutch citizenship and to go to the Netherlands whenever she desired. Furthermore, immigration policies seem to be perceived in degrees of violability, dependent on a migrant's personal situation and cultural norms. For instance, several interviewees suggested that while it is important to enter a destination country regularly, e.g. on a tourist visa, it is really not a violation to work without a work permit. Thus, historical links and personal and cultural 
perceptions of what is fair and unfair seem to shape compliant or resistant behaviour towards immigration policies, with important effects on policy effectiveness.

In this perspective, immigration policies may create constraints to migration, but may also provide opportunities for migration. Among all the migration policies relevant for Caribbean migration and in particular for migration from the three Guianas, two deserve particular attention because of their interesting effects: family reunification policies and travel visa requirements. Once Britain and the Netherlands implemented policies restricting the acquisition of residence and work permits, family formation and reunification policies provided an important migration channel, particularly for Guyanese aiming to emigrate to the US and Surinamese seeking to emigrate to the Netherlands. The US and Dutch family reunification policies differ in two important ways: first, US family reunification policies are a crucial component of US immigration policy and the concept of 'family' in US immigration extends to parents, children, brothers and sisters; this contrasts with a more limited concept of nuclear family in Dutch immigration policy, which limits the 'multiplier effect' of family reunification practices. Second, the applications' processing time may take just a few weeks in the Netherlands and up to 15 years in the US. As a result, US family reunification policies encourage strong and protracted contacts with family members abroad who may provide a migration channel over time. Conversely, the restricted and quick family reunification processes in the Netherlands curtailed similar ramifications, although even in this case family formation processes (i.e. new marriages) could provide an additional entry channel.

Such differences in immigration policies led to dissimilar emigration dynamics: Surinamese showed a weaker awareness of the whereabouts of family in the Netherlands. This was in stark contrast with the keen awareness among Guyanese of the whereabouts of their family members, particularly in the US and Canada. Interestingly, Guyanese referred to family members in Britain only remotely, claiming that 'they forgot about us' as they did not help relatives to emigrate when times were hard in Guyana. Conversely, knowledge of family in the US was very present with detailed accounts of who migrated, how they migrated, where they lived, who they 'sponsored' and who they 'could' sponsor. This also meant not only a great level of awareness of family migration histories but also very good general knowledge of visa policies, procedures, timing and costs associated with such 'sponsorships.'

Given the importance of family reunification policies in Guyanese and Surinamese emigration, the increasing restrictiveness of these policies both in the US and in the Netherlands had important consequence. More specifically, the 
increase in minimum income requirements for family reunification introduced in the 1990s may partly explain (temporary) decreases in immigration flows from Suriname to the Netherlands and from Guyana to the US. While Guyanese emigration to the US regained strength, Surinamese emigration has decreased to much lower rates. This contrasting evidence suggests that migration restrictions may be overcome by migrant networks as in the Guyanese case; however, migration policies may significantly hinder the migrant networks' role as facilitators of further migration, as the Surinamese case shows. Interestingly, in the aftermath of the introduction of income requirements to restrict family reunification, reports of irregular migration grew in both countries, further pointing to categorical substitution effects as Guyanese and Surinamese emigrants looked to bypass mounting obstacles to emigration. However, the perception of life in an irregular situation varied: Guyanese interviewees suggested that the US provides opportunities for a fairly decent life even without proper documentation within its large informal economy, a significant Guyanese community and very large undocumented population overall; the Netherlands, however, was portrayed as a difficult place to navigate without regular status, even with family support. It must be noted, however, that in addition to the actual opportunities available in the US and the Netherlands, these perceptions may reflect different expectations of standards of living and what good life is.

A second set of visible policy consequences is related to travel visa requirements. Travel visa requirements have been used by governments as a deterrent to reduce immigration of low-skilled workers and potential asylum seekers (Czaika and de Haas 2014). In chapter 3 we saw that travel visa regimes tend to reinforce the border regimes established with the former colonial state, so that countries with closed borders with the former colonial state also generally face restrictive travel visa requirements to other major destinations. Even mobility within the Caribbean region has been limited through the introduction of travel visa requirements, particularly to travel to Caribbean countries in the French and US colonial spheres. Consequently, regional migration often follows irregular channels as demonstrated by Guyanese and Surinamese migrants in French Guiana. Evidence emerged that many people are discouraged by travel visa requirements because the fees are prohibitive and the refusal rates are high, leading to the loss of non-refundable fees, as in the case of Guyanese seeking to obtain a travel visa for Britain, Canada or the US. On the other hand, the costs and difficulties of getting a visa may create incentives for people who are able to obtain a travel visa to overstay in order to seize this 'rare' chance and make their investment pay off. Ample evidence of this strategy emerged from recollections of Guyanese and Surinamese emigration in the 1980s and 1990s, when entire families took a chance to leave everything behind and emigrate with only a tourist visa in their possession. 
The contrast between the Guyanese and Surinamese migration policy environment and the free-migration conditions in French Guiana is remarkable. French Guianese migration, being oriented primarily within the French sphere of free movement, has largely remained unaffected by immigration policies of other major destination countries. This has resulted in a very different attitude towards emigration, which is relatively 'low-stress' and 'low-key'. Emigration is not rushed, it is not seen as a big event as it may be in Guyana when someone finally obtains a US visa after waiting for 10-15 years. Emigration from French Guiana to metropolitan France or one of its territories is rather the result of a personal decision. This resulted in the lack of strong emigration peaks as well as various forms of circulation: travel, short-term stays, returns and re-emigration were frequent among the interviewees; moreover, individual interviewees engaged in multiple forms of mobility. Unconstrained by travel, residence and work visas and permits, Guianese have been able to follow employment and educational opportunities, visit family and return in relation to their own timing.

\section{Colonialism, post-colonial ties and worldviews}

Former colonies generally have a concentration of emigrants in their former colonial state (Hooghe, Trappers et al. 2008; Constant and Tien 2009). However, the effects of post-colonial ties are not universal and while some bilateral corridors show great migration concentrations, e.g. Suriname-the Netherlands, others display much weaker post-colonial effects, e.g. Guyana-Britain. Previously we saw how the timing and sequence of introduction of border regimes and independence can explain the spatial diversification away from the former colonial state to alternative migration destinations. However, is there something more fundamentally problematic in the way we conceptualise post-colonial ties? The problem may lie in the fact that the notion of post-colonial ties hides a strong assumption: that colonialism has left an indelible (and positive) lasting mark that is not affected by post-independence national developments, including the formation of a national identity. However, this is not always the case.

When independence is desired and marks a departure from historical traditions, colonial history and ideals may no longer define identity and belonging, leading to weaker post-colonial ties. Hence, existing connection, e.g. language, culture, education, institutions, may have a much reduced effect on life in the independent country and in the selection of migration destinations. In Guyana, the population participated in the struggles for independence. Concurrently, Britain became increasingly eager to grant independence (Rabe 2005) and largely disengaged in Guyana's affairs after independence. Thus, independence marked a real point of departure. While colonial institutions were 
not totally dismantled, the Guyanese government took steps to assert its distinctiveness by removing references to London in the 1967 Constitution, introducing new economic models and reforming education. Such strong stances to set Guyana apart from its colonial past had important long-term consequences. These factors explain why post-colonial ties did not overcome the border regime barriers introduced by Britain or even lead to potential categorical shifts into irregular migration, which would have been possible by the fact that travel visa requirements were not introduced by Britain for Guyanese nationals until 1997. Likewise, other former British Caribbean colonies have seen a gradual decrease in levels of emigration to Britain, with continuous growth in emigration to North America.

Nevertheless, in some instances it seems correct to speak of post-colonial ties. When connections with the former colonial state run deep and shape a sense of belonging, they may explain continuing migration despite restrictive policy barriers. Within the Caribbean, the countries belonging to the Dutch, French and US spheres have retained strong orientation towards countries within their respective sphere, hence displaying much stronger post-colonial ties. Efforts at acculturation such as the 'Dutchification' process in Suriname and French assimilation of its overseas territories are expected to have more durable effects on identity. These bilateral corridors have also been strengthened over the years by the fact that all these countries, with the exception of Suriname, are non-sovereign dependencies with open borders to the metropolitan states. In Suriname, the Dutch government's ambivalence between the need to give independence to Suriname and a desire to hold on to its last large colonial possession led to great and continuous interconnectedness between Suriname and the Netherlands. Suriname's weak transformations of governance, institutional systems and legal structure in the post-independence period (Janssen 2011) failed to create a strong physical and mental separation. Thus, the Netherlands has largely remained the point of reference for many Surinamese, making Suriname a textbook example of when post-colonial ties have not just endured the passage of time, but have been nurtured and evolved over time.

However, Suriname also presents some ambiguity as opposite trends of weakening and strengthening ties to the Netherlands are visible at once. Scholars have remarked on the astounding growth of Dutch language usage in Suriname as well as the deep interconnectedness of Surinamese and Dutch societies as a result of the large volumes of migration, return and circulation. At the same time, evidence emerged on how the Netherlands is no longer seen as the 'promised land' and other countries are raising interest as Suriname gradually integrates regionally and strengthens its international connections. Generous scholarships to study in China are increasingly appealing, offering alternative options to the high 
administrative and financial barriers attached to education in the Netherlands. Thus, even when post-colonial ties are strong, they should not be considered as rigid and static factors, but as shifting sets of preferences that require a more refined and attentive understanding.

The qualitative assessment carried out in this comparative study is not appropriate to identify the exact extent to which the various aspects of postcolonial ties affect migration destinations and how these effects may have changed over time. However, it is possible to narrow down the list of important factors and assess their stability or sensitivity to change. The seven factors that emerged as important were: (i) language; (ii) cultural affiliation, belonging and prestige; (iii) political, institutional and ideological factors; (iv) educational factors; (v) economic, trade and aid connection; (vi) transport, infrastructure and communications; (vii) migrant networks. For Guyana, language was not influential in retaining a connection to Britain, while cultural affiliation, educational factors and economic ties were initially positively creating attachment to Britain, to varying degrees, but they weakened fairly rapidly. Concurrently, weak migrant networks in Britain and their rapid growth in North America increasingly weakened the cultural and physical connections with Britain. For Suriname, all factors were positively influencing post-colonial connections, although a weakening should be noted, particularly the cultural affiliations and prestige of the Netherlands, as previously indicated. Nonetheless, Surinamese networks in the Netherlands have an undisputable strong role in maintaining the focus of migration on the Netherlands. The case of French Guiana also presents positive and strong connections in all the seven factors. These factors, however, are also present to a large extent in other French territories, making them good substitutes for migration to metropolitan France. While the shared administrative systems make mobility easy and relatively low-cost, the freedom of movement across these territories ensures that ties are renewed and strengthened over time.

Given the speed of change in today's globalised world, post-colonial ties are bound to change. To understand how post-colonial ties will change in the future, it is essential to understand how the seven factors above, among others, may change and their potential effects on these historical relations. For instance, infrastructure could change relatively quickly, such as a new flight connection, but this does not mean automatically that the new flight destination will become an alternative migration destination weakening post-colonial ties unless other conditions are in place. Thus, this study has just started to tease apart this notion, but further research of post-colonial ties is advisable. A promising approach consists of using fuzzy-set Qualitative Comparative Analysis, which would allow determining, within a specific context such as the Caribbean, which of the potential 
factors associated with post-colonial links are most relevant in combination with the identification of necessary and sufficient conditions.

Still, the comparative nature of this study has produced a main conceptual finding: colonial and post-colonial experiences have created specific worldviews of potential migration destinations that evolve over time. Within these worldviews we find not only the former colonial state but also former colonial territories within the same sphere. However, shifting geopolitics affect and expand these worldviews. Former British Caribbean colonies have displayed a concentration of migration in former British Caribbean countries, but also a continuous growth in emigration to North America and other non-British Caribbean countries. Guyana offers rich examples of these shifting worldviews: for most Guyanese the world map is constructed of a dominant United States, followed by Canada, then the Anglophone world with Britain and the islands of Trinidad and Tobago, Barbados and a few other islands appearing, mainly in the British sphere, such as the British Virgin Islands but also the Dutch municipalities of St Eustatius and Curaçao.

Regional analysis shows that the former Dutch colonies have historically focused on the Caribbean countries in the Dutch sphere of influence, but even in this case the post-colonial effects are weakening. So, while Surinamese still find the Netherlands to be at the centre of their worldview and the Netherlands Antilles follow behind, the US and most recently China also appear on these mental world maps. Conversely, Caribbean countries in the French and US spheres retain strongly inwards oriented worldviews. French Guiana offered some clues to the dynamics underlying the population's orientation to France and all its overseas departments and territories. In addition to language and a sense of belonging to French society, migrating within the French sphere provides easy transferability of diplomas and skills and even the opportunity for job transfers within the public sector. And this can occur within a great variety of global locations that stretch from Réunion in the Indian Ocean to French Polynesia in the Pacific. Thus, French Guianese benefit from a wide range of opportunities without ever having to leave the French political sphere. Nevertheless, a certain curiosity and interest in new destinations are emerging, with reference to Canada and, to a lesser extent, the US, pointing to a possible future expansion of the Guianese worldview.

Shifts and in particular the expansion of worldviews seem to be associated with a population's aspirations to emigrate. The high standards of living in French Guiana and the wide range of migration possibilities within the French sphere have limited the expansion of their set of migration destinations. Conversely, for the Guyanese who face continued socio-economic difficulties and whose range of possible migration destinations has been curbed by highly 
restrictive migration policies, the inclination to scout for new possible destinations, thus expanding the migration worldview, remains high. Such a process of spatial diversification is gradual and accompanies other processes of transformation. Let us take transportation as an example. Emigration from Suriname to the US began to emerge in the late 1980s at a time when the middle classes started to take advantage of new flights from Paramaribo to Miami and New York. On these trips, Surinamese purchased goods to sell in Suriname, where most consumer goods were unavailable. Gradually, Surinamese migrants began to settle in these two cities. While Surinamese migration to the US has remained very small due to restrictive US immigration policies, through this organic process the US appeared as a new country in the Surinamese worldview of potential migration destinations.

\section{The role of the state: between risk production and risk reduction}

The focus of this study on border regimes and migration policies showed their importance in shaping certain characteristics of migration which may endure over the medium to long term. However, this study's ambition to capture the long-term evolution of migration patterns also brought to the surface a number of factors, be it ideological positions or various policies introduced by states, that altered developmental approaches, shifted the range of risks and opportunities among their populations, at times generating fears, anxieties and high levels of uncertainties, which affected migration aspirations. While this is in no way a new finding as it echoes arguments that have been previously advanced (Skeldon 2007), this study serves as further empirical evidence and a strong encouragement to look beyond the obvious, i.e. migration policies, and uncover the wider role of states in influencing migration aspirations and patterns.

A few specific lessons can be drawn from this study on the role of the state in shaping migration. A first important insight regards the effects of politics and governance in determining emigration, particularly since both Guyana and Suriname have had authoritarian governments. Previous macro-level empirical analyses found no significant effects of state-sanctioned political terror (Czaika and de Haas 2012) and the lack of political rights (de Haas 2010) on shifts in the emigrant population, suggesting that authoritarian governments, which often deploy these political strategies, may not lead to emigration as expected. A possible explanation for the lack of emigration may be that authoritarian governments tend to control the movement of their population, limiting exit (Dowty 1987; Matthews 1993). However, the cases of Guyana and Suriname provide examples of two distinct authoritarian regimes, which on the Political 
Terror Scale ${ }^{138}$ remained overall at a mid-level of political terror, ${ }^{139}$ that were strongly associated with important emigration flows.

This study expands our understanding of how political determinants may influence emigration in contexts where political terror has not expanded to the majority of the population, but where the population has been subjected to ethnicbased discrimination and anxieties, suspicion and distrust have dominated. Moreover, it provides some insights into how the length of authoritarianism may significantly affect the duration of emigration consequences. First, in Guyana and Suriname, ethnicity has played a major role in politics, leading to important forms of discrimination, not only in the political sphere but in all aspects of life. This took violent forms at times, but more generally it created ongoing anxieties that encouraged emigration. Second, these ethnic divisions were embedded in the political system and eventually became part and parcel of the oppressive authoritarian governments to which both the Guyanese and Surinamese populations were subjected. Periods of internal clashes and politically-motivated violence occurred, but overall these populations did not experience high levels of political terror. What dominated for several years, however, was a climate of suspicion and discrimination which contributed to increasing emigration.

An important distinction exists between the authoritarian governments in these two countries: the length of their authoritarian government and their oppressive conditions, which have had important effects on long-term emigration. In Guyana, authoritarian rule started four to five years after independence and lasted for 28 years with a profound effect on the country and Guyanese society, including devastating economic conditions, repression and lack of freedom felt at all levels of society. Over these three decades, Guyanese society was put under great strain both by deploying coping mechanisms (e.g. avoidance of political and community engagement) and by engaging in substantial emigration. Suriname's authoritarian episode started with a coup just over four years after independence, which was initially welcomed by large segments of the population as a possible shift away from ethnic politics and high levels of corruption. The peak of oppression occurred two years after the coup and targeted the high ranks of the political opposition and the educated elite, giving most of the population some insularity from oppression. Overall, Suriname's authoritarian period lasted less than seven years, which explains the growth of emigration during this period of

\footnotetext{
138 Gibney, Mark, Linda Cornett, Reed Wood, Peter Haschke, and Daniel Arnon. 2015. The Political Terror Scale 1976-2015. Accessed on July 6 2015, from the Political Terror Scale website: http: //www.politicalterrorscale.org.

139 There is an exception for Suriname, which reached the highest level of political terror in 1986 due to the War of the Interior.
} 
heightened political tensions. As authoritarianism was coming to an end, economic difficulties resulting in high poverty levels and shortages of basic goods persisted. Moreover, a new historical event, the War of the Interior of 1986-1992, would extend the political crisis with a visible emigration effect. These two case studies show that authoritarianism had important migration effects. However, Guyana's long-lasting authoritarian government and its low-level tactics of discrimination seem to have had a much stronger effect on the wider population and on emigration than in the case of Suriname, where the periods of heightened tension were concentrated in a shorter period and had direct effects on a smaller segment of the population.

This study also set out to understand whether and how the policies adopted in origin countries affect migration. In chapter 2, I proposed a schematic categorisation of state policies (see chapter 2, section 2.3 and Figure 2.1) that distinguished between migration and non-migration policies, policy objectives and policy tools and provided a simple guide to help us see how the state may affect migration in both direct and indirect ways. We saw in previous sections how border regimes and immigration policies produced important effects on emigration from Guyana and Suriname. What about the migration policies in these origin countries? Each of the three Guianas provides evidence that these states have made some efforts to regulate migration. The Guyanese state showed concerns over the high emigration of skilled Guyanese in the late 1960s, leading to the introduction of a Remigration Policy, a return policy in today's terminology, to attract Guyanese emigrants back to Guyana. During the negotiations for independence, the Surinamese government was also very active in securing special conditions regarding Dutch citizenship and continuing free mobility rights for Surinamese after independence, demonstrating both interest and power to shape migration policies at a critical time. Interestingly, the migration policies implemented by Guyana and Suriname around independence were promoting migration in opposite directions, reflecting the distinct positions towards independence previously discussed.

The French state has been keen on managing the population within its overseas territories, including in French Guiana. However, due to its inability to apply migration policies to regulate internal migration, the French state has regulated it by using socio-economic policies. In other words, unable to regulate internal migration, the French state has used non-migration policies and nonmigration tools to achieve migration objectives (Group 3 in the categorisation of state policies). Relying on a similar policy type, the Guyanese government introduced a ban on the export of foreign currency in the 1970s, which was meant to reduce the depletion of foreign currency in Guyana, but indirectly also to decrease emigration since foreign currency was being depleted by the rapid 
emigration of Guyanese. Despite its financial objective, this ban became a constraint to emigration and partly contributed to driving emigration 'underground' as people left suddenly without notifying even family members.

The three Guianas also offer valuable insights into how policies that do not have manifest migration objectives can have important consequences for migration. In particular, two specific non-migration policy areas have emerged as important for migration: economic development strategies, and social policies, particularly education and welfare. Across the three case studies, these policies have shaped migration in different directions, by either increasing uncertainties and the risks faced by the population or, contrarily, having a risk-reduction effect. In fact, although the three Guianas have all faced problems of high unemployment rates and lack of economic diversification, the intervention of the French state in French Guiana with significant financial and social transfers has acted as a 'stabiliser' that has recurrently slowed down emigration, while the more limited interventions of the Guyanese and Surinamese governments resulted in continued economic instability and important emigration volumes.

In the post-independence period, the Guyanese state pursued Marxistinspired co-operatives and nationalisation, which resulted in the departure of top executives and staff in management positions as well as business owners who feared the impending nationalisation of the private sector. The Surinamese state retained market-based neoliberal economic policies focused on multinational investments and external trade, a strategy that left much control of the economy in the hands of foreign investors. Despite these ideological differences, both Guyana and Suriname pursued similar reforms in agriculture: mechanisation was favoured in order to increase production and profitability, but it led to the displacement of small-scale farmers, increasing unemployment in agriculture and rural-urban migration (Standing and Sukdeo 1977; Hanley 1981; Canterbury 2007). While people from rural areas in western Suriname began to migrate to Paramaribo and to the Netherlands, Guyanese began to migrate to the rice fields in western Suriname as low-wage seasonal agricultural labour (Menke 1983). Other economic processes followed similar paths in Guyana and Suriname, such as the lack of economic diversification, the focus on big infrastructural projects, a reliance on the expansion of the public sector and the implementation of structural adjustment programmes (SAPs), which had similar effects on the economy, leading to important emigration consequences in Guyana and Suriname.

In French Guiana too, economic reasons and the search for employment have been motives for emigration, although at much lower rates. The economic development plans of the French state also involved the promotion of large-scale agriculture, but its impact would be significantly different. Here the French state 
aimed to create agricultural production where little or no pre-existing production existed. Thus, the plan involved heavy state subsidies and proposed large-scale immigration of non-Guianese farm workers, but it did not involve the displacement of local farm workers as in Guyana and Suriname. Quite the contrary, this development plan was meant to keep people in place and add labour force to the small Guianese population. This agricultural plan was largely downscaled due to internal protests and in the end it led to small-scale immigration with no evidence of effects on emigration, which continued on its growing trend. In this case, emigration was not the result of displacement but the lack of the job creation which was one of the main objectives of the plan.

Similarly, each of these states attempted to solve high unemployment rates through the growth of infrastructural projects and public sector employment. While these short-term solutions were eventually unable to compensate for the lack of economic diversification and left emigration trends largely unaffected in Guyana and Suriname, in French Guiana, the state's frequent introduction of new infrastructural projects and public sector expansion have contributed to creating some employment and keeping emigration at relatively low rates. The frequency and size of public financial interventions in French Guiana do not find parallels in Guyana and Suriname, where standards of living deteriorated over the 1980s and 1990s. As a result, emigration from these two countries continued to increase.

Social policies have been an important way in which these governments have intervened to solve problems affecting their societies but also, directly or indirectly, migration patterns. By social policies I refer to those interventions that target education and forms of social welfare that aim to improve the well-being of the population, particularly the disadvantaged (poor, discriminated minorities, etc.). The case studies showed how education was at the root of migration in many colonies, when members of the elite received an education in the colonial state to obtain knowledge and learn skills deemed useful in the colony. Gradually this trend spread to the middle classes. While Guyanese students generally pursued tertiary education in Britain or the West Indies because the quality of primary and secondary education in Guyana was well-regarded within the British sphere, in Suriname the elite sent their children to the Netherlands to study at an early age. In French Guiana, the school system was extremely limited until the 1970s, compelling young adults interested in secondary and tertiary education to go to metropolitan France.

The way in which education was organised after independence or departmentalisation (for French Guiana) continued to influence migration. In Suriname, although efforts were made to introduce curricula that taught the history of Suriname, school curricula largely continued to emphasise the values of 
the former colonial state, reinforcing the exceptional values of an education in the Netherlands. Similarly, in French Guiana, school curricula emphasize national history, which is essentially that of metropolitan France; only in the 2000s did school curricula introduce lessons on the history and diverse environment of French Guiana. In Guyana, after independence the promotion of decolonisation led to a full reform of education, with the redirection of the curricula towards local and regional issues, promoting the value of a national education rather than reinforcing the superiority of British education. However, Guyana's educational reform also provides the perfect example of how well-intended non-migration policies may have important unexpected migration consequences. By promoting an educational reform which granted free education and encouraged technical education, the government of Guyana promoted a great boost in the number of educated youth with increasing aspirations to professional occupations and social mobility. However, because the country's development did not keep up and employment opportunities did not grow as rapidly, eventually these educated young Guyanese met their increased aspirations abroad. As a result, gradually education became a ticket to emigration.

The three Guianas also offer examples of how states use social welfare policies not only to improve the well-being of citizens but also to affect migration. In Suriname, the Dutch government, concerned about rising emigration to the Netherlands in the late 1960s, introduced social projects on education, housing and health care with the intention of promoting well-being but with the ultimate objective to decrease emigration (Sedoc-Dahlberg 1990). However, these interventions were too limited to be effective. In French Guiana, the growing provision of social welfare introduced over the years, eventually leading to the same levels of compensation as in metropolitan France, has arguably decreased emigration aspirations. Currently, in Suriname the population reports on continuously improving social welfare provisions, particularly health services and medical specialisations such as cardiology. Conversely, social welfare provisions in Guyana continue to be much more limited and citizens rely on a very small safety net (e.g. small pensions, limited provision of health care). These low levels of social protection increase the risks faced by the population, such as the inability to afford medical care, which seem to have played and continue to play an emigrationencouraging role.

In sum, in the three Guianas the state has played a central role in shaping migration. While political and governance issues have been primary motives for emigration in Guyana and Suriname, the incorporation of French Guiana into France has given this country greater protection from coups and dictatorships. Remarkably, education and economic factors are important emigration drivers in these three countries, but while in Guyana and Suriname economic and education 
plans had unexpected consequences that contributed to emigration, the ability of the French state to create general stability, including social welfare packages that provide high levels of protection, has contributed to growing but still relatively low emigration from French Guiana. Similar migration-decreasing effects of social provisions were found in the case of Indonesia (Mahendra 2014). The French Guiana case also suggests that the lower emigration propensities found in many Caribbean non-sovereign countries may be linked to social welfare provisions, in addition or in lieu of political stability and economic diversification (McElroy and Albuquerque 1988; Mitchell and McElroy 2011).

\section{Concluding remarks and future research}

This study contributes to the literature on the determinants of international migration and, more particularly, it questions, both theoretically and empirically, the effectiveness of migration policies and the effects of border regimes and independence on migration patterns. Through this analytical angle and the exploration of the Caribbean region and the three Guianas, this study advances our understanding of the state and its role in shaping migration.

\section{a) Theoretical contributions}

First, I began by presenting a paradox regarding the role of borders in shaping migration and questioning the assumptions embedded in discussions of open and closed borders, particularly the notion that closed borders are necessary to prevent massive migrations. I also redressed the existing biases in migration research by putting the state in centre-stage without limiting its role to migration policies. Using an innovative approach which relies on conceptual scenarios, my analyses generated a more nuanced understanding of the effects of border regimes; this was done in a contextualized manner that also accounted for other state functions, such as politics, governance and processes of decolonisation and independence, and a variety of non-migration policies.

Through this effort, novel theoretical insights emerged starting with the differentiation of the timing and sequencing of independence and introduction of a border regime, and the identification of their various consequences on migration. Applied to the Caribbean case, this study also produced evidence of multiple migration substitution effects, introduced new conceptual elaborations on the role of post-colonial ties as well as insights into various ways in which states in origin countries influence migration, expanding our general view of the influence of the state on migration beyond migration policies. 
The findings suggest that independence, unlike non-sovereignty, has the potential to produce strong emigration peaks concentrated in the period around independence. Similarly, border regimes can have unanticipated consequences. Initially, the introduction of a border regime with the former colonial state generates short-term peaks of 'beat the ban' emigration, followed by a decrease in emigration. However, in the long term, emigration tends to reorient to other destinations or to other legal (or irregular) channels, leading to growing emigration volumes. Non-sovereign countries with open border regimes, on the other hand, do not display such rushed emigration peaks, presenting generally more slow and stable emigration patterns that respond to economic, educational or personal needs. Thus, the findings confirm that border regimes generally do not deter emigration and open borders do not necessarily result in huge and uncontrollable emigration.

The shifts in emigration patterns of closed border countries can be partly linked to migration policies in destination countries. While this study does not make any firm claims of migration policy effectiveness, the analyses of migration policies of four major destination countries, which included Britain, Canada, the Netherlands and the US, allow the identification of important policy effects on emigration patterns. In fact, inter-temporal, categorical, spatial substitution and also reverse substitution effects have occurred over the course of the evolution of emigration in Guyana and Suriname.

Following an invitation to move beyond analyses of migration volumes when we try to understand the effects of border regimes (Wihtol de Wenden 2007), this study explored in depth how borders influence the selection of migration. Indeed, independence and border regimes generated different reactions and affected the composition of migration by class, age and ethnic group. Through the elaboration of conceptual scenarios and comparative analysis we observed how the timing and sequencing of these two events generated emigration diversification towards new destinations and channelled emigrants in different migration policy categories to overcome migration policy barriers. Most importantly, this study found that by removing migration as a life course option, migration policies engender a different societal attitude in which migration becomes a prized objective pursued by any means rather than a means to access better educational, employment opportunities and living conditions.

\section{b) Other insights on the role of states}

This study has also generated new insights on the role of colonial history on migration decisions. It has identified that post-colonial ties have been interpreted statically and rigidly as an unchanging bilateral relation with the former colonial state. It is undeniable that colonialism has had important effects. For instance, 
worldviews, specifically mental maps of the world, are significantly different across the three Guianas and strongly reflect relations with the former colonial state and the colonial sphere as emigrants from former colonies follow some migration routes established during colonialism. However, migrants from independent countries do not simply engage in lasting path-dependent behaviours. Evidence from this study shows that worldviews are changing as a result of new national identities, geopolitical influences, media influence as well as migration policies. Ultimately, the relevance of post-colonial ties for migration will depend on how relations have developed in the post-independence period and whether post-colonial ties are a superficial tie of the past into the present (e.g. language, transport links) (instrumental preference) or are deep and long-lasting (e.g. cultural, institutional, symbol of prestige) (associative preference).

Through the examination of independence, border regimes and postcolonial ties, this study has produced new evidence of the role of the state in shaping migration both in origin and destination countries. Beyond the effects of economic opportunities, the three Guianas offered rich insights on the importance of politics, particularly in ethnically diverse populations, and education as a driver of migration, both as students emigrate to pursue further education and university graduates emigrate to pursue career aspirations. A major insight was the role of social policies in altering perceptions of the quality of life and shaping emigration aspirations. This study provided ample evidence of how the state plays a major role, on one hand by producing or sanctioning risks and uncertainties (e.g. political instability, weak law enforcement, corruption) which encourage the population to emigrate, or on the other hand by reducing risks, thus encouraging people to stay put (e.g. minimum wages, social welfare, enforcement of labour laws). Thus, this study shows that there is great value in moving beyond a myopic focus on migration policies to uncover how changes in various policy areas affect individuals' fears and expectations in the origin country, resulting in shifts in migration decisions. Furthermore, migration research gains greatly from a deeper understanding of the historical context, state formation processes and shifts in ideological positions and policies, all of which can help researchers understand the social mechanics which ultimately shape migration.

\section{c) Ideas for future research}

The findings that emerged from this study are specific to the Caribbean region. However, this framework and its conceptual elaborations may useful for future research on the changes in border regimes in other regions. The Pacific region, where similar transitions to independence and non-sovereign took place, the Maghreb as well as sub-Saharan Africa and the former Soviet Republics all offer rich terrain to further explore the effects of changes in political status, the 
introduction of border regimes and the long-term effects of colonial and postcolonial worldviews. With these cases, it would be possible to test the extent to which the inter-temporal and categorical effects of policies are applicable to other spheres of influence beyond small states and islands. However, it is encouraging that preliminary data analysis of total emigration flows from a small set of former British colonies suggest that 'now or never' migration peaks as a result of the 1962 Commonwealth Immigration Act and independence occurred elsewhere: moderate effects are visible in Malta, also a small country, in 1962 and 1964, the year of independence; similarly moderate effects are visible in Uganda at independence in 1962 and in Zimbabwe in 1962 and in 1964, preceding declared independence in 1965; most significantly, a large emigration peak was recorded from Tanzania in 1962, seemingly reflecting independence in December 1961.

Lastly, the three Guianas are ripe for further research on historical, present and future migration patterns. The growing connections among the three Guianas and their increasing links to other countries in the region suggest that future migration research could help us trace and build upon the current understanding of their historical migrations into the future. Intriguing developments in Suriname, and with some delay in Guyana, suggest that these countries may be on the cusp of a migration transition from emigration to immigration countries, following the strong immigration trends visible in French Guiana. The attractiveness of these countries within regional networks, their unique features with large uncontrolled territories and common perceptions of untouched resources that recall the old legend of 'El Dorado', suggest growing migration and a wonderful opportunity for migration researchers to gain new perspectives on the dynamics of migration transitions. 


\section{References}

Agunias, D. R. (2009). Institutionalizing diaspora engagement within migrant-origin governments. Closing the Distance: How Governments Strengthen Ties with Their Diasporas. D. Rannveig Agunias. Washington, D.C., Migration Policy Institute.

Aldrich, R. and J. Connell (1998). The Last Colonies. Cambridge, UK, Cambridge University Press.

Alexandre, R. (1977). Le Conseil General de la Guyane Française (1945-1977), Université de Bordeaux III.

Asis, M. M. B. (2008). How international migration can support development: a challenge for the Philippines. Migration and Development: Perspectives from the South. S. Castles and R. D. Wise. Geneva, International Organization for Migration.

Attali, S., E. Moriame, et al. (2008). Guyane: Un développement sous contraintes. R. Jean. Cayenne Cedex, INSEE, IEDOM, AFD.

Audebert, C. (2007). "Le cadre politico-institutionel des migrations antillaises: des dynamiques différenciées dams un contexte géopolitique segmenté." Études caribéennes (online) 8.

Bakker, E., L. Dalhuisen, et al. (1993). Geschiedenis van Suriname; Van stam tot staat. Zutphen, Walburg Pers.

Baksh, A. (1978). Education, Unemployment and Mobility in Guyana. PhD, The University of Alberta.

Beine, M., F. Docquier, et al. (2009). Diasporas. CESifo Working Paper Series No. 2607.

Beine, M., F. Docquier, et al. (2008). Brain Drain and its Determinants: A Major Issue for Small States. IZA Discussion Paper Series No. 3398. Bonn, Institute for the Study of Labor.

Belenus, R. (2006). Foreword: 19 Mars 1946: les quatres "Vieilles Colonies" sont erigées en départements français d'outre mer. 60 ans de Départementalisation: Catalogue collectif documents conservés dans les Bibliothèques de

Guadeloupe, de Guyane, de Martinique et de la Réunion. C.-C. d. I. e. d. R. Médiathèque Caraibe Bettino Lara, Conseil Générale de la Guadeloupe; LAMECA.

Belot, M. and T. J. Hatton (2010). Immigrant Selection in the OECD. Discussion Paper No. 571, The Australian National Univesity.

Bhagwati, J. (2003). "Borders Beyond Control." Foreign Affairs 82(1): 98-104.

Blancodini, P. and S. Tabarly (2010). La frontière,discontinuités et dynamiques.

Géoconfluences. Lyon, DGESCO - ENS de Lyon.

Bonjour, S. (2011). "The Power and Morals of Policy Makers: Reassessing the Control Gap Debate." International Migration Review 45(1): 89-112.

Borjas, G. J. (1999). "Immigration and Welfare Magnets." Journal of Labor Economics 17(4): 607-637. 
Boswell, C. (2007). "Theorizing Migration Policy: Is there a Third Way?" International Migration Review 41(1): 75-100.

Bovenkerk, F. (1981). "Why returnees generally do not turn out to be "agents of change": The case of Suriname." Nieuwe West-Indische Gids / New West Indian Guide 55th Year(3/4): 154-173.

Bovenkerk, F. (1987). Caribbean Migration to the Netherlands: From Elite to Working Class The Caribbean Exodus. B. B. Levine. Westport, CT and London, Praeger Publishers: 204-213.

Breton, D., S. Condon, et al. (2009). The challenges of population aging and migration in the French overseas départments. Population and Societies: Bulletin Mensuel d'Information de l'Institut National d'Etudes Démographiques.

Buddingh', H. (2001). Failure of a Model Decolonisation: Dutch-Surinamese Economic Relations. Twentieth-Century Suriname: Continuities and Discontinuities in a New World Society. R. Hoefte and P. Meel. Kingston, Jamaica, Ian Randle Publishers: 71-90.

Byron, M. (1999). Migration as a Way of Life: Nevis andthe Post-war Labour Movement to Britain. Small Worlds, Global Lives: Islands and Migration. R. King and J. Connell. London, Continuum International Publishing Group: 115-136.

Byron, M. and S. A. Condon (2008). Migration in Comparative Perspective: Caribbean Communities in Britain and France. New York, Routledge.

Calmont, A. (1988). "La population guyanaise en France." Equinoxe: Revue Guyanaise d'Histoire et de Geographie 12(26): 49-68.

Calmont, A. (1994). Mouvement de population entre la Guyane et la Caraibe: l'exemple de l'immigration haïtienne. Guadeloupe, Martinique et Guyane dans le monde américain: Réalités d'hier, mutations d'aujourd'hui, perspectives 2000. M. Burac. Paris, France et Schoelcher, Martinique, Éditions Karthala.

Calmont, A. (2008). "Les Africains en Guyane: Aspects multiformes d'une immigration invisible." EchoGéo 6(September/November).

Calmont, R. (1978). "L'émigration guyanaise en France." Equinoxe: Revue Guyanaise d'Histoire et de Geographie 7: 38-41.

Calmont, R. (1979). "Les Indonésiens en Guyane: le cas de la communauté javanaise de Sinnamary." Equinoxe: Revue Guyanaise d'Histoire et de Geographie 11(Octobre-Décembre): 24-37.

Calmont, R. (1981). "La communauté guyanaise en France." Equinoxe: Revue Guyanaise d'Histoire et de Geographie 14(Oct-Dec): 21-43.

Canterbury, D. (2007). "Caribbean agriculture under three regimes: Colonialism, nationalism and neoliberalism in Guyana." Journal of Peasant Studies 34(1): $1-28$.

Carnegie, C. V. (1987). A Social Psychology of Caribbean Migrations: Strategic Flexibility in the West Indies. The Caribbean Exodus. B. B. Levine. Westport, Connecticut, Praeger.

Castles, S. (2004). "Why migration policies fail." Ethnic and Racial Studies 27(2): 205227. 
Castles, S. and R. Delgado Wise, Eds. (2008). Migration and Development:

Perspectives from the South. Geneva, International Organization for Migration.

Castles, S. and M. J. Miller (2009). The Age of Migration. Basingstoke, Palgrave MacMillan.

Central Statistical Office, T. a. T. (1970). The emigration of professional, supervisory, middle level and skilled manpower from Trinidad and Tobago: 1962- 1968 Brain Drain. Port of Spain, Trinidad and Tobago.

Chaney, E. M. (1989). "The Context of Caribbean Migration." Center for Migration Studies special issues 7(1): 1-14.

Chappell, L., L. Sanchez, et al. (2009). Easing the Strain: Understanding brain drain and where policy can respond. Development on the Move Paper No. 3. London, Global Development Network and Institute for Public Policy Research.

Chin, H. E. and H. Buddingh' (1987). Surinam: Politics, Economics and Society. London and New York, France Pinter.

Christopher, A. J. (2002). "Decolonisation without independence." GeoJournal 56: 213-224.

Clarke, C. G. (1978). West Indians at home and abroad. Monograph Series No. 8. C. G. Clarke. Liverpool, Centre for Latin-American Studies, The University of Liverpool.

Clegg, P. (2005). The UK Caribbean Overseas Territories: Extended Statehood and the Process of Policy Convergence. Extended Statehood in the Caribbean: Paradoxes of quasi colonialism, local autonomy and extended statehood in the USA, French, Dutch and British Caribbean. L. de Jong and D. Kruijt. Amsterdam, Rozenberg Publishers.

Clegg, P. (2014). "Guyana, its Foreign Policy, and the Path to Development." The Round Table: The Commonwealth Journal of International Affairs 103(4): 399-410.

Condon, S. A. and P. E. Ogden (1991). "Afro-Caribbean Migrants in France: Employment, State Policy and the Migration Process." Transactions of the Institute of British Geographers 16(4): 440-457.

Condon, S. A. and P. E. Ogden (1991). "Emigration from the French Caribbean: the Origins of an Organized Migration." International Journal of Urban and Regional Research 15(4): 505-523.

Constant, A. F. and B. N. Tien (2009) "Brainy Africans to Fortress Europe: For Money or Colonial Vestiges?" IZA Discussion Papers No. 4615.

Constant, F. (1987). "La politique française de l'immigration antillaise de 1946 à 1987." Revue européenne de migrations internationales 3(3): 9-30.

Czaika, M. and H. de Haas (2011). The effectiveness of immigration policies: a conceptual review of empirical evidence. IMI Working Papers No. 33. Oxford, International Migration Institute.

Czaika, M. and H. de Haas (2012). "The Role of Internal and International Relative Deprivation in Global Migration." Oxford Development Studies 40(4): 423442. 
Czaika, M. and H. de Haas (2013). "The Effectiveness of Immigration Policies." Population and Development Review 39(3): 487-508.

Czaika, M. and H. de Haas (2014). The Effect of Visa Policies on International Migration Dynamics. IMI Working Paper Series 89/DEMIG Project Papers $\underline{18}$, International Migration Institute, University of Oxford.

Czaika, M. and H. de Haas (2014). "The Globalization of Migration: Has the World Become More Migratory?" International Migration Review 48(2): 283-323.

Davison, R. B. (1962). West Indian Migrants: Social and Economic facts of Migration from the West Indies. London, Oxford University Press.

de Bruijne, A. (2001). A City and a Nation: Demographic Trends and Socioeconomic Development in Urbanising Suriname. Twentieth-Century Suriname: Continuities and Discontinuities in a New World Society. R. Hoefte and P. Meel. Kingston, Jamaica, Ian Randle Publishers: 23-47.

de Bruijne, A. and A. Schalkwijk (1994). Kondreman en P'tata: Nederland als referentiekader voor Surinamers. Amsterdam and Paramaribo, Instituut voor Sociale Geografie, Universiteit van Amsterdam and Leo Victor.

De Giorgi, G. and M. Pellizzari (2009). "Welfare migration in Europe." Labour Economics 16(4): 353-363.

de Haas, H. (2005). "International migration, remittances and development: Myths and facts." Third World Quarterly 26: 1269-1284.

de Haas, H. (2006). Engaging Diasporas: How governments and development agencies can support diaspora involvement in the development of origin countries. Oxford, International Migration Institute.

de Haas, H. (2010). Migration transitions: a theoretical and empirical inquiry into the developmental drivers of international migration. IMI Working Paper No. 21. Oxford, International Migration Institute, University of Oxford.

de Haas, H. (2011). The determinants of international migration: conceptualizing policy, origin and destination effects. IMI Working Papers No. 32. Oxford, International Migration Institute.

de Haas, H. and T. Fokkema (2010). "Intra-Household Conflicts in Migration Decisionmaking: Return and Pendulum Migration in Morocco." Population and Development Review 36(3).

de Haas, H., K. Natter, et al. (2014). Compiling and coding migration policies: Insights from the DEMIG POLICY database. IMI Working Paper Series/DEMIG Project Papers, IMI 87/DEMIG 16. Oxford, International Migration Institute, University of Oxford.

de Haas, H., K. Natter, et al. (2014). Growing restrictiveness or changing selection? The nature and evolution of migration policies. IMI Working Paper Series/DEMIG Project Papers, IMI 96/DEMIG 22, International Migration Institute, University of Oxford.

de Haas, H. and S. Vezzoli (2011). Leaving matters: the nature, evolution and effects of emigration policies. IMI Working Papers Series, International Migration Institute, University of Oxford.

Dew, E. (1978). The difficult flowering of Surinam: ethnicity and politics in a plural society. The Hague, Martinus Nijhoff. 
Docquier, F. and M. Schiff (2009). "Measuring Skilled Migration Rates: The Case of Small States." World Bank Policy Reserch Working Paper No. 4827.

Domenach, H. and M. Picouet (1988). Dynamique de la population et migration en Guyane. La nature et l'homme. O.-I. f. d. R. s. p. 1. D. e. Coopération. Cayenne, Orstom.

Douki, C. (2007). The Liberal Italian State and Mass Emigration. Citizenship and Those Who Leave. N. L. Green and F. Weil. Urbana and Chicago, University of Illinois Press.

Dowty, A. (1987). Closed Borders: The Contemporary Assault on Freedom of Movement. New Haven and London, Twentieth Century Fund.

Dulam, T. and P. H. Franses (2011). Emigration, wage differentials and brain drain: The case of Suriname. Econometric Institute Report 2011-33. Paramaribo, Suriname.

Easterly, W. and A. Kraay (2000). "Small States, Small Problems? Income, Growth, and Volatility in Small States." World Development 28(11): 2013-2027.

Economist Intelligency Unit (2013). Guyana Country Profile: Outlook for 2014-15. F. Mackie.

Fanon, F. (1952). Black Skin, White Masks. London, Pluto Press.

Fassmann, H. and R. Munz (1992). "Patterns and Trends of International Migration in Western Europe." Population and Development Review 18(3): 457-480.

Fitzgerald, D. (2006). "Inside the Sending State: The Politics of Mexican Emigration Control." International Migration Review 40(2): 259-293.

Flahaux, M.-L. (2014). The influence of migration policies in Europe on return migration to Senegal. IMI Working Paper Series/DEMIG Project Papers, IMI 93/DEMIG 19. Oxford, International Migration Institute, University of Oxford.

Flyvbjerg, B. (2006). "Five Misunderstandings About Case-Study Research." Qualitative Inquiry 12(2): 219-245.

Freeman, G. (1995). "Modes of Immigration Politics in Liberal Democratic States." International Migration Review 29(4): 881-902.

Freeman, G. P. (1987). Caribbean Migration to Britain and France: From Assimilation to Selection. The Caribbean Exodus. B. B. Levine. Westport, CT and London, Praeger.

Gahunde, C. (2012). Causes and Influential Factors of Migration in Rural Areas of Guyana: the Case of Black Bush Polder. Georgetown, Guyana, University of Guyana.

Gamlen, A. (2006). Diaspora Engagement Policies: What are they, and what kinds of states use them? Centre on Migraiton, Policy and Society Working Paper Series, No. 32. Oxford, COMPAS.

Gamlen, A. (2014). "Diaspora Institutions and Diaspora Governance." International Migration Review 48: S180-S217.

Gaztambide-Géigel, A. (2004). "The Invention of the Caribbean in the 20th Century." Social and Economic Studies 53(3): 127-157,177.

Giacottino, J.-C. (1995). Les Guyanes: Guyana, Surinam, Guyane française. Paris, Presses Universitaires de France. 
Gibney, M., L. Cornett, et al. (2015). The Political Terror Scale 1976-2015, The Political Terror Scale.

Gowricharn, R. (2004). "Moral capital in Surinamese transnationalism." Ethnic and Racial Studies 27(4): 607-621.

Gowricharn, R. and J. Schuster (2001). Diaspora and Transnationalism: The Case of the Surinamese in the Netherlands. Twentieth-Century Suriname: Continuities and Discontinuities in a New World Society. R. Hoefte and P. Meel.

Kingston, Jamaica, Ian Randle Publishers: 155-173.

Granger, S. (2007). Guyane et Surinam, à l'intersection des migrations caraibes et sudaméricaines. Dynamiques migratoires de la Caraibe. A. C. a. C. Audebert. Paris, Karthala et GEODE Caraibe. Revue Terres d'Amérique n6: 287 301.

Grieco, E. M. (2003). The Federated States of Micronesia: The "Push" to Migrate. Migration Information Source. Migration Policy Institute. Washington, D.C., Migration Policy Institute.

Grosfoguel, R. (1996). "Colonial Caribbean Migrations to the Metropoles in Comparative Perspective." Journal of Social Sciences 3(1+2): 20-39.

Guengant, J.-P. (1993). "Migrations : moins de départs, plus d'arrivées." Antiane 22: 30-32.

Hanley, E. R. (1981). 'All Ah We Hustlin Now': Economic and social change in an East Indian Community in Guyana PhD, University of Edinburgh.

Harris, J. R. and M. P. Todaro (1970). "Migration, unemployment and development: A two-sector analysis." American Economic Review 60: 126-142.

Hassankhan, M. (1997). The influence of migration on political developments in Suriname. Comparative History of Migration within the Caribbean and to Europe. Oxford Brookes University.

Hatton, T. J. and J. G. Williamson (2002). What Fundamentals drive World Migration? NBER Working Paper Series. Cambridge, MA, National Bureau of Economic Research.

Head, K., T. Mayer, et al. (2010). "The erosion of colonial trade linkages after independence." Journal of International Economics 81(1): 1-14.

Heffernan, M. (1995). French Colonial Migration. The Cambridge Survey of World Migration. R. Cohen. Cambridge, Cambridge University Press.

Hendry, I. (2011). British overseas territories law. Oxford, Hart Publishing.

Hezel, F. X. and T. B. McGrath (1989). "The Great Flight Northward: FSM Migration to Guam and the Northern Mariana Islands." Pacific Studies 13(1): 47-64.

Hintzen, P. C. and R. R. Premdas (1982). "Guyana: Coercion and Control in Political Change." Journal of Interamerican Studies and World Affairs 24(3): 337-354.

Hirschman, A. O. (1978). "Exit, Voice and the State." World Politics 31(1): 90-107.

Ho-Choung-Ten, J.-P. (1978). "L'immigration indienne en Guyane dans la deuxième moitié du XIXè siècle." Equinoxe: Revue Guyanaise d'Histoire et de Geographie 6(Janvier-Mars): 52-61.

Ho-Choung-Ten, J.-P. (1980). "Immigration et développement économique: l'expérience du BIPIG à Saint-Jean (1949-1959)." Equinoxe: Revue Guyanaise d'Histoire et de Geographie 12(Janvier-Mars): 48-53. 
Hoefte, R. (1987). "Control and resistance: Indentured labor in suriname." Nieuwe West-Indische Gids/New West Indian Guide: 1-22.

Hoefte, R. (1998). In Place of Slavery: A Social History of British Indian and Javanese Laborers in Suriname. Gainsville, University Press of Florida.

Hollifield, J. F. (1992). "Migration and International Relations: Cooperation and Control in the European Community." International Migration Review 26(2): 568-595.

Hooghe, M., A. Trappers, et al. (2008). "Migration to European Countries: A Structural Explanation of Patterns, 1980-2004." International Migration Review 42(2): 476-504.

Hope, K. R. (1977). "Development Administration in Post-Independence Guyana." International Review of Administrative Sciences 43(67): 67-72.

Horowitz, M. M. (1960). "Metropolitan Influences in the Caribbean: The French Antilles." Annals of the New York Academy of Sciences 83(5): 802-808.

Hugo, G. and C. Stahl (2004). Labor Export Strategies in Asia. International Migration: Prospects and Policies in a Global Market. D. S. Massey and E. J. Taylor. Oxford, Oxford University Press.

Hurpeau, B. (2012). Panorama de la population immigrée en Guyane, INSEE AntillesGuyane.

Insanally, A., M. Clifford, et al., Eds. (2006). Regional Footprints: The Travels and Travails of Early Caribbean Migrants. Jamaica, Latin American-Caribbean Centre (UWI).

Insee (2015). Comptes définitifs 2010 Guyane: Une activité spatiale moins dynamique, compensées par la demande intérieure. Insee Flash: Guyane. Cayenne Cedex, Insee. 14.

James, C. E. (2007). Les Canadiens d'origine caribéenne à Toronto: Analyse des freins au rêve migratoire. Dynamiques migratoires de la Caraibe. Paris, Editions Karthala et GEODE Caraibe.

Janssen, R. (2011). In search of a path: An analysis of the foreign policy of Suriname from 1975 to 1991. Leiden, KITLV Press.

Jeffrey, H. (1991). The State in Guyanese Society. Problems of Development of the Guianas. H. Jeffrey and J. Menke. Paramaribo, Suriname, Anton de Kom University of Suriname: 78-94.

Jolivet, M.-J. (1982). La question créole: Essai de sociologie sur la Guyane française. Paris, O.R.S.T.O.M.

Jolivet, M.-J. (1985). "Migrations et histoire dans la "Caraïbe française"." Cahiers ORSTOM XXI(1): 99-113.

Jones, B. and E. Stephenson (1995). Society, culture and politics in French Guiana. French and West Indian: Martinique, Guadeloupe and French Guiana Today. R. D. E. Burton and F. Reno. London and Basingstoke, U.K., Macmillan Caribbean: 56-74.

Jubithana-Fernand, A. (2009). International Migration in Suriname. Migração internacional na Pan-Amazônia. L. E. Aragón. Belém, Brazil, UFPA NAEA. 
Kalpoe, R. (1983). The Bauxite Sector. The impact of migration on the social and economic transformation in Suriname. J. Menke. Paramaribo, Institute of Economic and Social Research, University of Suriname.

Karran, K. (2007). L'émigration vers la Grande Bretagne: les cas des femmes indocaribéennes. Dynamiques migratoires de la Caraibe. Paris, Karthala et GEODE Caraibe.

King, R. and J. Connell (1999). Island Migration in a Changing World. Small Worlds, Global Lives: Islands and Migration. R. King and J. Connell. London, Continuum International Publishing Group: 1-26.

Kirton, C. and P. Lewis (2015). Guyana Country Case Study. Migration and Development: Perspectives from Small States. W. H. Khonje. London, The Commonwealth Secretariat: 92-121.

Koser, K. and F. Laczko (2010). The Future of Migration: Building Capacities for Change. World Migration Report. Geneva, Switzerland, IOM.

Krishnadath, J. (1983). The Sugar Sector. The impact of migration on the social and economic transformation in Suriname. J. Menke. Paramaribo, Institute of Economic and Social Research, University of Suriname.

Kureková, L. (2011). From Job Search to Skill Search: Political Economy of Labor Migration in Central and Eastern Europe. PhD Thesis, Central European University.

Laëthier, M. (unknown). Recherches et migrations en Guyane: état des lieux. Institutions: 11-13.

Laing, E. A. (1979). "Independence and Islands: The Decolonization of the British Caribbean." NYUJ Int'l L. \& Pol. 12: 281.

Lamur, H. E. (1973). The Demographic Evolution of Surinam 1920-1970: A sociodemographic analysis. $\mathrm{PhD}$ in Social Sciences, University of Amsterdam.

Langer, J. (1999). Towards a conceptualization of border: the Central European experience. Curtains of Iron and Gold: Reconstructing Borders and Scales of Interaction. H. Eskelinen and J. Oksa. Aldershot, Ashgate: 25-42.

Lee, E. S. (1966). "A Theory of Migration." Demography 3(1): 47-57.

Léobal, C. (2013). Saint-Laurent-du-Maroni: une porte sur le fleuve. Matoury, Guyane, Ibis Rouge Editions.

Levine, B. B., Ed. (1987). The Caribbean Exodus. Westport, Connecticut and London, Praeger.

Levine, B. B. (1987). The Puerto Rican Exodus: Development of the Puerto Rican Circuit. The Caribbean Exodus. B. B. Levine. Westport, Connecticut and London, Praeger.

Lézy, E. (2000). Guyane, Guyanes: Une géographie "sauvage" de l'Orénoque à l'Amazone. Paris, Belin.

Lucassen, J. (1995). Emigration to the Dutch Colonies and the USA. The Cambridge Survey of World Migration. R. Cohen. Cambridge, Cambridge University Press.

Mabogunje, A. L. (1970). "Systems Approach to a Theory of Rural-Urban Migration." Geographical Analysis 2: 1-18. 
Mahendra, E. (2014). Financial Constraints, Social Policy and Migration: Evidence from Indonesia. IMI Working Paper Series/DEMIG Project Papers, IMI101/DEMIG 25. Oxford, International Migration Institute, University of Oxford.

Mahoney, J. and D. Rueschemeyer (2003). Comparative Historical Analysis: Achievements and Agendas. Cambridge, Cambridge University Press.

Maingot, A. P. (1983). Caribbean migration as a structural reality, Latin American and Caribbean Center, Florida International University.

Mam-Lam-Fouck, S. (1979). "La Guyane et le problème de la décolonisation." Equinoxe: Revue Guyanaise d'Histoire et de Geographie 11(OctobreDécembre): 53-61.

Marie, C.-V. and J.-L. Rallu (2004). "Migrations croisées entre DOM et Métropole: l'emploi comme moteur de la migration." Espace populations sociétés 2004/2: 237-252.

Marie, C.-V. and J.-L. Rallu (2012). Les tendances démographiques et migratoires dans les régions ultrapéripheriques: quel impact sur leur cohésion économique, sociale et territoriale? U. d. 1. C. d. R. Ultrapériphériques, INED.

Marie, C.-V., F. Temporal, et al. (2012). Migrations, Famille et Vieillissement: Défis et enjeux pour la Guyane. Antianéchos. Paris, INSEE Antille-Guyane; INED. 21.

Mars, P. (2001). "Ethnic Politics, Mediation, and Conflict Resolution: The Guyana Experience." Journal of Peace Research 38(353).

Marshall, D. (1987). A History of West Indian Migrations: Overseas Opportunities and "Safety-Valve" Policies. The Caribbean Exodus. B. B. Levine. Westport, CT, Praeger Publishers.

Massey, D. S. (1990). "Social Structure, Household Strategies, and the Cumulative Causation of Migration." Population Index 56: 3-26.

Massey, D. S. (1999). "International Migration at the Dawn of the Twenty-First Century: The Role of the State." Population and Development Review 25(2): 303-322.

Massey, D. S. (2005). Backfire at the Border: Why Enforcement without Legalizaton Cannot Stop Illegal Immigration. Trade Policy Analysis. C. Institute. Washington, D.C., CATO Institute. 29.

Massey, D. S., J. Arango, et al. (1993). "Theories of International Migration: A Review and Appraisal." Population and Development Review 19(3): 431-466.

Massey, D. S., J. Arango, et al. (1998). Worlds in Motion: Understanding international migration at the end of the millenium. Oxford, Clarendon Press.

Matthews, M. (1993). The Passport Society: Controlling Movement in Russia and the USSR. Boulder, San Francisco, Oxford, Westview Press.

Mayda, A. M. and K. Patel (2004). OECD Countries Migration Policy Changes. Appendix to 'International Migration: A Panel Data Analysis of Economic and Non-Economic Determinants'. A. M. Mayda.

Mayor of London and Transport for London (2006). Generations: Celebrating 50 years of Caribbean recruitment. T. f. London. London. 
McElroy, J. and K. Sanborn (2005). "The propensity for dependence in small Caribbean and Pacific islands." Bank of Valletta Review 31.

McElroy, J. L. (2011). "Island demography: A review of selected caribbean contributions." Island Studies Journal 6(2): 245-260.

McElroy, J. L. and K. d. Albuquerque (1988). "Migration Transition in Small Northern and Eastern Caribbean States." International Migration Review 22(3): 30-58.

McElroy, J. L. and K. B. Pearce (2006). "The advantages of political affiliation:

Dependent and independent small-island profiles." The Round Table 95(386): 529-539.

McIlwaine, C. (2008). The postcolonial practices of international migration: Latin American migration to London. London, Department of Geography, Queen Mary, University of London.

McKenzie, D. J. (2005). Paper walls are easier to tear down: passport costs and legal barriers to emigration. Policy Research working paper. Washington, D.C., World Bank.

Médéa, L. (2010). Reunion: An Island in Search of an Identity. Pretoria, Unisa Press.

Meel, P. (2001). Not a Splendid Isolation: Suriname's Foreign Affairs. TwentiethCentury Suriname: Continuities and Discontinuities in a New World Society. R. Hoefte and P. Meel. Kingston, Jamaica, Ian Randle Publishers: 128-154.

Menke, J. (1983). The impact of migration on the social and economic transformation of Suriname. J. Menke. Paramaribo, Institute of Economic and Social Research, University of Suriname.

Menke, J. (1990). The role of the state in the development process of Suriname: 19481990. Joint Conference: The problems of development of the Guianas, University of Guyana; Anton de Kom University of Suriname.

Menke, J. (1991). The State in the Development Process of Suriname 1948-1990. Problems of Development of the Guianas. H. Jeffrey and J. Menke. Paramaribo, Suriname, Anton de Kom University of Suriname.

Menke, J. (1998). Restructuring urban employment and poverty: The case of Suriname. Paramaribo, SWI Press.

Mhango, B. (1983). Guyanese migrant labour in the lumber sector. The impact of migration on the social and economic transformation in Suriname. J. Menke. Paramaribo, Institute of Economic and Social Research, University of Suriname.

Milia, M. (1997). "Histoire d'une politique d'émigration organisée pour les départements d'outre-mer, 1952-1963." Pouvoirs dans la Caraïbe (online) Special Number.

Mitchell, S. A. and J. L. McElroy (2011). "Emigrant and Immigrant Small Island Profiles." Bank of Valletta Review 43(Spring).

Monsels, L. (1983). The demographic and socio economic consequences of international migration in Suriname. The impact of migration on the social and economic transformation in Suriname. J. Menke. Paramaribo, Institute of Economic and Social Research, University of Suriname. 
Moore, B. (2001). Decolonization by Default: Suriname and the Dutch Retreat from Empire. International Diplomacy and Colonial Retreat. K. Fedorowich and M. Thomas. London, Frank Cass: 228-250.

Movement Guyanais de Decolonisation (MOGUYDE) (1977). Quelques Textes Essentiels. R. Delannon. Cayenne.

Neumayer, E. (2006). "Unequal access to foreign spaces: how states use visa restrictions to regulate mobility in a globalized world." Transactions of the Institute of British Geographers 31(1): 72-84.

Nicholson, D. A. (1976). Some Aspects of Rural-Urban Migration: The Case of Ithaca, a Village in Guyana. Master of Science in Sociology, The University of the West Indies.

Nicholson, M. (1985). Migration of Caribbean women in the Health Care Field: A cast study of Jamaican nurses. PhD, City University of New York, Graduate Faculty of Sociology.

Oostindie, G. (2006). "Dependence and autonomy in sub-national island jurisdictions: The case of the Kingdom of the Netherlands." The Round Table 95(386): 609-626.

Oostindie, G. (2008). Migration and its legacies in the Dutch colonial world. Dutch Colonialism, Migration and Cultural Heritage. G. Oostindie. Leiden, KITLV Press.

Oostindie, G. (2009). Migration paradoxes of non-sovereignty: A Comparative Perspective on the Dutch Caribbean. Governance in non-independent Caribbean: challenges and opportunities in the 21st century. P. Clegg and E. Pantojas-Garcia. Kingston and Miami, Ian Randle Publishers.

Orozco, M. (2003). Remitting Back Home and Supporting the Homeland: The Guyanese Community in the U.S. Inter-American Dialogue Working Paper, GEO Project, U.S. Agency for International Development.

Ortega, F. and G. Peri (2009). The Causes and Effects of International Mobility: Evidence from OECD Countries 1980-2005. NBER Working Paper Series, No. 14833. Cambridge, MA.

Osinsky, P. and J. Eloranta (2015 forthcoming). Comparative Historical Analysis: Some Insights from Political Transitions of the First Half of the Twentieth Century, Appalachian State University.

Owen, T. and A. Grigsby (2012). In Transit: Gangs and Criminal Networks in Guyana. Working Paper Series, No 11. S. A. Survey. Geneva, Switzerland, Graduate Institute of International and Development Studies.

Özden, C.., C. R. Parsons, et al. (2011). "Where on Earth is Everybody? The Evolution of Global Bilateral Migration 1960-2000." The World Bank Economic Review 25(1): 12-56.

Palmer, R. W. (1974). "A Decade of West Indian Migration to the United States, 19621972: An Economic Analysis." Social and Economic Studies 23(4): 571.

Peach, C. (1968). West Indian Migration to Britain: A Social Geography. London, Oxford University Press.

Peach, C. (1991). The Caribbean in Europe: Contrasting patterns of migration and settlement in Britain, France and the Netherlands. Research Paper in Ethnic 
Relations. Coventry, U.K., Centre for Research in Ethnic Relations, University of Warwick.

Peach, C. (1995). Anglophone Caribbean Migration to the USA and Canada. The Cambridge Survey of World Migration. R. Cohen. Cambridge, Cambridge University Press.

Pécoud, A. and P. de Guchteneire, Eds. (2007). Migration without Borders: Essays on the Free Movement of People. Paris / New York, UNESCO Publishing / Berghahn Books.

Pérez Caldentey, E. and K. Schmid (2006). The Performance of CARICOM Economies in the 1990s: The Current Effect on Migration and Conflict Potential. Intra-Caribbean Migration and the Conflict Nexus. T. Lesser, B. Fernandez-Aldaro, L. Cowie and N. Bruni. Ottawa, Canada, Human Rights Internet.

Piantoni, F. (2009). L'enjeu migratoire en Guyane française: une géographie politique. Matoury, Guyane, Ibis Rouge Editions.

Piantoni, F. (2009). "La question migratoire en Guyane française: Histoire, société et territoires." Hommes et migrations 1278(march-april): 198-216.

Piantoni, F. (2015 forthcoming). Les migrations contemporaines en Guyane. Les patrimoines en Guyane (provisional title). unedited.

Polity IV (2010). Country Report 2010: Guyana. Polity IV Individual Country Regime Trends, 1946-2010. C. f. S. P. a. INSCR.

Premdas, R. R. (1999). "Recovering democracy: problems and solutions to the Guyana quagmire." Pouvoirs dans la Caraibe (online)(11).

Price, R. (2013). "The Maroon Population Explosion: Suriname and Guyane." New West Indian Guide 87: 323-327.

Rabe, S. G. (2005). U.S. Intervention in British Guiana: A Cold War Story. Chapel Hill, The University of North Carolina Press.

Rallu, J.-L. (1997). "La population des départements d'outre-mer. Evolution récente, migrations et activité." Population (French Edition) 52(3): 699-727.

Ravenstein, E. G. (1885). "The Laws of Migration." Journal of the Statistical Society of London 48(2): 167-235.

Redfield, P. (2000). Space in the Tropics: From Convicts to Rockets in French Guiana. Berkeley, University of California Press.

Reubsaet, T. J. M. (1984). "The Surinamese in the Netherlands: A Research Note." Journal of Ethnic and Migration Studies 11(3): 301-308.

Roopnarine, L. (2013). Guyana Population Movement and Societal Development. IDS 50th Anniversary Working Paper Series, No. 7/12. Georgetown, Guyana, Institute of Development Studies, University of Guyana, Turkeyen.

Runs, A. (2006). Surinamese Immigrants in the United States of America: A Quest for Identity? Master Thesis, CEDLA, Universiteit van Amsterdam.

Sackey, J. A. (1977). The migration of high level personnel from Guyana: toward an alternative analysis. G. University of Guyana. Georgetown, University of Guyana.

Samers, M. (1997). "The Production of Diaspora: Algerian Emigration from Colonialism to Neo-Colonialism (1840-1970)." Antipode 29(1): 32-64. 
Santiago, C. E. (unknown). Political Status, Minimum Wages and Pureto Rican Migration. Unidad de Investigaciones Economicas. San Juan, Puerto Rico, Universidad de Puerto Rico, Departamento de Economia.

Schwarzbeck, F. (1982). "La Guyane: un Département français comme les autres?" Equinoxe: Revue Guyanaise d'Histoire et de Geographie(15): 1-17.

Seawright, J. and J. Gerring (2008). "Case Selection Techniques in Case Study Research: A Menu of Qualitative and Quantitative Options." Polit Res Q 61(2): 294-308.

Sedoc-Dahlberg, B. (1984). "Refugees from Suriname." Refuge 3(3): 5-10.

Sedoc-Dahlberg, B. (1990). Suriname: 1975-89. Domestic and Foreign Policies under Military and Civilian Rule. The Dutch Caribbean: Prospects for Democracy. B. Sedoc-Dahlberg. New York, Gordon and Breach. 5.

Segal, A. (1975). Population Policies and Caribbean Crisis. Population Policies in the Caribbean. A. L. Segal. Lexington, Massachusetts, Lexington Books.

Segal, A. (1987). The Caribbean Exodus in a Global Context: Comparative Migration Experiences. The Caribbean Exodus. B. B. Levine. Westport, CT, Praeger Publishers: 44-64.

Segal, A. (1998). The Political Economy of Contemporary Migration. Globalization and Neoliberalism: The Caribbean Context. T. Klak. Boulder, Rowma \& Littlefield Publishers, Inc.

Skeldon, R. (1997). Migration and development: A global perspective. Essex, Longman.

Skeldon, R. (2005). Globalization, Skilled Migration and Poverty Alleviation: Brain

Drains in Context. Working Paper Series T15. G. a. P. Development

Research Centre on Migration. Sussex, Development Research Centre on Migration, Globalisation and Poverty.

Skeldon, R. (2007). On Migration and the Policy Process. Where Next for Policy Studies? Connections Across Disciplines and Domains. International and Theoretical Perspectives on Social Policies: A Week of Policy Dialogue. Hong Kong.

Standing, G. (1977). Socialism and Basic Needs in Guyana. Population and Employment Working Paper Series, WEP 2-21/WP.61. I. L. Office. Geneva, ILO.

Standing, G. and F. Sukdeo (1977). "Labour migration and development in Guyana." International Labour Review 116(3): 303-313.

Stark, O. and D. E. Bloom (1985). "The New Economics of Labor Migration." American Economic Review 75(2): 173-178.

Stark, O. and S. Yitzhaki (1988). "Labour migration as a response to relative deprivation." Journal of Population Economics 1(1): 57-70.

Strachan, A. J. (1980). "Government sponsored return migration to Guyana." Area 12(2): 165-169.

Strachan, A. J. (1983). "Return Migration to Guyana." Social and Economic Studies 32(3): 121.

Strauss, A. and J. Corbin (1998). Basics of qualitative research: Techniques and procedures for developing grounded theory. Thousand Oaks, CA, Sage. 
Strikwerda, C. (1999). "Tides of Migration, Currents of History: The State, Economy, and the Transatlantic Movement of Labor in the Nineteenth and Twentieth Centuries." International Review of Social History 44(03): 367-394.

Suddaby, R. (2006). "From the Editors: What Gounded Theory is Not?" Academy of Management Journal 49(4): 633-642.

Sumption, M. (2012) "Visas for Entrepreneurs: How Countries are Seeking Out Immigrant Job Creators." Migration Information Source.

Sumption, M. and K. Hooper (2014) "Selling Visas and Citizenship: Policy Questions from the Global Boom in Investor Immigration."

Taylor, S. and J. Bers (2010). Country Studies Series: Suriname. Waltham, Massachusetts, Coexistence International, Brandeis University.

Teitelbaum, M. S. (1984). "Immigration, refugees, and foreign policy." International Organization 38(03): 429-450.

Temporal, F., C.-V. Marie, et al. (2011). "Insertion professionelle des jeunes ultramarins: DOM ou métropole?" Population-F 66(3-4): 555-600.

Thery, D. (1986). "Antillo-Guyanais de Metropole." Antiane: la revue economique des Antilles et de la Guyane (INSEE) 1: 23-25.

Thielemann, E. R. (2006). The Effectiveness of Governments' Attempts to Control Unwanted Migration. Immigration and the Transformation of Europe. C. R. Parsons and T. Smeeding. Cambridge, Cambridge University Press.

Thomas-Hope, E. (1978). The establishment of a migration tradition: British West Indian movements to the hispanic Caribbean in the century after emancipation. Monograph Series No. 8. C. G. Clarke. Liverpool, Centre for Latin-American Studies, The University of Liverpool.

Thomas-Hope, E. (1980). "Hopes and Reality in the West Indian Migration to Britain." Oral History 8(1): 35-42.

Thomas-Hope, E. (1996). "The Dynamic of Caribbean Migration Culture." Journal of Social Sciences 3(1+2): 3-19.

Thomas-Hope, E. (2000). Trends and Patterns of Migration to and from Caribbean Countries.

Thomas, C. Y. (1982). Guyana: The IMF-World Bank Group and the General Crisis. Georgetown, University of Guyana.

Thomas, C. Y. (2013). 30 Years after the Third World Debt Crisis: Sovereign Debt Stress in CARICOM (With Specific Reference to Guyana). University of Guyana Special Series Working Paper \#1/12 to commemorate the 50th Anniversary (1963-2013) of the University of Guyana. Turkeyen, Georgetown, Institute of Development Studies, University of Guyana.

Thorndike, T. (1990). Suriname and the military. The Dutch Caribbean: Prospects for Democracy. B. Sedoc-Dahlberg. New York, Gordon and Breach. 5: 35-62.

Todaro, M. P. and L. Maruszko (1987). "Illegal Migration and US Immigration Reform: A Conceptual Framework." Population and Development Review 13(1): 101-114.

United Nations (2013). Trends in International Migrant Stock: Migrants by Destination and Origin, United Nations Department of Economic and Social Affairs, Population Division. 
US Department of State, B. f. I. N. a. L. E. (2006). International Narcotics Control Strategy Report, Volume I: Drug and Chemical Control.

van Amersfoort, H. (2011). How the Dutch Government stimulated the unwanted immigration from Suriname. IMI Working Papers, No. 47. International Migration Institute, International Migration Institute.

van Dijck, P. (2001). Continuity and Change in a Small Open Economy: External Dependency and Policy Inconsistencies. Twentieth-Century Suriname: Continuities and Discontinuities in a New World Society. R. Hoefte and P. Meel. Kingston, Jamaica, Ian Randle Publishers: 40-70.

van Niekerk, M. (2005). Surinam Country Study. A part of the report on Informal Remittance Systems in Africa, Caribbean and Pacific (ACP) countries. P. a. S. C. ESRC Centre on Migration. Oxford, ESRC Centre on Migration, Policy and Society (COMPAS).

Vezzoli, S., M. Villares-Varela, et al. (2014). Uncovering international migration flow data: Insights from the DEMIG databases. IMI Working Paper Series/DEMIG Project Papers, IMI 88/DEMIG 17, International Migration Institute, University of Oxford.

Vizot, A. and L. Chevalier (1947). "Le problème démographique de la Guyane française et les perspectives d'immigration." Population 4(Second Year): 796800.

Wallace, C. (2002). "Opening and closing borders: Migration and mobility in EastCentral Europe." Journal of Ethnic and Migration Studies 28(4): 603-625.

Wihtol de Wenden, C. (2007). The frontiers of mobility. Migration without Borders: Essays on the Free Movement of People. A. Pécoud and P. de Guchteneire. Paris / New York, UNESCO Publishing / Berghahn Books.

Young, R. J. C. (2003). Postcolonialism: A Very Short Introduction. Oxford, New York, Oxford University Press.

Ypeij, A. (unknown). Gendered Travels: Single mother's experiences at the global/local interface.

Zelinsky, W. (1971). "The Hypothesis of the Mobility Transition." Geographical Review 61(2): 219-249.

Zolberg, A. R. (2007). The Exit Revolution. Citizenship and Those Who Leave: The Politics of Emigration and Expatriation. N. L. Green and F. Weil. Urbana and Chicago, University of Illinois Press.

Zoomers, A. and T. van Naerssen (2006). International migration and national development in sub-Saharan Africa. Veiwpoints and policy initiatives in the countries of origin. R. University, Ministry of Foreign Affairs and the MInistry of Social Affairs and Employment. 


\section{Appendices}

\section{Appendix A}

Table A1. - Emigrant population rates in the Caribbean region, 1960 and 2000

\begin{tabular}{|c|c|c|c|c|c|c|}
\hline $\begin{array}{c}\text { Directio } \\
\text { n of } \\
\text { change }\end{array}$ & Country & $\begin{array}{l}\text { Emigra } \\
\text { nt pop, } \\
1960(\% \\
\text { of total } \\
\text { pop) }\end{array}$ & $\begin{array}{l}\text { Emigra } \\
\text { nt pop, } \\
2000 \text { (\% } \\
\text { of total } \\
\text { pop) }\end{array}$ & $\begin{array}{c}\text { Change in } \\
\text { emigrant } \\
\text { population } \\
\text { (as \% of total } \\
\text { population), } \\
1960 \text { to } 2000\end{array}$ & Political status & $\begin{array}{c}\text { Former } \\
\text { Colonial } \\
\text { State } \\
\text { (FCS) }\end{array}$ \\
\hline \multirow[t]{19}{*}{ Increase } & Guyana & 5.98 & 48.45 & 710.38 & Independent & GBR \\
\hline & Suriname & 8.55 & 52.30 & 511.94 & Independent & NLD \\
\hline & Martinique & 10.00 & 44.25 & 342.31 & Non-sovereign & FRA \\
\hline & Montserrat & 22.18 & 92.40 & 316.52 & Non-sovereign & GBR \\
\hline & Netherlands Antilles & 21.33 & 82.35 & 286.10 & Non-sovereign & NLD \\
\hline & Aruba & 2.99 & 11.14 & 272.41 & Non-sovereign & NLD \\
\hline & Belize & 6.28 & 20.42 & 225.05 & Independent & GBR \\
\hline & Trinidad and Tobago & 7.39 & 23.78 & 221.76 & Independent & GBR \\
\hline & Guadeloupe & 18.85 & 57.30 & 203.97 & Non-sovereign & FRA \\
\hline & Jamaica & 12.85 & 36.03 & 180.37 & Independent & GBR \\
\hline & Barbados & 12.29 & 34.19 & 178.13 & Independent & GBR \\
\hline & Grenada & 21.94 & 58.85 & 168.22 & Independent & GBR \\
\hline & Antigua \& Barbuda & 20.97 & 55.18 & 163.17 & Independent & GBR \\
\hline & Dominica & 23.56 & 61.82 & 162.41 & Independent & GBR \\
\hline & St. Lucia & 11.61 & 29.43 & 153.45 & Independent & GBR \\
\hline & $\begin{array}{l}\text { St. Vincent \& the } \\
\text { Grenadines }\end{array}$ & 20.94 & 51.49 & 145.93 & Independent & GBR \\
\hline & St. Kitts and Nevis & 25.69 & 62.67 & 143.91 & Independent & GBR \\
\hline & Bahamas & 6.93 & 11.80 & 70.23 & Independent & GBR \\
\hline & Puerto Rico & 28.43 & 39.08 & 37.45 & Non-sovereign & USA \\
\hline \multirow[t]{6}{*}{ Decline } & French Guiana & 5.94 & 4.79 & -19.37 & Non-sovereign & FRA \\
\hline & Anguilla & 57.99 & 32.21 & -44.46 & Non-sovereign & GBR \\
\hline & Virgin Islands, British & 463.04 & 84.07 & -81.84 & Non-sovereign & GBR \\
\hline & Turks and Caicos & 86.41 & 27.65 & -68.00 & Non-sovereign & GBR \\
\hline & Cayman Islands & 15.53 & 3.77 & -75.75 & Non-sovereign & GBR \\
\hline & Virgin Islands, US & 77.50 & 40.42 & -47.85 & Non-sovereign & USA \\
\hline
\end{tabular}

Sources: Emigrant population changes calculated by author using World Bank Global Bilateral Migration Database and UN Population Estimates.

Former Colonial States from CEPII database, with author's additions.

Year of independence and political status compiled by author. 
Table A2. - Sample questions of semi-structured interviews for emigrants and returnees

General personal information

- What is your place of birth?

- Did you ever move within <Guyana > with your family? For what reason?

- Did you ever move internally within $<$ Guyana $>$ independently? For what reason?

- What was your father's occupation?

- What was your mother's occupation?

\section{Let's talk about your studies}

- What was the last school you attended in $<$ Guyana $>$ (highest level of education achieved in $<$ Guyana $>$ )?

- Did you continue your education abroad? What level of education? In which country/ies?

- What is the highest diploma/degree you have attained? In what year did you receive your diploma/degree? Where from?

Pre-migration context - conditions in $<$ Guyana $>$

- Periods of activity and inactivity - before migration

\begin{tabular}{|l|l|}
\hline Period & Activity/Inactivity \\
\hline & \\
\hline & \\
\hline
\end{tabular}

- Assets and businesses owned in Suriname and elsewhere, either in the past or currently

\begin{tabular}{|l|l|}
\hline Period & Asset/business \\
\hline & \\
\hline & \\
\hline
\end{tabular}

Pre-migration context-migration network

- Did anyone in your family live outside $<$ Guyana $>$ before you left $<$ Guyana $>$ ? Who? In which country was this person? When did this person migrate? How long did this person stay (there)? Did this person migrate to any other country afterwards? For how long?

- Did anyone outside of your family migrate before you left <Guyana>? In which country was this person? What was the relation between the two of you? When did this person migrate? How long did this person migrate for? Did this person migrate elsewhere afterwards? For how long? 


\section{Pre-migration context - migration decisions}

- When did you start thinking about migration? What was happening in your life then?

- For what reasons would you say you wanted to leave $<$ Guyana $>$ at this time? If the answer is 'the economic situation' then pursue this further by asking questions such as 'what was it like to be here'? What did the economic situation feel like for you? What was missing? Job opportunities, wages, attitude/work standards, opportunities to advance?

- What other events were occurring to make you feel like migration was a good option for you at this time? Raise any specific events/developments that were occurring at this time (UK MIGRATION POLICY, INDEPENDENCE). Were these relevant at all for migration decisions? If so, explain how.

- Were there any personal reasons (breakup, marriage, divorce, death in family, etc.) that made you think that migration was a good option? Would it be ok to explain what this may have been?

- Who were you talking to about your migration intentions as you were deciding to migrate? People in <Guyana>? Abroad (where exactly)? What were their suggestions?

- At what point did you decide that you had to emigrate? (what does it take for migration to take place?)

- For what reasons did you prefer to go to 'country of stay' rather than to another country? Which steps did you take to reach the 'country of stay'? Enrolled at university, applied for a scholarship, participated in Green Card lottery, saved money, contacted friends/relatives in 'country of stay'? In which year did you initiate these steps?

- Did you travel alone or with family/friends in your first migration trip? Were any of these people residing outside of Suriname?

- Who decided ultimately about your trip/migration?

- Did anybody contribute to finance your migration? Did any of these individuals reside abroad?

- As you were making the decision to migrate, was there perhaps another 'country aimed for' that you couldn't go to? (DID YOU CONSIDER UK, IF THEY WENT TO North America?) What steps did you take to reach the 'country aimed for'? Why couldn't you go?

Migration in progress - migration decisions in country of destination

- When did you arrive in the 'country of stay'?

- When you arrived, did you think that this would be: 
- your final destination that you had planned to go from the outset

- you didn't have a clear idea about the country where you wanted to go

- $\quad$ or you had in mind to go elsewhere (it was therefore a transit country)?

- At the beginning, how long did you plan to stay in the 'country of stay'?

- And how long did you stay in the end?

EXPLAIN: Opportunities for living or working in a country may depend on the type of document you have. Therefore I would like to retrace together with you the different types of documents and residence permits that you may have had or not when you left Suriname and while you lived abroad. Could we try to retrace this together? The questions concern all countries where you lived. If some countries don't require any residence permits, don't hesitate to let me know.

- What kind of visa were you able to secure during your stay?

- RESIDENCE PERMITS - When you arrived in 'Name of the country', did you :

- $\quad$ Not Need any Residence Permit in this country (NNRP)

- Have a Visa (V)

- Have a Residence Permit (permit of stay, residence permit, refugee status...) (RP)

- Not have a permit (NP)

- Other

- And then? Did your situation change?

- WORK PERMITS - And with regard to the sphere of work: when you arrived in 'name of the country' did you:

- $\quad$ Not need any work permit (you had the right to work without ever requesting a legal authorisation) (NNWP)

- Have a work permit (you had a permit allowing you to work in whatever company, in whatever type of occupation) (WP)

- Have a selective work permit, on request or limited to a specific activity (for every new employment you had to request and obtain a new permit) (SWP)

- No work permit (in principle, you didn't have the right to work in this country) (NWP)

- Other

- And then? Did your situation change?

- I am assuming that your nationality is Guyanese/Surinamese/French. Did you acquire a new nationality later on? When? Which nationality? 


\section{Language}

- When you arrived in 'country of stay', would you say that you were able to speak the official language:

- without any difficulty

- with some difficulty

- not at all

- Did you follow any language course to improve your proficiency of the official language during your stay in this country?

\section{Migration in progress - step-wise migration decisions}

- Was there a country that you wanted to reach just afterwards? Which country?

- $\quad$ And which country did you want to reach at the very end?

\section{Potential return (for Returnees skip to the next section)}

- Have you ever intended to return? When? What factors influence your decision to return (conditions in COD, residence/migration policy, conditions in Suriname)?

\section{RETURN TRIPS (for Returnees)}

- I would now like to ask you some more questions about the circumstances in which you returned to $<$ Guyana $>$ to stay or live there. From which country did you come?

- When you returned back to $<$ Guyana $>$, for how long did you intend to stay?

- For what reasons did you return to live in Suriname?

- Where there any events in $<$ Guyana $>$ that prompted you to return?

- Where there any events in the 'country of residence' that prompted you to return?

- With whom did you return?

- Which person decided about your return? Yourself, family members, others?

- Do/did these persons live outside $<$ Guyana $>$ or in $<$ Guyana $>$ ?

- How would you qualify this return to $<$ Guyana $>$ ?

- It happened as you wanted

- It did not happen as you wanted

- It partially happened as you wanted 
- Please explain.

- Was there any re-emigration at any point? What events/factors led you to re-emigrate? Was there anything in your personal life, in <Guyana $>$, in (the destination country)? How did you choose which country to re-emigrate to?

- And how did you make your decision to return to <Guyana $>$ again?

- If the answer above is no, Have you ever thought of re-emigrating? Why? 
Table A3. - Interviewees' main demographic and migration information

\begin{tabular}{|l|l|l|l|l|l|l|}
\hline Country & $\begin{array}{l}\text { Type of } \\
\text { interviewee }\end{array}$ & $\begin{array}{l}\text { Year of } \\
\text { birth }^{\mathbf{1 4 0}}\end{array}$ & Gender & $\begin{array}{l}\text { Ethnic } \\
\text { group }\end{array}$ & $\begin{array}{l}\text { Rural/ } \\
\text { urban }^{141}\end{array}$ & $\begin{array}{l}\text { Country of } \\
\text { destination }\end{array}$ \\
\hline Guyana
\end{tabular}

\footnotetext{
${ }^{140}$ The year of birth roughly groups the interviewees to correspond with the historical periods covered in the individual case study analyses. What this categorisation indicates is that in the case of Guyana, 8 interviewees were able to provide first-hand accounts of Guyana's conditions up until independence in 1966 as all these individuals would have been at least 16 years of age. In addition to these 8 people, 17 people born between 1951 and 1969 were able to provide information that contributed to the second historical period considered that covered 1967-1985 and so on. Because the historical periods covered in each case study differ, these groupings also differ.

${ }^{141}$ This distinction was blurred at times because over the years some rural areas have been incorporated into the city, such as Lelydorp in Suriname, which is now an integral part of Greater Paramaribo (de Bruijne 2001).

142 The sum may be higher than the total of migrants and returnees because some people migrated to multiple destinations over the years.

1431966 was selected as this would include people up to the age of 16 in 1982, when a process of decentralisation took place, which hypothetically could lead to shifts in migration patterns.
} 


\section{Appendix B}

Figure A1. The Caribbean Region: countries in the analysis framed in boxes ${ }^{144}$

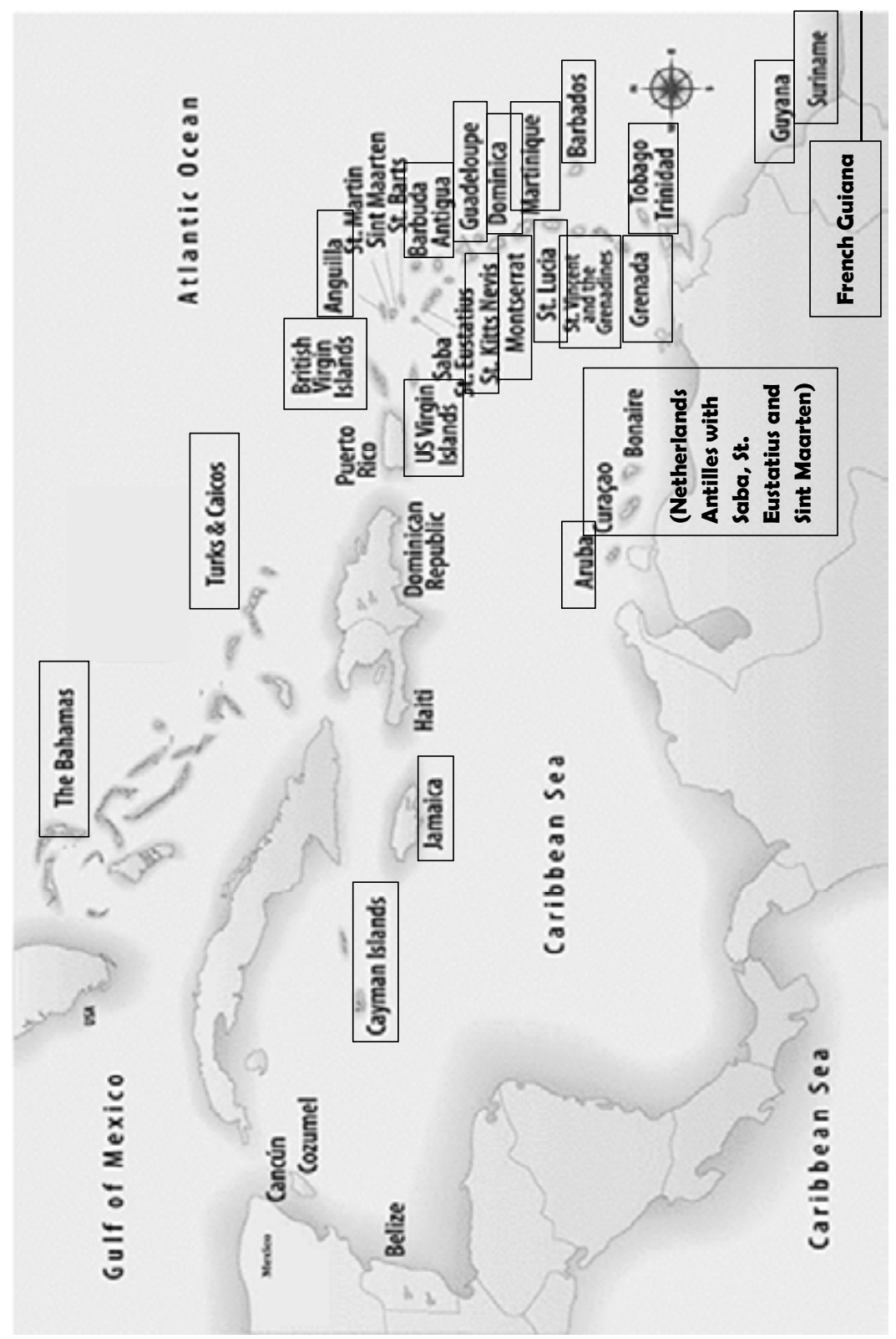

${ }^{144}$ Map downloaded from LocationCaribbean website, available at http: //www.locationcaribbean.com/caribbean-map. 
Figure A2. Political Status Change in the Caribbean Region - Timeline 1800-2013

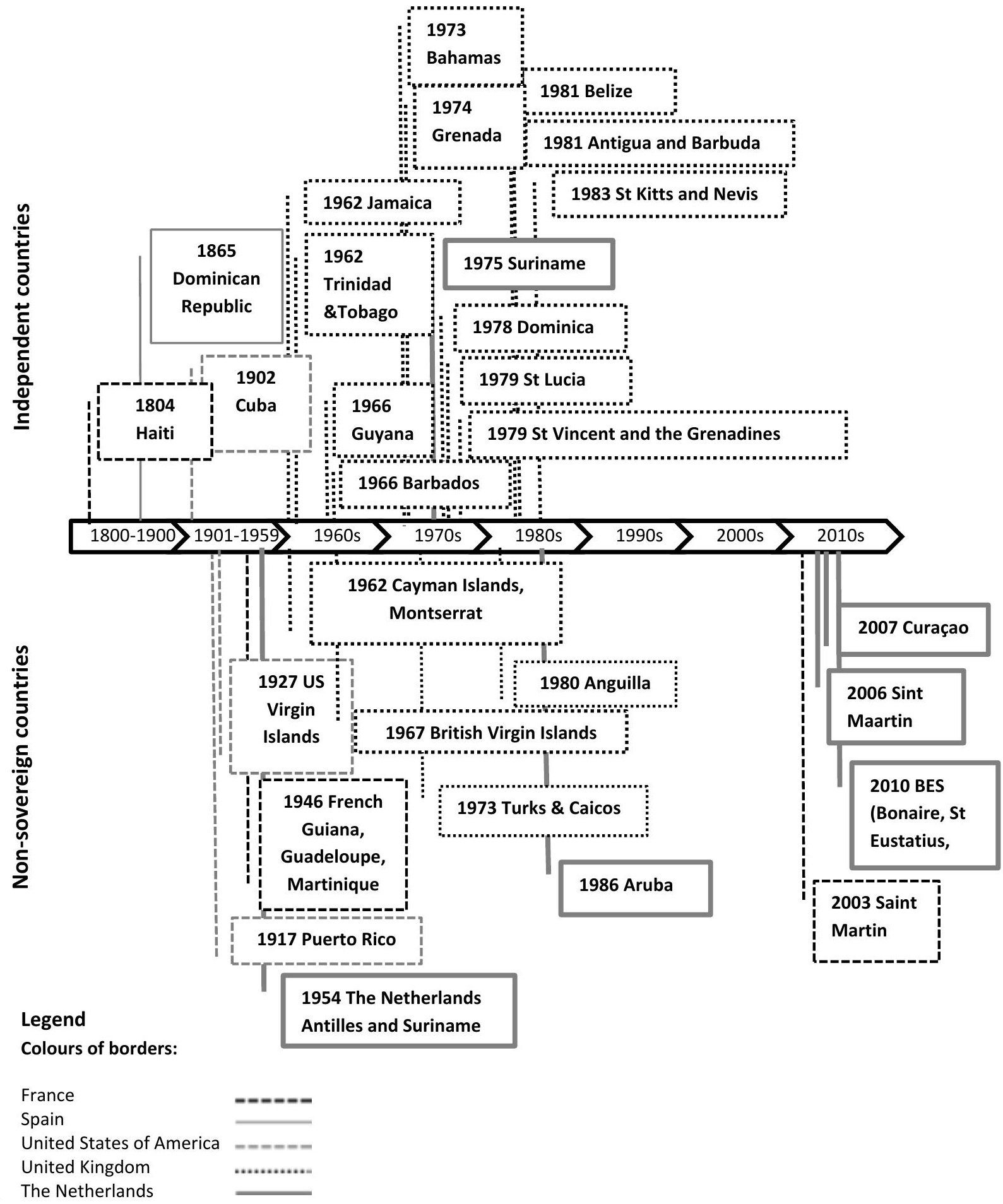


Table A1. Proportion of intra-Caribbean migrants by country of destination in the Caribbean in 2000, for each Caribbean country of origin sorted by closed and open borders

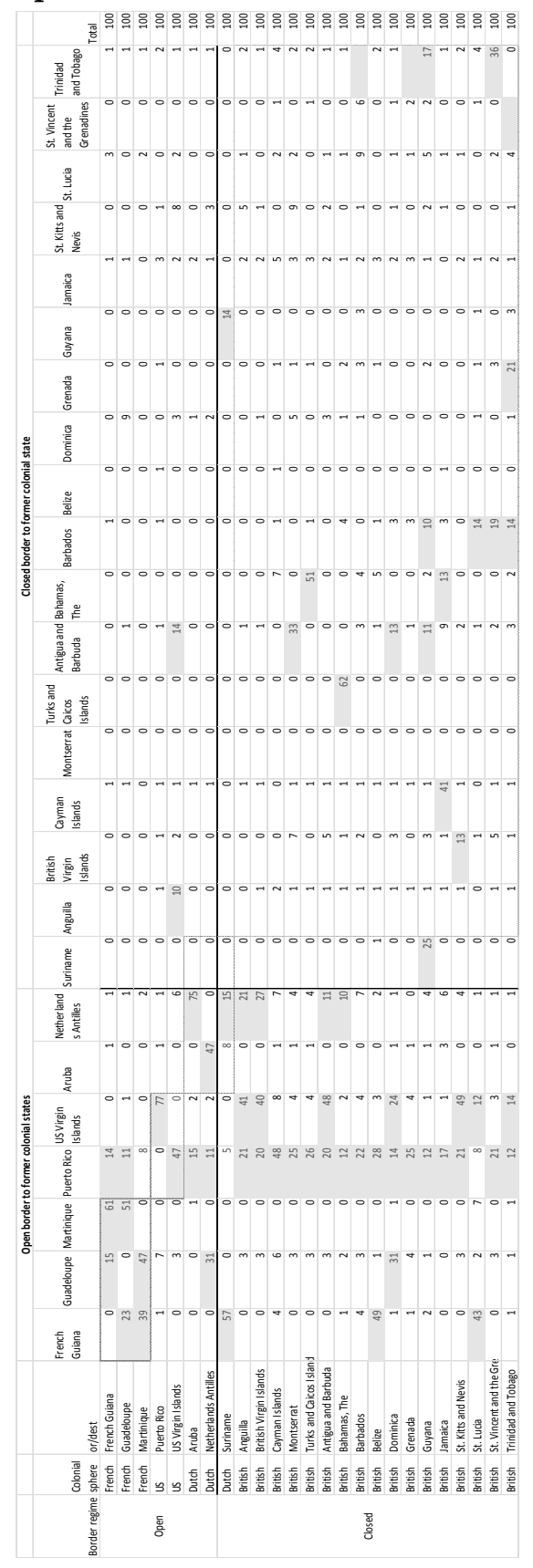


Figure A3. Evolution of visa restrictiveness of France, the Netherlands, Britain and US towards nationals from Caribbean countries, by former colonial state and type of relation with the former colonial state

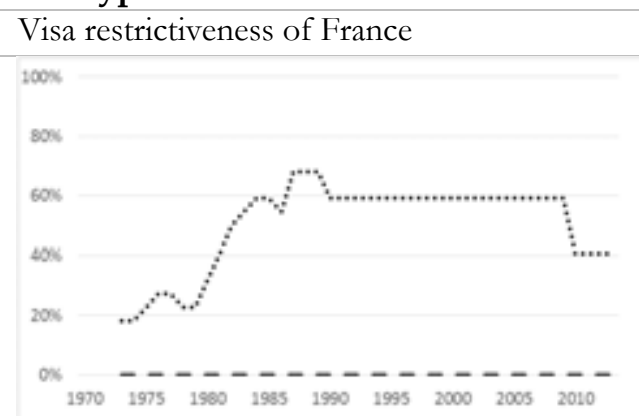

Visa restrictiveness of the Netherlands
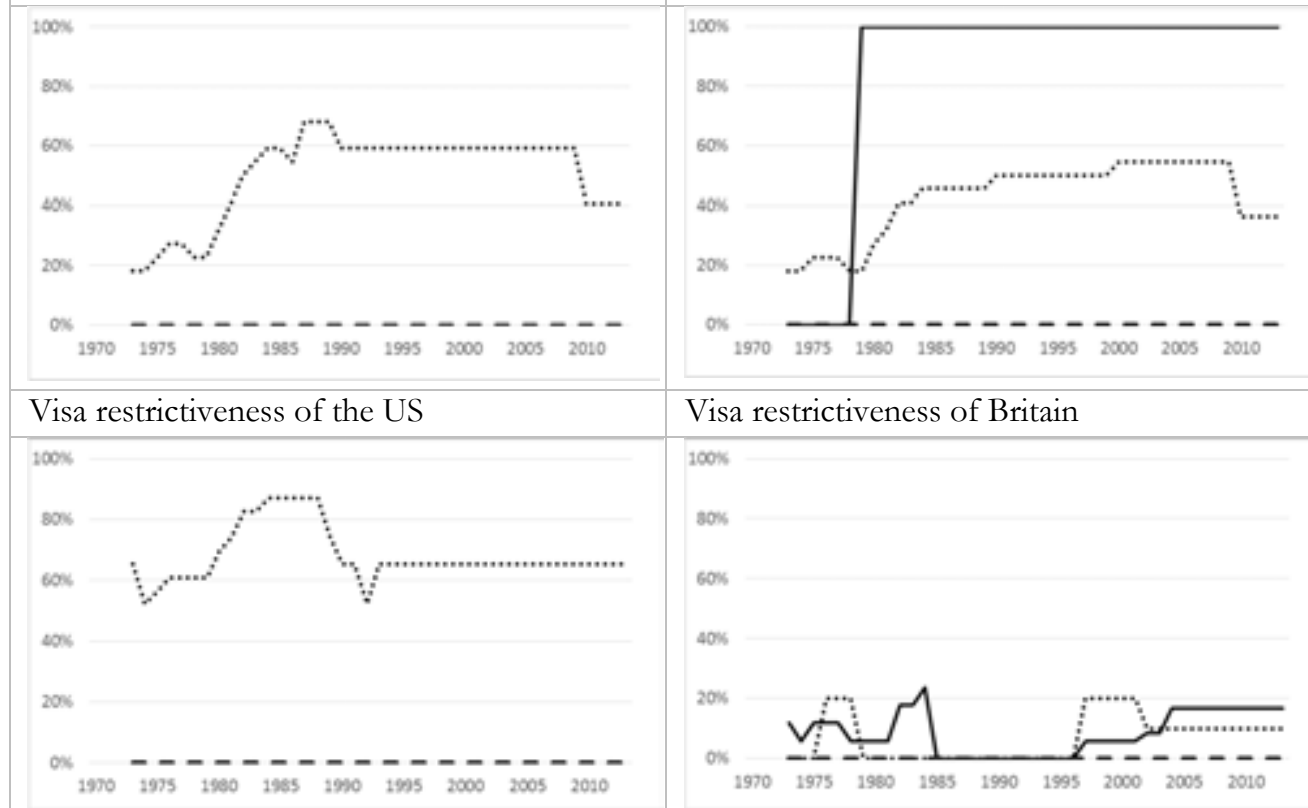

Legend

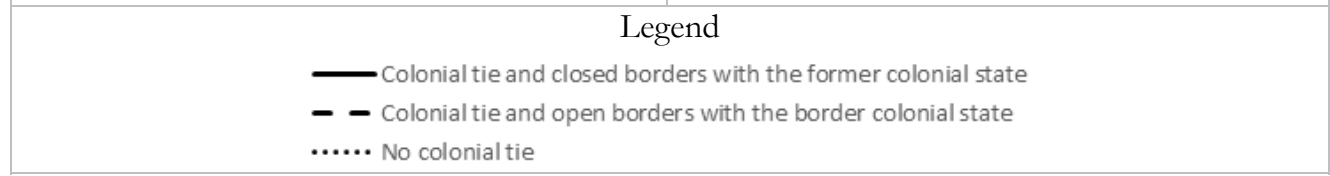

Source: DEMIG VISA 
Figure A4. Evolution of visa restrictiveness of open or closed Caribbean countries with their former colonial state towards nationals from Caribbean countries, by border regime of Caribbean countries of origin

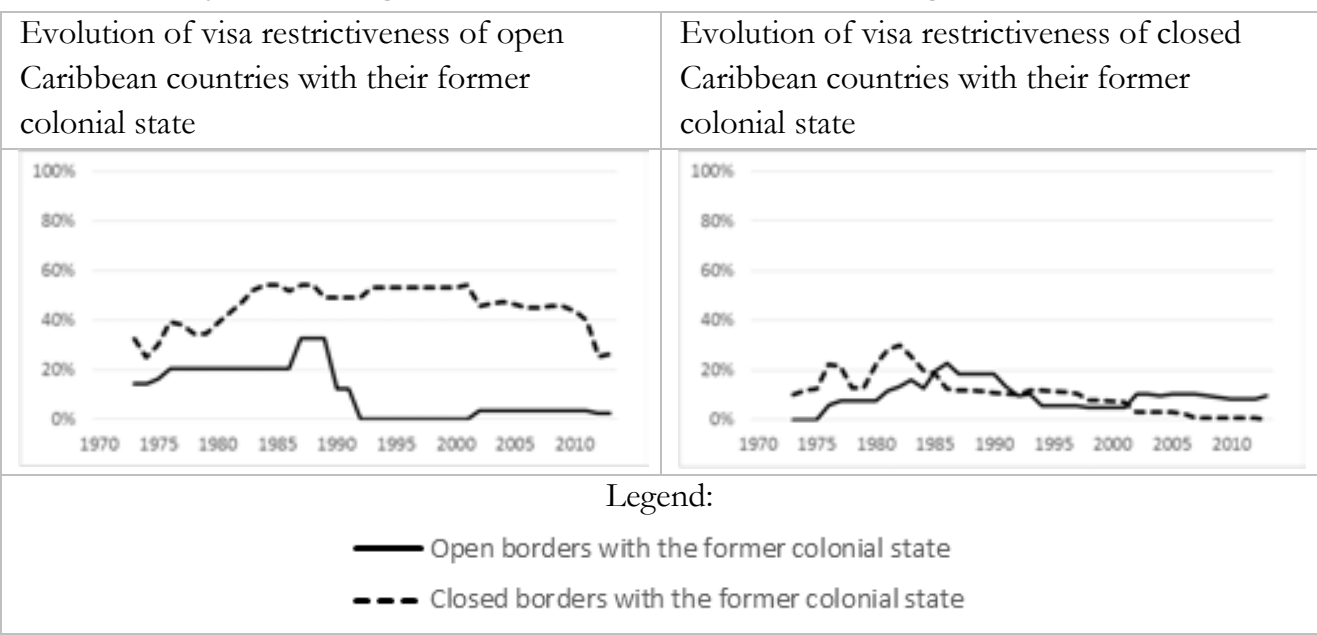

Source: DEMIG VISA

Figure A5. Evolution of overall emigration intensities by extra- and intraregional migration and by border regime (\% of migrants among the population born in the countries), 1960-2000

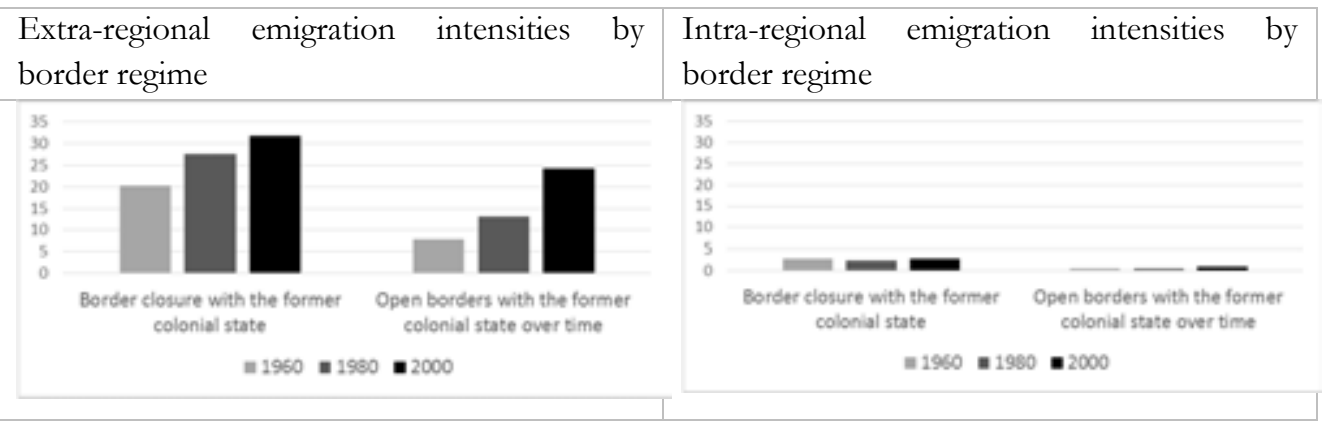

Source: DEMIG VISA 


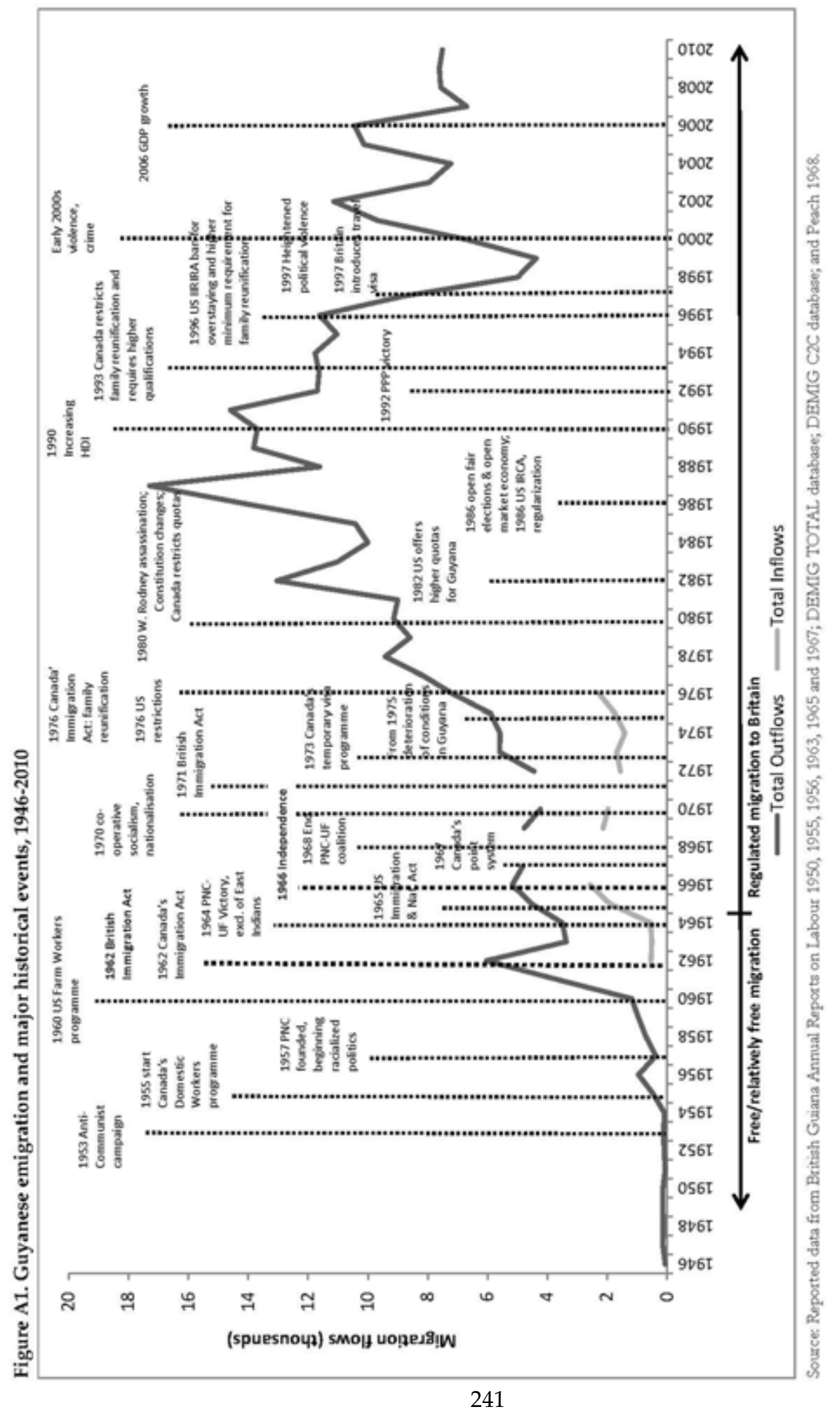




\section{Appendix D}

Figure A1. Suriname-born individuals residing abroad, by country of residence and Suriname's population size, 1960-2000

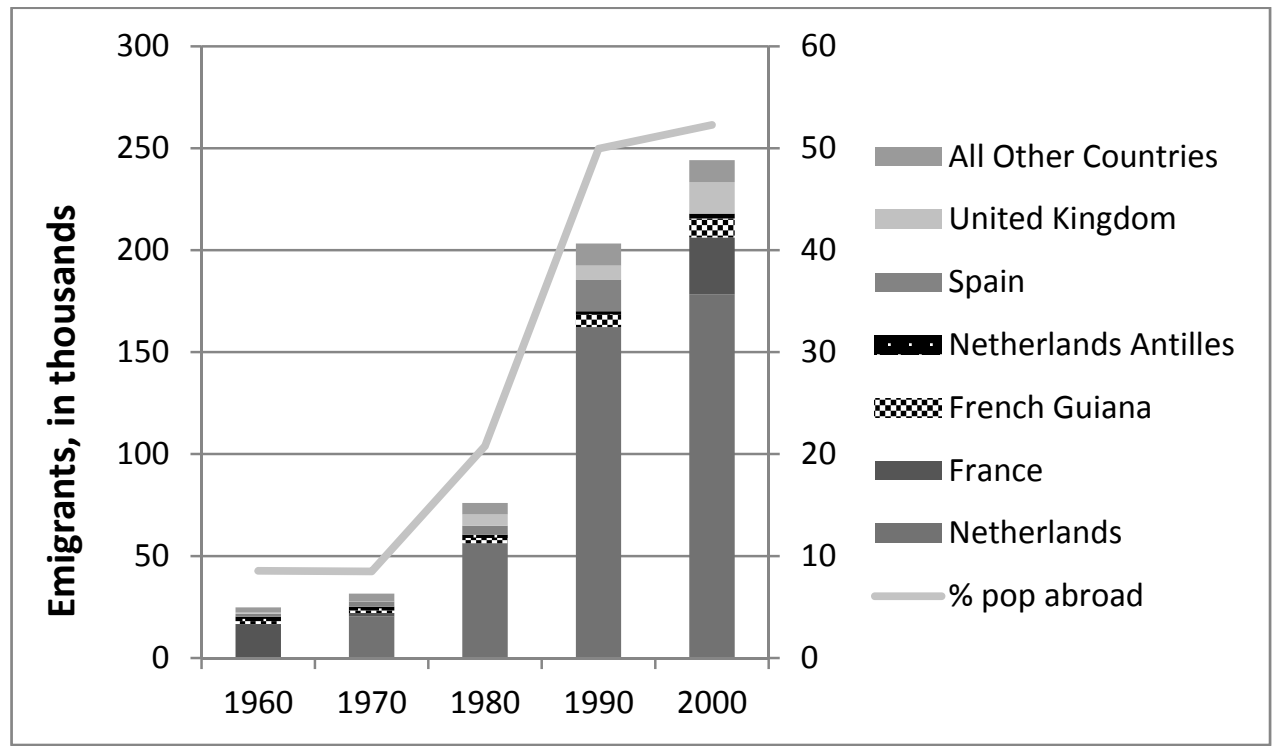

Sources: World Bank Global Bilateral Migration Database and UN Population Estimates 


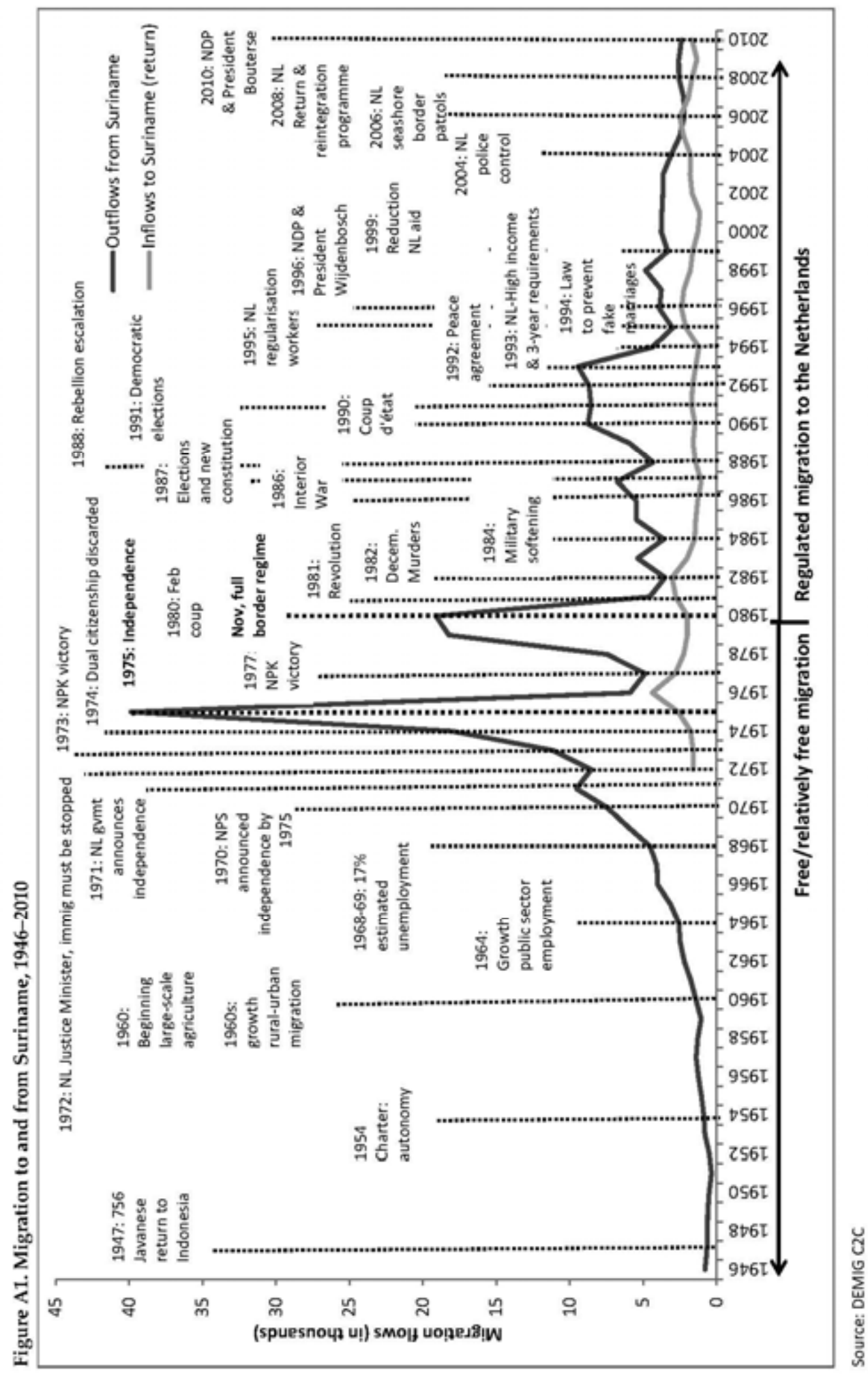


Table A1. Mean Yearly Migration per 1000 Inhabitants, by ethnic group, 19641970

\begin{tabular}{lccc}
\hline & Immigration & Emigration & Net migration \\
Creole & 5.2 & 17.9 & -12.7 \\
Hindustani & 1.1 & 4.8 & -3.7 \\
Javanese & 0.6 & 1.6 & -1.0 \\
\hline
\end{tabular}

Source: Data extracted from Tables 65-67 in Lamur 1973

Figure A3. Average change in restrictiveness of Dutch migration policies, 1945$2014^{145}$

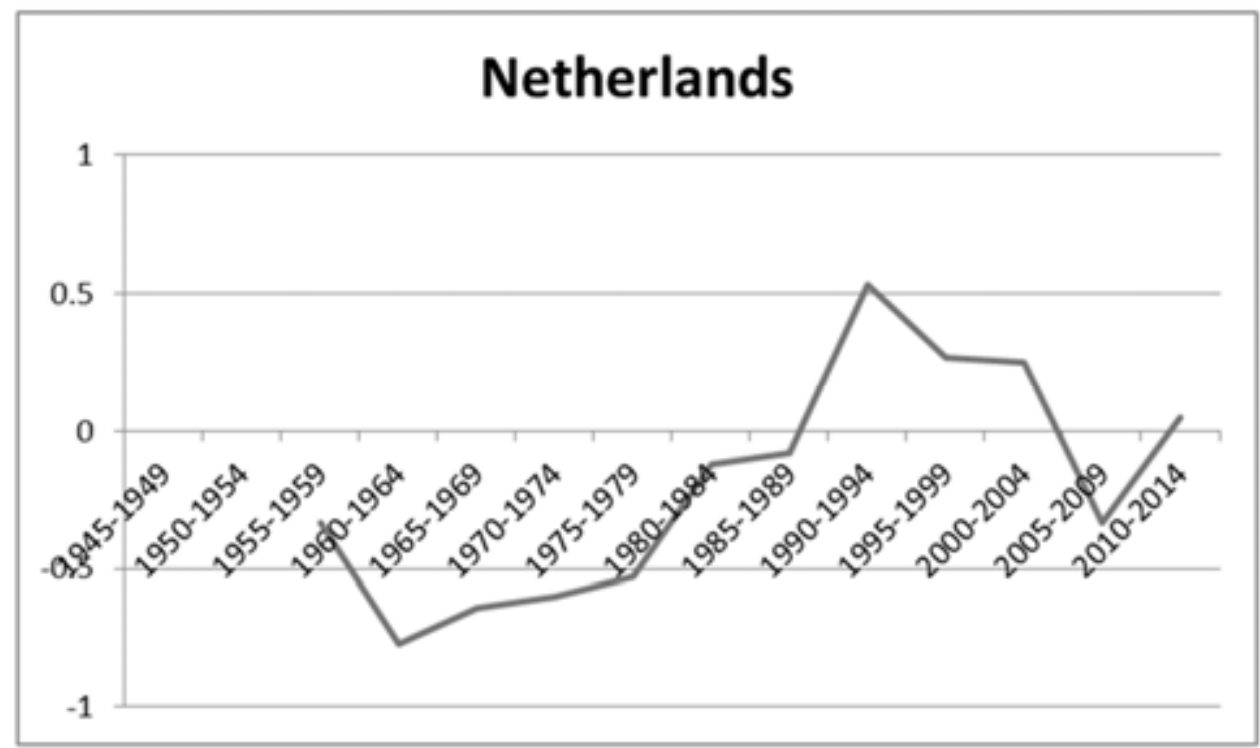

Source: DEMIG POLICY

\footnotetext{
145 This graph shows the average score of all migration policy changes introduced by the Netherlands, with a score above 0 indicating that the number of restrictive policy changes introduced was larger than the number of less restrictive policy changes in that particular year, while a score below 0 means that less restrictive changes dominated. This average does not distinguish across different policy areas and migrant categories and does not account for policies that may not have been applicable to Surinamese migration, e.g. Dutch language and culture tests for family reunification, which were implemented but do not affect Dutch-speaking Surinamese. However, this graph points to the increasing restrictiveness of Dutch migration policy changes since the late 1980s, a period that was significant for Surinamese migration to the Netherlands.
} 
Figure A4. Emigrants by land of emigration and main emigration reason, 2004$2012^{146}$

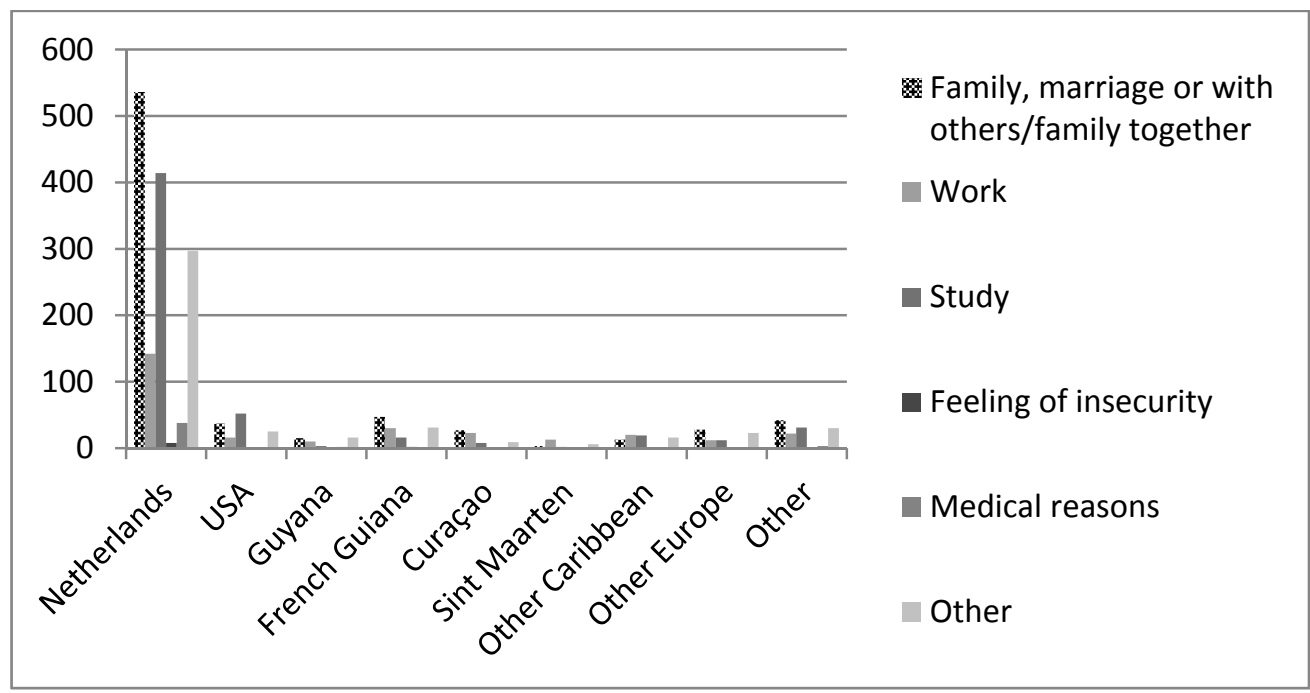

Source: Eighth Census of Suriname, published September 2013, Table 31

\footnotetext{
${ }^{146}$ Data of emigrant stock that may include emigrants who left before 2004 but did not know or did not answer what year they emigrated; these categories are not disaggregated in Table 31 of the Eighth Census of Suriname.
} 


\section{Appendix E}

Figure A1. Guyane-born population in metropolitan France, 1954-2006

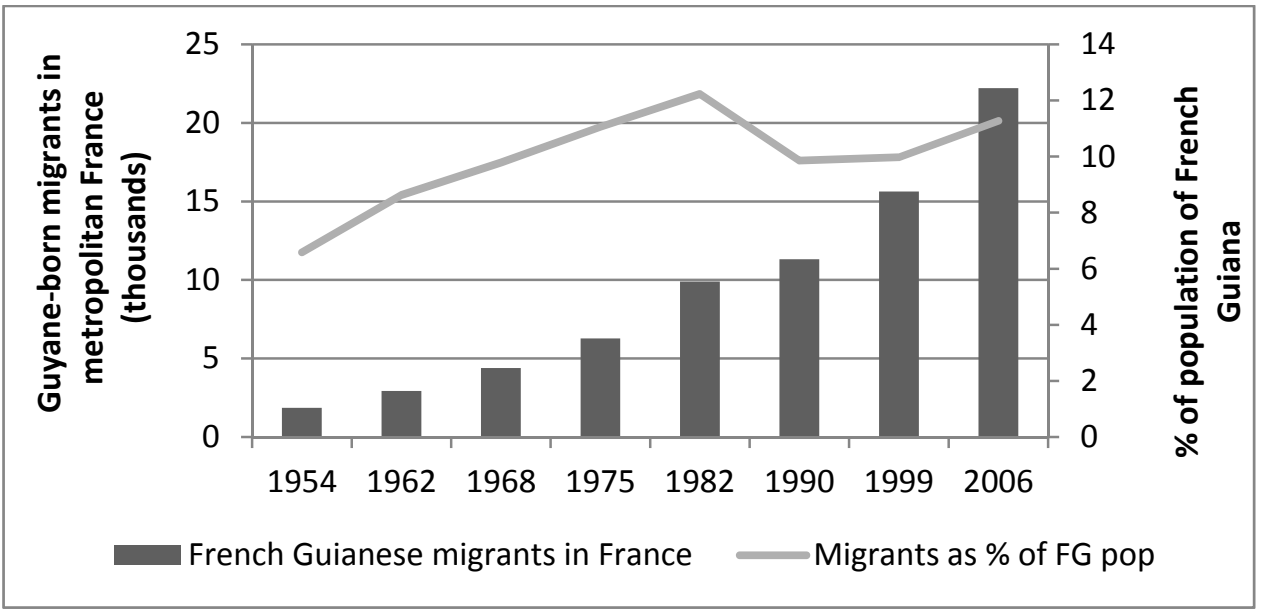

Source: Censuses of metropolitan France, Marie et Rallu 2004, INSEE data ${ }^{147}$

\footnotetext{
${ }^{147}$ Data available at http: //www.insee.fr/fr/insee regions/guyane/themes/ter/ter2010/ter2010 03 gy.pdf, accessed February 2014.
} 


\section{Summary}

Public debates on migration periodically incite calls for increased border controls, be it through fences or heightened border patrols, or through selective migration policies to exclude the entry of 'undesirable' immigrants. Yet, research has produced mixed findings on the effects of migration policies: while they may lead to their intended objectives and decrease immigration levels, they also generate important unexpected effects, such as diversion of migration to ever riskier migration routes and irregular flows. This study contributes to this debate by examining the migratory effects of the establishment of border regimes in a specific historical and geographical context: the closure of the border by former colonial states as part of Caribbean former colonies' movement to independence. Specifically, this study investigates the short- and long-term migration effects of independence and the establishment of border regimes as well as the role of historical connections, often referred to as post-colonial ties, in shaping migration patterns. Covering the period between the 1950s to the 2010s, this study complements existing migration literature by contributing new concepts and empirical evidence on the role of the origin and destination states in shaping Caribbean migration patterns, specifically migration volumes, timing, composition (class, gender, ethnic group, age) and destination.

This study was inspired by evidence of high emigration rates in the Caribbean region, particularly from independent Caribbean countries with closed border regimes. Paradoxically countries with open borders with their former colonial states, such as French Guiana, did often not experience equally large-scale emigration. Furthermore, although post-colonial ties are generally expected to encourage migration from former colonies to former colonial state, actual migration patterns in the Caribbean question this assumption. In fact, while migration from some countries is heavily concentrated on the former colonial state, such as from Suriname to the Netherlands, others have experienced a strong diversion to alternative destinations, such as from Guyana to North America, rather than to Britain, the former colonial state. These distinctive migration outcomes invited the analysis of the migration drivers and the dynamics at play.

Conceptually, this study primarily explored whether the closure of the border generated the four unanticipated migration substitution effects of migration policies hypothesised by Hein de Haas (cf. 2011). However, by focusing on the decolonisation period, this study also examined the effects of migration policies in their interaction with the migratory effects of independence and state formation processes. By also considering the political changes and socio-economic developments associated with decolonisation, this study analyses the more general role of the state in shaping migration patterns beyond migration policies per se, 
including economic, education, social welfare and agricultural conditions. Redressing the receiving country bias, this study also purposefully focused on analysing the role of state policies in migration processes from an origin country perspective.

The Caribbean region provides an ideal case to examine theoretical ideas and contesting hypotheses on the effects of open and closed borders, political status changes and post-colonial ties. The Caribbean case also provides a valuable analytical angle to conduct critical analyses on the role of the state in shaping migration patterns. First, the 25 former colonies considered in this study underwent rapid change in political status between the 1960s and the 1980s; but while 13 gained independence and experienced border closure by their former colonial state, 12 former colonies moved to an autonomous non-sovereign status and various combinations of border regulations. Second, four hundred years of colonial past make this region highly suitable for investigating how (colonial and) post-colonial ties shape migration between former colonies and their former colonial states before and after independence. Within the region, three case studies, Guyana, Suriname and French Guiana, often referred to as the three Guianas, allowed in-depth analysis of how these factors shaped the timing, volume, composition and direction of migration over the past few decades.

This study relies on a conceptual framework which expands the view of the state in migration through a classification of migration and non-migration policies, providing examples of intended and unintended policy effects. Chapter 2 of this study elaborates theoretical scenarios to illustrate the complex effects of independence and the establishment of border controls on the timing, volume, composition and destination of migration. Chapter 3 discusses overall trends and patterns of Caribbean migration and explores how the various combinations of political status transitions and border regimes established by former colonial states as well as Caribbean countries have affected migration. A detailed analysis of border regimes and travel visa requirements shows that Caribbean countries which have open border regimes with their former colonial state also have lower travel visa requirements to other major destinations in Europe, North America and within the Caribbean. Conversely, independent countries which had the borders with their former colonial state closed, are also subjected to high levels of travel visa requirements by other major destinations in Europe, North America and within the Caribbean. This suggests a certain migration policy convergence, whereby main destination countries generally impose similar migration restrictions on the same origin country. The chapter then presents descriptive statistical analyses of long-term emigration patterns identifying associations between border regimes and post-colonial ties on overall, extra-regional and intra- 
regional emigrations in the period between 1960 and 2010. The findings are discussed below.

Chapters 4 to 6 build upon the insights from the conceptual framework, the theoretical scenarios and the descriptive analyses of the Caribbean to present complementary in-depth analyses of migrations in Guyana, Suriname and French Guiana. Chapters 4 and 5 examine the evolution of Guyanese and Surinamese emigration, respectively, from the 1950s until the 2010s and analyse how the establishment of border regimes and independence have shaped the timing, volume, composition and direction of emigration. These case studies show that it is crucial to understand the state's position with regards to independence and the establishment of border regimes given its role in shaping the population's perceptions of these important changes and, subsequently, their migration decisions. Chapter 6 examines the effects of French Guiana's incorporation into the French State on Guianese emigration patterns from the early 1950s to the 2010s. This case shows the importance of the French state in stabilising the standards of living in French Guiana and how this, in combination with free migration, reduces migration aspirations. Finally, chapter 7 presents a comparative analysis of the Caribbean region and the three case studies and summarises the main findings on the role of border regimes, political status, post-colonial ties and the wider role of the state in migration.

Five main insights can be drawn. First, countries that have experienced the closure of a border regime, mainly independent countries but also British dependencies, have paradoxically witnessed stark increases in emigration intensity over time, often against the expectations and intentions of policy makers. In contrast, Dutch, French and US non-sovereign countries, generally show slower growth in emigration and increasing immigration, paradoxically as a consequence of their open border regimes and non-sovereign status vis-à-vis their metropolitan states. Thus, while closed borders do not reduce emigration in the long term, open borders do not necessarily lead to very large migration, but more often to higher (circular) mobility, including short-term visits and return flows. Second, both the establishment of border regimes and independence help to explain the occurrence of unintended strong, albeit temporary, emigration hikes, while such peaks do not appear in the absence of migration restrictions as in the case of French Guiana. Third, the contrasting cases of Guyana and Suriname suggest that differences in the timing and sequencing of independence and border regime establishment significantly affects the spatial orientation of post-colonial migration patterns. When immigration restrictions are introduced before independence, emigration destinations may diversify away from the former coloniser, such as in the case of (former British) Guyana. On the other hand, border closure at and after independence may reinforce the colonial orientation of such migrations, such as in 
the case of Suriname. Fourth, strong relations between former colonies and former colonial states after independence seem to strengthen post-colonial ties and encourage migration to the former colonial state. Conversely, the growth of relations with other states, such as through trade, education and media exposure, encourages people to expanded worldviews (mental maps) of potential migration destinations in which the former colonial state and other countries in the same colonial sphere are no longer exclusively considered. Lastly, while border regimes and migration policies greatly influence emigration, in the long-term political and socio-economic conditions as well as stability, which are effected by a wide range of non-migration policies, offer important explanations for variations in colonial and post-colonial migration patterns across countries and over time.

The study makes three important methodological contributions. First, it adds to an understudied research field: comparative research of Caribbean migrations across former colonial spheres. Second, it puts the three Guianas on the mental map of migration researchers; these countries provide not only rich migration histories that include the earliest state-led labour migrations, but they also provide valuable examples of very dynamic contemporary migration patterns. Third, this study showed that there is great value in using in-depth case studies in a historical comparative perspective to explore themes, such as independence and post-colonial ties, which to date have been weakly conceptualised in migration research.

To conclude, this study expands our understanding of migration in four ways. First, it contributes conceptual insights and empirical evidence on the unanticipated effects of border regimes on migration volumes, timing, composition and destination as well as our understanding of migration dynamics in the absence of border regimes. Second, it provides a conceptual framework to understand the role of independence and non-sovereignty on migration patterns as well as a systematic approach to examine the potential migration substitution effects of political status changes and the establishment of border regimes by former colonial states and destination countries. Third, this study advances an improved and expanded conceptualisation of post-colonial ties which moves beyond the conventional bilateral relations between former colonies and their respective former colonial states. Instead, it proposes that colonial ties have evolved in response to post-colonial experiences, reacting to new geopolitical relations, which have shaped specific worldviews and new choices of migration destination. Fourth, it provides evidence of how states, particularly in origin countries, influence migration in indirect but important ways through various non-migration policies affecting general political, ideological, economic, technological and social conditions in origin countries. 


\section{Valorisation}

\section{Social and economic relevance of this study and its findings}

This study's findings are highly relevant to current public and policy debates on migration. They expand our understanding of the effects of migration policies and migration as part of broader political and socio-economic processes. Moreover, the study provides rich evidence of migration as a response to important structural changes, often driven by policy reforms and the uncertainties they create. The practical, relevant and nuanced examples that emerge from this study can contribute to the improvement of public debate and the reduction of alarmism and fears of migrant invasions.

The main focus on the migration effects of political status changes and the establishment of border regimes generated a number of valuable insights. To start, states and their borders change more frequently than we may realize and these changes are likely to have significant migration effects. Independence movements continue today around the world as observed in South Sudan and the ongoing quests for independence by the Basque country, in Catalonia and most recently, Scotland. At the same time, regional blocs are dismantled, such as the former Soviet bloc, while others gain strength and emphasize rights of free movement, e.g. European Union, ECOWAS, ASEAN and CARICOM. The dearth of research on the migratory effects of these shifts often leads to migration predictions that are based on simplistic wage-based assumptions. For example, the various enlargement phases of the European Union have been accompanied by expectations of large migration flows from lower-income to higher-income countries. However, this has not been uniformly the case. Most recently, in Britain, public debate centered around expectations of mass invasion of Bulgarian and Romanian workers after the lifting of work restrictions, but these expectations proved unfounded. Thus, while political status and border regime changes are likely to have migration consequences, such effects are not simply based on wage-differentials but on a complex interplay of multiple factors associated with these moments of transition, which are described next.

Changes in political status and border regimes have important social repercussions, affecting people's feelings of uncertainty and their perceptions of the future, often generating deep anxieties. Thus, in an attempt to reduce risk and uncertainty, these events may incite migration aspirations as people seek to secure entry into another country perceived to be safer. However, perceptions among the population vary according to specific groups of people, such as the working class, students or a specific ethnic/regional group, and the contextual conditions in which 
political independence is obtained and borders are closed. So the potential for ethnic- or class-based discrimination and fear of personal and financial losses may lead people to oppose independence and to migrate as independence approaches. Conversely, those with favorable expectations of the country's future may find independence to be a time of renewed opportunities leading to lower emigration and also to small increases in return and immigration.

An important message from this study is that open borders do not necessarily lead to very large migration volumes. When open borders are retained, as in the case of many former colonies which gained autonomous non-sovereign status, anxieties are minimized, reducing migration aspirations. Contrasting to closed border settings, migration displays more stable patterns, primarily following educational and employment opportunities in the country of origin and destination. Moreover, open borders allow various forms of mobility, including travel for tourism and family visits and short-term stays. As expected, the living conditions in the country of origin remain an important determinant and migration may escalate rapidly at times of severe socio-economic and political crises including conflict- in the origin country. Thus, rather than very large migrations, open borders encourage higher (circular) mobility, including short-term visits and return flows.

This study found strong evidence that while migration policies may affect migration in the intended manner, they may also generate important 'substitution effects'. Impending border closure triggered important short-term migration hikes, while the introduction of migration policies that targeted potential migrant workers generated deflection to other destinations or/and migration policy categories, i.e. family reunification or tourist visas followed by overstaying. Thus, policy-makers should be aware that when migration policies are introduced, migration may shift in unexpected ways, including generating increases in irregular migration or encouraging migrants to explore new crossing and entry points or altogether different destinations.

The findings also suggest that timing and sequencing of events should be given full attention in studying migration and migration policy effects. For example, in the case of independence and border regime establishment, evidence shows that closing the border before or after independence led to the development of alternative migration destinations or the concentration of migration in the former colonial state, respectively. In addition, researchers should consider both short- and long-term migration effects of migration policies. We have seen that border regimes generated an immediate shift in migration followed by a long-term adjustment process. The rapid migration increase before policy implementation, followed by a rapid decline give the false impression that the policy produced the 
desired objective of reducing migration. However, the policy generated an increase in migration that would not have occurred otherwise, and in the long-term migration tended to steadily increase again, as migrants found ways to overcome restrictive migration policies. It is only when observing migration trends in the medium to long term that these effects become apparent.

Migration policies interact with other processes of political, social and economic transformation, which may be crucially important in shaping migration patterns. At times, policy reforms that have no direct association with migration may shift migration aspirations. For example, the introduction of free tertiary education may initially decrease migration as students are able to pursue further studies in the country of origin; however, should a job market not develop to accommodate an increasing number of skilled workers, such educational reform may lead to long-term emigration rises. This highlights how migration is closely associated with a wide variety of events and policy changes which impact living conditions in origin and destination countries and people's migration aspirations. Even in this case, the timing of the introduction of migration policies in relation to other important socio-economic events such as political elections, important reforms such as the introduction of free tertiary education or of a new taxation system in origin and destination countries may affect migration patterns.

To conclude, this study suggests that in contexts of high uncertainty people try to find a sense of security in many ways (e.g. by pursuing an education), including but not exclusively through migration. However, within a country, certain segments of the population may feel secure, or a policy may increase their security, while the same policy may increase the uncertainties of other segments of the population. For example, the provision of social services may diminish anxieties and reduce emigration aspirations, minimizing the effects of independence and border closure, or in most context reducing uncertainty during economic downturns. However, young adults may be more affected by impending border closures and decide to emigrate regardless of social service provision such as job trainings, while other people may feel that a heftier taxation system to support the expansion of the social system is unacceptable, becoming the basis for emigration. Thus, when considering possible migration effects, it is imperative to consider the complex interaction of multiple factors and their distinct migratory effects on segments of the population according to political ideology, class, ethnicity, gender and age.

\section{Innovation of findings}

The main innovation of this study rests in having generated evidence concerning the unanticipated effects of independence, the establishment of border regimes and 
major migration policies introduced by destination countries over the years. The conceptual framework developed in this study is a valuable tool offering a systematic approach to understand such unanticipated migration substitution effects. The inclusion of the analysis of migration patterns in a non-sovereign country that has retained open borders with the metropolitan state also adds new empirical evidence of migration drivers and dynamics in open border contexts. As just shown, important original insights have also emerged on the importance of the timing and sequence of events and the need to consider who will be affected by these events - i.e. class, ethnicity, age and gender - and their perspectives on upcoming changes.

This study advances an improved and expanded conceptualisation of postcolonial ties which moves beyond decontextualised definitions and proposes that both colonial and post-colonial experiences create specific worldviews, i.e. mental world maps. These worldviews can vary greatly from country to country, even neighbouring countries, with the passage of time and with the deepening of relations with new potential destination countries, such as through commercial and educational links.

This study's findings provide explicit evidence of how political, ideological, economic, technological and social factors affect emigration in origin countries. Because states often regulate these areas through policy-making, these findings reveal the wider role of states, including origin countries, in shaping migration. In particular, the more state policies generate uncertainties, the more they may increase migration aspirations as segments of the population attempt to reduce their risks through migration to 'safer' countries. Conversely, by acting as 'stabilisers' of political and socio-economic conditions, states may reduce migration aspirations.

\section{Non-academic target audience}

This study provides ample evidence of interest to policy-makers, border control agencies and other government authorities responsible for migration. For these government authorities, this study provides nuanced evidence of short- and longterm effects of border regimes, political status change as well as non-migration policies that may alter migration in origin and destination countries, such as economic reforms, mechanization, ideological shifts, authoritarianism and educational reforms. This evidence can also enrich current debates that surround the quest for independence and state formation in various locations throughout the world.

This study's findings should also be of great interest to development experts, given the multiple links between development and migration processes. In 
particular, the case studies offer insights on the role of economic strategies, labour displacement and rural-urban migrations; the effects of the increase in education levels and the growth of professional aspirations which may generate strong migration aspirations; and the role of social security provisions in reducing risk and uncertainties and their links to decreasing migration aspirations. Development experts can gather evidence on how socio-economic development generates responses that at once stimulate and reduce emigration. Thus, this study provides further evidence that development efforts whose main purpose is to reduce mobility are likely to fail in this objective.

The topics touched upon with this study are also valuable to journalists and reporters on migration issues. By providing evidence of potential unanticipated effects of closed border regimes and the long-term migration effects of continuous open borders, journalists and reporters find important evidence to challenge heavily politicized and divided migration debates. Moreover, this study offers good examples of the mechanisms underlying important historical migrations, such as Surinamese migration to the Netherlands, and offers richer migration stories that are rooted in wider and longer term processes of economic development, inequality, conflict and discrimination, ongoing and increasingly selective migration policy and travel restrictions. With such evidence, a fresh message could be relayed to the public, which moves away from the sensationalisation and criminalisation of migration to emphasize the mounting aspirations for better opportunities and improved living conditions among people in developing countries.

\section{Output}

The insights from this study are appropriate for dissemination through a series of outlets and publications both for an academic audience and in a more accessible version for the public. Among academic journals, I aim to publish the various chapters in journals such as International Migration Review, Population and Development Review and International Migration. Publications in non-academic publications will aim to provide accurate empirical evidence, clarify concepts and promote more nuanced pictures of migration. Examples of these outlets are blogs, editorials, interviews with journalists and participation in public debates. To disseminate information on the case studies, I plan to develop country profiles to be published on the website of the Migration Policy Institute, an important source of migration information freely available to the public online.

The findings from this study will also greatly contribute to my teaching curriculum. I find that teaching becomes more engaging when textbook material is complemented with a researcher's work. Moreover, by sharing research findings, 
not only will the students gain from hands-on research, but researchers also gain from the students' comments and feedback, making it a very valuable process.

Given the utility of the findings to development workers, the author plans to participate in debates on development strategies so as to promote greater understanding on the potential migration effects of many development policies. Moreover, I intend to participate in conferences attended by policy-makers, such as Metropolis, where this study's insights may provide points of reflection and raise awareness of the possible unexpected consequences of conventional migration policies.

The time and resource investment required for these dissemination activities will be available within the context of my current position as a researcher and lecturer at the University of Amsterdam. 


\section{Curriculum Vitae}

Simona obtained a Bachelor's degree in Anthropology at the University of California, Berkeley, United States in 2003 and a Master's degree in International Policy Studies with a specialization in International Development from the Monterey Institute of International Studies, United States, in 2007. This same year, she also obtained a Master's in Migration Sciences from the European University in Rome.

Simona is currently a researcher and lecturer at the University of Amsterdam, Faculty of Social and Behavioral Sciences. Before working at the University of Amsterdam, Simona held a 3-month Visiting Research Fellowship at the Koninklijk Instituut voor Taal-, Land- en Volkenkunde (KITLV) / The Royal Netherlands Institute of Southeast Asian and Caribbean Studies, Leiden. From 2008 to 2015, Simona was a Research Officer at the International Migration Institute (IMI), University of Oxford, where she worked on a project entitled 'Determinants of International Migration' which examined how origin and destination states and their migration policies affect the size, direction and composition of international migration. At IMI, she also researched migration and development initiatives in Mexico, Morocco, Ghana, Senegal and Serbia and contributed to the Transatlantic Dialogues on Migration and Development project, which compared migrations from Morocco to Europe and from Mexico to the United States. Simona was also a major contributor to the Global Migration Futures project, particularly leading the adoption and adaptation of the scenario methodology for the study of the future of migration.

In 2007, Simona worked at the International Organization for Migration in Rome, where she gained an understanding of applied migration and development projects through the Migration for the Development in Africa (MIDA) project. While at IOM Rome, she also conducted primary research on unaccompanied Afghan minors seeking asylum in Italy to document their journeys from Afghanistan, Pakistan and Iran to Italy. Before entering academia, Simona worked in the public sector as an administrator in a public school district in East Palo Alto, California and an office manager and controller in a software company in Cambridge, Massachusetts, United States. 


\section{Maastricht Graduate School of Governance Dissertation Series}

Silvia Consuelo Gómez Soler

Civil Conflict and Education: How Does Exposure to Civil Conflict Affect Human Capital Accumulation? Evidence from Standardized Exit Exams in Colombia

MGSoG Dissertation Series, nr 64 (2015)

Paula Nagler

Occupational Choice in the Developing World

MGSoG Dissertation Series, nr 63 (2015)

Jasmin Kientzel

Determinants of Professional Commitment to Environmental Sustainability

MGSoG Dissertation Series, nr 62 (2015)

Mehmet Güney Celbiş

Regional Policies: Convergence, Trade, and the Allocation of Public Capital

MGSoG Dissertation Series, nr 61 (2015)

Florian Henning

Living Up to Standards

Interoperability Governance and Standards Adoption in Government Information

Networks

MGSoG Dissertation Series, nr 60 (2015)

Niels P. Groen

The Never-ending Project

Understanding E-Government Project Escalation

MGSoG Dissertation Series, nr 59 (2015)

Derek Copp

Teacher-based Reactivity to Provincial Large-scale Assessment in Canada

MGSoG Dissertation Series, nr 58 (2015) 
Michaella Vanore

Family-Member Migration and the Psychosocial Health Outcomes of Children in Moldova and Georgia

MGSoG Dissertation Series, nr 57 (2015)

\section{Sonja Fransen}

The Economic and Social Effects of Remittances and Return Migration in Conflict-Affected Areas:

The Case of Burundi

MGSoG Dissertation Series, nr 56 (2015)

Ibrahim Khalil Conteh

The Impact of Floods on Primary School Education in Zambia

MGSoG Dissertation Series, nr 55 (2015)

\section{Richard Bluhm}

Growth Dynamics and Development

Essays in Applied Econometrics and Political Economy

MGSoG Dissertation Series, nr 54 (2015)

Nevena P. Zhelyazkova

Work-Family Reconciliation and Use of Parental Leave in Luxembourg

Empirical Analysis of Administrative Records

MGSoG Dissertation Series, nr 53 (2015)

Sachin Kumar Badkas

Metachoice and Metadata

Innovating with Environmental Policy Analysis in Europe

MGSoG Dissertation Series, nr 52 (2014)

Irina S. Burlacu

An Evaluation of Tax-Benefit Systems Impact on the Welfare of Frontier Workers

The Case of Luxembourg and Belgium

MGSoG Dissertation Series, nr 51 (2014) 
Borders, independence and post-colonial ties

Özge Bilgili

Simultaneity in Transnational Migration Research:

Links Between Migrants' Host and Home Country Orientation

MGSoG Dissertation Series, nr 50 (2014)

Yulia Privalova Krieger

Reshaping the Big Agenda: Transnational Politics and Domestic Resistance

Financial crisis and social protection reform in Bosnia and Herzegovina

MGSoG Dissertation Series, nr 49 (2014)

Marieke van Houte

Moving Back or Moving Forward?

Return migration after conflict

MGSoG Dissertation Series, nr 48 (2014)

Oxana Slobozhan

Global Governance in the Management of Natural Resources

The Case of the Extractive Industries Transparency Initiative (EITI)

MGSoG Dissertation Series, nr 47 (2014)

Luis Bernardo Mejia Guinand

The Changing Role of the Central Planning Offices in Latin America:

A Comparative Historical Analysis Perspective (1950-2013)

MGSoG Dissertation Series, nr 46 (2014)

Cheng Boon Ong

Ethnic Segregation in Housing, Schools and Neighbourhoods in the Netherlands

MGSoG Dissertation Series, nr 45 (2014)

Luciana V. Cingolani

Bureaucracies for Development: Oxymoron or Reality?

Studies on State Capacity in Challenging Governance Contexts

MGSoG Dissertation Series, nr 44 (2014) 
Carlos Cadena Gaitán

Green Politics in Latin American Cities - Sustainable Transport Agendas

MGSoG Dissertation Series, nr 43 (2014)

Katie Kuschminder

Female Return Migration and Reintegration Strategies in Ethiopia

MGSoG Dissertation Series, nr 42 (2014)

Metka Hercog

Highly-Skilled Migration and New Destination Countries

MGSoG Dissertation Series, nr 41 (2014)

Margaret Agaba Rugadya

Can Remittances Influence the Tenure and Quality of Housing in Uganda?

MGSoG Dissertation Series, nr 40 (2014)

Ilire Agimi

New Governance Under Limited Statehood

The Case of Local Government Reform in Kosovo

MGSoG Dissertation Series, nr 39 (2014)

Kristine Farla

Empirical Studies on Institutions, Policies and Economic Development

MGSoG Dissertation Series, nr 38 (2013)

Marina Petrovic

Social Assistance and Activation in the Pursuit of Happiness:

Shedding New Light on Old Policy Solutions to Social Exclusion

MGSoG Dissertation Series, nr 37 (2013)

\section{Laura Torvinen}

Assessing Governance Assessments; The Case of Mozambique

Governance Assessments in the Context of Aid Effectiveness Discourse

MGSoG Dissertation Series, nr 36 (2013) 
Biniam Egu Bedasso

Institutional Change in the Long Shadow of Elites

Essays on Institutions, Human Capital and Ethnicity in Developing Countries

MGSoG Dissertation Series, nr 35 (2013)

Sepideh Yousefzadeh Faal Deghati

Childhoods Embargoed

Constructing and Reconstructing Multidimensional Child Poverty in Iran 1984-2009

MGSoG Dissertation Series, nr 34 (2013)

Robert Bauchmüller

Investing in Early Childhood Care and Education:

The Impact of Quality on Inequality

MGSoG Dissertation Series, nr 33 (2013)

Martin Rehm

Unified Yet Separated

Empirical Study on the Impact of Hierarchical Positions within Communities of Learning MGSoG Dissertation Series, nr 32 (2013)

Dorcas Mbuvi

Utility Reforms and Performance of the Urban Water Sector in Africa

MGSoG Dissertation Series, nr 31 (2012)

Lina Salanauskaite

Distributional Impacts of Public Policies:

Essays in Ex-Ante and Ex-Post Evaluation

MGSoG Dissertation Series, nr 30 (2012)

Esther Schüring

To Condition or not - is that the Question?

An Analysis of the Effectiveness of Ex-Ante and Ex-Post Conditionality in Social Cash Transfer Programs

MGSoG Dissertation Series, nr 29 (2012) 
Joe Abah

Strong Organisations in Weak States

Atypical Public Sector Performance in Dysfunctional Environments

MGSoG Dissertation Series, nr 28 (2012)

Zina Samih Nimeh

Social Citizenship Rights: Inequality and Exclusion

MGSoG Dissertation Series, nr 27 (2012)

Lenka Eisenhamerová

Legitimacy of 'Humanitarian Military Intervention'

MGSoG Dissertation Series, nr 26 (2011)

Sonila Tomini

Informal Payments for Health Care Services in Albania

MGSoG Dissertation Series, nr 25 (2011)

Jinjing Li

Dynamic Microsimulation in Public Policy Evaluation

MGSoG Dissertation Series, nr 24 (2011)

Aziz Atamanov

Rural Nonfarm Employment and International Migration as Alternatives to Agricultural Employment:

The Case of Kyrgyzstan

MGSoG Dissertation Series, nr 23 (2011)

Frieda Vandeninden

Poverty Alleviation: Aid and Social Pensions

MGSoG Dissertation Series, nr 22 (2011)

Juliana Nyasha Tirivayi

The Welfare Effects of Integrating AIDS Treatment with Food Transfers:

Evidence from Zambia

MGSoG Dissertation Series, nr 21 (2011) 
Agnieska Ewa Sowa

Who's Left Behind? Social Dimensions of Health Transition and Utilization of Medical

Care in Poland

MGSoG Dissertation Series, nr 20 (2011)

Emmanaouil Sfakianakis

The Role of Private Actors in the Provision of Public Goods with Applications to

Infrastructure and Financial Stability

MGSoG Dissertation Series, nr 19 (2011)

Siu Hing Lo

White Collars Green Sleeves

An Interonganizational Comparison of Determinants of Energy-Related Behaviors among Office Workers

MGSoG Dissertation Series, nr 18 (2011)

Treena $\mathrm{Wu}$

Constraints to Human Capital Investment in Developing Countries:

Using the Asian Financial Crisis in Indonesia as a Natural Experiment

MGSoG Dissertation Series, nr 17 (2011)

Henry Espinoza Peña

Impact Evaluation of a Job-Training Programme for Disadvantaged Youths:

The Case of Projoven

MGSoG Dissertation Series, nr 16 (2011)

Florian Tomini

Between Family and Friends

Understanding the Interdependency of Private Transfers

MGSoG Dissertation Series, nr 15 (2010)

Michał Polalowski

The Institutional Transformation of Social Policy in East Central Europe:

Poland and Hungary in comparative and historical perspective

MGSoG Dissertation Series, nr 14 (2010) 
Maha Ahmed

Defining, Measuring and Addressing Vulnerability:

The Case of Post Conflict Environments

MGSoG Dissertation Series, nr 13 (2010)

Pascal Beckers

Local Space and Economic Success

The role of spatial segregation of migrants in the Netherlands

MGSoG Dissertation Series, nr 12 (2010)

\section{Victor Cebotari}

Conplicting Demands in Ethnically Diverse Societies

Ethnopolitical Contention and Identity Values in Europe

MGSoG Dissertation Series, nr 11 (2010)

Dennis Gyllensporre

Competing and Complementary Perspectives on the EU as a Crisis Management Actor:

An Examination of the Common Security and Defence Policy through the Lenses of

Idealism and Realism

MGSoG Dissertation Series, nr 10 (2010)

Judit Vall Castello

Business Cycle and Policy Effects on Labour Market Transitions of Older and Disabled

Workers in Spain

MGSoG Dissertation Series, nr. 9 (2010)

Keetie Roelen

False Positives or Hidden Dimensions: the definition and measurement of child poverty

MGSoG Dissertation Series, nr. 8 (2010)

Denisa Maria Sologon

Earning Dynamics in Europe

MGSoG Dissertation Series, nr. 7 (2010) 
Borders, independence and post-colonial ties

Melissa Siegel

Money and Mobility: Migration and Remittances

MGSoG Dissertation Series, nr. 6 (2010)

Jessica S. Hagen-Zanker

Modest Expectations: Causes and effects of migration on migrant households in source countries

MGSoG Dissertation Series, nr. 5 (2010)

Mirtha R. Muniz Castillo

Human Development and Autonomy in Project Aid: Experiences from four bilateral projects in Nicaragua and El Salvador

MGSoG Dissertation Series, nr. 4 (2009)

Christiane Arndt

Governance Indicators

MGSoG Dissertation Series, nr. 3 (2009)

Britta Augsburg

Microfinance - Greater Good or Lesser Evil?

MGSoG Dissertation Series, nr. 2 (2009)

Geranda Notten

Measuring and Managing Poverty Risks

MGSoG Dissertation Series, nr. 1 (2008) 